\title{
ELECTRODEPOSITION OF ALUMINUM FROM \\ ALKYL BENZENE ELECTROLYTES
}

by

Guido A. Capuano

A thesis submitted to the Faculty of Graduate Studies and Research in partial fulfillment of the requirements for the degree of Doctor of Philosophy

Department of Mining and Metallurgical Engineering, McGill University, Montreal, Canada. March 1973.

C) Guido A. Capuano 1973 
To my son Paul 


\begin{abstract}
Aluminum was electrodeposited onto metallic substrates from a number of electrolytes consisting essentially of an $\mathrm{AlBr}_{3}$ solute of commercial purity and technical grade alkylbenzene solvents or solvent mixtures. Bright, fine grained, and adherent aluminum coatings $0.5 \mathrm{mil}(.013 \mathrm{~mm})$ thick were obtained at cathode efficiencies of the order of $70-85 \%$ and at anode efficiencies approaching 100\%. The best electrolytes have been found to be those based upon ethylbenzene and diethylbenzene solvents with toluene as a less expensive diluent.

The electrolytes have been found to operate most efficiently and reproducibly at specific conductances between 3.0 and $4.0 \times 10^{-3} \Omega^{-1} \mathrm{~cm}^{-1}$. The conductance can be maintained at these levels by the periodic addition of $\mathrm{HBr}$ gas.

A cell for studying the polarization behavicur of organic-based electrolytes was developed and was used to determine cathode charge transfer overvoltages for the ethylbenzene-toluene (1:1 volume), $\mathrm{AlBr}_{3}$ (50 wt. \%) electrolytes. The charge transfer overvoltage was found to be $40 \mathrm{mV}$ at current densities of $10 \mathrm{~mA} / \mathrm{cm}^{2}$ and the heats of activation for the electrodeposition process were of the order of $4 \mathrm{Kcal} / \mathrm{mole}\left(27\right.$ to $\left.67^{\circ} \mathrm{C}\right)$. Experimental Tafel plots indicated that the electrodeposition process takes place in steps of 3 electrons. The ions responsible for the plating of aluminum are thought to be $\pi$, hydroxy $\pi$ and bromo $\pi$ complexes.

Name: Guido A. Capuano, M.Sc.

Title of Thesis: Electrodeposition of. Aluminum from Alkyl Benzene Electrolytes. Department: Mining and Metallurgical Engineering. Degree: Doctor of Philosophy.
\end{abstract}




\section{RESUME}

Des revêtements mêtalliques d'aluminium ont été réalisés par l'électrolyse d'un nombre d'électrolytes organiques. Ces électrolytes sont composés essentiellement de bromure d'aluminium et d'alk' . nzènes, pureté "technical grade".

Des couches d'aluminium ductiles, cohérentes et bien adjacentes, ayant une structure à grain fin et dont l'apparence était brillante, d'un gris-blanc, et d'une épaisseur de $0.013 \mathrm{~mm}$, ont été obtenues avec un rendement cathodique de l'ordre de 70 à $85 \%$ et d'un rendement anodique d'environ $100 \%$.

On a trouvé que les meilleurs électrolytes étaient ceux à base d'ethylbenzene et de diethylbenzene ayant le toluene comme diluant. On a trouvé en plus que les électrolytes donnaient leur meilleur rendement à une conductibilité spécifique située entre 3.0 et $4.0 \times 10^{-3} \Omega^{-1} \mathrm{~cm}^{-1}$. La conductibilité peut être gardée à ce niveau par l'addition périodique de $\mathrm{HBr}$ gazeux.

Une cellule pour l'étude des polarisations d'électrolytes à base de solvants organiques a été conçue et réalisée. On a étudié la polarisation cathodique d'un électrolyte contenant ethylbenzene-toluene 1:1 (volume) et $\mathrm{AlBr}_{3}$ à $50 \%$ poids. Des surtensions de transfert de charge de $40 \mathrm{mV}$ ont été mesurées à des intensités de courant de $10 \mathrm{~mA} / \mathrm{cm}^{2}$. La chaleur d'activation a été calculée comme étant de l'ordre de $4 \mathrm{Kcal} / \mathrm{mole}$ entre 27 et $67^{\circ} \mathrm{C}$.

Des tracés de l'équation de Tafel ont indiqué que la réduction électrolytique de l'aluminium a lieu par le transfert de 3 électrons. On croit que les ions responsables pour la réduction électrolytique de l'aluminium sont les complexes $\pi$, hydroxy $\pi$ et bromo $\pi$ de l'aluminium. 
TABLE OF CONTENTS

Page
PANE - INTRODUCTION

1.0 GENERAL . . . . . . . . . . . . . . 2

1.1 Statement of the Problem. . . . . . . . 3

2.0 LITERATURE REVIEW . . . . . . . . . . . 5

2.1 Grouping of Solutes anä Solvents . . . . . . 5

A. The Ethyl Bromide-Aromatic Type of Electrolyte ............ . . 6

B. The Amino-Aromatic Type of Electrolyte . . 9

C. The Ether Type of Electrolyte....... 10

D. The Amino and Amide Type of Electrolyte . . 15

E. Aromatic Type of Electrolyte . . . . . 17

2.2 Tabulation of the Existing Electrolytes and Their.

Disadvantages . . . . . . . . . 18

2.3 Some Unsuccessful Previous Work ... . . . 27

2.4 Summary of Part One . . . . . . . . . 28

PART TWO - EXPERIMENTAL AND RESULTS 30

3.0 EXPLORA TORY INVESTIGATION . . . . . . . 32

3.1 Theoretical Concepts. . . . . . . . . . . 33

A. Dielectric Constant of the Solvent . . . . 33

B. Electrical Conductivity. . . . . . . . 33

C. Strength of Aluminum Complexing . . . . . 34

D. Suitable Solutes............. 34 


\section{TABLE OF CONTENTS (Cont'd)}

3.1 (Cont'd)

E. Some Aromatic Complexes of Aluminum. . .

F. Binary Aromatic Complexes of Aluminum .

G. Electrolytic Decomposition of Organic Solvents . . . . . . . . . . 38

H. Mechanisms of Aluminum Electrodeposition . 40

I. Summary. . . . . . . . . . . . . 40

3.2 Exploratory Experiments . . . . . . . . 41

3.3 Summary of Results of the Exploratory Investigation ............ 42

3.4 Other Solutes Investigated . . . . . . . . 42

3.5 Conclusions Drawn from the Exploratory Investigation ..............

4.0 A STUDY OF ELECTROLYTES BASED UPON ETHYLBENZENE AND DIETHYLBENZENE . . . . . . 42

4.1 The Investigation . . . . . . . . . . . 46

4.2 Experimental Details . . . . . . . . 47

A. Apparatus . . . . . . . . . . . 47

B. Materials ............. . 51

C. Experimental Procedure ........ . 52

D. Standard Operating Conditions. . . . . . 53

E. Cathode and Anode Sizes and Immersion Areas............ 53

F. Cathodic Current Density . . . . . . . 54

G. Cathodic and Anodic Current Efficiency ... 54

H. Choice of Current Density . . . . . . 55 


\section{TABLE OF CONTENTS (Cont'd)}

4.2 (Cont'd)

I. Aluminum Coating Thickness. . . . . . . 60

J. Plating Time........... . 60

4.3 Results................ . 60

5.0 LIFE AND CONTROL OF THE ELECTROLYTES. . . . 90

5.1 Possible Techniques for Increasing Life and

Maintaining Performance of Electrolytes .... 91

5.2 Experimental Details. . . . . . . . . . 92

A. Apparatus ............. . . 92

B. Materials ............. 96

C. Preparation of $\mathrm{AlBr}_{3}$ and Electrolyte. . . . . 96

D. Preparation of Metal Surfaces for Plating. . . 98

E. Plating Procedure............ 99

F. Standard Operating Conditions . . . . . . 99

G. Results. . . . . . . . . . . 100

5.3 Ethyl Bromide Addition to Increase Electrolyte

Life . . . . . . . . . . . . 100

5.4 Hydrogen Bromide Addition to Increase Electrolyte Life . . . . . . . . . . . 105

5.5 Electrolyte Performance... . . . . . . 108

5.6 Electrolyte Performance at Higher Current Densities............. 111

5.7 Electrolyte Performance Over a Long Period of Time . . . . . . . . . . . 113

5.8 Control of the Electrolyte . . . . . . . . 113

5.9 Summary . . . . . . . . . . . . 119 
TABLE OF CONTENTS (Cont'd)

6.0 CATHODIC POLARIZATION IN THE ETHYLBENZENE-

Page

TOLUENE SYSTEM . . . . . . . . . . . . 120

6.1 Theoretical Concepts . . . . . . . . . . 120

A. Electrode Potential. . . . . . . . 121

B. Electrode-Solution Interface. . . . . . 121

C. Overvoltage . . . . . . . . 122

D. Electrode Kinetics . . . . . . . . 125

i) Butler-Volmer Equation. . . . . . . 126

ii) The Tafel Equation. . . . . . . . . 128

iii) Heat of activation at constant overvoltage . . 129

iv) Heat of activation at constant current density .......... . 130

6.2 Magnitude of Heat of Activation . . . . . . . 131

6.3 Criteria Used to Develop a Cell for Cathode Polarization Studies. . . . . . . . 131

6.4 Possible Structures of the Reference Electrode. . . 132

6.5 Cell and Reference Electrode Design. . . . . . 135

6.6 Polarization Measurements in Aqueous Electrolytes. 137

6.7 Measurements Obtainable from the Cell . . . . . 138

6.8 Determination of Concentration Polarization . . . 142

6.9 The Principal Investigation: Organic Electrolyte. . 143 
6.10 Materials . . . . . . . . . . . 144

A. Organic Electrolytes . . . . . . . . 144

i) Purity of the electrolyte . . . . . . 144

ii) Purity of the aluminum anode used .... 145

B. Aqueous Electrolytes. . . . . . . . 145

6.11 Apparatus. . . . . . . . . . . 146

A. Electrolytic Cell. . . . . . . . . 146

B. Electrical Equipment. . . . . . . . 152

C. Thermostatic Pump . . . . . . . . 152

D. Remote Control Switch Box. . . . . . . 152

E. Magnetic Stirrer. . . . . . . . . 152

F. Electrical Circuit . . . . . . . . 153

6.12 Experimental Procedure . . . . . . . . 153

A. Preparation and Filling Up of the Polarization Cell. .............

B. Pre-electrolysis . . . . . . . . 155

6.13 Preliminary Tests: Aqueous Electrolytes . . . 155

A. Determination of Relative IR Drops Between Electrodes. . . . . . . . . 155

B. Cathode Overvoltage Determination: Aqueous System ............. 156

C. Standard Operating Conditions. ...... 
TABLE OF CONTENTS (Cont'd)

$\underline{\text { Page }}$

6.14 Measurements of Cathode Overvoltage: Organic System . . . . . . . . . . . .

6.15 Accuracy and Precision of the Overvoltage Measurements. . . . . . . . . . 158

6. 16 Results and Observations . . . . . . . 159

A. Preliminary Determination of IR Drops, Aqueous Electrolyte . . . . . . . 160

B. Cathodic Polarization: Aqueous Solution . . 164

C. Cathodic Polarization - Organic Electrolyte, Specific Conductance: $4.0 \times 10^{-3} \Omega^{-1} \mathrm{~cm}^{-1}$.

D. Cathodic Polarization - Organic Electrolyte, Specific Conductance: $3.0 \times 10^{-3} \Omega^{-1} \mathrm{~cm}^{-1}$.

E. Cathodic Polarization - Organic Electrolyte, Specific Conductance: $2.0 \times 10^{-3} \Omega^{-1} \mathrm{~cm}^{-1}$.

F. Cathodic Polarization - Organic Electrolyte, Specific Conductance: $1.0 \times 10^{-3} \Omega^{-1} \mathrm{~cm}^{-1}$.

PART THREE -- DISCUSSION AND CONCLUSIONS 200

7.0 DISCUSSION . . . . . . . . . .

7.1 Comparison of Cathode Efficiencies: EthylbenzeneToluene and Diethylbenzene-Toluene Systems .

7.2 Overall Comparison of Ethylbenzene and Diethylbenzene Electrolytes .........

A. Conductivity of Ethylbenzene and Diethylbenzene Electrolytes. . . . . . . 205

B. Inflammability of the Electrolytes. . . . . 205

C. Summary of Ethylbenzene vs. Diethylbenzene Comparison . . . . . . . . . . 210 
TABLE OF CONTENTS (Cont'd)

7.3 Electrolyte Life .............. $\frac{\text { Page }}{211}$

7.4 Control of the Electrolyte (Ethylbenzene-Toluene $1: 1,50$ wt. $\left.\% \mathrm{AlBr}_{3}\right)$........... 212

7.5 Throwing Power............. 213

7.6 Plating Quality .............. 213

7.7 Value of the New Electrolytes . . . . . . . 216

7.8 Discussion of Cathodic Charge Transfer Overvoltage Measurements ......... 217

A. Absolute Values of Charge Transfer Overvoltage $\eta_{\mathrm{tC}}$ from Alkylbenzene Electrolytes, Compared with Overvoltages from Aqueous Electrolytes. . . . . . . . . 217

B. Effect of Specific Conductance on Charge Transfer Overvoltages. . . . . . . . 218

7.9 The Effect of Temperature on Cathodic Charge Transfer Overvoltages . . . . . . . 221

A. Heat of Activation of Ethylbenzene-Toluene Electrolytes. . . . . . . . . 221

B. The Effect of Applied Potential on Heat of Activation . . . . . . . . . 222

7.10 Calculation of Kinetic Parameters . . . . . 223

A. Exchange Current Density $\left(i_{0}\right) \ldots . . . .223$

B. Kinetic Parameters $\lambda, \beta$ and $\nu \ldots . .225$

C. The Two Slopes of Tafel Line . . . . . . . 229

7.11 Mechanisms of Dissolution and Deposition of Aluminum ............ 
TABLE OF CONTENTS (Cont'd)

7.12 The Fffect of Moisture $\frac{\text { Page }}{235}$

7.12 The Effect of Moisture.........

7.13 The Effect of Bromine .......... 237

7.14 Effect of Both Moisture and Bromine ..... 238

7.15 Mechanisms of Aluminum Electrodeposition . . 239

A. Assuming Two Consecutive Slopes in Tafel Line. . . . . . . . . . . 240

a) Postulating monomeric aĩuminum complexes........... . . 240

b) Postulating dimeric aluminum complexes. . 240

B. Assuming One Slope (High Overvoltage) in the Tafel Line . . . . . . . . . 241

a) Postulating monomeric aluminum bromide complexes ............ 241

b) Postulating dimeric aluminum bromide complexes . . . . . . . . . 242

7.16 Other Reactions at the Cathode . . . . . . 242

7.17 Summary As To the Electrodeposition Mechanism . . . . . . . . . . . . 243

7. 18 Suggestions for Further Work. . . . . . . . 244

8.0 CONCLUSIONS. . . . . . . . . . . . . 245

9.0 ORIGINAL CONTRIBUTION TO KNOWLEDGE . . . . . 248 
TABLE OF CONTENTS (Cont'd)

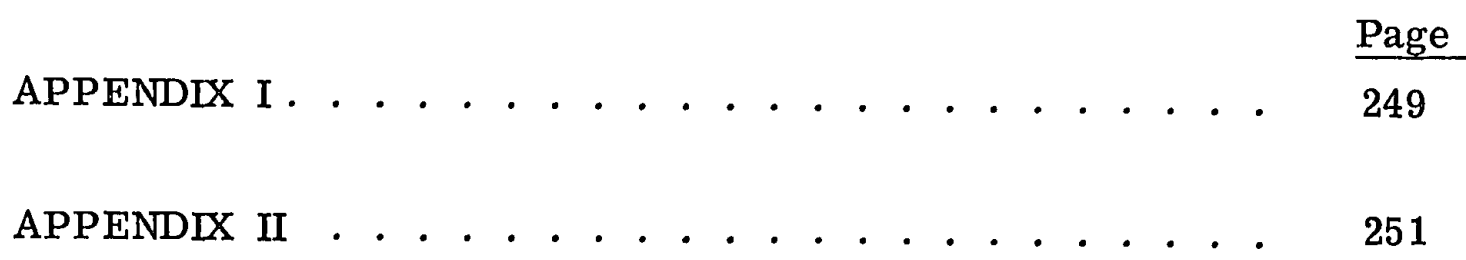

APPENDIX III . . . . . . . . . . . . 253

APPENDIX IV ..................... 256

APPENDIX V . . . . . . . . . . . . 275

APPENDIX VI .................... 281

APPENDIX VII . . . . . . . . . . . . . 288

APPENDIX VIII. . . . . . . . . . . . 300

APPENDIX IX .................... 302

LIST OF SYMBOLS. . . . . . . . . . . . 304

ACKNOWLEDGEMENTS . . . . . . . . . . . 308

REFERENCES . . . . . . . . . . . . 309 
PART ONE

INTRODUCTION 


\section{PART ONE - INTRODUCTION}

\subsection{GENERAL}

Aluminum has properties which render it particularly useful as a coating material. However, it is very difficult to electrodeposit and as a result these useful properties have not been exploited to any extent by the electroplating industry.

In particular, the coherent natural oxide film formed by aluminum makes it highly corrosion resistant and it can be made even more resistant by anodizing with coatings which then may be dyed to attractive shades of colour.

Aluminum is, moreover, somewhat weak as a structural and container material and thus steel electroplated with aluminum should combine the most beneficial properties of both metals for many uses.

Although very little aluminum electroplating has been carried out to date, aluminum has been coated on to other metals (particularly steel) by vacuum deposition, hot dipping, and by physical cladding techniques. Unfortunately, none of these methods provides the complete, adherent, and uniform coatings which are the product of electroplating. Thus the desirability of electroplating aluminum onto other metals has led to considerable research into developing practical electrolytes and plating techniques. However, as the literature survey of this thesis shows, the research to date has had only a limited success.

It has been the object of this research to find a practical room temperature electrolyte for the plating of aluminum onto other metals 
and to investigate the basic electrochemistry of aluminum electrodeposition processes from organic electrolytes.

\subsection{Statement of the Problem}

The electrodeposition of aluminum has proven to be extremely difficult and only limited commercial success has been attained. The principal reason is that aluminum, because of its high position in the electromotive series, can not be easily deposited from aqueous solutions. Hydrogen gas is evolved before the applied potential is sufficiently high to deposit aluminum.

Fused-salt procedures for electroplating aluminum avoid this problem by utilizing molten aluminum salts, usually the chloride or the bromide, dissolved in various inorganic and organic salts, such as potassium chloride, sodium chloride, and ethyl pyridinium bromide. Molten salt electroplating has not, however, found any large scale application due, most likely, to the complexity of the procedures and to uneven plating quality.

Some early investigators claimed that aluminum could be deposited from aqueous solutions $1,2,3$, None of their findings could be verified, however, and no aqueous process has ever been successful. The analogy between ammonia and water led other workers 4 to attempt to electrodeposit aluminum from liquid ammonia. Again, no success was recorded from these systems.

It was soon recognized that moisture should be absent for the successful electrodeposition of aluminum. It was natural, then, to turn 
to organic solvents to provide a suitable room temperature electrolyte. Investigations into aluminum electrodeposition from organic electrolyte up to 1954 have been reviewed by $\mathrm{Castle}^{5}$ and more recently by Brenner. 6,7

Since the beginning of the century several procedures for the electrodeposition of aluminum from organic electrolytes have been put forward. Although some of them obtained a fair degree of success, none has yet attained significant industrial acceptance. The various reasons for this incomplete success will be demonstrated in the following literature review and theoretical concepts sections. 


\subsection{LUTERATURE REVIEW}

This section describes the findings of previous investigations into the electrodeposition of aluminum from organic electrolytes. The most significant investigations are summarized in Tables 2-1 to 2-5.

\subsection{Grouping of Solutes and Solvents}

The organic electrolytes studied to date can be effectively classified according to the following groups of solutes and solvents.

Solutes:
A. Aluminum Halides
B. Aluminum Organo Compounds

Solvents:
A. Ethyl Bromide with or without an aromatic (8-17)
B. Amino-Aromatic (18-20)
C. Ether (21-47)
D. Amino or Amide with or without Ether (48-51)
E. Aromatic (52-56)

With the exception of the aromatic solvents, which were used in some cases in their technical grades, all the solvents and solutes were in their anhydrous form. Purification and protection from atmospheric moisture were therefore necessary in almost all cases. 
A. The Ethyl Bromide-Aromatic Type of Electrolyte (Table 2-1)

Plotnikov $^{8}$ (1902) discovered that aluminum bromide dissolved in ethyl bromide yields a solution of good electrical conductivity. He deposited crystalline aluminum from this solution upon a carbon electrode, but gave no operating conditions except the necessity of excluding moisture from the operating bath.

On further study, H. E. Patten ${ }^{9}$ confirmed the deposition of aluminum from Plotnikov's electrolyte using a solution containing 40.9 weight $\%$ $\mathrm{AlBr}_{3}$, platinum electrodes, and a current density of $2.3 \mathrm{~mA} / \mathrm{cm}^{2}$. He found, however, that the aluminum deposits redissolved when the current was turned off. By quickly shifting the electrodes from the solution to $95 \%$ alcohol, loose scales of aluminum were removed from the cathode. Bromine was liberated at the anode.

Wertyporoch and Wohl ${ }^{10}$ (1931) made many physical chemical tests on combinations of aluminum salts in various organic solvents and mixtures. These workers found that the conductivity of a solution of $\mathrm{AlBr}_{3}$ in ethyl bromide was increased by the addition of benzene and that the conductivity also increased with time. During electrolysis of the aluminum bromide in ethyl bromide solution, equal amounts of aluminum were transferred to the cathode and anode, while upon addition of hexaethylbenzene, most of the aluminum went to the anode and most of. the hexaethylbenzene to the cathode.

Later Wertyporoch and Adamus ${ }^{11}$ found that dry hydrobromic acid gas or, in a similar way, hydrochloric acid gas, in a solution 
of aluminum bromide in benzene, restited in the separation of a layer of thick oil containing three components: aluminum bromide, hydrobromic acid and benzene. The oil layer had excellent conductivity, and upon passing a D.C. current aluminum deposited at the cathode while bromine (or chlorine) was liberated at the anode.

At the same time Blue and Mathers, ${ }^{12}$ working independently, reported that aluminum of high purity could be deposited easily in a bright crystalline, adherent form from a solution prepared by dissolving metallic aluminum in ethyl bromide and benzene using aluminum bromide as a starter or catalyst. Toluene, xylene, $\beta$-tetrahydronaphthalene, and kerosene could be substituted for benzene under certain conditions and ethyl chloride, methyl chloride and ethylene dichloride for ethyl bromide. The aluminum adhered well to platinum, copper, steel and cast iron but not to magnesium or aluminum. The bath had a current efficiency of $60 \%$ and over at both electrodes, and high throwing power. ${ }^{13}$ The electrolyte was found not to deteriorate and it could be operated indefinitely if moisture were excluded.

A new, cheaper and more efficient bath was later reported by Blue and Mathers. ${ }^{14}$ The bath consisted of: 4 gms of aluminum, $20 \mathrm{gms}$ of aluminum bromide, $20 \mathrm{gms}$ of aluminum chloride, $80 \mathrm{~cm}^{3}$ of benzene, $40 \mathrm{~cm}^{3}$ of xylene and $40 \mathrm{~cm}^{3}$ of ethyl bromide. According to the authors the bath gave a cathode current efficiency of $75 \%$ and above. They recommended, ${ }^{15}$ however, that the aluminum bromide be prepared prior to use, by the reaction of aluminum metal and 
bromine, followed by a fusion with the aluminum chloride to insure complete dryness of the salts.

Two years later Downie ${ }^{16}$ described a similar process whereby aluminum is deposited from a solution consisting of $\mathrm{AlBr}_{3}$, ethyl bromide, benzene and xylene, the ethyl bromide being included to prevent the solution from being affected by the atmosphere. External cooling by water and an absence of moisture were required, but the metal was said to be clean, smooth and strongly adherent.

R.J. Heritage, ${ }^{17}$ in an attempt to reproduce Downie's or Blue and Mathers' results, obtained dull gray aluminum deposits. The bath operated successfully for 250 hours when protected from atmospheric moisture. At 5 to $20 \mathrm{~mA} / \mathrm{cm}^{2}$, the current efficiencies were about $50 \%$. The bath was considered unsuitable for operation on a large scale because of the violence of reaction occurring in its preparation and the continuous evolution of $\mathrm{HBr}$ during electrolysis.

N. I. Ternovaya and O.K. Kudra ${ }^{18}$ studied some ternary systems and reported the following observations: (a) deposits of aluminum powder were obtained from benzene and toluene solution of $\mathrm{AlBr}_{3}-\mathrm{KBr}$; (b) porous deposits resulted from electrolysis of Al halides in other solvents (xylene, toluene and ethyl bromide); (c) excellent aluminum dendrites were obtained from benzene solutions of $\mathrm{AlBr}_{3}$ with the addition of $\mathrm{NH}_{4}$ halides; (d) needle shaped crystalline deposits of aluminum separated from ethyl bromide solutions with the addition of lithium, sodium and potassium halides. Thin layers of aluminum 
were obtained from pyridine solutions of $\mathrm{AlBr}_{3}$.

Ternovaya and Kudra concluded that while the conductivity of the electrolyte is increased by the addition of alkali halides, the quality of the coatings worsened. Therefore the addition of alkali halides to improve the low conductivity of these baths is not compatible with a good coating quality.

\section{B. The Amino-Aromatic Type of Electrolyte (Table 2-2)}

Wier and Hurley, 19 in an attempt to substitute ethyl bromide with a less volatile and less reactive compound, prepared a new electrolyte by mixing two moles of anhydrous aluminum chloride with 1 mole of ethyl pyridinium bromide, preferably in a dry, oxygen-free atmosphere. Benzene (or toluene) was added to this solution until a second layer, principally excess benzene, formed on the top of the plating solution.

Plating was carried out in a protected atmosphere using an $\mathrm{Al}$ anode at cathode current density of approximately $10 \mathrm{~mA} / \mathrm{cm}^{2}$ and an applied potential in the order of 1 volt. Plates of $0.006 \mathrm{~mm}$ thick gave cathodic current efficiencies of $92 \%$ at $10 \mathrm{~mA} / \mathrm{cm}^{2}$ current density. Safranek, Schickner and Faust ${ }^{20}$ improved the Wier and Hurley bath, and used it for making electroformed aluminum wave guides. Dense, strong and ductile aluminum walls 0.65 to $1.0 \mathrm{~mm}$ thick were produced. Their plating bath consisted of a dispersion of toluene in a toluene solution of the fusion product of ethyl pyridinium bromide and aluminum chloride, with methyl $\mathrm{t}$-Butyl ether as an addition agent. 
R.J. Heritage, ${ }^{26}$ on the other hand, in an attempt to use the Wier and Hurley bath, obtained aluminum deposits that were dark and brittle.

Couch and Brenner ${ }^{24}$ considered the Wier, Hurley and Safranek bath as being the best available at the time. However, they reported it as being very sensitive to moisture and electrolytic decomposition, the latter being especially severe if the mole ratio of aluminum chloride and ethyl pyridinium bromide was not properly adjusted or if the current density was too high.

Miller and Baker ${ }^{21}$ obtained a U.S. patent for an electrolyte of the following composition: for each mole of guanidine - $\mathrm{HCl}$, 1.7 - 2.9 moles $\mathrm{AlCl}_{3}$ or $\mathrm{AlBr}_{3}$, at least 0.4 mole benzene, toluene or xylene, 0.4 mole of naphthalene as a brightener and $0.02-0.03$ mole of LiH as a moisture scavenger.

Electrolysis was carried out at $30^{\circ} \mathrm{C}$ in an argon atmosphere with stirring at a current density of $20 \mathrm{~mA} / \mathrm{cm}^{2}$. A reversal of D. C. current and a superimposed 60 cycle A.C. potential were also employed. Like the Wier and Hurley bath this electrolyte suffered from the problems of being very sensitive to moisture and of electrolytic decomposition of the solvents.

C. The Ether Type of Electrolyte (Table 2-3)

V.A. Plotnikov 22 (1907) found that aluminum bromide dissolved in ether to give a low conductivity solution. 
Keyes and Swann ${ }^{23}$ and co-workers (1928) employed aluminum Grignard reagents for the electrodeposition. Smooth coatings were obtained at $20^{\circ} \mathrm{C}$ from ether solutions of diethyl-aluminum-iodide or ethyl-aluminum-diiodide in an atmosphere of dry nitrogen. High applied potentials of the order of 40 volts were required, however, to produce a current density of $20 \mathrm{~mA} / \mathrm{cm}^{2}$.

Couch and Brenner ${ }^{24}$ (1952) of the National Bureau of Standards (NBS) were the next to attempt to electrodeposit aluminum from an etheral solution. They prepared a bath consisting of a diethyl ether solution, $2-3$ molar $\mathrm{AlCl}_{3}$ (anhydrous) plus 0.5 to 1.0 molar LiH. The bath was operated at room temperature with current densities of 10 to $20 \mathrm{~mA} / \mathrm{cm}^{2}$. Ductile deposits up to $.75 \mathrm{~mm}$ thick were obtained using $\beta \beta^{\prime}$-dichloroethyl ether as a brightener and with periodic reversal of current.

On further study of the stability and operating life of the bath, Connor and Brenner 25 concluded that the life of the bath could be improved by: a) the use of lithium aluminum hydride rather than lithium hydride; b) the use of coarse paper anode diaphragms; c) additions of fresh plating solution when the bath voltage for a constant current density began to increase and, d) addition of solid $\mathrm{AlCl}_{3}$ to the bulk of the bath when lithium aluminum hydride failed to rejuvenate the bath. However, electrolytic decomposition at the anode caused bath deterioration, and it was also found that the aluminum dissolved from the anode was not available for plating. The maximum amount of $\mathrm{Al}$ deposited was there- 
fore equivalent to the aluminum introduced into the electrolyte as $\mathrm{AlCl}_{3}$. R.J. Heritage and co-workers ${ }^{26,27}$ preferred the NBS bath to any other existing at the time (1957). They were able, in fact, to operate this bath successfully in a sealed cell for 2000 hours. Deposits up to $4 \mathrm{~mm}$ thick without trees were obtained by using periodic current reversal and 2, 2'-dichlorodiethyl ether as an addition agent. The hardness of the deposit, however, dropped from 80 to 40 Vickers during operation of the bath due, apparently to the elimination of the $\mathrm{Cu}$ and Fe impurities from the electrolyte.

Since the atmosphere above the solution contains ether vapours, which are extremely inflammable, the authors recommended that all electrical connections to the bath should be made in such a way as to eliminate any chance of arcing, i.e., all electrical connections must be made with the current off.

Alm and Binstock ${ }^{28}$ studied and slightly modified the NBS bath. Their new procedure, called the NAL KOTE process, was used for the cladding of nickel-plated uranium reactor cores.

Ether was dried over sodium and the bath temperature was maintained between 20 and $30^{\circ} \mathrm{C}$. An unidentified regenerating capsule, was placed in the plating cell.

A polarity reversal cycle of 600 seconds direct at $5 \mathrm{~mA} / \mathrm{cm}^{2}$ and 60 seconds reverse at $20 \mathrm{~mA} / \mathrm{cm}^{2}$ was used. Deposits up to $0.6 \mathrm{~mm}$ were produced. 
The adhesion of the deposit was improved by a preliminary treatment in which the nickel plated part was made anodic in the solution at $15 \mathrm{~mA} / \mathrm{cm}^{2}$ for 5 minutes, followed by swirling the part in the bath for 5 to 10 seconds. Plating of the part was carried out immediately after this treatment.

Elze et al. ${ }^{29}$ made a study of the crystal structure of the deposit obtained from the NBS bath. The effects of some additives were also studied. Tetrahydrofuran and xylene produced compact, crystalline coatings, xylene giving the smaller crystals. The addition of 5,6 , benzoquinolin $(0.09$ to $0.18 \mathrm{~g} / 1)$ produced compact deposits in which the grains were rounded. Microscope studies also showed the presence of spiral growth patterns but these were not present in samples plated at current densities above $120 \mathrm{~mA} / \mathrm{cm}^{2}$.

Cooke and Kritzer ${ }^{30}$ successfully used the NBS bath for the deposition of aluminum on magnesium. K. Ziegler ${ }^{31}$ prepared another ether bath containing an aluminum ethyl-sodium fluoride complex. This bath required low power consumption for metal deposition, due to its high electrical conductivity. However, as in the case of the previously described ether bath, it was considered to be too hazardous to be recommended for general plating.

Hess and co-workers at General Electric ${ }^{32-36}$ scaled up the NBS bath to a 200 gallon operation for the electroforming of a $76 \mathrm{~cm}$ (30 in.) diameter parabolic mirror to be used as a solar energy concentrator. Production of a large $3 \mathrm{~m}(10 \mathrm{ft}$.) diameter mirror, involv- 
ing a 2000 gal. plating facility is under continuing (1973) study for NASA-Langeiy Research Center by the G. E. Missile and Space Division. Workers at Battelle Memorial Institute used the NBS bath as an alternative method for aluminum cladding of uranium fuel elements. Uranium electroclad with $.3 \mathrm{~mm}$ of aluminum over a $.013 \mathrm{~mm}$ nickel or nickel-plus-copper electroplate resisted corrosion for more than $100 \mathrm{hrs}$. in boiling water. Hot pressing the electroclad composite improved the corrosion resistance.

The Battelle group $37-42$ also modified the NBS bath so as to reduce the inflammability of the bath by reducing the amount of ether or by replacing part of the ether with a quaternary ammonium salt such as 2-ethoxyethyl trimethylammonium chloride.

The NBS bath was used at Electro-Optical Systems ${ }^{43-44}$ to electroform solar mirrors and to deposit an aluminum matrix about boron fibers to yield a strong, light weight structure. They were able to produce stronger aluminum from the NBS bath by adding to it a magnesium plating solution of undisclosed nature. No magnesium was found in the deposit. They also replaced a third of the ethyl ether in a conventional NBS bath with anisole, thus obtaining an even stronger deposit: 21,400 psi yield strength and 25,700 psi ultimate tensile strength.

Withers and Abrams at General Technicologies Corporation ${ }^{45}$ used the NBS bath to electroform composites containing boron filaments. They controlled the solution by density measurement to give the $\mathrm{AlCl}_{3}$ content, and by resistivity measurement to give the hydride content. 
Workers at Bendix Corporation ${ }^{46}$ studied the NBS bath and found that the life of the bath could be considerably lengthened by cleaning the anodes twice a day and by avoiding the use of anode diaphragms which had been suggested by the inventors of the NBS baths 24,25 .

N. Ishibashi et al. ${ }^{47}$ obtained a U.S. Patent for a bath comprising, as solvent, at least one member from the group consisting of tetrahydrofuran and its derivatives and, as solutes: (a) an aluminum halide and (b) at least one of lithium aluminum hydride and lithium hydride, in which the molar ratio of the solutes is 1 to 3 . There have been no reports as to the effectiveness of this electrolyte.

In spite of the many inconveniences mentioned for the ether process, particularly the inflammability of the electrolytes, the quality of the electroplating has been good, and virtually all practical aluminum plating to date has been carried out with the ether type process.

\section{The Amino and Amide Type of Electrolyte (Table 2-4)}

In 1933 Blue and Mathers ${ }^{48}$ deposited aluminum alloys containing up to $17 \%$ aluminum from a solution containing $25 \mathrm{~g}$ of ferric chloride, $1 \mathrm{~g}$ of aluminum chloride and $30 \mathrm{~cm}^{3}$ of formamide. The solution was electrolyzed at room temperature and at a current density of $15 \mathrm{~mA} / \mathrm{cm}^{2}$, using an aluminum anode and a copper cathode. They were not able, however, to plate pure aluminum from this electrolyte. Murphy and Dumas ${ }^{49}$ (1956) prepared a bath containing 25.6 mole $\% \mathrm{AlCl}_{3}, 15.2$ mole \% 2-ethylhexylamine, and 59.2 mole \% ethyl ether. Bright adherent deposits of $\mathrm{Al}$ were obtained at 20 - 120 
$\mathrm{mA} / \mathrm{cm}^{2}$. In making up the bath, $\mathrm{AlCl}_{3}$ was first dissolved in ether, and the solution was slowly added to the amine with cooling. The plating cell was fitted with a reflux condenser to prevent loss of solvent. Menzies and Salt ${ }^{51}$ reported poor deposits from this bath when commercial purity $\mathrm{AlCl}_{3}$ was used.

B. O. Holland ${ }^{50}$ obtained deposits of excellent appearance from a bath consisting of a formamide solution containing 4 mole $\% \mathrm{AlCl}_{3}$, 6 volume \% nitrobenzene, and 3 volume \% benzoyl chloride. Electrolysis was performed at $50^{\circ} \mathrm{C}$ and $25-30 \mathrm{~mA} / \mathrm{cm}^{2}$ with an anode to cathode spacing of $1.6 \mathrm{~cm}$ and an applied potential of 12.5 volts. Cathode efficiencies were in the order of $65-70 \%$ and $.060 \mathrm{~mm}$ deposits were obtained in $12-15 \mathrm{~min}$.

The dark deposit was changed to a bright, smooth, reflective coating by flash pickling for 1 second in $5 \% \mathrm{HCl}$. Menzies and Salt ${ }^{51}$ reported, however, that the formamide bath of Holland was difficult to operate and that it did not give a coherent protective coating of aluminum by plating at $50^{\circ} \mathrm{C}$ and $20-150 \mathrm{~mA} / \mathrm{cm}^{2}$. Simanavicius et $\mathrm{al}^{52}$ believe that the Holland deposit was not aluminum but an aluminum alloy with heavy metals, which were present as impurities in the electrolyte. More recently Menzies and Salt ${ }^{51}$ prepared a new bath by adding sublimed and purified $\mathrm{AlCl}_{3}$ dissolved in ethyl ether to a solution of butyl amine in ethyl ether with cooling. Complete exclusion of moisture from the system was necessary. A bath containing $36.7 \% \mathrm{AlCl}_{3}, 12.28 \%$ butyl amine, and $51.02 \%$ ethyl ether gave crack-free $\mathrm{Al}$ coating up to 
$0.1 \mathrm{~mm}$ thick at $100 \mathrm{~mA} / \mathrm{cm}^{2}\left(20^{\circ} \mathrm{C}\right)$. Nodular growth was obtained at lower current densities.

\section{E. Aromatic Type of Electrolyte (Table 2-5)}

E. L. Lalbin 53 (1916) obtained a patent in Great Britain for a bath containing aluminum chloride and acetonitrile, xylene or toluene. Deposits could be made either smooth or powdery by suitable adjustment of the current density. Alkali fluorides up to about one percent were added to increase the conductivity. Subsequent workers were not, however, able to reproduce plating from these electrolytes.

Menzel ${ }^{54}$ (1940) described a process for electrodepositing aluminum from a bath which consisted of solutions of aluminum-alkyls and $\mathrm{AlCl}_{3}$ in a solvent inert to the aluminum-alkyl, namely xylene. The solution separated into two layers, the upper layer being xylene, which also acted as a protective layer, and the lower being the electrolyte. It was claimed that if the bath became contaminated with water it could be regenerated by distillation. Experimental results such as thickness and quality of the coating were not reported.

P.F. Kalynzhuaya ${ }^{55}$ deposited aluminum in the form of separate crystals from a fresh solution of $\mathrm{AlBr}_{3}$ in xylene, by using $\mathrm{Cu}, \mathrm{Fe}$ or stainless steel cathodes. Electrolysis of the lower layer of xylene$\mathrm{AlBr}_{3}$ mixtures, gave aluminum as a dense cathodic deposit with an efficiency of $55-65 \%$. Passage of current through the electrolyte eventually yielded tar-like materials and caused a decrease in efficiency. The tar formation was more rapid in $\mathrm{AlCl}_{3}$-xylene systems than in 
$\mathrm{AlBr}_{3}$-xylene systems.

More recently Simanavicius and Levinskiene ${ }^{52,56}$ reported that the electrolysis of xylene containing $>25$ mole $\% \mathrm{AlBr}_{3}$ yielded fine crystals of $\mathrm{Al}$ on an $\mathrm{Al}$ cathode at current densities of $1-200 \mathrm{~mA} / \mathrm{cm}^{2}$. Lower concentrations of $\mathrm{AlBr}_{3}$ were not suitable for good plating. The best coatings were obtained from $\mathrm{AlBr}_{3}$ solutions in the technical mixtures of $\mathrm{o}^{-}, \mathrm{p}-$, and $\mathrm{m}$-xylenes. The conductivity of $\mathrm{AlBr}_{3}$ in xylene increased on aging of the solution, which was accelerated by the passage of an electric current. For example, a freshly prepared solution of 25 mole $\% \mathrm{AlBr}_{3}$ in xylene had a specific electrical conductivity of $1.5 \times 10^{-4} \mathrm{ohm}^{-1} \mathrm{~cm}^{-1}$, while a 5 day old one had $9.4 \times 10^{-4} \mathrm{ohm}^{-1} \mathrm{~cm}^{-1}$. Hydrogen was liberated on the cathode together with aluminum and the cathodic current efficiency $(65-70 \%)$ decreased as the cathodic current density was increased. A significant increase of the electric conductivity of the electrolyte was noted up to saturation with gaseous $\mathrm{FIBr}$. The deposits were dark gray when the solution was stirred. Electrolysis at room temperature and 30 volts with platinum anodes did not produce good results, the aluminum deposited on the cathode being in the form of separate coarse crystals.

\subsection{Tabulation of the Existing Electrolytes and Their Disadvantages}

The existing organic electrolytes for the electroplating of aluminum are summarized in Tables 2-1 to 2-5. The main disadvantages of these electrolytes are as follows: 
1. The ethyl bromide is usually evolved and the reactions during electrolyte preparation are violent and highly exothermic.

2. The amino aromatic type of electrolyte is expensive and difficult to prepare. The electrolytes decompose during electrolysis. They are very sensitive to moisture and oxygen.

3. The ether type has the great disadvantage of being extremely inflammable in addition to being very sensitive to moisture.

4. The amino and amide types of electrolytes have been used to plate aluminum with some success, especially when using them in conjunction with etheral solutions of aluminum halides. However, high purity of solutes and solvents is required in the etheral solutions and the combined electrolytes suffer from the same problem of high inflammability as the ether electrolytes.

5. The aromatic type of electrolytes is less inflammable, less difficult to prepare and less expensive than the other organic electrolytes. The quality of coatings, however, has not been good. 
SUMMARY OF EXISTING ELECTROLYTES FOR THE ELECTRODEPOSITION OF ALUMINUM

Table 2-1

Ethyl Bromide - Aromatic Type of Electrolyte

\begin{tabular}{|c|c|c|c|c|}
\hline Date & Authors & Solvents & Solutes & Remarks \\
\hline 1902 & Plotnikov $^{8}$ & Ethyl bromide & $\mathrm{AlBr}_{3}$ & $\begin{array}{l}\text { Dull gray coatings were } \\
\text { deposited upon a carbon } \\
\text { electrode. }\end{array}$ \\
\hline 1904 & Patten $^{9}$ & Ethyl bromide & $\mathrm{AlBr}_{3}$ & $\begin{array}{l}\text { Confirmed Plotnikov results. } \\
\text { Coating redissolved if current } \\
\text { was turned off. }\end{array}$ \\
\hline 1934 & $\begin{array}{l}\text { Wertyporoch } \\
\text { and Adamus }\end{array}$ & $\begin{array}{l}\text { Hydrobromic acid or } \\
\text { ethyl bromide and } \\
\text { benzene }\end{array}$ & $\mathrm{AlBr}_{3}$ & $\begin{array}{l}\text { Conductivity increased when } \\
\text { an aromatic was added to the } \\
\text { ethyl bromide- } \mathrm{AlBr}_{3} \text { solution. }\end{array}$ \\
\hline 1934 & Blue and Mathers 12,14 & $\begin{array}{l}\text { Ethyl bromide, benzene, } \\
\text { toluene and xylene }\end{array}$ & $\begin{array}{l}\mathrm{AlBr}_{3} \text { and } \\
\mathrm{AlCl}_{3}\end{array}$ & $\begin{array}{l}\text { Electrolyte difficult to prepare } \\
\mathrm{HBr} \text { evolved during electrolysi } \\
\text { Coatings were unattractive. }\end{array}$ \\
\hline 1938 & Downie $^{16}$ & $\begin{array}{l}\text { Ethyl bromide, benzene, } \\
\text { toluene }\end{array}$ & $\mathrm{AlBr}_{3}$ & $\begin{array}{l}\text { Same remarks as per Blue } \\
\text { and Mathers bath. }\end{array}$ \\
\hline 1962 & Ternovaya $^{18}$ & $\begin{array}{l}\text { Benzene, toluene, xylene } \\
\text { and ethyl bromide }\end{array}$ & $\begin{array}{l}\mathrm{AlBr}_{3}+\text { Halides } \\
\text { of } \mathrm{Na}, \mathrm{K}, \mathrm{Li}, \mathrm{NH}_{4}\end{array}$ & $\begin{array}{l}\text { Conductivity was increased } \\
\text { by halide additions but the } \\
\text { coating quality deteriorated. }\end{array}$ \\
\hline
\end{tabular}


Table 2-2

Amino - Aromatic Type of Electrolyte

\begin{tabular}{|c|c|c|c|c|}
\hline Date & Authors & Solvents & Solutes & Remarks \\
\hline 1951 & Hurley and Wier ${ }^{19}$ & Toluene & $\begin{array}{l}\text { Ethyl pyridinium } \\
\text { bromide }+\mathrm{AlCl}_{3}\end{array}$ & $\begin{array}{l}\text { The electrolyte was difficult to } \\
\text { prepare and too sensitive to } \\
\text { oxygen and moisture. Solute } \\
\text { is excessively expensive. }\end{array}$ \\
\hline 1955 & $\begin{array}{l}\text { Safranek, Schickner } \\
\text { and Faust }\end{array}$ & $\begin{array}{l}\text { Toluene }+ \\
\text { t-butyl ether }\end{array}$ & $\begin{array}{l}\text { Ethyl pyridinium } \\
\text { bromide }+\mathrm{AlCl}_{3}\end{array}$ & $\begin{array}{l}\text { Same remarks as per Hurley } \\
\text { and Wier. However, thicker } \\
\text { coatings were obtained. }\end{array}$ \\
\hline 1956 & Miller and Baker ${ }^{21}$ & $\begin{array}{l}\text { Guanidine } \cdot \mathrm{HCl} \\
\text { benzene, toluene, } \\
\text { xylene, naphthalene }\end{array}$ & $\begin{array}{l}\mathrm{AlCl}_{3}, \mathrm{AlBr}_{3} \\
\mathrm{LiH}\end{array}$ & $\begin{array}{l}\text { Same remarks as per Hurley } \\
\text { and Wier bath. }\end{array}$ \\
\hline
\end{tabular}


Table 2-3

Fther Type of Electrolyte

\begin{tabular}{|c|c|c|c|c|}
\hline Date & Authors & Solvents & Solutes & Remarks \\
\hline 1907 & Plotnikov $^{22}$ & Ether & $\mathrm{AlBr}_{3}$ & $\begin{array}{l}\text { First to find that aluminum } \\
\text { bromide dissolves in ether } \\
\text { to give a low conductivity } \\
\text { bath. }\end{array}$ \\
\hline 1928 & Keyes and Swann ${ }^{23}$ & Ether & $\begin{array}{l}\text { Diethyl aluminum } \\
\text { iodide }\end{array}$ & $\begin{array}{l}\text { Too high potential required: } \\
40 \text { volts neecessary to produce } \\
20 \mathrm{~mA} / \mathrm{cm}^{2} \text {. }\end{array}$ \\
\hline 1952 & Brenner et al. 24,25 & $\begin{array}{l}\text { Ether }+ \\
\beta \beta^{\prime} \text { dichloroethyl } \\
\text { ether }\end{array}$ & $\mathrm{AlCl}_{3}+\mathrm{LiAlH}_{4}$ & $\begin{array}{l}\text { Excellent aluminum deposits. } \\
\text { Electrolyte undergoes electro- } \\
\text { lytic decomposition at the } \\
\text { anode. Too inflammable for } \\
\text { industrial uses. }\end{array}$ \\
\hline 1955 & Heritage et al. 26,27 & $\begin{array}{l}\text { Ether }+ \\
\beta \beta^{\prime} \text { dichlorodiethyl } \\
\text { ether }\end{array}$ & $\mathrm{AlCl}_{3}+\mathrm{LiAlH}_{4}$ & $\begin{array}{l}\text { Same remarks as per Brenner's } \\
\text { bath. Heritage obtained } \\
\text { thicker coatings. }\end{array}$ \\
\hline 1958 & Alm and Binstock ${ }^{28}$ & Ether & $\mathrm{AlCl}_{3}+\mathrm{LiAlH}_{4}$ & $\begin{array}{l}\text { Same remarks as per Brenner's } \\
\text { bath. Alm and Binstock plated } \\
\text { and cladded aluminum on nickel } \\
\text { plated uranium reactors. }\end{array}$ \\
\hline 1959 & Ezle et al. ${ }^{29}$ & Ether & $\mathrm{AlCl}_{3}+\mathrm{LiAlH}_{4}$ & $\begin{array}{l}\text { Same remarks as per Brenner's } \\
\text { bath. Ezle et al. studied the } \\
\text { crystal structure of aluminum } \\
\text { coatings. }\end{array}$ \\
\hline
\end{tabular}


Table 2-3 (Cont'd)

Ether Type of Electrolyte

\begin{tabular}{|c|c|c|c|c|}
\hline Date & Authors & Solvents & Solutes & Remarks \\
\hline 1959 & Cooke and Kritzer 30 & Ether & $\mathrm{AlCl}_{3}+\mathrm{LiAlH}_{4}$ & $\begin{array}{l}\text { Same remarks as per Brenner's } \\
\text { bath. Cooke et al. plated } \\
\text { aluminum on magnesium sub- } \\
\text { strates. }\end{array}$ \\
\hline 1962 & Ziegler and Lehmkuhl ${ }^{31}$ & Ether & $\begin{array}{l}\text { Aluminum ethyl } \\
\text { sodium fluoride }\end{array}$ & $\begin{array}{l}\text { Same remarks as per Brenner's } \\
\text { bath. The electrolyte was, } \\
\text { however, much more conductive. }\end{array}$ \\
\hline 1965 & Hess et al. $32-36$ & Ether & $\mathrm{AlCl}_{3}+\mathrm{LiAlH}_{4}$ & $\begin{array}{l}\text { Same remarks as per Brenner's } \\
\text { bath. Hess et al. electro- } \\
\text { formed a } 1 \text { meter diameter } \\
\text { mirror to be used as a solar } \\
\text { energy concentrator. }\end{array}$ \\
\hline $1953-68$ & $\begin{array}{l}\text { Schickner, Beach, } \\
\text { McGraw and others }\end{array}$ & $\begin{array}{l}\text { Ether }+ \\
2 \text {-ethoxyethyl } \\
\text { trimethylammonium } \\
\text { chloride }\end{array}$ & $\mathrm{AlCl}_{3}+\mathrm{LiAlH}_{4}$ & $\begin{array}{l}\text { Same remarks as per Brenner's } \\
\text { bath. Inflammability of the } \\
\text { bath was decreased. }\end{array}$ \\
\hline 1968 & Lui et al. 44,45 & $\begin{array}{l}\text { Ether + } \\
\text { anisole }\end{array}$ & $\begin{array}{l}\mathrm{AlCl}_{3}+\mathrm{LiAlH}_{4} \\
\text { magnesium salts }\end{array}$ & $\begin{array}{l}\text { Same remarks as per Brenner's } \\
\text { bath. An aluminum plated } \\
\text { matrix about boron fibers } \\
\text { yielded a strong, light weight } \\
\text { structure. }\end{array}$ \\
\hline
\end{tabular}


Table 2-3 (Cont'd)

Ether Type of Electrolyte

\begin{tabular}{|c|c|c|c|c|}
\hline Date & Authors & Solvents & Solutes & Remarks \\
\hline 1968 & Withers and Abrams ${ }^{46}$ & Ether & $\mathrm{AlCl}_{3}+\mathrm{LiAlH}_{4}$ & $\begin{array}{l}\text { Same remarks as per Brenner's } \\
\text { bath. } \mathrm{AlCl}_{3} \text { in the electrolyte } \\
\text { was controlled by density } \\
\text { measurement and the hydride } \\
\text { content by resistivity measure- } \\
\text { ments. }\end{array}$ \\
\hline 1969 & Clay et al. ${ }^{47}$ & Ether & $\mathrm{AlCl}_{3}+\mathrm{LiAlH}_{4}$ & $\begin{array}{l}\text { Same remarks as per Brenner's } \\
\text { bath. Bath life was prolonged } \\
\text { by cleaning the Al anode twice } \\
\text { a day. }\end{array}$ \\
\hline
\end{tabular}


Table 2-4

Amino and Amide Type of Electrolyte

\begin{tabular}{|c|c|c|c|c|}
\hline Date & Authors & Solvents & Solute & Remarks \\
\hline 1933 & Blue and Mathers ${ }^{48}$ & Formamide & $\mathrm{AlCl}_{3}$ & $\begin{array}{l}\text { Aluminum alloys were plated, } \\
\text { but no pure aluminum. }\end{array}$ \\
\hline 1951 & Murphy and Dumas 49 & $\begin{array}{l}\text { Ethylhexylamine + } \\
\text { ether }\end{array}$ & $\mathrm{AlCl}_{3}$ & $\begin{array}{l}\text { Electrolyte was difficult to } \\
\text { prepare; cooling and refluxing } \\
\text { were required. Commercial } \\
\text { purity solute gave poor deposits. }\end{array}$ \\
\hline 1961 & Holland 50 & $\begin{array}{l}\text { Formamide, nitro- } \\
\text { benzene, benzoyl } \\
\text { chloride }\end{array}$ & $\mathrm{AlCl}_{3}$ & $\begin{array}{l}\text { It is believed that Al alloys } \\
\text { were deposited instead of } \\
\text { Al metal. }\end{array}$ \\
\hline 1965 & Menzies and Salt ${ }^{51}$ & Butyl amine, ether & $\mathrm{AlCl}_{3}$ & $\begin{array}{l}\text { Bath difficult to prepare; } \\
\text { sublimation of solute and } \\
\text { drying of solvent were re- } \\
\text { quired. }\end{array}$ \\
\hline
\end{tabular}


Table 2-5

Aromatic Type of Electrolyte

\begin{tabular}{|c|c|c|c|c|}
\hline Date & Author & Solvents & Solutes & Remarks \\
\hline 1916 & Lalbin $^{53}$ & $\begin{array}{l}\text { Acetonitrile, } \\
\text { toluene, or } \\
\text { xylene }\end{array}$ & $\mathrm{AlCl}_{3}$ & $\begin{array}{l}\text { Doubtful results. Other } \\
\text { workers were not able to } \\
\text { obtain aluminum deposits. }\end{array}$ \\
\hline 1940 & Menzel $^{54}$ & Xylene & $\begin{array}{l}\mathrm{AlCl}_{3}+ \\
\text { aluminum alkyl }\end{array}$ & $\begin{array}{l}\text { The solute was expensive and } \\
\text { difficult to prepare. Thick- } \\
\text { ness and quality of coatings } \\
\text { were not reported. }\end{array}$ \\
\hline 1952 & Kalynzhuaya ${ }^{55}$ & Xylene & $\begin{array}{l}\mathrm{AlBr}_{3} \\
\mathrm{AlCl}_{3}\end{array}$ or & $\begin{array}{l}\text { A tar-like material was ob- } \\
\text { tained especially with } \mathrm{AlCl}_{3} \\
\text { upon the passage of the } \\
\text { current through the electrolyte. }\end{array}$ \\
\hline 1965 & $\begin{array}{l}\text { Levinskiene and } \\
\text { Simanavicius } 56,52\end{array}$ & Xylene & $\mathrm{AlBr}_{3}$ & $\begin{array}{l}\text { Obtained aluminum coatings } \\
\text { from electrolytes }>25 \text { mole } \% \\
\mathrm{AlBr}_{3} \cdot \quad \text { Coatings were dark. }\end{array}$ \\
\hline
\end{tabular}




\subsection{Some Unsuccessful Previous Work (Table 2-6)}

W. R. Mott ${ }^{58}$ attempted to plate aluminum without success from a solution of $\mathrm{AlBr}_{3}$ in acetone and $\mathrm{AlBr}_{3}$ in methyl and ethyl alcohol.

H. Rßhler ${ }^{59}$ deposited some metals from formamide but failed to deposit aluminum from this solvent.

Keyes and $\mathrm{Swann}^{23}$ attempted to plate aluminum from an electrolyte of aluminum formate in glacial acetic acid with no success. Aluminum acetate was dissolved in many different solvents such as: benzyl alcohol, acetanhydride, furfural, methyl alcohol, acetone, isobutyl alcohol, amyl alcohol and nitrobenzene. None of these solutions passed any current even at 110 volts.

Methyl sulphate was tried as a solvent because of its high dielectric constant, but none of the salts of aluminum was soluble in this medium. Aluminum malonic ester was electrolyzed in $\mathrm{CS}_{2}$ but no deposit was obtained.

Dirkse and Briscoe ${ }^{60}$ succeeded in depositing traces of aluminum from ethanolamine solutions of aluminum salts, but they we re unsuccessful with acetamide, aniline, pyridine, benzoyl chloride and glacial acetic acid solutions. Similarly Blue and Mathers $\mathbf{s}^{48}$ found that pure aluminum could not be deposited from a solution of $\mathrm{AlCl}_{3}$ in formamide, while Muller, Holzl, Knaus, Planiszig and Prett ${ }^{61}$ were unable to deposit the metal from a solution of $\mathrm{AlBr}_{3}$ in anhydrous pyridine. Attempts by Beal and $\mathrm{Mann}^{62}$ to deposit aluminum from aluminum perchlorate solutions in the monoethyl ether of ethylene glycol (cellosolve) 
Table 2-6

Unsuccessful Electrolytes

\begin{tabular}{|c|c|c|c|c|}
\hline Date & Authors & Solvents & Solute & Remarks \\
\hline 1904 & $\begin{array}{c}\text { Mott }^{58} \\
\end{array}$ & $\begin{array}{l}\text { Acetone, } \\
\text { Alcohol }\end{array}$ & $\underset{\|}{\mathrm{AlBr}_{3}}$ & No plating \\
\hline 1910 & Rohler ${ }^{59}$ & Formamide & $\mathrm{AlBr}_{3}$ & " \\
\hline 1924 & $\begin{array}{l}\text { Muller, Holzl, } \\
\text { Knaus, Planiszig, } \\
\text { and Prett } 61\end{array}$ & Pyridine & $\mathrm{AlBr}_{3}$ & " \\
\hline 1930 & Keyes and Swann ${ }^{23}$ & $\begin{array}{l}\text { Acetic acid } \\
\text { Benzyl alcohol } \\
\text { Acetanhydride } \\
\text { Furfural } \\
\text { Methyl alcohol } \\
\text { Acetone } \\
\text { Isobutyl alcohol } \\
\text { Amyl alcohol } \\
\text { Nitrobenzene } \\
\text { Carbon disulfide }\end{array}$ & $\begin{array}{l}\text { Al formate } \\
\mathrm{Al} \text { acetate } \\
" 1 \\
" \\
" \\
" \\
" \\
" \\
\text { " } \\
\text { Al malonic ester }\end{array}$ & $\begin{array}{l}\text { " } \\
" 1 \\
" 1 \\
" 1 \\
" 1 \\
" 1 \\
" 1\end{array}$ \\
\hline 1938 & Dirkse and Briscoe 60 & $\begin{array}{l}\text { Acetamide } \\
\text { Aniline } \\
\text { Benzoyl chloride }\end{array}$ & $\begin{array}{c}\text { Al halide } \\
" \\
"\end{array}$ & $\begin{array}{l}11 \\
" 1\end{array}$ \\
\hline 1938 & Beal and Mann 62 & Cellosolve & Al halide & $"$ \\
\hline
\end{tabular}


also were not successful.

Tests by Wertyporoch and Adamus ${ }^{63}$ and Wertyporoch and Silber 64 showed that a number of aldehydes and aromatic hydrocarbons readily dissolve $\mathrm{AlBr}_{3}$ and $\mathrm{AlCl}_{3}$ but that the solutions are either poor or non conductors.

\subsection{Summary of Part One}

The literature review has shown that a great many organic electrolytes have been proposed for the electrodeposition of aluminum. However, the ether electrolyte is the only one which produces good plating and hence it is the only one to have found practical use. Moreover, because of cost, inflammability of the ether electrolytes and the difficulty of electrolyte preparation, the electroplating of aluminum from ether electrolytes has been restricted, in particular to very specialized space applications. 
PART TWO

EXPERIMENTAL AND RESULTS 


\section{PART TWO - EXPERIMENTAL AND RESULTS}

The experimental part of this research has been divided into the following four sections:

I. An exploratory programme in which the suitability of a number of types of electrolytes for aluminum electrodeposition was investigated.

II. A more detailed study of two of the more effective electrolyte systems (ethylbenzene, diethylbenzene).

III. A study of the life of the most effective electrolyte and an examination of methods for maintaining good electrolyte performance.

IV. A study of cathode polarization behaviour and deposition mechanisms in the ethylbenzene-toluene system. 


\subsection{EXPLORATORY INVESTIGATION}

The difficulty of plating aluminum from aqueous electrolytes was emphasized in section 1.1 of this work. The literary review has shown, moreover, that aluminum can be electrodeposited from many organic electrolytes and yet, to date, none has had any significant industrial success.

The object of this exploratory investigation was to find a roomtemperature electrolyte suitable for the electrodeposition of aluminum on an industrial scale. The following properties were considered essential for an acceptable electrolyte:

A. The solvent component of the electrolyte must be capable of easily dissolving an aluminum salt.

B. Good electrical conductivity.

C. Capability of releasing aluminum ions to yield metal on electrolysis.

D. Resistance of the solvent to its own electrolytic decomposition.

E. Stability in contact with the atmosphere.

F. Simplicity of preparation.

G. Low inflammability (high flash point).

H. Ability to provide decorative, ductile and well adherent aluminum coatings.

I. Low cost. 


\subsection{Theoretical Concepts}

In addition to considering the above criteria for the commercial success of the electrolytes, an attempt was made to find a basis for the choice of electrolytes from which aluminum plating would be possible. The theoretical criteria considered are discussed in the following section.

\section{A. Dielectric Constant of the Solvent}

Criteria based on experience with aqueous solutions do not always apply to organic solvents. For example, aqueous solvents having a high dielectric constant have been considered ideal for dissolving solutes having polar molecules to produce electrolytes of high conductivity. This criterion does not always apply, however, to organic solvents. Ether, for instance, which has a dielectric constant of 4.5 is equally as good a solvent ${ }^{7}$ for polar molecules of aluminum salt as HCN which has a dielectric constant of 95 .

\section{B. Electrical Conductivity}

The electrical conductivity of the solvent has also been found to give no indication of the value of a solvent. Water and other polar solvents such as acetone and alcohol, which form conducting solutions, have themselves an appreciable conductivity of about $10^{-7} \mathrm{ohm}^{-1} \mathrm{~cm}^{-1}$. Ether, on the other hand, with a conductivity of only $10^{-13} \mathrm{ohm}^{-1} \mathrm{~cm}^{-1}$ and toluene with a conductivity of only $10^{-14} \mathrm{ohm}^{-1} \mathrm{~cm}^{-1}$ have formed electrolytes equally as conductive as acetone and alcohol. 


\section{Strength of Aluminum Complexing}

In addition to having a high electrical conductivity an electrolyte must be able to release aluminum from its ion to yield a metal on electrolysis. Brenner ${ }^{6}$ suggests that the best electrolytes are composed of solvents and solutes that can coordinate mutually, i.e., Lewis acids plus Lewis bases.

The only solvents which can be used successfully to plate aluminum are those containing weak coordination centres, for example, the oxygen atom of an ether or the double bond of an aromatic hydrocarbon. Solvents with more unsaturated and hence stronger coordinating centres such as nitrogen or carbonyl groups, form too stable an aluminum complex and the aluminum is not released from the complex upon electrolysis.

Solvents which have no coordination ability, e.g., aliphatic hydrocarbons, do not, however, form suitably conductive solutions.

\section{Suitable Solutes}

The most useful solutes yet found are: certain anhydrous halides, metal alkyls, hydrides and borohydrides. The conventional solutes such as salts of oxyacids which are useful for aqueous solutions have been found to be of no value in non aqueous plating.

Further advances depend, then, on the development of the chemistry of aluminum complexes, and most likely of aromatic complexes, and as Brenner has pointed out, it is likely that the type of complex which will completely solve the problem of depositing reactive metals has yet to be 
prepared.

\section{E. Some Aromatic Complexes of Aluminum}

Since the aromatic hydrocarbons belong to the category of solvents having weak coordination centres, a literary review of the complexes formed by aromatic hydrocarbons with aluminum halides was made.

Gustavson $^{66}$ (1878) found that when anhydrous aluminum bromide or chloride react with benzene or toluene in the presence of a hydrogen halide, a red oily liquid is formed. Cryoscopic studies gave evidence of complex formation. The assigned empirical formulas $\mathrm{Al}_{2} \mathrm{Br}_{6} \cdot 6 \mathrm{C}_{6} \mathrm{H}_{6}$ and $\mathrm{Al}_{2} \mathrm{Br}_{6} \cdot 6 \mathrm{C}_{6} \mathrm{H}_{5} \mathrm{CH}_{3}$ do not indicate, however, the role of the hydrogen halide in the complex.

J.F. Norris and D. Rubinstein 67 prepared the red liquid from aluminum bromide and toluene in the presence of hydrogen bromide, and evaporated the mixture at room temperature at 10 to $11 \mathrm{~mm}$ of mercury, absolute pressure. The non volatile product was identified as having the formula $\mathrm{Al}_{2} \mathrm{Br}_{6} \cdot \mathrm{C}_{6} \mathrm{H}_{5} \mathrm{CH}_{3}$. The ratio of $\mathrm{C}_{6} \mathrm{H}_{5} \mathrm{CH}_{3}$ to $\mathrm{Al}_{2} \mathrm{Br}_{6}$ ranged from $6: 1$ in dilute solutions of $\mathrm{AlBr}_{3}$ to $1: 1$ in concentrated $\mathrm{AlBr}_{3}$ solutions.

H. C. Brown and H.W. Pearsall ${ }^{68}$ and H.C. Brown and W.J. Wallace ${ }^{69}$ later suggested the formation of $\sigma$ (sigma) complexes or salt of carbonium ions $\left(\mathrm{ArH}_{2}{ }^{+}\right)$, which are formed by the reaction:

$$
\begin{aligned}
& \mathrm{ArH}+\mathrm{HX}+\mathrm{Al}_{2} \mathrm{X}_{6} \rightleftarrows \mathrm{ArH}_{2}{ }^{+}+\mathrm{Al}_{2} \mathrm{X}_{7}^{-} \\
& \text {or: } \quad \mathrm{ArH}+\mathrm{HX}+\frac{1}{2} \mathrm{Al}_{2} \mathrm{X}_{6} \rightleftarrows \mathrm{ArH}_{2}^{+}+\mathrm{AlX}_{4}^{-}
\end{aligned}
$$


where ArH is an aromatic hydrocarbon, and $\mathrm{X}$ a halogen. The formation of these ions can explain the considerable conductivity of these electrolytes.

Brown and Wallace ${ }^{69}$ further determined that the solubility of $\mathrm{HBr}$ increases from benzene to mesitylene in the following order: benzene < toluene $<\mathrm{m}$-xylene $<$ mesitylene. This behaviour was also found for hydrogen chloride, ${ }^{53}$ i.e., the solubility increases in the order chlorobenzene $<$ benzene $<$ toluene $<$ m-xylene $<$ mesitylene. In both cases the stability of the complexes has been determined to increase in these same ascending orders.

\section{F. Binary Aromatic Complexes of Aluminum}

Menskutkin ${ }^{70}$ (1908) reported on the basis of thermal analysis studies that no complexes were formed between aluminum halides and benzene, toluene, or xylene, unless hydrogen bromide or moisture were present in the solvents.

Plotnikov and Gratianskii ${ }^{71}$ (1947) concluded from melting pointcomposition studies, however, that aluminum bromide does, in fact, form complexes with benzene, $\mathrm{p}$-xylene and $\mathrm{m}$-xylene and that the complexes melt incongruently at $37,31.2$, and 34.5 degrees centigrade. They assigned the empirical formula $\mathrm{AlBr}_{3} \cdot \mathrm{ArH}$ where $\mathrm{ArH}$ is an aromatic hydrocarbon. A study by Eley and King ${ }^{72}$ confirmed Plotnikov's conclusions with regard to the formation of the complex $\mathrm{AlBr}_{3} \cdot \mathrm{C}_{6} \mathrm{H}_{6}$ with an incongruent melting point of $37^{\circ} \mathrm{C}$. 
Van Dyke ${ }^{73}$ (1950) concluded from vapor pressure - composition studies and cryoscopic measurements, however, that these complexes should be formulated as $\mathrm{Al}_{2} \mathrm{Br}_{6} \cdot 2 \mathrm{C}_{6} \mathrm{H}_{6}$ since aluminum bromide exhibits the dimeric molecular weight in benzene solutions.

One year later Eley and King ${ }^{74}$ reported that a spectrometric investigation of solutions of aluminum bromide in benzene showed a characteristic absorption band at $2785 \stackrel{\circ}{\AA}$. These authors attributed this absorption band to an $\mathrm{Al}_{2} \mathrm{Br}_{6} \cdot \mathrm{n}_{6} \mathrm{H}_{6}$ complex with $\mathrm{n}$ probably having the value of 1 . These authors also showed that the aluminum bromide-benzene solutions obey Beer's law over a wide range of concentration, thus providing strong evidence against dissociation of $\mathrm{Al}_{2} \mathrm{Br}_{6}$ into $2 \mathrm{AlBr}_{3}$ as suggested by Plotnikov. ${ }^{71}$

H.C. Brown and W.J. Wallace, ${ }^{75}$ on the other hand, reported on the basis of vapor pressure composition-phase studies at $17.7^{\circ} \mathrm{C}$, the existence of solid compounds $\mathrm{Al}_{2} \mathrm{Br}_{6} \cdot \mathrm{ArH}$ in benzene and toluene, and also the existence of a dimeric formula $\mathrm{Al}_{2} \mathrm{Br}_{6}$ for aluminum bromide in these solvents. They suggested that the complexes are probably $\pi$ complexes $^{76}$ with the structure:

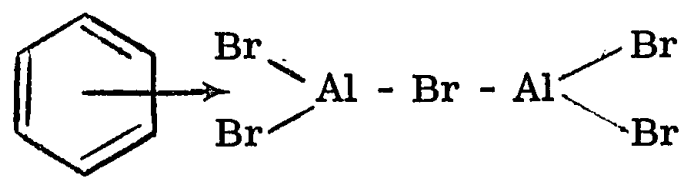

that is $\mathrm{Al}_{2} \mathrm{X}_{6}+\mathrm{ArH} \rightarrow\left(\mathrm{Al}_{2} \mathrm{X}_{5} \cdot \mathrm{ArH}\right)^{+}+\mathrm{X}^{-}$

According to Brown and Wallace ${ }^{75}$ the increase in intensity of the colour of the solution of aluminum bromide in the ascending order: 
benzene, toluene, m-xylene to mesitylene, found by Eley and King ${ }^{74}$ in their spectrometric investigations, supports the conclusion that these solutions contain an increasing concentration of $\mathrm{Al}_{2} \mathrm{Br}_{6} \cdot \mathrm{ArH}$ complexes in this solvent order.

Lebedev and Korshak $77,78,79$ suggested the formula for the complex compounds of aluminum halides with organic solvents to be: $\left(\mathrm{AlX}_{2} \cdot \mathrm{nSlv} .\right)^{+}\left(\mathrm{AlX}_{4}\right)^{-}$where Slv. denotes solvent. Kessler with co-workers ${ }^{80}$ considered this scheme to be the most probable, and adopted the value of 2 for $n$.

It is clear from the above discussion that the exact structure of binary and ternary aluminum halide-aromatic complexes has not yet been completely established.

\section{G. The Electrolytic Decomposition of Organic Solvents}

Since the organic solvent forms an important part of the electrolyte, knowledge concerning the behaviour of the solvent itself during electrolysis is of prime importance.

The importance of examining solvent behaviour is well-illustrated in the case of aqueous electrolytes for which intensive investigations into the electrolysis of water and the decomposition potentials and overvoltages of hydrogen and oxygen have helped considerably in devising electrodeposition procedures. Knowledge about the electrolytic behaviour of organic solvents is limited, however, and only about a dozen organic solvents ${ }^{7}$ have been investigated. 
The electrolysis of organic liquids has been found to result in complex electrode reactions with the formation of compounds often more complex than the initial organic liquids. To complicate analysis of these systems, more than one compound may be formed and some of these may be in the form of tars. ${ }^{55}$ Thus the electrolysis of pure solvents is: often more in the nature of an electrolytic synthesis than a decomposition.

Gillet $^{81}$ electrolysed various solutions of anhydrous diethyl ether, and obtained products showing that ether itself can react at both electrodes. Gillet further reported that sometimes ether is the only reacting substance, the solutes being only conducting additives. The dynamic potentials involved indicated that the electrolytic decomposition of ether is a true electrode reaction, and that the decomposition is responsible for the faradaic current. Furthermore the decomposition takes place at a definite electrode potential, independent of the nature of the solute.

Levinskiene and Simanavicius ${ }^{82}$ studied the electrolysis of aluminum bromide in xylene and obtained polarization curves showing that two processes were taking place on the cathode during the electrolysis. They deduced that the process taking place at $0.65-0.70$ volts on a platinum cathode or at $0.15-0.20$ volts on a copper cathode, was a reduction of the carbonium ions $67,68 \quad\left[\mathrm{C}_{6} \mathrm{H}_{4}\left(\mathrm{CH}_{3}\right)_{2} \mathrm{H}\right]{ }^{+}$to form a mixture of xylene and dihydroxylene; the decomposition potential being independent of the HBr concentration. 
It was seen in Section 3.2-E that one of the possible complexes formed in the presence of $\mathrm{HBr}$ is:

$$
\mathrm{C}_{6} \mathrm{H}_{4}\left(\mathrm{CH}_{3}\right)_{2}+\mathrm{HBr}+\mathrm{Al}_{2} \mathrm{Br}_{6} \rightarrow \mathrm{C}_{6} \mathrm{H}_{4}\left(\mathrm{CH}_{3}\right)_{2} \mathrm{H}^{+}+\mathrm{Al}_{2} \mathrm{Br}_{7}^{-}
$$

The proposal that the positive ions $\mathrm{C}_{6} \mathrm{H}_{6}\left(\mathrm{CH}_{3}\right)_{2} \mathrm{H}^{+}$are reduced on the cathode as a distinct process was confirmed by microscopic observation of the cathode during electrolysis. Drops of a clear liquid were formed on the cathode and these were identified as being a mixture of xylene and dihydroxylenes. The probable reaction mechanism for the process was suggested to be the following:

$$
2\left[\mathrm{C}_{6} \mathrm{H}_{4}\left(\mathrm{CH}_{3}\right)_{2} \mathrm{H}\right]^{+}+2 \mathrm{e}^{-} \rightarrow \mathrm{C}_{6} \mathrm{H}_{4}\left(\mathrm{CH}_{3}\right)_{2}+\mathrm{C}_{6} \mathrm{H}_{6}\left(\mathrm{CH}_{3}\right)_{2}
$$

\section{H. Mechanism of Aluminum Electrodeposition}

The mechanism of the second reduction process, namely the reduction of aluminum is considered by Levinskiene et $\mathrm{al}^{82}$ to be as follows: aluminum is assumed to be deposited on the cathode from $\mathrm{AlBr}_{2}{ }^{+}$ions combined with a certain number of organic molecules and possibly also from neutral $\mathrm{AlBr}_{3}$ molecules, the separation of the latter from the complex occurring in the layer at the cathode. The following scheme was suggested:

$$
\mathrm{AlBr}_{2} \cdot \mathrm{n}\left(\mathrm{CH}_{4}\right)\left(\mathrm{CH}_{3}\right)_{2}++3 \mathrm{e}^{-} \rightarrow \mathrm{Al}+\mathrm{nC}_{6} \mathrm{H}_{4}\left(\mathrm{CH}_{3}\right)_{2}+2 \mathrm{Br}^{-}
$$

The process begins at the cathode potential of -0.10 to -0.15 volts.

\section{Summary}

In summary, analysis of the existing information on organic electrolysis and metallo-organic complexing suggested that the solvents 
most worth studying would be those with relatively weak coordination centres, i.e., those forming relatively weak aluminum complexes. The most promising solvents having weak coordination centres appeared to be benzene and its alkyl and halo derivatives. The most suitable solutes appeared to be the aluminum halides.

\subsection{Exploratory Experiments}

The exploratory investigation focussed upon binary electrolytes consisting of an aromatic hydrocarbon and an aluminum halide, usually aluminum bromide. If the binary electrolyte appeared to be promising, a more common and less expensive solvent, e.g., benzene or toluene, was added to the electrolytes and the behaviour of the ternary system was tested.

In brief, the study consisted of a series of experiments in which aluminum was plated onto a metal cathode, usually copper, from an aluminum anode via the various experimental electrolytes. All experiments were carried out under standard conditions so that the behaviour of the electrolytes could be directly compared.

The investigation was centered upon finding practical electrolytes and for this reason technical grade solvents and solutes were employed throughout this part of the work.

Details of the experiments in the exploration investigation have been described in full in a previous thesis. ${ }^{83}$ 


\subsection{Summary of Results of the Exploratory Investigation}

The results of the exploratory tests are summarized in Table 3-1. The appearance of the aluminum coatings from selected electrolytes is shown in the photograph of Figure 3-1.

The plating performance recorded in Table $3-1$ is qualitative, and it has been estimated on the basis of appearance of the coating, its adherence to the substrate, and the consistency of performance of the electrolyte.

The tests clearly indicated that solvents in the ethylbenzene family are the most promising for aluminum plating. Plating quality has been the best with electrolytes based upon ethylbenzene and diethylbenzene and a majority of electrolytes based on these solvents avoid gas evolution.

Other materials of the same nature which might be used are: tertiary butylbenzene, normal amylbenzene, and the chloro, bromo and iodo derivatives of the previously mentioned solvents.

\subsection{Other Solutes Investigated}

Although the literature indicated that aluminum bromide was likely to be the most promising solute, a number of experiments were carried out using alternate halides, i. e., $\mathrm{AlCl}_{3}$ and $\mathrm{AlI}_{3} \cdot$ Neither $\mathrm{AlCl}_{3}$ nor $\mathrm{AlI}_{3}$ was satisfactory.

3.5 Conclusions Drawn from the Exploratory Investigation The exploratory investigation showed clearly that the most promising of the alkyl benzene solvents for the purpose of aluminum electrodeposition 
were ethylbenzene and diethylbenzene. The experiments also showed that the addition of toluene to the ethylbenzene and diethylbenzene electrolytes (solute of $\mathrm{AlBr}_{3}$ ) resulted in improved plating efficiency and electrolyte performance. $\mathrm{AlBr}_{3}$ was determined to be the only suitable solute. 


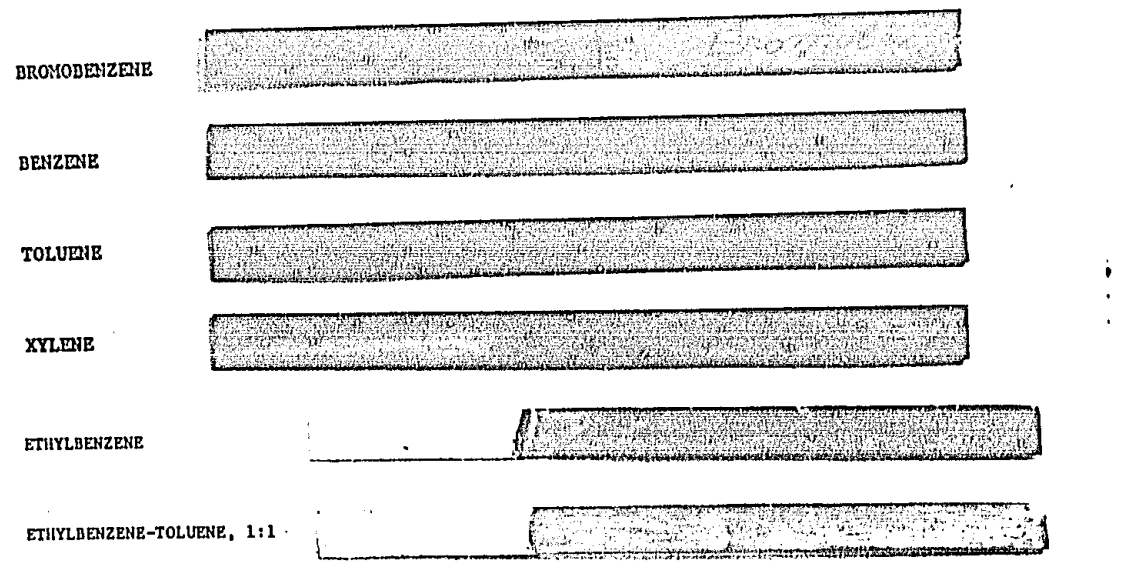

Figure 3-1. Appearance of aluminum coatings from selected exploratory electrolytes. 
Table 3-1: Summary of Results of the Exploratory Investigations

\begin{tabular}{|c|c|c|c|}
\hline Solvents & $\begin{array}{c}\text { Gas } \\
\text { Evolution }\end{array}$ & $\begin{array}{l}\text { Plating } \\
\text { Quality }\end{array}$ & Results and Comments \\
\hline Benzene & - & $\begin{array}{l}\overline{\text { Non }} \\
\text { Metallic }\end{array}$ & $\begin{array}{l}\text { Only asphalt like } \\
\text { material plated. }\end{array}$ \\
\hline Bromobenzene & - & $\begin{array}{l}\text { Non } \\
\text { Metallic }\end{array}$ & $\begin{array}{l}\text { Only asphalt like } \\
\text { material plated. }\end{array}$ \\
\hline Toluene & None & Poor & Black deposits. \\
\hline Xylene & $\mathrm{H}_{2}$ & Fair & Dark grey coatings. \\
\hline Ethylbenzene & None & Very Good & $\begin{array}{l}\text { Cathode efficiency up } \\
\text { to } 80 \% \text {. }\end{array}$ \\
\hline Ethylbenzene-Toluene $(1: 1)^{*}$ & None & Excellent & $\begin{array}{l}\text { Improved electrolyte per- } \\
\text { formance over ethyl- } \\
\text { benzene alone. }\end{array}$ \\
\hline Ethylbenzene-Benzene $(1: 1)$ & None & Good & \\
\hline Ethylbenzene-Xylene $(1: 1)$ & $\mathrm{H}_{2}$ & Good & \\
\hline Ethylbenzene-Cymene $(1: 1)$ & None & Good & \\
\hline Ethylbenzene-Bromobenzene (1:1) & 1) None & Good & \\
\hline Diethylbenzene & None & Very Good & $\begin{array}{l}\text { Cathode efficiency up } \\
\text { to } 75 \% \text {. }\end{array}$ \\
\hline Diethylbenzene-Toluene $(1: 1)$ & None & Excellent & $\begin{array}{l}\text { Improved electrolyte per- } \\
\text { formance over diethyl- } \\
\text { benzene alone. }\end{array}$ \\
\hline Diethylbenzene-Benzene $(1: 1)$ & None & Good & \\
\hline Triethylbenzene & None & Fair & $\begin{array}{l}\text { Low cathode efficiency } \\
(20 \%) \text {. }\end{array}$ \\
\hline Triethylbenzene-Benzene $(1: 1)$ & - & Poor & Black coating. \\
\hline Trimethylbenzene (Mesitylene) & $\mathrm{H}_{2}$ & Good & $\begin{array}{l}\text { Cathode efficiency up to } \\
75 \% \text {. }\end{array}$ \\
\hline Trimethylbenzene-Benzene $(1: 1)$ & $\mathrm{H}_{2}$ & Fair & \\
\hline \multicolumn{4}{|l|}{ Tetramethylbenzene (Durene) } \\
\hline $20 \%$ in Toluene & $\mathrm{H}_{2}$ & Good & $\begin{array}{l}\text { Durene is solid at room } \\
\text { temperature. }\end{array}$ \\
\hline $20 \%$ in Benzene & - & No Plating & \\
\hline Isopropylbenzene & None & Good & \\
\hline Isopropylbenzene-Benzene $(1: 1)$ & None & Good & \\
\hline Isopropylbenzene-Toluene $(1: 1)$ & None & Good & \\
\hline Methylisopropylbenzene (Cymene & e) - & Poor & Black coating. \\
\hline Cymene-Benzene & - & No Plating & \\
\hline
\end{tabular}




\subsection{A STUDY OF ELECTROLYTES BASED UPON ETHYL- BENZENE AND DIETHYLBENZENE}

Ethylbenzene and diethylbenzene were the most promising solvents found in the exploratory experiments and thus the second part of the experimental investigation was concentraied upon experimental studies of plating from electrolytes based on these two solvents.

The aims of the study were to determine the most suitable electrolyte compositions and operating conditions. In addition the effects of the addition of less expensive solvents, such as xylene, toluene and benzene at various concentrations were studied.

Electrode current efficiency, electrolyte conductivity, and plating quality were considered to be the most important factors and they were determined as a function of plating time for each solvent or solvent pair at various $\mathrm{HBr}$ concentrations.

\subsection{The Investigation}

The solvents and solvent mixtures investigated were:

1. Ethylbenzene

2. Toluene

3. Ethylbenzene - toluene $1: 4$

4. Ethylbenzene - toluene $1: 1$

5. Xylene

6. Ethylbenzene - xylene $1: 4$

7. Ethylbenzene - xylene 1:1

8. Diethylbenzene

9. Diethylbenzene - toluene $1: 4$ 
10. Diethylbenzene-toluene $1: 1$

11. Benzene

12. Diethylbenzene-benzene $1: 4$

13. Diethylbenzene-benzene 1:1

The solute in each system was aluminum bromide in concentrations of $36.4 \%, 45.4 \%$, and $53.4 \% \mathrm{AlBr}_{3}$ (weight).

\subsection{Experimental Details}

\section{A. Apparatus}

The electrolysis cell used (Fig. 4-1) consisted of a $400 \mathrm{ml}$ electrolytic pyrex beaker and a $2.5 \mathrm{~cm}$ thick Teflon cover (Commercial Plastic and Supply Corporation, Montreal), through which two flat aluminum anodes, each $11 / 2 \mathrm{~cm}$ wide, $1 \mathrm{~mm}$ thick and $18 \mathrm{~cm}$ long, and a copper cathode $1 \mathrm{~cm}$ wide, $0.5 \mathrm{~mm}$ thick and $18 \mathrm{~cm}$ long were inserted. These sizes were chosen for convenience due to the limited space in the cell cover.

A "Tacussel" direct reading conductimeter type CD7A (TechnEurop, Montreal) was used at a frequency of 5000 Hertz for the conductivity determination. The conductivity cell used ("Tacussel" Type CM .01/G) contained two black platinized platinum electrodes having an area of $5 \times 5 \mathrm{~mm}$ and placed $0.4 \mathrm{~cm}$ apart. The cell was $15.5 \mathrm{~cm}$ long and $0.8 \mathrm{~cm}$ in diameter. It was calibrated ${ }^{85}$ with triple distilled water and reagent grade $\mathrm{KCl}$ (Appendix II). 
Figure 4-1

Detail of Electrolysis Cell
A. Inlet of dry argon, saturated with solvent vapour
B. Argon outlet
C. Teflon cap with "O" ring seal
D. Anode and cathode connections through corks
E. Pyrex $400 \mathrm{ml}$ electrolysis beaker
F. Aluminum anode
G. Copper cathode
H. Aluminum anode
I. Thermometer
J. Conductivity cell
K. Teflon covered magnetic stirrer
L. Electrolyte 


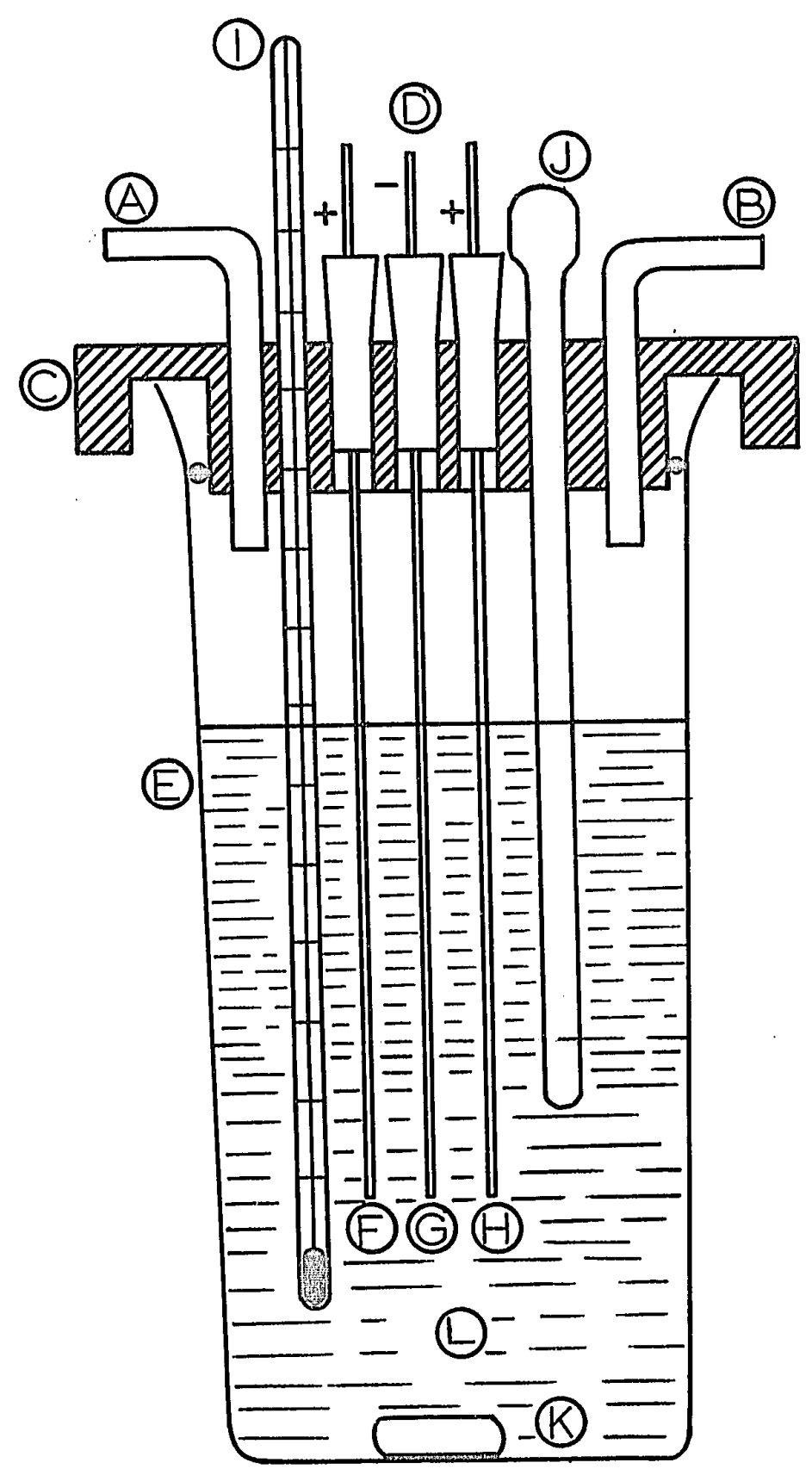


A silver coulometer was used for the calibration of the ammeter and for the study of cathodic current efficiency. The silver coulometer consisted of: a $100 \mathrm{ml}$ platinum crucible (Johnson Matthey and Mallory Limited, Toronto) containing $75 \mathrm{ml}$ of $15 \%$ weight solution of silver nitrate. A spectrograde $0.6 \mathrm{~cm}$ diameter silver anode (Johnson Matthey and Mallory Limited, Toronto) was suspended in the $\mathrm{AgNO}_{3}$ solution and held in position by fastening it with a screw on a plastic bar.

Stirring of the coulometer was accomplished by using a micro magnet Teflon covered bar in conjunction with an external magnetic stirrer (Fisher Scientific, Montreal).

The coulometer was connected in series with the aluminum electrolysis cell, and the quantity of electricity passed through the circuit was calculated directly from the amount of silver deposited on the wall of the platinum crucible, assuming $100 \%$ current efficiency.

D.C. current was supplied by a 10 ampere, 25 volt "ART" rectifier (ART Electronics Inc., St. Paul, Minnesota, U.S.A.). (See Fig. 4-2.)

The potential applied during electrolysis was measured on a high impedance "Tacussel" (TechnEurop, Montreal) electronic millivoltmeter type S70AS (max. potential 8 volts) and the current was recorded on a calibrated "Tacussel" milliammeter, type MAR298, which could be read to 1 milliampere. Potentials higher than 8 volts were measured on a "Simpson" type 311-2 vacuum tube volt-ohmmeter (Payette Radio Ltée, Montreal). 
Figure 4-2

Diagram of Electrical Circuit 


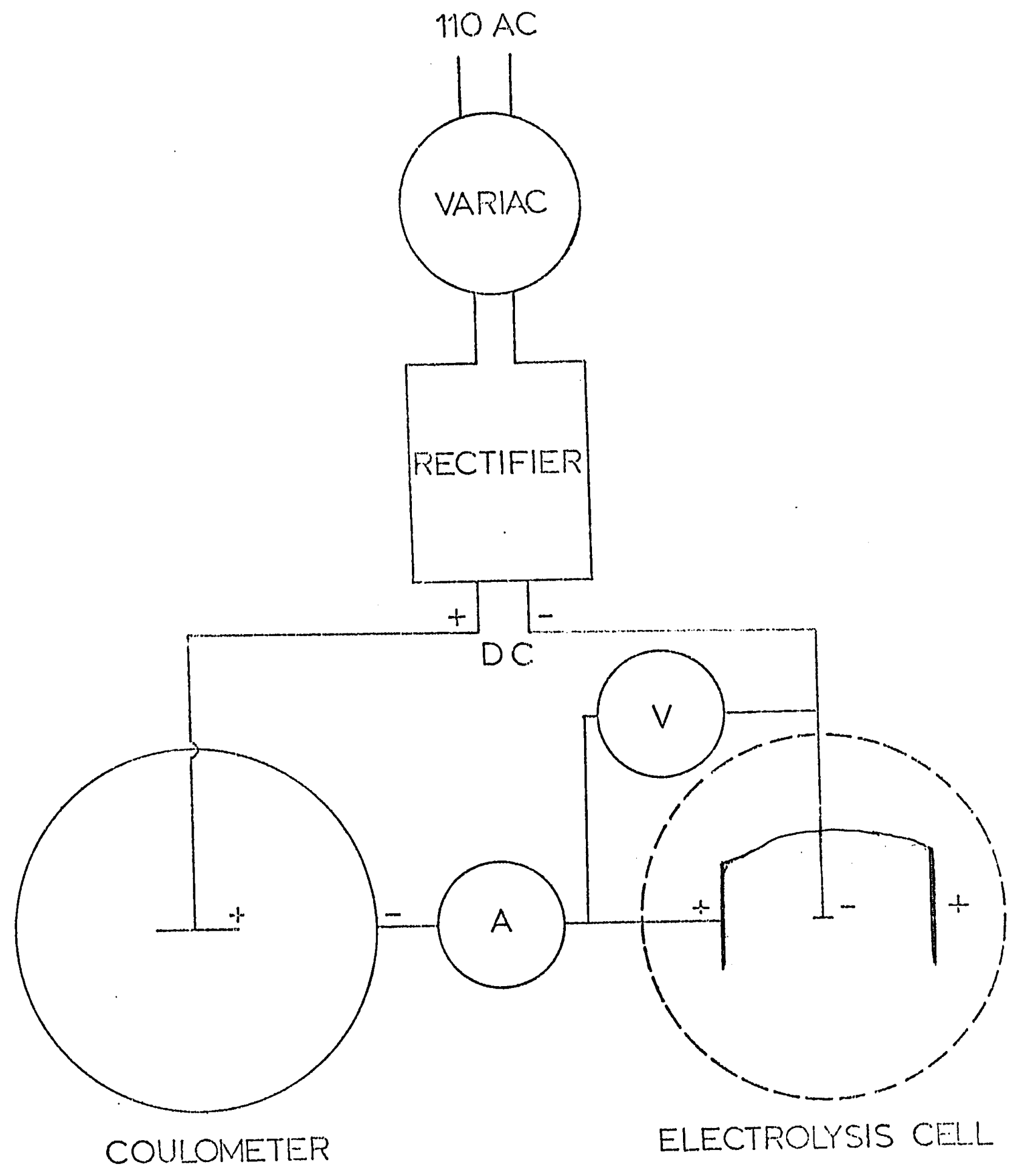


B. Materials

Copper Cathode:

Aluminum Anode:

Aluminum Bromide:

Argon:

Benzene:

Diethylbenzene:

Ethylbenzene:

Toluene:

Xylene:
Cold rolled copper sheet, manufactured to SAE71 (99.9+\% copper) supplied by Drummond McCall Ltd. , Montreal.

Alcan aluminum sheet $2 \mathrm{~S}$ grade (99\% minimum purity aluminum), Drummond McCall Ltd., Montreal.

Anhydrous, Technical grade. Alpha Inorganics Inc., Beverly, Massachusetts, U.S.A.

Technical grade. $99.99 \%$ Ar, 20 p.p.m. $\mathrm{N}_{2}$,

20 p.p.m. $\mathrm{O}_{2}, 10$ p.p.m. $\mathrm{H}_{2}$. Canadian Liquid

Aid Ltd., Montreal.

99.8\% minimum. Matheson of Canada, Ltd. , Whitby, Ontario.

Reagent grade. Fisher Scientific, Montreal. Technical grade. Matheson, Coleman \& Bell, Norwood (Cincinnati), Ohio; and East Rutherford, N. J., U.S.A.

Technical grade. Matheson, Coleman \& Bell, Norwood (Cincinnati), Ohio; and East Rutherford, N. J., U.S.A.

Commercial grade. Chemical division of the Esso Imperial Oil Ltd., Montreal. Technical grade. The Eastman Organic Chemicals, Rochester, N.Y., U.S.A. 


\section{Experimental Procedure}

100 to 250 grams of aluminum bromide were dissolved in $200 \mathrm{ml}$ of solvent in the $400 \mathrm{ml}$ electrolysis beaker, from which air had been displaced by dry argon. The electrolyte was then agitated by a magnetic stirrer until the salt had gone into solution.

No heating or cooling was necessary during preparation or electrolysis, and no purification of the solute or redistillation of the solvent was required.

The copper cathode was first cleaned in a $1 / 3$ nitric (reacted with a small amount of copper), $1 / 3$ phosphoric, $1 / 3$ acetic acid solution containing 0.5 per cent hydrochloric acid (all by volume). The copper cathode was washed with water and dried with acetone, then warm air. The copper thus treated was quickly put in the plating bath to avoid air oxidation of the cleaned copper surface.

The 2 aluminum anodes were then inserted in the cell through the Teflon cover, and split corks were inserted through the cover holes to hold the electrodes in place.

Electrolysis was performed at $10 \mathrm{~mA} / \mathrm{cm}^{2}$ for $11 / 2$ hours while passing a flow of dry argon above the electrolyte. Two $8 \mathrm{~mm}$ pyrex glass tubes, sealed in the Tefion cover, permitted the admittance and escape of argon. The argon was dried by passing it through a bed of drierite and it was subsequently saturated with the solvent by bubbling through the same type of solvent as was being used in the electrolyte. The latter operation helped to keep the evaporation rate of the electro- 
lyte to a minimum.

The electrolyte was mildly agitated throughout each experiment by means of a Teflon covered magnetic bar, and external magnetic stirrer. After the finish of each plating experiment ( $11 / 2$ hours) the cathode and anodes were removed from the cell, rinsed in a bath of water and acetone, and dried for 2-3 minutes at $115^{\circ} \mathrm{C}$. The electrodes were weighed before and after each experiment to determine the anode and cathode current efficiencies.

\section{Standard Operating Conditions}

Conditions which were kept constant through the ethylbenzene and diethylbenzene series of experiments were:

(i) Electrodes: identical electrodes were used in all the tests.

(ii) Operating temperature: $30 \pm 5^{\circ} \mathrm{C}$.

(iii) Current density: cathode current density was the operating parameter held constant in all tests. The current density was as in the exploratory section $10.0 \pm 0.1 \mathrm{~mA} / \mathrm{cm}^{2}$ based upon the immersion area of the copper cathode at the beginning of each test.

E. Cathode and Anode Sizes and Immersion Areas

An earlier study of cathodic current efficiency versus anode size 83 (Appendix I) revealed that virtually no change was encountered in changing anode width from $i$ to $3 \mathrm{~cm}$, while maintaining copper cathode width at $1 \mathrm{~cm}$. 
An anode width of $11 / 2 \mathrm{~cm}$ was therefore chosen and two of these aluminum anodes were placed in the cell through the cover. The anodes were placed $3 \mathrm{~cm}$ apart and the cathode was placed centrally between them. This arrangement provided for an equal aluminum coverage on both sides of the cathode.

The width of the copper cathode was chosen to be $1 \mathrm{~cm}$ and an attempt was made to maintain the immersion depth in the electrolyte at $5 \mathrm{~cm}$. This provided an immersion area of $10 \mathrm{~cm}^{2}$ since both sides of the cathode were electroplated with aluminum. This immersed area, however, was difficult to maintain because the solvent slowly evaporated during the electrolysis, and the level had to be continuously restored by adding additional solvent.

F. Cathodic Current Density

Cathode current density was calculated from the current passed and the area of the cathode surface which had been covered with aluminum. The plated area was measured after the electrolysis with a caliper.

\section{G. Cathodic and Anodic Current Efficiency}

Current efficiency was calculated from Faraday's Law of Electrolysis by comparing the mass of metal dissolved at the anode and the mass of metal plated at the cathode with the theoretical quantity $(100 \%$ current efficiency) which should have been dissolved or deposited. The theoretical quantities were determined from the amount of silver simultaneously 
plated in the coulometer.

\section{H. Choice of Current Density}

An experimental study of cathode efficiencies as a function of current density was carried out using: a) an ethylbenzene-toluene 1:1 and $53.4 \%$ (weight) aluminum bromide electrolyte, and b) a diethylbenzenetoluene $1: 1$ and $53.4 \%$ (weight) aluminum bromide electrolyte.

Experiments were carried out at various current densities as outlined in Section 4.1-C on a single batch of electrolyte (for each system) to eliminate errors which might have arisen from composition variation.

A new cathode was used for each current density test, i.e., for each experimental point, and the electricity passed in each test was 0.15 ampere hours. The results are presented in Tables 4-1 and 4-2 and cathode efficiency is plotted as a function of current density in Figures 4-3 and 4-4.

The graphs show that the cathode efficiency drops smoothly from over $80 \%$ at $5 \mathrm{~mA} / \mathrm{cm}^{2}$ to under $50 \%$ at $30 \mathrm{~mA} / \mathrm{cm}^{2}$. An arbitrary standard plating current density of $10 \mathrm{~mA} / \mathrm{cm}^{2}$ was therefore chosen on the basis of these results to give in the order of $.01 \mathrm{~mm}$ of aluminum plating in $11 / 2$ hours plating time. All subsequent tests were performed at this $10 \mathrm{~mA} / \mathrm{cm}^{2}$ current density. 
TABLE $4-1$

Electrodeposition of Aluminum onto Copper

Solvent: Ethylbenzene-Toluene 1:1

Solute: $\mathrm{AlBr}_{3}$ (50 wt. percent)

Current density: 5 to $40 \pm .1 \mathrm{~mA} / \mathrm{cm}^{2}$

\begin{tabular}{cc}
\hline $\begin{array}{c}\text { Cathodic Current Density, } \\
\mathrm{mA} / \mathrm{cm}^{2}\end{array}$ & $\begin{array}{c}\text { Average Cathode Efficiency } \\
\%\end{array}$ \\
\hline 5.0 & 85.0 \\
10.0 & 77.0 \\
15.0 & 75.0 \\
20.0 & 64.0 \\
30.0 & 44.0 \\
40.0 & 40.0
\end{tabular}


TABLE 4-2

Electrodeposition of Aluminum onto Copper

Solvent: Diethylbenzene-Toluene 1:1

Solute: $\mathrm{AlBr}_{3}$ (50 wt. percent)

Current density: 5 to $65 \pm .1 \mathrm{~mA} / \mathrm{cm}^{2}$

\begin{tabular}{cc}
\hline $\begin{array}{c}\text { Cathodic Current Density, } \\
\mathrm{mA} / \mathrm{cm}^{2}\end{array}$ & $\begin{array}{c}\text { Average Cathode Efficiency } \\
\%\end{array}$ \\
\hline 5.0 & 83.5 \\
10.0 & 75.0 \\
13.0 & 69.0 \\
18.5 & 73.0 \\
25.0 & 60.0 \\
28.5 & 42.0 \\
42.5 & 27.0 \\
65.0 & 16.0
\end{tabular}




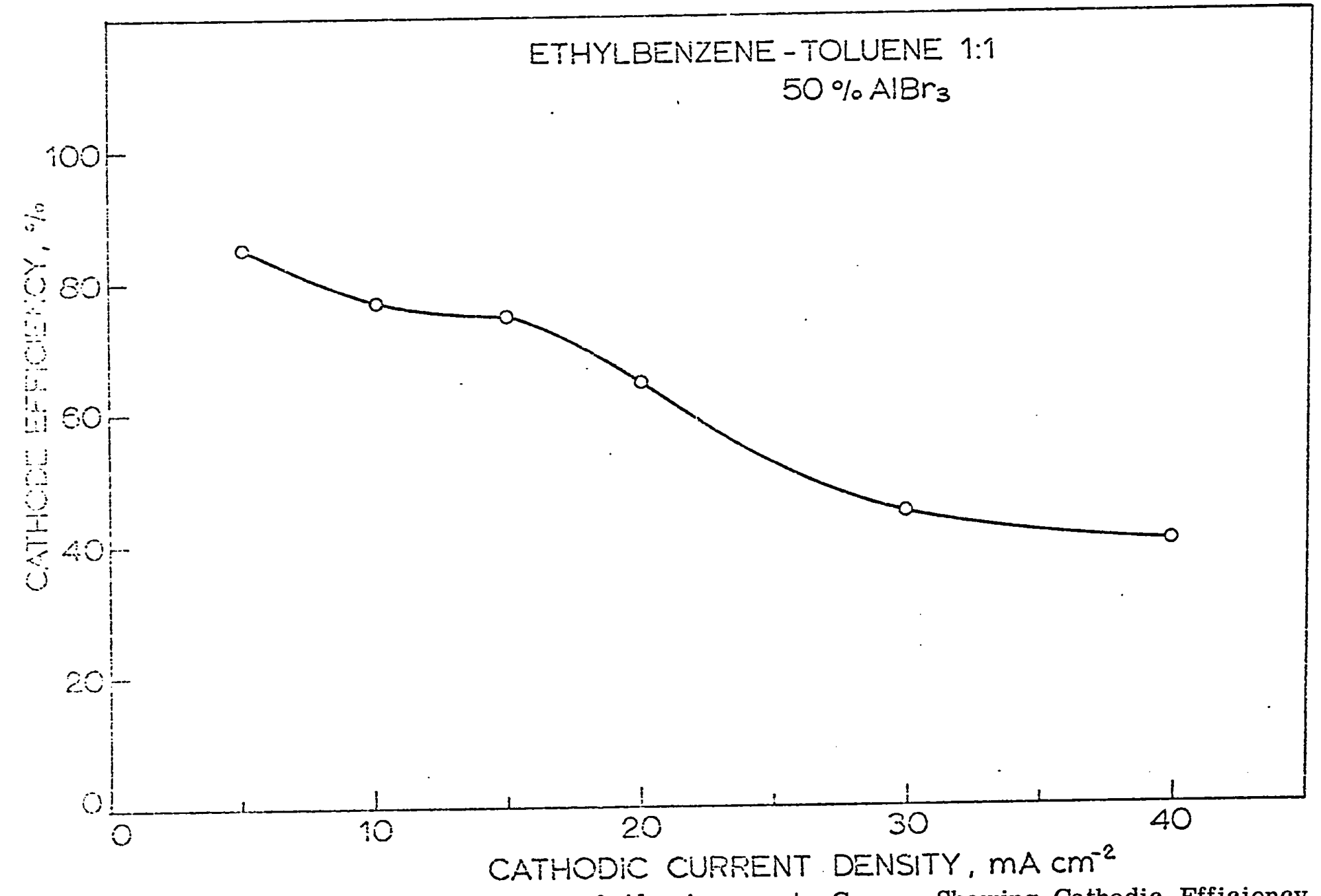

Figure 4-3. Electrodeposition of Aluminum onto-Copper Showing Cathodic Efficiency as a Function of the Cathodic Current Density. Average Coating Thickness: $.013 \mathrm{~mm}$ 


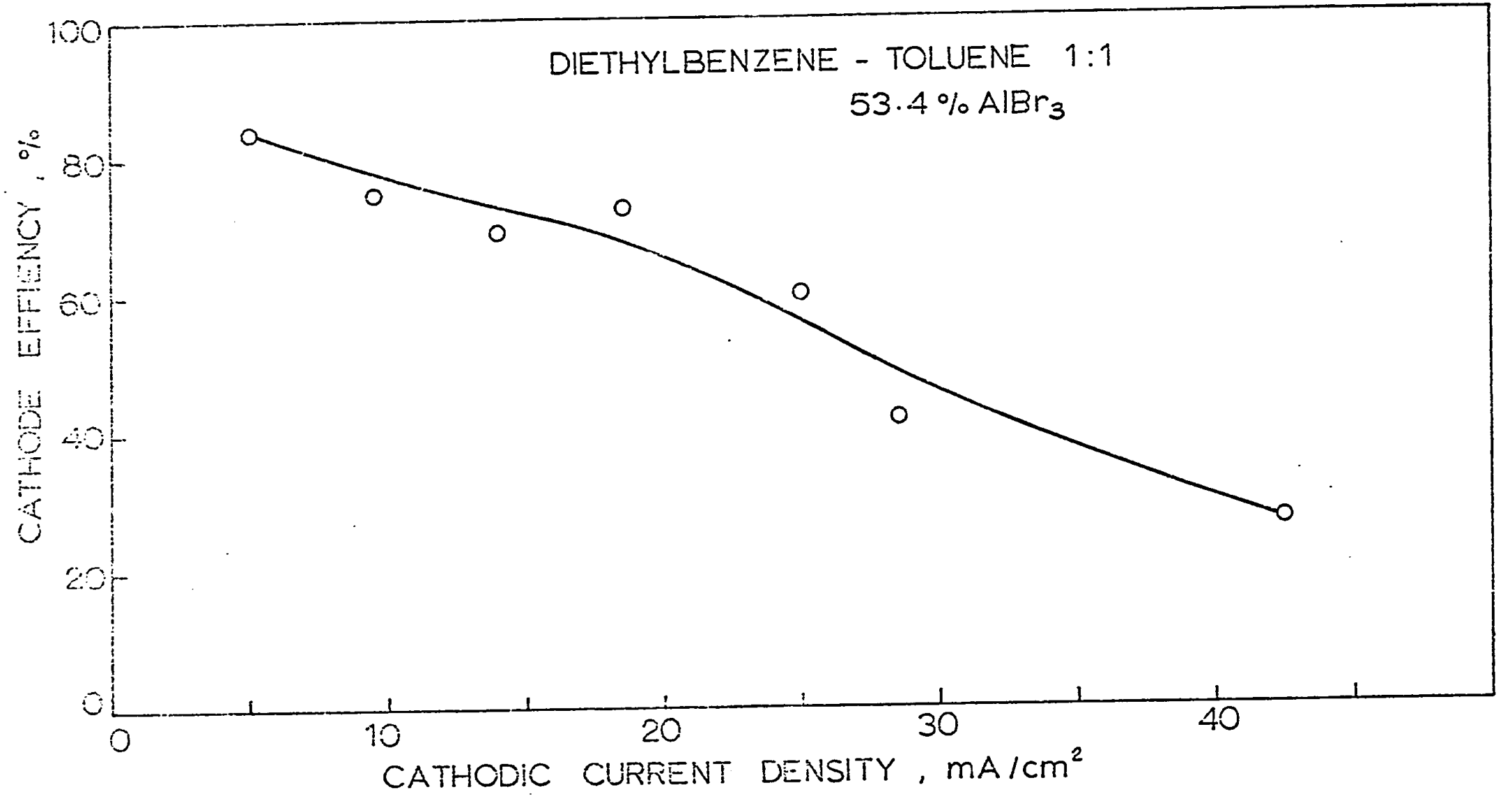

Figure 4-4. Electrodeposition of Aluminum onto Copper Showing Cathodic Efficiency as a Function of the Cathodic Current Density. Average Coating Thickness: $.013 \mathrm{~mm}$. 


\section{Aluminum Coating Thickness}

The thickness of the aluminum coating was calculated from the mass of aluminum deposited and the area of cathode covered with the aluminum deposit. The density of aluminum was taken as being

$2.7 \mathrm{~g} / \mathrm{cm}^{3}$ for these calculations.

\section{J. Plating Time}

The efficiency of a plating system usually decreases with increasing thickness of the coating. Arbitrary plating time had therefore to be made. A thickness of $0.013 \mathrm{~mm}$ was chosen, as this thickness is considered to be the minimum coverage necessary for good corrosion protection. 84

The time required to plate $0.013 \mathrm{~mm}$ of aluminum ( $80 \%$ cathode efficiency, $10 \mathrm{~mA} / \mathrm{cm}^{2}$; Fig. 4-3) is approximately $11 / 2$ hours. All tests were made for this $11 / 2$ hour plating period starting with a new cathode.

\subsection{Results}

The results reported for each experimental system include: cathode and anode current efficiencies, electrolyte conductivity and comments on plating quality and electrolyte behaviour.

Anode and cathode current efficiencies are plotted as a function of the total electricity passed (amp hours litre ${ }^{-1}$ ) through the particular batch of electrolyte. Each point on the current efficiency graphs represents the current efficiency for $11 / 2$ hours of plating starting from a new clean copper cathode. The graphs also show the conductance of 
the electrolyte as a function of electricity passed. The specific conductance values shown on the graphs were measured at ambient temperature and have been corrected to $25^{\circ} \mathrm{C}$ as described in Appendix III.

A table containing all experimental data corresponding to the graphical presentation is given (Appendix IV) for each system.

Anode and cathode efficiencies, conductivities, and thicknesses have been averaged and are reported for the interval between 5 to 15 amp hour litre ${ }^{-1}$. Results from experiments carried out in the period prior to $5 \mathrm{amp}$ hour litre ${ }^{-1}$ are not taken into the average, as in the majority of experiments, conductivity and cathode efficiency are still increasing considerably during this period. A plateau is usually found after 5 amp hour litre ${ }^{-1}$.

Detailed results for electrolytes based upon ethylbenzene and ethylbenzene mixtures, were reported in a previous research work. 83 A summary of these results is presented in the discussion section of this thesis (p. 202).

Results of electrolytes based upon diethylbenzene and diethylbenzene mixtures with toluene and benzene (including toluene and benzene alone) are presented on the following pages. 
A. Electrolyte: Diethylbenzene - 36.4 wt. percent AlBr3

Experimental conditions: Standard, 24 tests of $11 / 2$ hours each.

Observations and Results: Table A. IV-1 (Appendix IV), Figure 4-5.

Two layers of liquid were formed when aluminum bromide was dissolved in the diethylbenzene. The bottom layer consisted of a heavy brown aluminum complex representing about $30 \%$ of the total liquid volume; some demixing took place while the first 7 amp hours of electricity were passed per liter of solution. The heavy bottom layer of liquid (aluminum complex) was reduced to about $20 \%$ of the total liquid during this period. The volume of the aluminum complex increased gradually as further electricity was passed and it became about $90 \%$ of the total liquid volume after passing 13 amp hours of electricity per liter of solution.

No evolution of gas was observed and attractive aluminum coatings were obtained in all the tests of this electrolyte.

Average values for the system were:

Anode efficiency: $101.5 \%$

Cathode efficiency: $40.2 \%$

Applied potential: 28.5 volts

Specific conductance: $0.26 \times 10^{-3} \Omega^{-1} \mathrm{~cm}^{-1}$

Coating thickness: $0.006 \mathrm{~mm}$ 
B. Electrolyte: Diethylbenzene -45.4 wt. percent AlBr3

Experimental conditions: Standard, 24 tests of $11 / 2$ hours each.

Observations and Results: Table A.IV-2 (Appendix IV), Figure 4-5.

As in the case of the $36.4 \% \mathrm{AlBr}_{3}$ in diethylbenzene electrolyte, two layers were formed upon dissolving the aluminum bromide in the solvent, and the denser brown aluminum complex was about $40 \%$ of the total liquid at the beginning of the experiment. This heavy bottom layer of liquid was reduced to about $30 \%$ of the total liquid during initial current flow, and then it grew continuously so that after 9 amp hours of electricity per litre of solution had been passed, only a single layer remained.

Excellent aluminum coatings were obtained from this electrolyte and no gas evolution was noticed during the experiment.

Average values for this system were:

Anode efficiency: $102.9 \%$

Cathode efficiency: $41.7 \%$

Applied Potential: 10.5 volts

Specific conductance: $1.03 \times 10^{-3} \Omega^{-1} \mathrm{~cm}^{-1}$

Coating thickness: $0.008 \mathrm{~mm}$ 
C. Electrolyte: Diethylbenzene - 53.4 wt. percent $\mathrm{AlBr}_{3}$

Experimental conditions: Standard, 26 tests of $11 / 2$ hours each.

Observations and Results: Table A.IV-3 (Appendix IV), Figure 4-5.

The electrolyte of this experiment consisted entirely of a brown aluminum complex and no demixing of the solution was noticed, a result differing from the two layers observed in the cases of 36.4 and 45.4 wt. percent $\mathrm{AlBr}_{3}$ in diethylbenzene electrolytes.

Attractive coatings were obtained from these experiments and no gas evolution was detected through the experiment.

Average values for this system were:

Anode efficiency: $107.3 \%$

Cathode efficiency: $58.7 \%$

Applied potential: 6.5 volts

Specific conductance: $1.36 \times 10^{-3} \Omega^{-1} \mathrm{~cm}^{-1}$

Coating thickness: $0.010 \mathrm{~mm}$ 


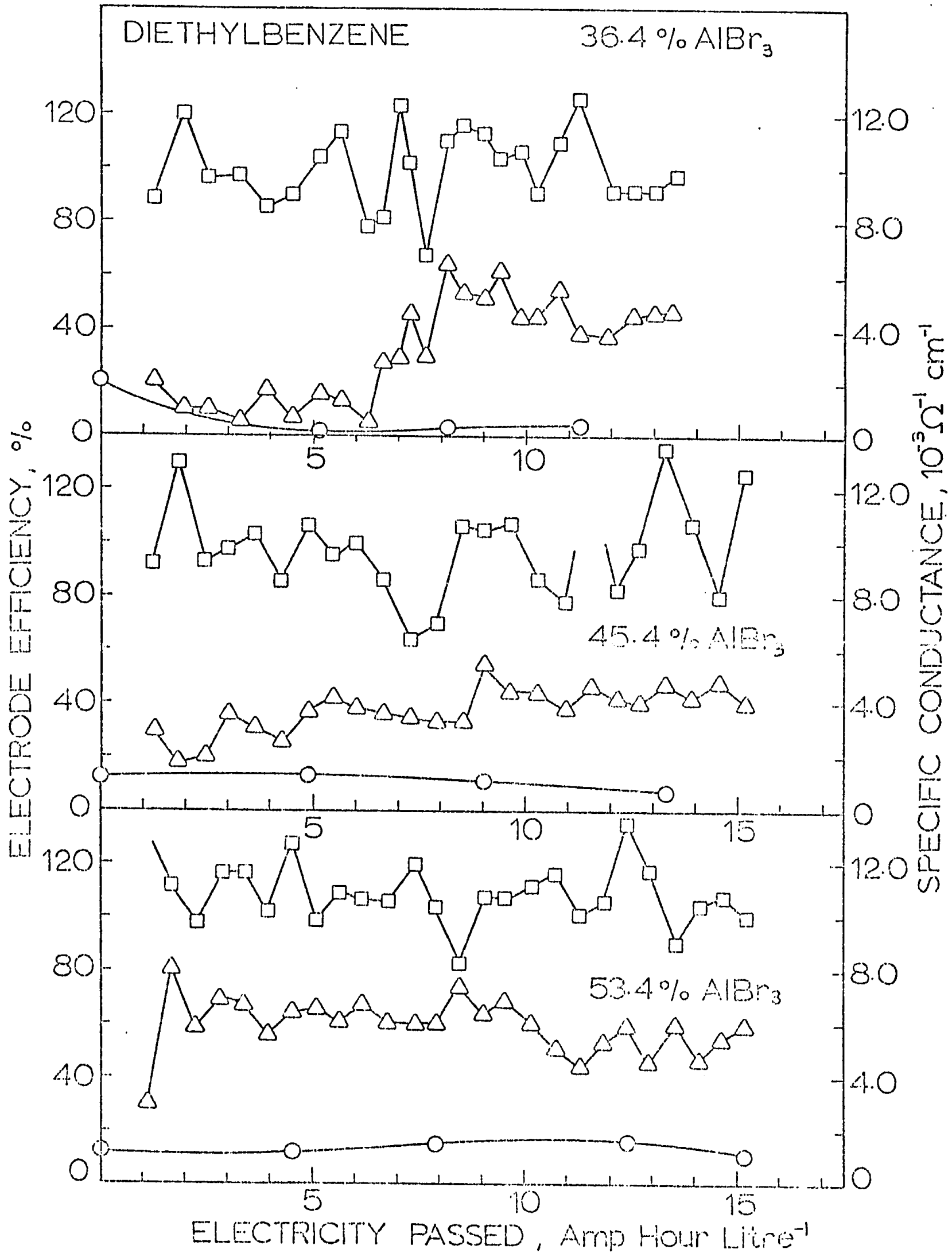

Figure 4-5. Anode and Cathode Efficiency and Specific Conductance as a Function of Electricity Passed Through the Electrolyte. $\square$ Anode Efficiency, $\triangle$ Cathode Efficiency, $O$ Specific Conductance. 
D. Electrolyte: Toluene - 36.4 wt. percent $\mathrm{AlBr}_{3}$

Experimental conditions: Standard, 19 tests of $11 / 2$ hours each.

Observations and Results: Table A.IV-4 (Appendix IV), Figure 4-6.

Two layers were observed in this electrolyte, the bottom aluminum complex layer representing about $50 \%$ of the total liquid.

The coatings obtained from this electrolyte were black and non adherent, although a grey aluminum coating was obtained after a total of $16 \mathrm{amp}$ hours of electricity per litre of solution had been passed. No gas evolution was detected.

Average values for this system were:

Anode efficiency: $103.5 \%$

Cathode efficiency: $26.5 \%$

Applied potential: 7.1 volts

Specific conductance: $1.95 \times 10^{-3} \Omega^{-1} \mathrm{~cm}^{-1}$

Coating thickness: $0.005 \mathrm{~mm}$ 
E. Electrolyte: Toluene -45.4 wt. percent $\mathrm{AlBr}_{3}$

Experimental conditions: Standard, 17 tests of $11 / 2$ hours each.

Observations and Results: Table A.IV-5 (Appendix IV), Figure 4-6.

As in the previous experiment two layers were obtained upon dissolving aluminum bromide in toluene. The bottom layer, representing about 80 percent of the total liquid at the beginning of the experiment, became a single layer after 5 amp hours of electricity had been passed per litre of electrolyte.

Black and non adherent coatings were obtained. No gas evolution was noticed.

Average values for the system were:

Anode efficiency: $98.0 \%$

Cathode efficiency: $8.5 \%$

Applied potential: 3.9 volts

Specific conductance: $4.12 \times 10^{-3} \Omega^{-1} \mathrm{~cm}^{-1}$

Coating thickness: $0.002 \mathrm{~mm}$ 
F. Electroly te: Toluene -53.4 wt. percent $\mathrm{AlBr}_{3}$

Experimental conditions: Standard, 18 tests of $11 / 2$ hours each.

Observation and Results: Table A.IV-6 (Appendix IV), Figure 4-6.

A single dark layer was obtained in this experiment upon dissolving the aluminum bromide in toluene. No demixing was obtained throughout the experiment and no gas evolution was observed.

The coatings obtained were biack and pasty.

Average values for this system were:

Anode efficiency: $104.9 \%$

Cathode efficiency: $15.1 \%$

Applied potential: 3.0 volts

Specific conductance: $4.44 \times 10^{-3} \Omega^{-1} \mathrm{~cm}^{-1}$

Coating thickness: $0.003 \mathrm{~mm}$ 


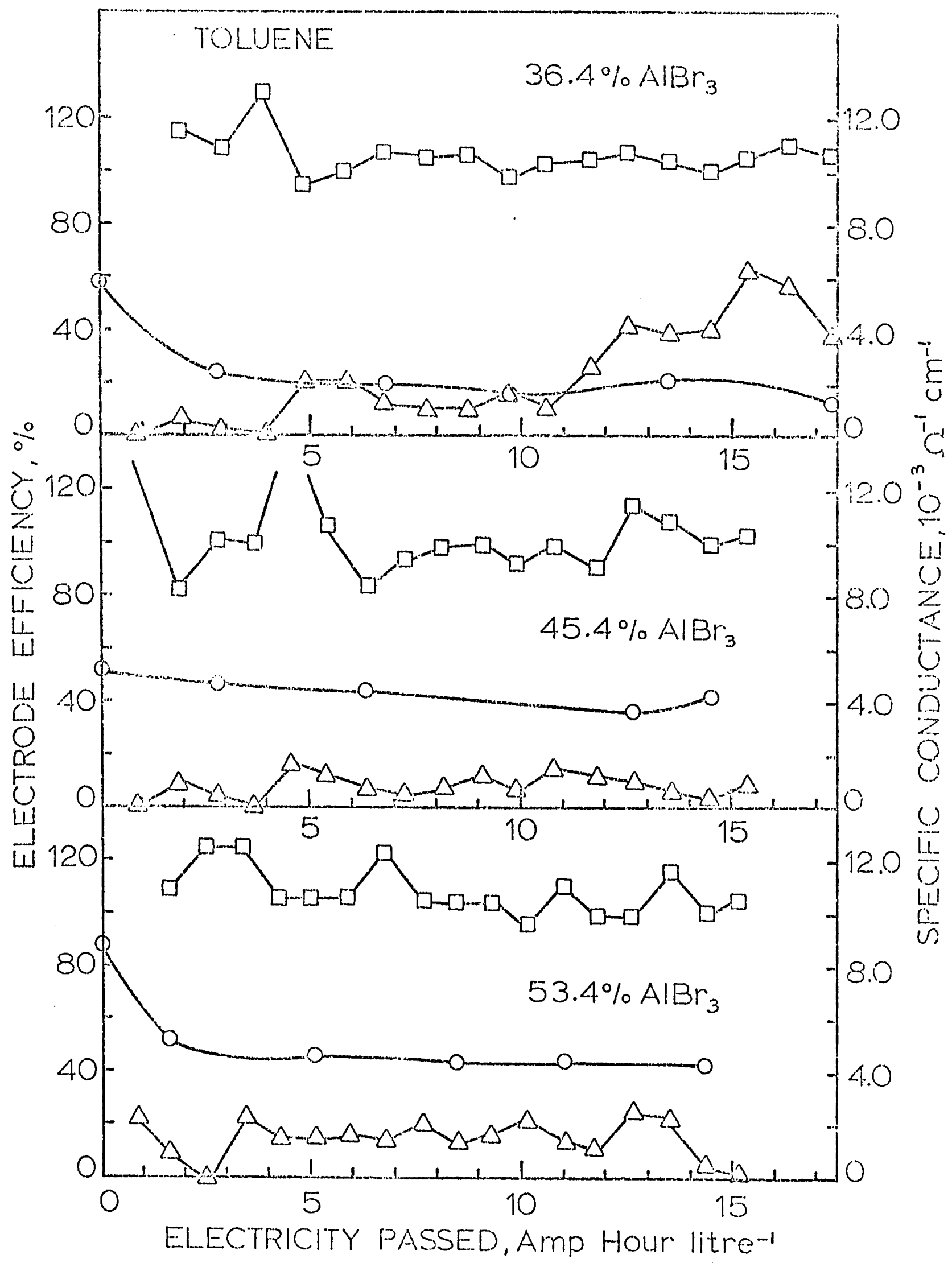

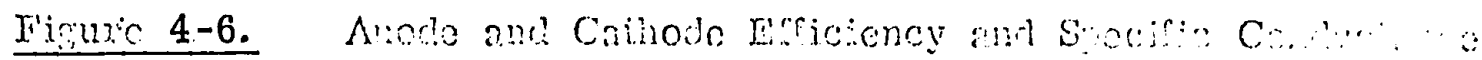
as a linction of lilectricity passed lingourh the riectrolyte.

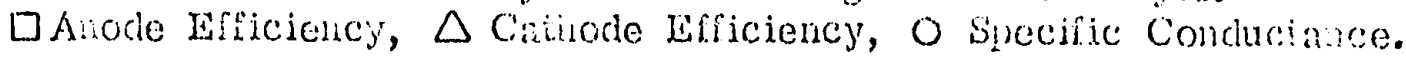


G. Electrolyte: Diethylbenzene-Toluene $1: 4^{*}-36.4$ wt. percent $\mathrm{AlBr}_{3}$

Experimental conditions: Standard, 24 tests of $11 / 2$ hours each.

Observations and Results: Table A. IV-7 (Appendix IV), Figure 4-7.

Two layers were present in this electrolyte, the bottom layer consisting of about $25 \%$ of the total liquid at the beginning of the experiment. At the end of the plating (15 amp hour litre ${ }^{-1}$ ), however, the bottom layer (aluminum complex) represented about $80 \%$ of the total liquid volume.

White grey coatings having good adhesion were obtained throughout the experiment and no gas evolution was observed. However, some small dark spots, due probably to undissolved suspended particles of solute, were present on the coatings.

Average values for the system were:

Anode efficiency: $109.9 \%$

Cathode efficiency: $40.4 \%$

Applied potential: 29.8 volts

Specific conductance: $0.23 \times 10^{-3} \Omega^{-1} \mathrm{~cm}^{-1}$

Coating thickness: $0.007 \mathrm{~mm}$

*Volume Basis. 
H. Electrolyte: Diethylbenzene-Toluene 1:4 - 45.4 wt. percent $\mathrm{AlBr} 3$

Experimental conditions: Standard, 25 tests of $11 / 2$ hours each.

Observations and Results: Table A.IV-8 (Appendix IV), Figures 4-7.

As opposed to the $36.4 \% \mathrm{AlBr}_{3}$ in diethylbenzene-toluene $1: 4$ electrolyte, no demixing was observed in this electrolyte. No gas evolution was noted. The aluminum coatings were very attractive throughout the experiment.

Average values for this system were:

Anode efficiency: $100.7 \%$

Cathode efficiency: $49.7 \%$

Applied potential: 7.6 volts

Specific conductance: $0.99 \times 10^{-3} \Omega^{-1} \mathrm{~cm}^{-1}$

Coating thickness: $0.009 \mathrm{~mm}$ 
I. Electrolyte: Diethylbenzene-Toluene 1:4 - 53.4 wt. percent $\mathrm{AlBr}_{3}$

Experimental conditions: Standard, 23 tests of $11 / 2$ hours each.

Observations and Results: Table A. IV-9 (Appendix IV), Figures 4-7.

A single layer was obtained in this experiment as in the case of the 45.4 percent $\mathrm{AlBr}_{3}$ electrolyte $(\mathrm{H})$.

Coatings were excellent and no gas was evolved throughout this series of experiments.

Average values for the system were:

Anode efficiency: $109.0 \%$

Cathode efficiency: $74.8 \%$

Applied potential: 5.5 volts

Specific conductance: $1.62 \times 10^{-3} \Omega^{-1} \mathrm{~cm}^{-1}$

Coating thickness: $0.012 \mathrm{~mm}$ 
73

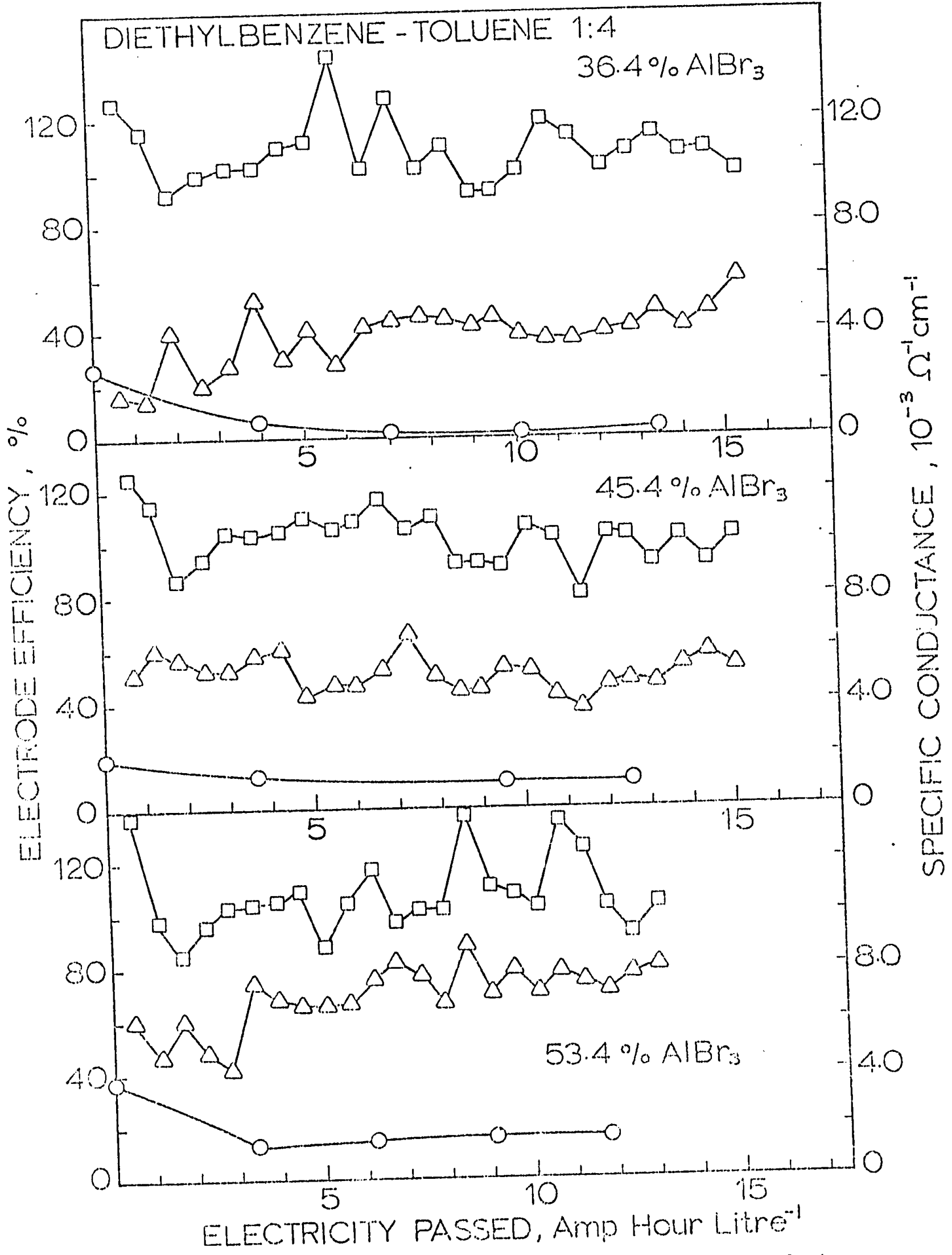

Figure 4-7. Anode and Cathode Efficiency and Specific Conductance as a Function of Electricity Passed Through the Electrolyte.

$\square$ Anode Efficiency, $\triangle$ Cathode Efficiency, $O$ Specific Conductance. 
J. Electrolyte: Diethylbenzene-Toluene 1:1-36.4 wt. percent $\mathrm{AlBr}_{3}$

Experimental conditions: Standard, 25 tests of $11 / 2$ hours each.

Observations and Results: Table A.IV-10 (Appendix IV), Figures 4-8.

Two layers were present at the beginning of the experiment, the dark bottom layer representing about $25 \%$ of the total liquid volume. This aluminum complex layer increased, however, to about $80 \%$ of the liquid volume by the time the tests were terminated.

Coatings were excellent and no gas evolution was noticed during the experiment.

Average values for the system were:

Anode efficiency: $102.6 \%$

Cathode efficiency: $64.4 \%$

Applied potential: 8.6 volts

Specific conductance: $0.92 \times 10^{-3} \Omega^{-1} \mathrm{~cm}^{-1}$

Coating thickness: $0.012 \mathrm{~mm}$ 
K. Electrolyte: Diethylbenzene-Toluene 1:1 - 45.4 wt. percent AlBr3

Experimental conditions: Standard, 25 tests of $11 / 2$ hours each.

Observations and Results: Table A. IV-11 (Appendix IV), Figure 4-8.

A single liquid layer was obtained in this experiment. No gas evolution was noticed and the aluminum coatings were excellent throughout the experiment.

Average values for this system were:

Anode efficiency: $104.5 \%$

Cathode efficiency: $62.9 \%$

Applied potential: 8.0 volts

Specific conductance: $1.11 \times 10^{-3} \Omega^{-1} \mathrm{~cm}^{-1}$

Coating thickness: $.011 \mathrm{~mm}$ 
L. Electrolyte: Diethylbenzene-Toluene 1:1 - 53.4 wt. percent $\mathrm{AlBr}_{3}$

Experimental conditions: Standard, 25 tests of $11 / 2$ hours each.

Observations and Results: Table A.IV-12 (Appendix IV), Figure 4-8.

As with the previous system (K), a single layer was obtained with this electrolyte. No demixing occurred.

Excellent coatings were obtained and no gas evolution was noticed during the experiment.

Average values for the system were:

Anode efficiency: $106.8 \%$

Cathode efficiency: $68.0 \%$

Applied potential: 5.3 volts

Specific conductance: $1.76 \times 10^{-3} \Omega^{-1} \mathrm{~cm}^{-1}$

Coating thickness: $0.012 \mathrm{~mm}$ 
77

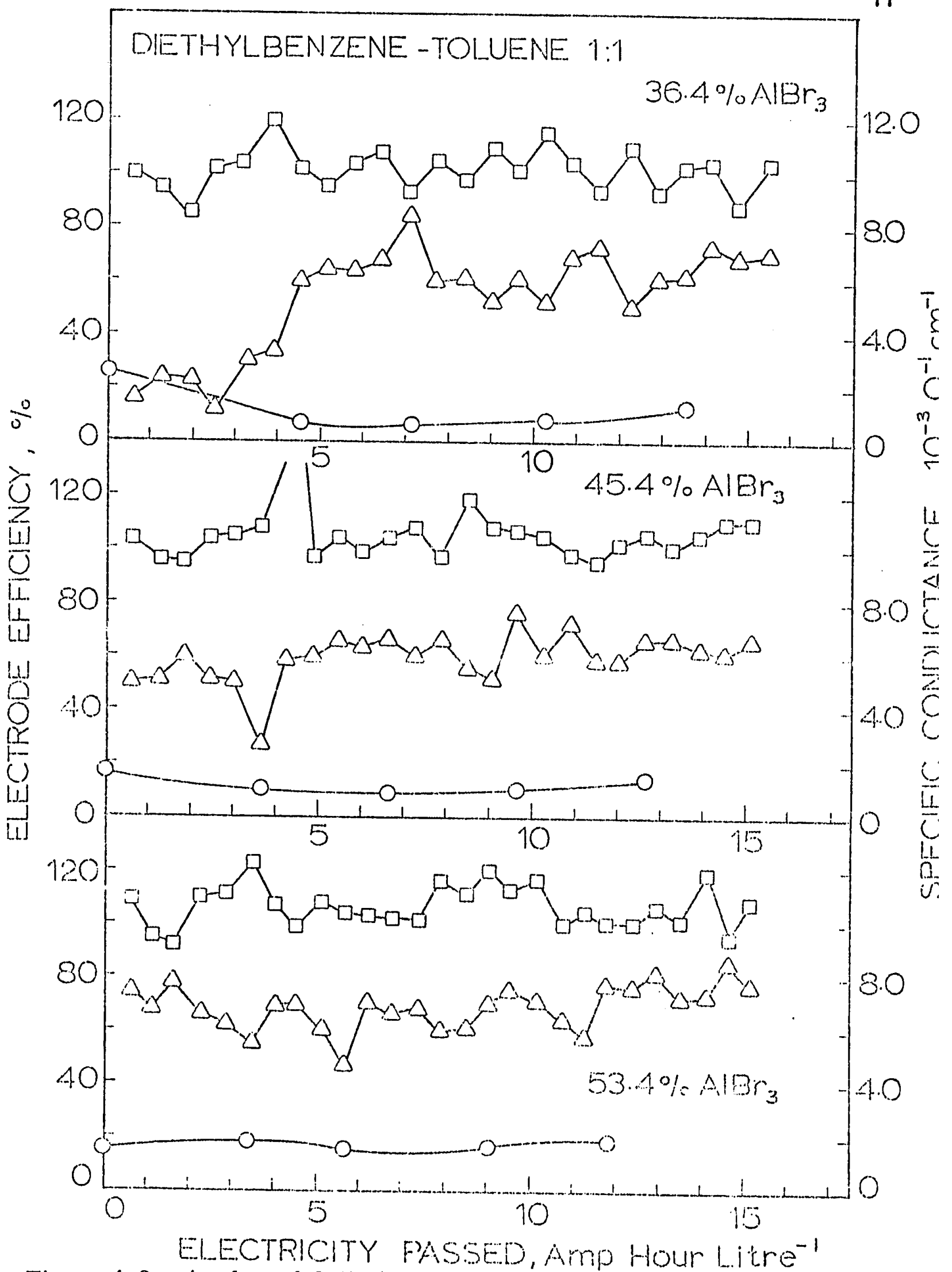

Figure 4-8. Anode and Cathode Efficiency and Specific Conductance as a. Function of Electricity Passed Through the Electrolyte.

$\square$ Anode Efficiency, $\triangle$ Cathode Efficiency, $O$ Specific Conductance. 
M. Electrolyte: Benzene $-36.4 \mathrm{wt}$. percent $\mathrm{AlBr}_{3}$

Experimental conditions: Standard, 2 tests of $11 / 2$ hours each.

Observations and Results:

Two layers of liquid were formed when aluminum bromide was dissolved in benzene. The bottom layer consisted of a brown aluminum complex representing about $40 \%$ of the total liquid volume.

A tar like material was deposited in both the anode and the cathode and no aluminum was plated.

The anode was only slightly dissolved at the end of each experiment. Although the anodic and cathodic efficiencies were very low, the conductivity of the electrolyte was relatively high.

Average values for the system were:

Anode efficiency: $6.0 \%$

Cathode efficiency: $0.0 \%$

Applied potential: 2.8 volts

Specific conductance: $5.5 \times 10^{-3} \Omega^{-1} \mathrm{~cm}^{-1}$

Coating thickness: $0.0 \mathrm{~mm}$ 
N. Electrolyte: Benzene - 4.5.4 wt. percent $\mathrm{AlBr}_{3}$

Experimental conditions: Standard, 2 tests of $11 / 2$ hours each.

Observations and Results:

As in the case of the $36.4 \% \mathrm{AlBr}_{3}$ in benzene electrolyte, two layers were formed upon dissolving the aluminum bromide in the solvent. The bottom brown aluminum complex was about $80 \%$ of the total liquid. Non-metallic material was collected at the anode and cathode in each test. No aluminum was plated.

The anode was only slightly attacked. The conductivity of the electrolyte was relatively high.

Average values for the system were:

Anode efficiency: $8 \%$

Cathode efficiency: $0.0 \%$

Applied potential: 2.6 volts

Specific conductance: $5.8 \times 10^{-3} \Omega^{-1} \mathrm{~cm}^{-1}$

Coating thickness: $0.0 \mathrm{~mm}$ 
O. Electrolyte: Benzene -53.4 wt. percent $\mathrm{AlBr}_{3}$

Experimental conditions: Standard, 2 tests of $11 / 2$ hours each.

Observations and Results:

A single layer was formed upon dissolving the aluminum bromide. in benzene. As in the case of the 36.4 and the 45.4 percent $\mathrm{AlBr}_{3}$ in benzene electrolytes, a non metallic tar like material was deposited at both the anode and the cathode. No aluminum was plated.

The anode was only slightly corroded and the conductivity of the electrolyte was relatively high.

Average values of the system were:

Anode efficiency: $10 \%$

Cathode efficiency: $0.0 \%$

Applied potential: 2.5 volts

Specific conductance: $6.0 \times 10^{-3} \Omega^{-1} \mathrm{~cm}^{-1}$

Coating thickness: $0.0 \mathrm{~mm}$ 
P. Electrolyte: Diethylbenzene-Benzene $1: 4-36.4$ wt. percent $\mathrm{AlBr}_{3}$

Experimental conditions: Standard, 24 tests of $11 / 2$ hours each.

Observations and Results: Table A.IV-13 (Appendix IV), Figure 4-9.

Two layers were present in this electrolyte at the beginning of the experiment. The bottom aluminum complex layer consisted of about $20 \%$ of the total liquid. At the end of the experiment, however, the bottom layer represented about $80 \%$ of the entire liquid.

Attractive coatings were obtained throughout the experiment and no gas evolution was observed. However, the anodic and cathodic efficiencies were low. The specific conductance was, on the other hand, almost as high as in the benzene electrolytes.

Average values for this system were:

Anode efficiency: $24.8 \%$

Cathode efficiency: $27.4 \%$

Applied potential: 4.1 volts

Specific conductance: $5.50 \times 10^{-3} \Omega^{-1} \mathrm{~cm}^{-1}$

Coating thickness: $0.008 \mathrm{~mm}$ 
Q. Electrolyte: Diethylbenzene-Benzene 1:4 - 45.4 wt. percent $\mathrm{AlBr}_{3}$

Experimental conditions: Standard, 25 tests of $11 / 2$ hours each.

Observations and Results: Table A.IV-14 (Appendix IV, Figure 4-9.

As in the case of the 36.4 percent $\mathrm{AlBr}_{3}$ electrolyte (P), 2 layers were found upon dissolving $\mathrm{AlBr}_{3}$ in the solvent. The bottom alumin um complex layer represented about $35 \%$ of the total liquid at the beginning of the experiment. However, the bottom layer increased in volume to form a single layer after passing 7 amp hours of electricity per litre of solution.

The coatings were dark, and electrode efficiencies were low. Average values for the system were:

Anode efficiencies: $27.9 \%$

Cathode efficiencies: $36.9 \%$

Applied potential: 4.8 volts

Specific conductance: $4.48 \times 10^{-3} \Omega^{-1} \mathrm{~cm}^{-1}$

Coating thickness: $0.007 \mathrm{~mm}$ 
R. Electrolyte: Diethylbenzene-Benzene 1:4 - 53.4 wt. percent $\mathrm{AlBr} 3$

Experimental conditions: Standard, 25 tests of $11 / 2$ hours each.

Observations and results: Table IV.A-15 (Appendix IV), Figure 4-9.

As opposed to the previous sets of experiments with this solvent mixture (36.4 and 45.4 wt. $\% \mathrm{AlBr}_{3}$ ), no demixing was noticed in this electrolyte, the entire liquid consisting of a brown aluminum complex. However, coatings were dark and the anodic and cathodic efficiencies were low.

Average values for the system were:

Anode efficiency: $38.0 \%$

Cathode efficiency: $52.7 \%$

Applied potential: 4.3 volts

Specific conductance: $3.46 \times 10^{-3} \Omega^{-1} \mathrm{~cm}^{-1}$

Coating thickness: $0.010 \mathrm{~mm}$ 


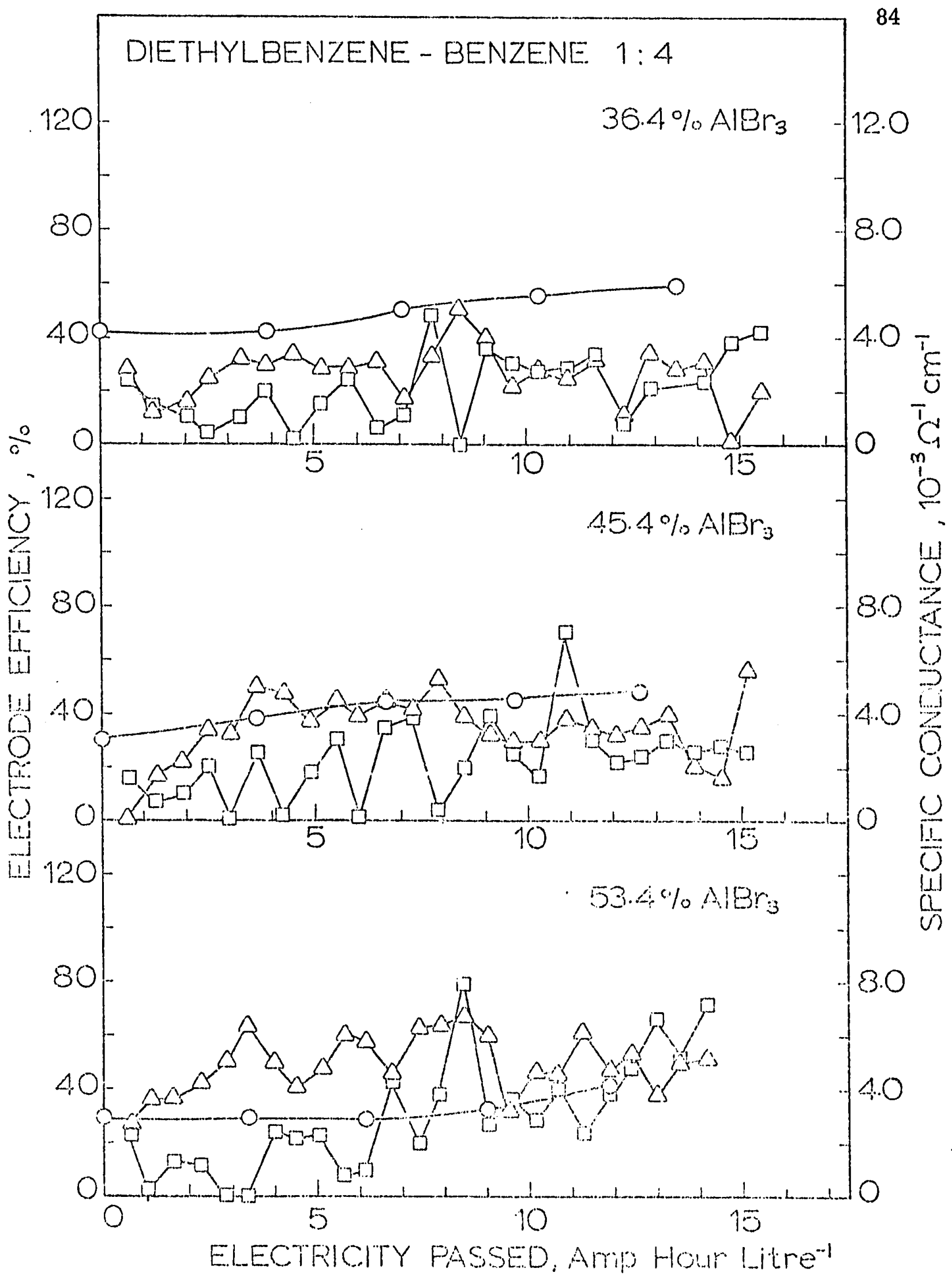

Figure 4-9. Anode and Cathode Efficiency and Specific Conductance as a Function of Electricity Passed Through the Electrolyte. $\square$ Anode Efficiency, $\triangle$ Cathode Efficiency, $\bigcirc$ Specific Conductance. 
S. Electrolyte: Diethylbenzene-Benzene $1: 1-36.4 \mathrm{wt}$. percent $\mathrm{AlBr}_{3}$

Experimental conditions: Standard, 25 tests of $11 / 2$ hours each.

Observations and Results: Table A.IV-16 (Appendix IV), Figure 4-10.

Two layers were present at the beginning of the experiment, the bottom complex layer representing about $25 \%$ of the entire liquid. At the end of plating (14 amp hour litre ${ }^{-1}$ ) the bottom layer represented about $60 \%$ of the total liquid.

Attractive coatings were obtained and no gas evolution was noticed throughout the experiment. The cathode efficiency was rather low.

Average values for the system were:

Anode efficiency: $83.1 \%$

Cathode efficiency: $29.0 \%$

Applied potential: 18.4 volts

Specific conductance: $0.47 \times 10^{-3} \Omega^{-1} \mathrm{~cm}^{-1}$

Coating thickness: $0.007 \mathrm{~mm}$ 
T. Electrolyte: Diethylbenzene-Benzene 1:1 - 45.4 wt. percent $\mathrm{AlBr}_{3}$

Experimental conditions: Standard, 25 tests of $11 / 2$ hours each.

Observations and Results: Table A. IV-17 (Appendix IV), Figure 4-10.

As in the case of the 36.4 percent $\mathrm{AlBr}_{3}$ electrolytes, 2 layers were found upon dissolving $\mathrm{AlBr}_{3}$ in the solvent and the brown aluminum complex was about $30 \%$ of the total liquid at the beginning of the experiment. The bottom layer grew, however, to about $80 \%$ of the entire liquid volume by the end of the experiment.

Excellent coatings were obtained and no gas evolution was noticed throughout the experiment.

Average values for this system were:

Anode efficiency: $103.6 \%$

Cathode efficiency: $56.7 \%$

Potential applied: 5.7 volts

Specific conductance: $1.41 \times 10^{-3} \Omega^{-1} \mathrm{~cm}^{-1}$

Coating thickness: $0.010 \mathrm{~mm}$ 
U. Electrolyte: Diethylbenzene-Benzene 1:1 - 53.4 wt. percent AlBr 3

Experimental conditions: Standard, 25 tests of $11 / 2$ hours each.

Observations and Results: Table A.IV-18 (Appendix IV), Figure 4-10.

As in the previous experiments, two layers were formed upon dissolving the aluminum bromide in this solvent pair.

The bottom layer, representing about 80 percent of the total liquid at the beginning of the experiment, became a single layer after 2 amp hours of electricity had been passed per litre of electrolyte.

A low cathodic efficiency was recorded which is a rather anomalous result as in most systems the cathodic current efficiency increases with the concentration of the solute.

Average values for the systen were:

Anode efficiency: $102.6 \%$

Cathode efficiency: $15.3 \%$

Applied potential: 33.3 volts

Specific conductance: $0.44 \times 10^{-3} \Omega^{-1} \mathrm{~cm}^{-1}$

Coating thickness: $0.002 \mathrm{~mm}$ 


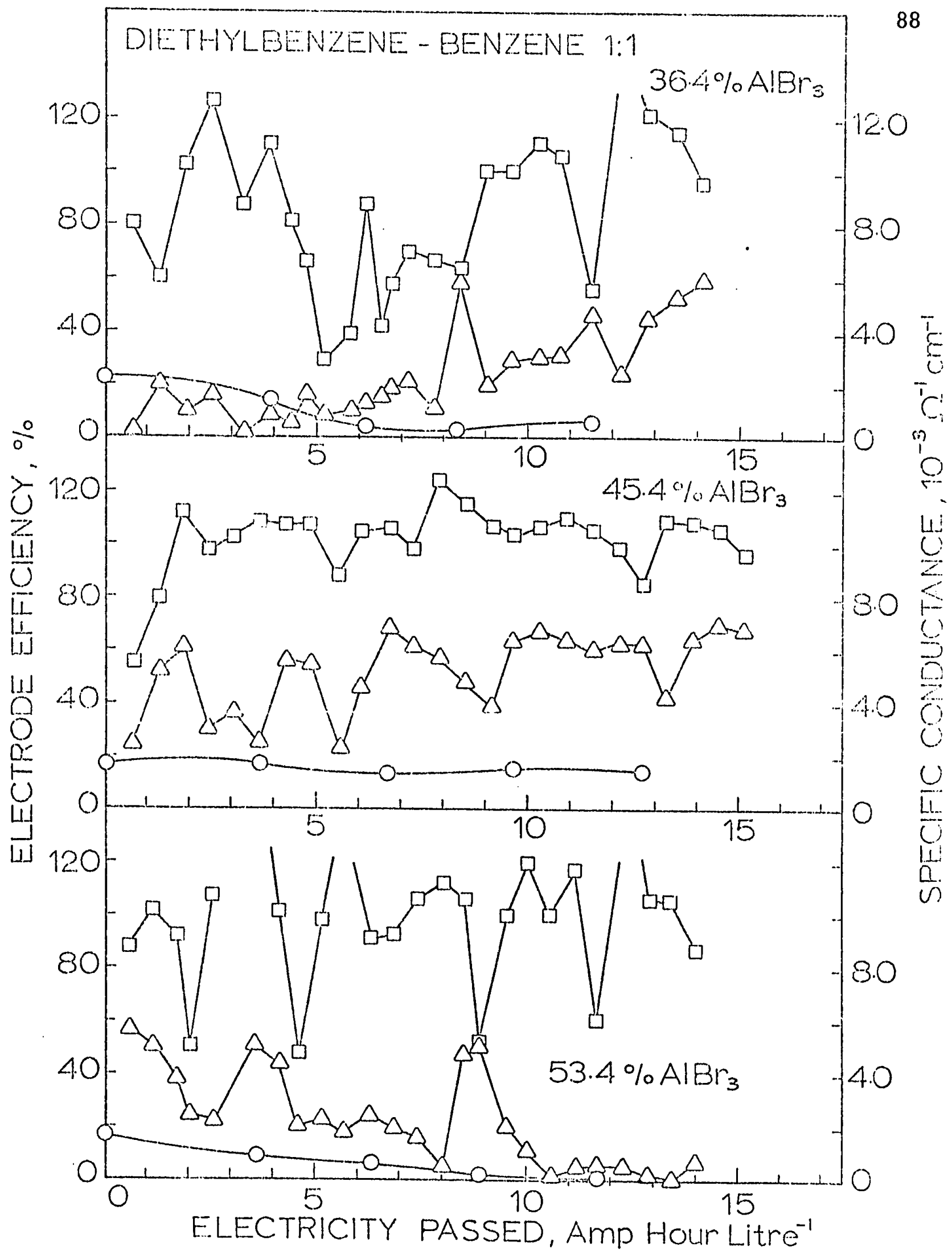

Figure 4-10. Anode and Cathode Efficiency and Specific Conductance as

a Function of Electricity Passed Through the Electrolyte.

$\square$ Anode Efficiency, $\Delta$ Cathode Efficiency, $O$ Specific Conductance. 
To summarize, it can be said that this series of tests clearly indicated that the diethylbenzene-toluene pair, 43.4 to 53.4 wt. percent $\mathrm{AlBr}_{3}$, were the best electrolytes of those investigated. The presence of benzene in the electrolytes has been shown to have a deleterious effect on the diethylbenzene electrolytes.

The suitability of the diethylbenzene based electrolytes is further discussed in Section 7.1 in which the results are compared with their ethylbenzene system counterparts (p. 201 ). 


\subsection{LIFE AND CONTROL OF THE ELECTROLYTES}

Results from the study on alkyl benzene electrolytes in the preceding section showed that, whereas anode efficiencies are in the order of $100 \%$, the best cathode efficiencies are only about $75 \%$ (e.g., Fig. 4-8). Hence there is an accumulation of aluminum in the electrolyte. It became evident that if this accumulation were permitted to continue the electrolyte life must be severely limited.

The object of this part of the investigation was to determine methods for extending the life of the electrolytes, for maintaining effectiveness of plating and for controlling the performance of the electrolytes.

The electrolyte used throughout this part of the work was based upon the ethylbenzene-toluene 1:1 solvent pair. The two specific studies were:

1. Investigation into the use of ethyl bromide and hydrogen bromide additions as addition agents to extend the useful life of the electrolytes.

2. Determination of methods for predicting and controlling the performance of the electrolytes, particularly using specific conductance or chemical analysis as indicators of performance. 


\subsection{Possible Techniques for Increasing Life and Maintaining Performance of Electrolyte}

There appeared to be two basic techniques to overcome the above mentioned aluminum ion excess:

1. Electrowin the aluminum using an inert anode. This method, unfortunately, would have the effect of evolving bromine at the anode which would degrade the electrolyte by the bromination of the alkyl benzene. 56

2. Effectively to create more electrolyte by adding bromine ions in some form and solvent to consume the dissolved aluminum.

Although this latter procedure would seem to have the effect of creating a continually expanding volume of electrolyte, this has not been found to be the case because the electrolyte volume increase has fortuitously just been offset by electrolyte entrainment losses as the plated cathodes are removed. Thus, this latter procedure was adopted.

Two methods of adding bromine ions were examined: ethyl bromide and $\mathrm{HBr}$ gas. The general experimental procedure was to carry out an extended number of $11 / 2$ hour tests totalling about two weeks total test time on each bath of electrolyte, during which time the electrolyte was rejuvenated with $\mathrm{HBr}$ or ethylbromide. The evaluation of good performance was based upon the efficiency of aluminum plating at the cathode and the specific conductance of the electrolyte. 


\subsection{Experimental Details}

\section{A. Apparatus}

The apparatus used in this investigation was the same as that used in the preceding study (Section 4-2) except for the electrolysis cell which, in this case, was a 1 litre Pyrex Resin Reaction Vessel (Fig. 5-1). The anode configuration was either a $2 \mathrm{~S}$ aluminum alloy cast into a cylinder and fitted against the wall of the Vessel (cylindrical anode $1.3 \mathrm{~cm}$ thick), or a pair of flat aluminum anodes each $2 \mathrm{~cm}$ wide, $1 \mathrm{~mm}$ thick and $18 \mathrm{~cm}$ long. A copper or steel cathode $2 \mathrm{~cm}$ wide, $0.5 \mathrm{~mm}$ thick and $18 \mathrm{~cm}$ long was centrally placed in the cell through the lid, fastened with split corks. The size of cathode was chosen for convenience due to the limited space in the cell cover. As mentioned in Section 4-2, the effect of anode size versus cathodic current efficiency showed practically no difference in current efficiency when anodes of different size were used.

A "Tacussel" potentiostat type 20PRT-10X (TechnEurop Montreal) was used to supply constant current, and a "Tacussel" high impedance digital millivoltmeter type ARIES 1000 with an accuracy of $0.1 \%$ of the full scale reading was used to measure the potential across the electrodes. A "Tacussel" ammeter type MAR-298 with an accuracy of $1.0 \%$ of the full scale reading was used for the measurement of the current density (Fig. 5-2). The conductimeter and conductivity cell were the same as those used in Section 4-2.

Usually three experiments were carried out simultaneously by connecting three of the abovementioned cells in series (Fig. 5-3). 
93

\author{
Figure 5-1 \\ Detail of Electrolysis Cell
}
A. Dry argon inlet
B. Argon outlet and liquid (solvent) seal
C. Reaction kettle
D. Electrical contact
E. Aluminum anode
F. Copper or steel cathode
G. Aluminum anode
H. Magnetic stirrer (Teflon cover ed)
L. Electrolyte 


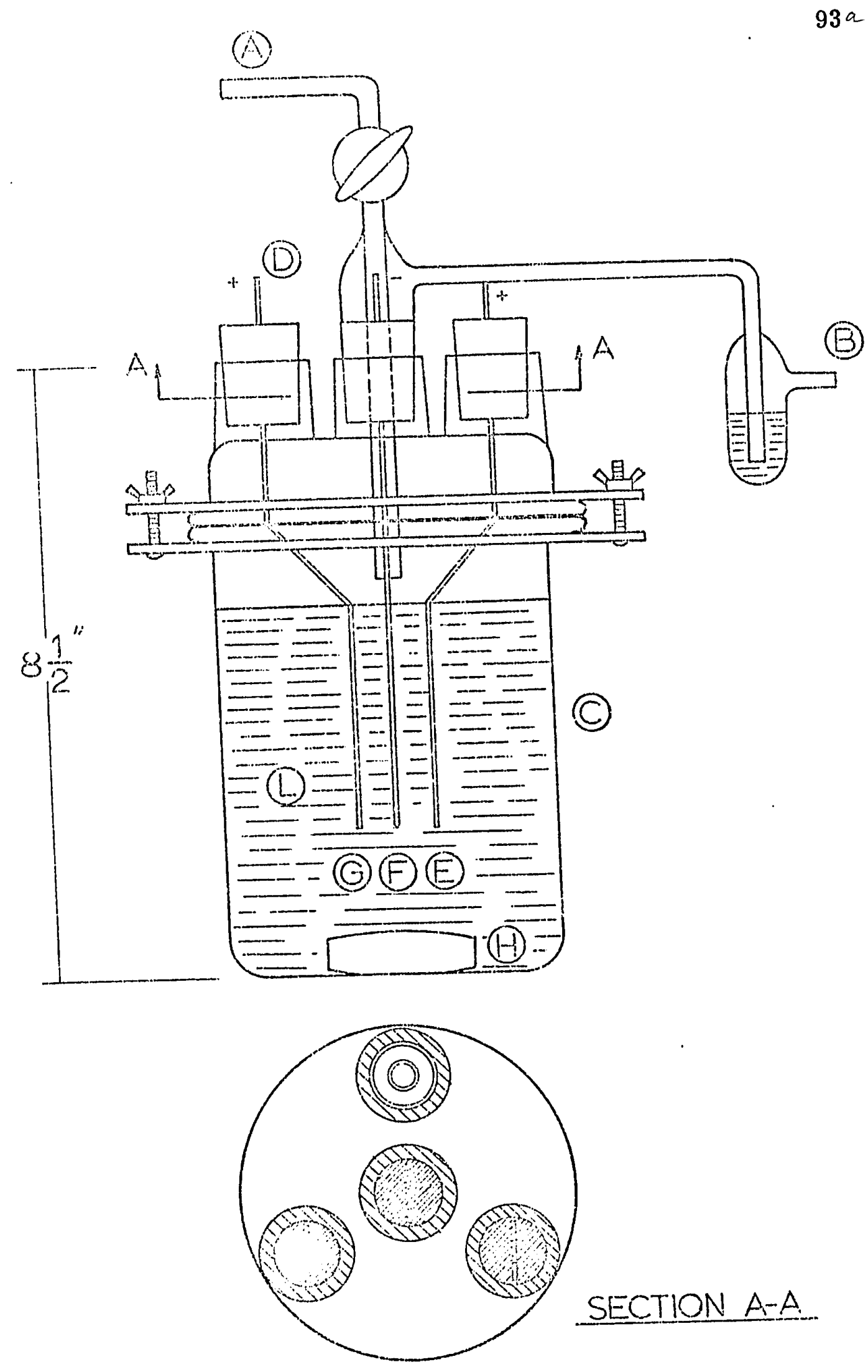




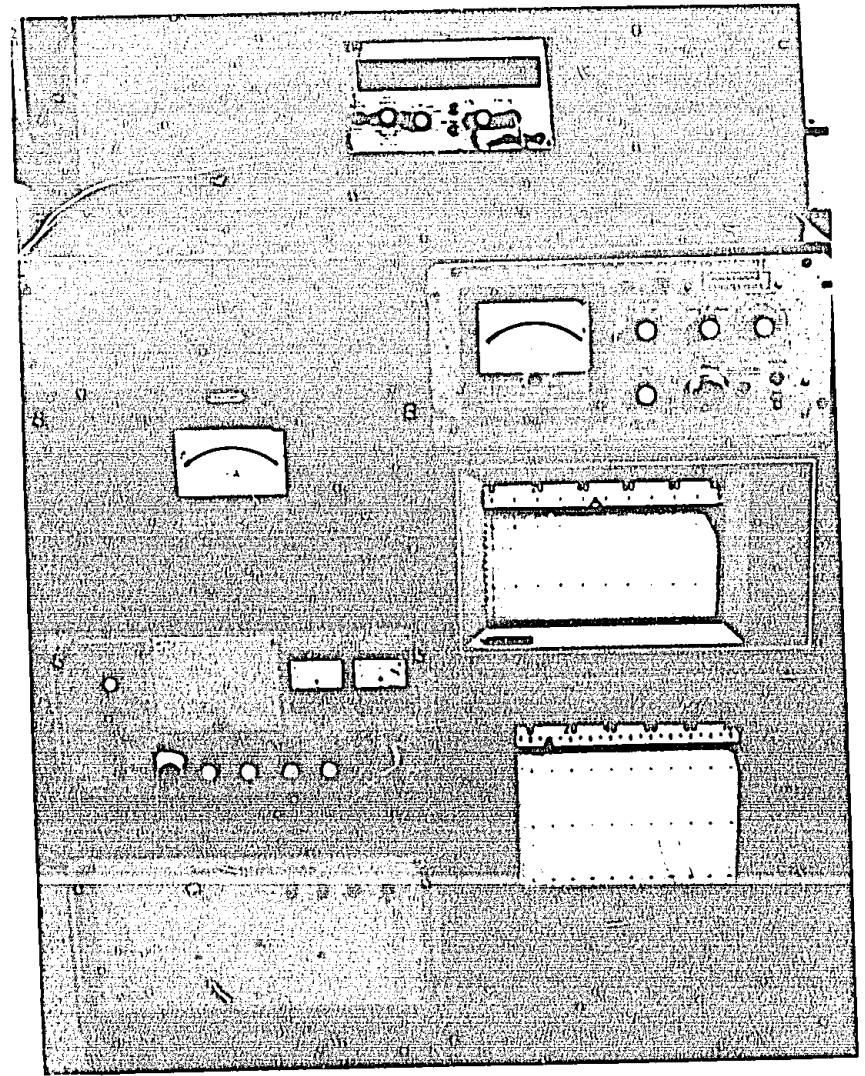

Figure 5-2. Control and Measurement Equipment. From lower left corner: Potentiostat, Milliameter, Digital Millivoltmeter, and Recording Conductimeter. For Circuit Diagram see Figure 6-6. 


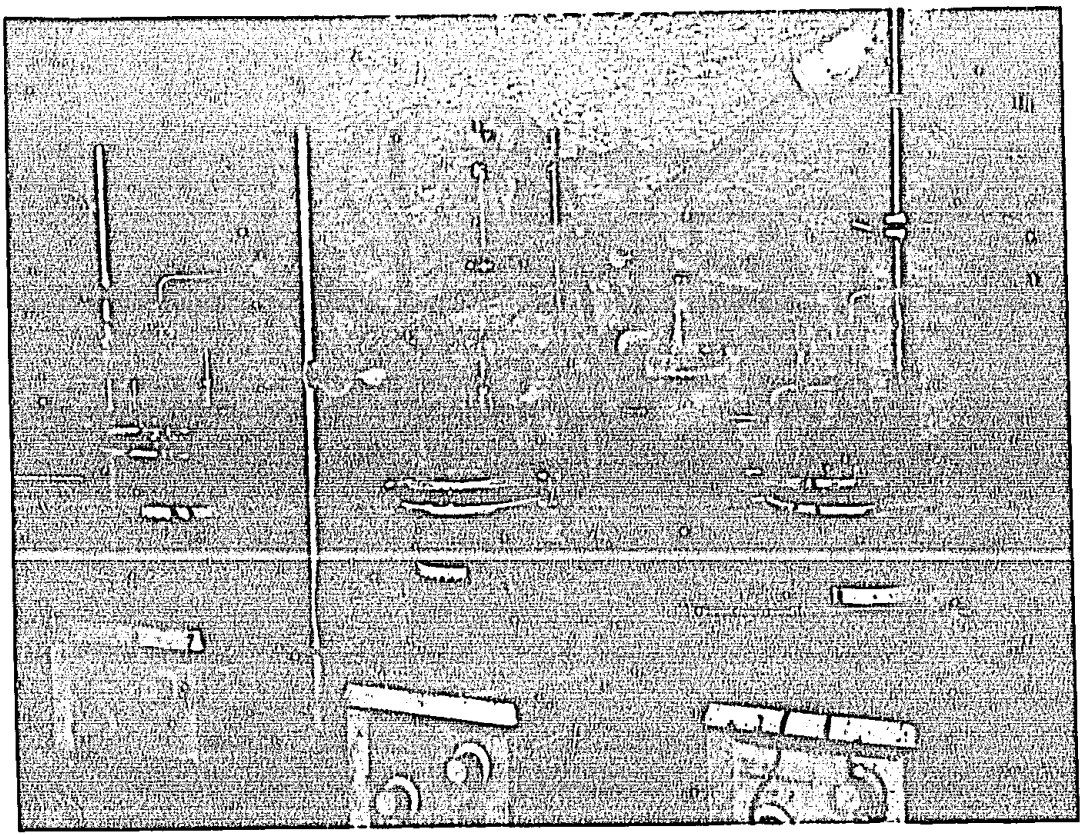

Figure 5-3. Experimental Arrangement of Three Electrolysis cells in Series. For Details See Figure 5-1. 
B. Materials

The materials used were the same as those described in the preceding section except for the aluminum bromide. For this work, the $\mathrm{AlBr}_{3}$ was prepared from aluminum and liquid bromine, since the product was found to be less expensive and more satisfactory than the purchased material which contained considerable moisture due to the hygroscopic behaviour of this salt.

\section{Preparation of $\mathrm{AlBr}_{3}$ and Electrolyte}

50 grams of aluminum $(99.9+\% \mathrm{Al})$ were placed in the Reaction Kettle (Fig. 5-4) in small squares of sheet $2 \mathrm{~cm} \times 2 \mathrm{~cm} \times 1 \mathrm{~mm}$ thick. The kettle was placed in a cooling water bath and a water refluxer (to reflux bromide vapour) was fitted.

Liquid bromine was added to the Kettle via a separatory funnel, drop by drop, pausing after $5 \mathrm{ml}$ (14.6 grams) of bromine had been added to permit initiation of the $\mathrm{AlBr}_{3}$ formation reaction. Further drop by drop additions of bromine were made until 450 grams had been added, typically requiring two hours. The system was cooled after the reaction was complete and the excess bromine was displaced with argon.

The $\mathrm{AlBr}_{3}$ salt was brown in colour and it was in the form of a solid cake.

The electrolytes were prepared by first saturating $575 \mathrm{ml}$ of ethyl benzene-toluene 1:1 solution with water by blowing water-laden argon through the solvents. The solvent was then added to the fresh 
Figure $5-4$

Apparatus for the Preparation of Aluminum Bromide.

A. Water Cooling Bath

B. Liquid Bromine

C. Aluminum Pieces 


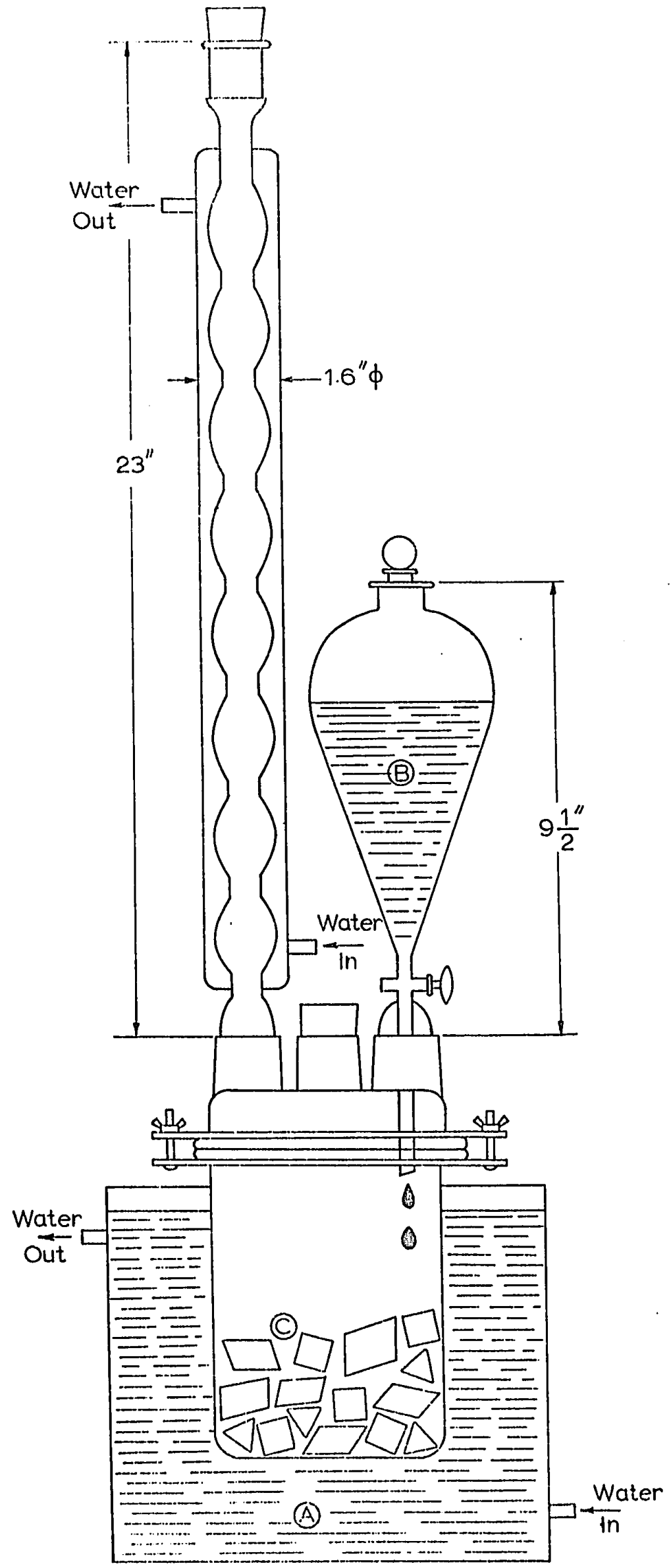


$\mathrm{AlBr}_{3}$ salt in the reaction kettle and the solution was stirred magnetically using a Teflon covered magnetic bar, during which time the kettle lid was in place with argon flowing above the liquids.

As is typical with all the alkyl benzene electrolytes, the formation of the electrolyte was gentle and no cooling was required. The electrolyte was finally transferred into the dry electrolytic cell (Fig. 5-1) through a connecting glass tube containing a glass wool or a fritted glass filter, by applying a small positive pressure of dry argon.

\section{Preparation of Metal Surfaces for Plating}

The preparation of a copper cathode was described in Section 4-2 of this thesis. A surface preparation technique was also developed for steel since this metal was used in several tests and also because it is likely to be the most important commercial substrate. W.C. Schickner ${ }^{86}$ had previously developed a procedure in which he treated steel surfaces with dilute oleic acid before aluminum plating. His method would, however, introduce a contaminant to the electrolyte, and hence an alternative technique was developed.

Good plating adhesion was achieved by using the following steel cathode preparation: pickling with $\mathrm{HCl} 1: 1$ for 60 seconds, rinsing with water, methyl alcohol, and then with ethylbenzene solvent mixtures saturated with the aluminum electrolyte. This saturated solution was prepared by adding 1 to 5 percent electrolyte to the solvent pair followed by stirring until the solvent acquired a yellowish colour. In addition to activating the steel surface, this solution removes the last 
traces of water on the cathode by the formation of an $\mathrm{Al}(\mathrm{OH})_{3}$ precipitate and it also avoids introducing a foreign surface preparation substance into the electrolyte.

\section{E. Plating Procedure}

The metal piece to be plated (cathode) was placed centrally in the plating cell by means of its support in the lid of the cell. In general, the sheet cathodes were supported by means of a tight fitting split cork inserted in the central hole of the lid (Fig. 5-1). During the placement of the electrodes, entrainment of air in the cell was minimized by flushing with argon (or nitrogen).

The plating was controlled by maintaining a constant current density of $10 \pm 0.1 \mathrm{~mA} / \mathrm{cm}^{2}$ of cathode area unless otherwise specified. Maintenance of this current density for the ethylbenzene-toluene 1:1, $50 \% \mathrm{AlBr}_{3}$ electrolyte required typically 2-6 volts. Agitation of the system was obtained by magnetic stirring. After plating, the cathode was removed and excess electrolyte was washed off with water. A $0.013 \mathrm{~mm}$ coating was obtained in approximately $11 / 2$ hours of plating.

\section{F. Standard Operating Conditions}

Conditions which were kept constant through this series of experiments were:

i) Electrodes: identical cathodes were used in all the tests. The anodes were either flat or cylindrical as noted for each specific part of the work. 
ii) Current density: cathode current density was the operating parameter held constant in all tests. The current density was usually set at $10.0 \pm 0.1 \mathrm{~mA} / \mathrm{cm}^{2}$. These values were based upon the immersion area of the copper cathode at the beginning of each test.

iii) Temperature: the temperature was uncontrolled but it remained at $30 \pm 5{ }^{\circ} \mathrm{C}$. Cathodic and anodic current efficiency, aluminum coating thickness and plating time were determined in the same way as in Section 4.2 of this thesis.

\section{G. Results}

The results reported for each experimental system include: anode and cathode current efficiencies, specific conductance of the electrolyte and comments on plating quality and electrolyte behaviour. The specific conductance values were measured at ambient temperature $\left(30 \pm 5^{\circ} \mathrm{C}\right)$ and have been corrected to $25^{\circ} \mathrm{C}$ as described in Appendix III.

\subsection{Ethyl Bromide Addition to Increase Electrolyte Life}

In this set of experiments ethyl bromide was used to complex the excess of aluminum ions left in solution as a result of unequal anode and cathode efficiencies. Ethyl bromide was examined first because it has the advantage over hydrogen bromide that it can be handled in liquid form at room temperature. 
The conditions for this set of experiments were as follows:

Anode shape: Cylindrical (see Fig. 5-5)

Electrolyte: Ethylbenzene-toluene 1:1, 50 wt. $\% \mathrm{AlBr}_{3}$

Experimental conditions: Standard, plating test of $1 \frac{1 / 2}{2}$ hours on copper cathodes

Bath conductivity: Adjusted with ethyl bromide

Observations and Results: Table A. VI-1 (Appendix VI), Figure 5-6.

When ethyl bromide was added to the electrolyte a violent reaction occurred and some $\mathrm{HBr}$ gas was evolved. $\mathrm{HBr}$ gas evolution was also observed during the subsequent electroplating of aluminum. In addition, the aluminum anode reacted chemically with the ethyl bromide in solution both during electrolysis and also when current was not being passed.

This result is illustrated by an experiment in which the cylindrical aluminum anode was left in the solution for 4 days, electrolysis being performed for approximately $1 / 3$ of that time. During this test 8 grams of aluminum dissolved from the anode while only 1.5 grams were plated onto cathodes, thus demonstrating the serious excess input of aluminum into the electrolyte which resulted from the ethyl bromide additions.

The rejuvenating effect of ethyl bromide is, however, spectacular, as is shown in Figure 5-6, as indicated primarily by the specific conductance of the electrolyte. It can be noted that at the $4,7.2$, and 10.2 amp hour litre ${ }^{-1}$ positions on Figure 5-6, the specific conductance drops to 0.1 or $0.2 \times 10^{-3} \Omega^{-1} \mathrm{~cm}^{-1}$. This is the consequence of leaving the anode in the electrolyte overnight, during which time con- 


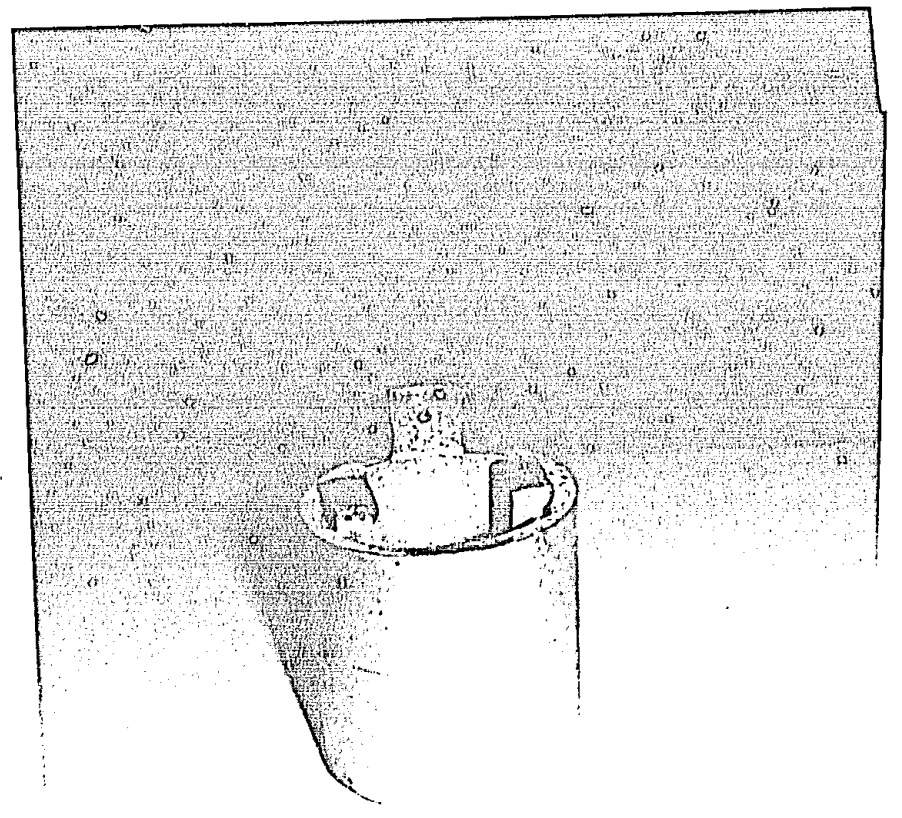

Figure 5-5. Photograph of Cast Aluminum Cylindrical Anode. 


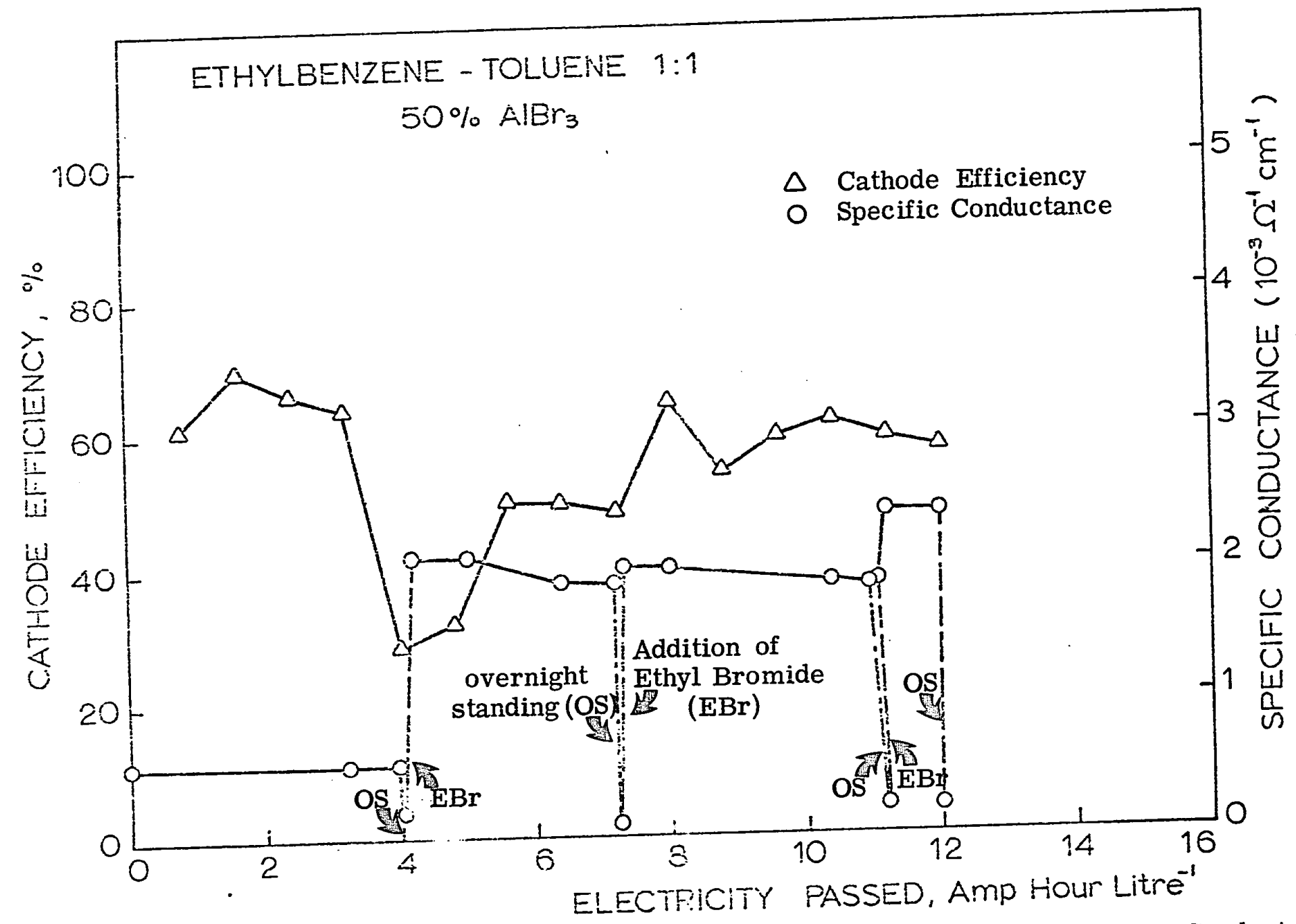

Figure 5-6. Graph Showing the Extensive Lowering of Electrolyte Specific Conductance When the Aluminum Anode is Left in the Electrolyte Overnight (Current Off). The Recovery of the Specific Conductance Due to the Addition of Ethyl Bromide Is Clearly Shown. 
siderable excess aluminum has been dissolved. The electrolyte is virtually useless at these low conductance levels because large voltages ( 30 volts) are required for plating.

It can be noted, however, that additions of ethyl bromide (approximately $10 \mathrm{ml}$ per litre of electrolyte) quickly bring the specific conductance up to $3 \times 10^{-3} \Omega^{-1} \mathrm{~cm}^{-1}$ which is suitable for electroplating, requiring only 5 or 6 volts for cell operation.

The general effect of aluminum excess in solution on the cathode efficiency is less noticeable, but it was noted that if the electrolyte is operated for too long without adding ethyl bromide (or $\mathrm{HBr}$ ), the cathode efficiency begins to drop as indicated by the sharp decrease in cathode efficiency in Figure 5-6 between 3 and 4 amp hour litre ${ }^{-1}$ of electricity passed. The cathode efficiency can be restored, though somewhat slowly by additions of ethyl bromide or $\mathrm{HBr}$.

It was clear from these experiments that the most responsive indication of electrolyte condition is specific conductance and that as long as the specific conductance is above $2 \times 10^{-3} \Omega^{-1} \mathrm{~cm}^{-1}$, the cathode efficiency would be acceptable, i.e., $60 \%$ or above. This relationship and its use as a control parameter is discussed in detail in Section 5-8B. To summarize these experiments, it was shown that ethyl bromide suitably improves electrolyte performance by complexing excess aluminum ions. Ethyl bromide has two major disadvantages, however, in that it chemically attacks the anode and it causes evolution of $\mathrm{HBr}$ during the additions and during electrolysis. For these reasons it was abandoned 
in favour of $\mathrm{HBr}$ as an addition agent.

Average values for the $11 / 2$ hour plating tests while examining ethyl bromide additions were:

Anode efficiency: $290 \%$

Cathode efficiency: $55.9 \%$

Applied potential: 8.1 volts

Coating thickness: $0.010 \mathrm{~mm}$

\subsection{Hydrogen Bromide Addition to Increase Electrolyte Life}

Since ethyl bromide was not completely suitable as an addition agent, hydrogen bromide was tested for the purpose of complexing the excess aluminum ions in solution.

The experiments for this system were performed as follows:

Anode shape: Cylindrical (see Fig. 5-5)

Electrolyte: Ethylbenzene-toluene 1:1 volume, 50\% wt. $\mathrm{AlBr}_{3}$

Plating conditions: Standard, plating test of $11 / 2$ hours on copper sheets

Bath conductivity: Adjusted with hydrogen bromide

Observation and Results: Table A.VI-2 (Appendix VI), Figure 5-7.

The results of $\mathrm{HBr}$ addition were similar to those previously discussed for ethyl bromide, but $\mathrm{HBr}$ was not subsequently evolved during the electrolysis and thus it was considered to be a more useful aluminum complexing material. The presence of $\mathrm{HBr}$ in solution resulted in considerable chemical attack on the anode during standing so that $\mathrm{HBr}$ was no more advantageous than ethyl bromide in this respect. 


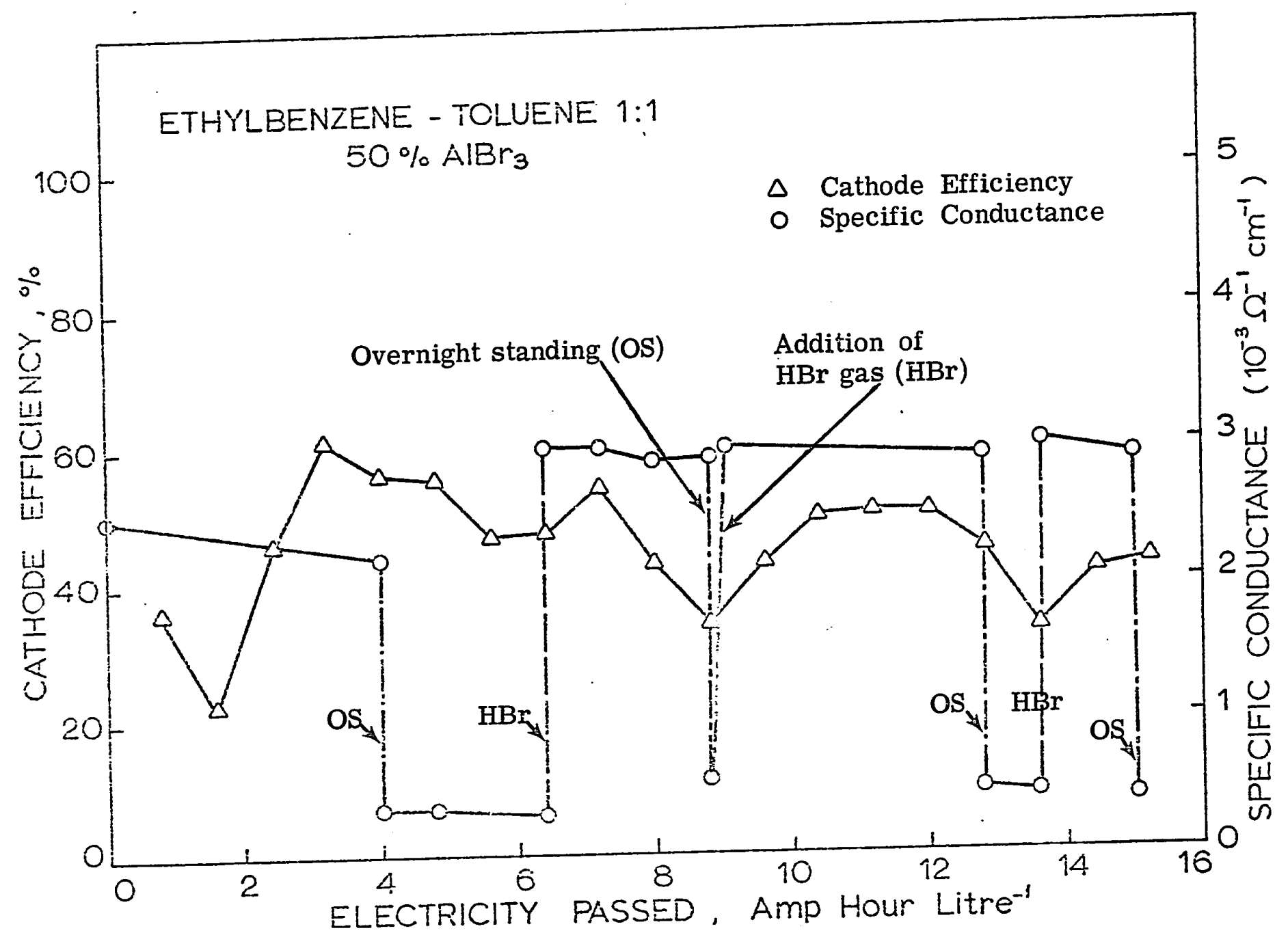

Figure 5-7. Graph Showing the Extensive Lowering of Electrolyte Specific Conductance When Anode is Left in the Electrolyte Overnight (Current Off).

Whe Recovery of the Specific Conductance Due to the Addition of $\mathrm{HBr}$ is shown. 
Figure 5-7 shows the effect of leaving the anode in the electrolyte without passing current (at points 4, 8.8, 12.8, and 13.6 amp hour litre ${ }^{-1}$ ), i.e., the specific conductance of the electrolyte drops to unacceptably low values. The addition of $\mathrm{HBr}$ quickly restores the conductance to the desired level (in this case $3 \times 10^{-3} \Omega^{-1} \mathrm{~cm}^{-1}$ ), thus rendering the electrolyte useful once again.

Two basic points of understanding were gained from these tests.

1. The aluminum anode should not be left in the electrolyte while the bath is not being used. This results in rapid aluminum dissolution and thus a large aluminum excess in solution. The specific conductance and electrolyte performance are adversely affected.

2. Free $\mathrm{HBr}$ in the electrolyte is the principal determining factor of electrical conductivity. This $\mathrm{HBr}$ can be provided by ethyl bromide which produces $\mathrm{HBr}$ by direct action on the benzenic ring of the solvent:

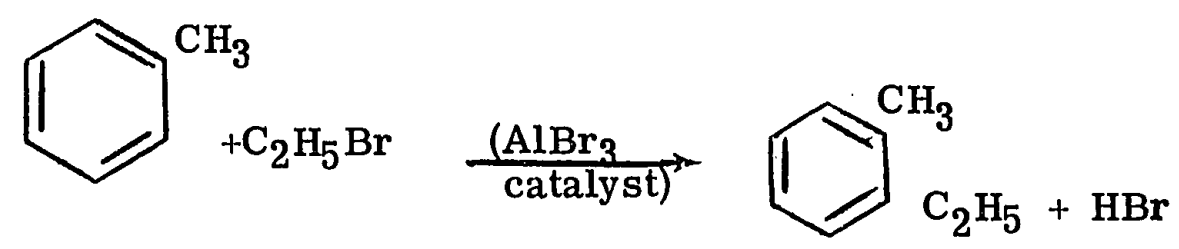
or directly by adding $\mathrm{HBr}$. 
It is thought that $\mathrm{HBr}$ forms the $\sigma$ complex, e.g., Section 3.1 (p. 33) and that the latter contributes to the conductivity. Furthermore $\mathrm{HBr}$ reacts with any excess of $\mathrm{Al}$ ions plus excess solvent to produce an increased quantity of suitable electrolyte.

Average values for this system were:

Anode efficiency: $320 \%$

Cathode efficiency: $44.6 \%$

Applied potential: 12.3 volts

Coating thickness: $0.008 \mathrm{~mm}$

In summary, hydrogen bromide was considered to be the more acceptable addition agent for restoring the aluminum imbalance in the electrolyte, and all further additions were of this form.

\subsection{Electrolyte Performance}

Based upon the results of the previous section, a longer electrolyte performance test was undertaken using $\mathrm{HBr}$ as an addition agent and with specific conductance as an indication of electrolyte performance.

The anodes were removed from solution overnight to avoid excessive chemical dissolution of the anode aluminum while not passing current.

It was thought at this point to also investigate steel as a metallic substrate. Four cells were connected in series which permitted the simultaneous testing of 4 electrolyte baths over a period of 2 weeks. 
The experiments were designed as follows:

Anode shape: Flat

Electrolyte: Ethylbenzene-toluene 1:1, 50\% $\mathrm{AlBr}_{3}$

Plating conditions: Standard, plating tests of $11 / 2$ hour each on copper substrates except for

Bath D where steel cathodes were used.

Stirring: Well agitated by magnetic stirrer (Teflon covered)

Specific Conductance: 3 to $4 \times 10^{-3} \Omega^{-1} \mathrm{~cm}^{-1}$ adjusted with

$\mathrm{HBr}$ gas additions

Current density: $10 \pm .1 \mathrm{~mA} / \mathrm{cm}^{2}$

Observations and Results: Table A. VI-3 (Appendix VI), Figure 5-8.

The procedure followed during these tests was to always maintain the specific conductance within the range of 3 to $4 \times 10^{-3} \Omega^{-1} \mathrm{~cm}^{-1}$, this being accomplished by bubbling $\mathrm{HBr}$ gas into the electrolyte via a glass diffuser. It was found that by taking the precaution of removing the anode from the electrolyte while the bath was not in operation, the conductance dropped only very slowly and, in fact, during the tests reported in Figure 5-8, only one $\mathrm{HBr}$ addition was made (after 7 days) to each bath.

Excellent aluminum coatings were obtained throughout the tests on both copper and steel substrates. Average values for the baths were: $\frac{\text { Bath A }}{111.7 \%} \frac{\text { Bath B }}{104.0 \%} \frac{\text { Bath C }}{103.9 \%} \frac{\text { Bath D }}{113.6 \%}$ $\begin{array}{lllll}\text { Anode efficiency: } \quad 111.7 \% & 104.0 \% & 103.9 \% & 113.6 \%\end{array}$ $\begin{array}{lllll}\text { Cathode efficiency: } \quad 71.2 \% & 70.3 \% & 66.9 \% & \mathbf{7 5 . 9} \%\end{array}$ (steel substrate) 


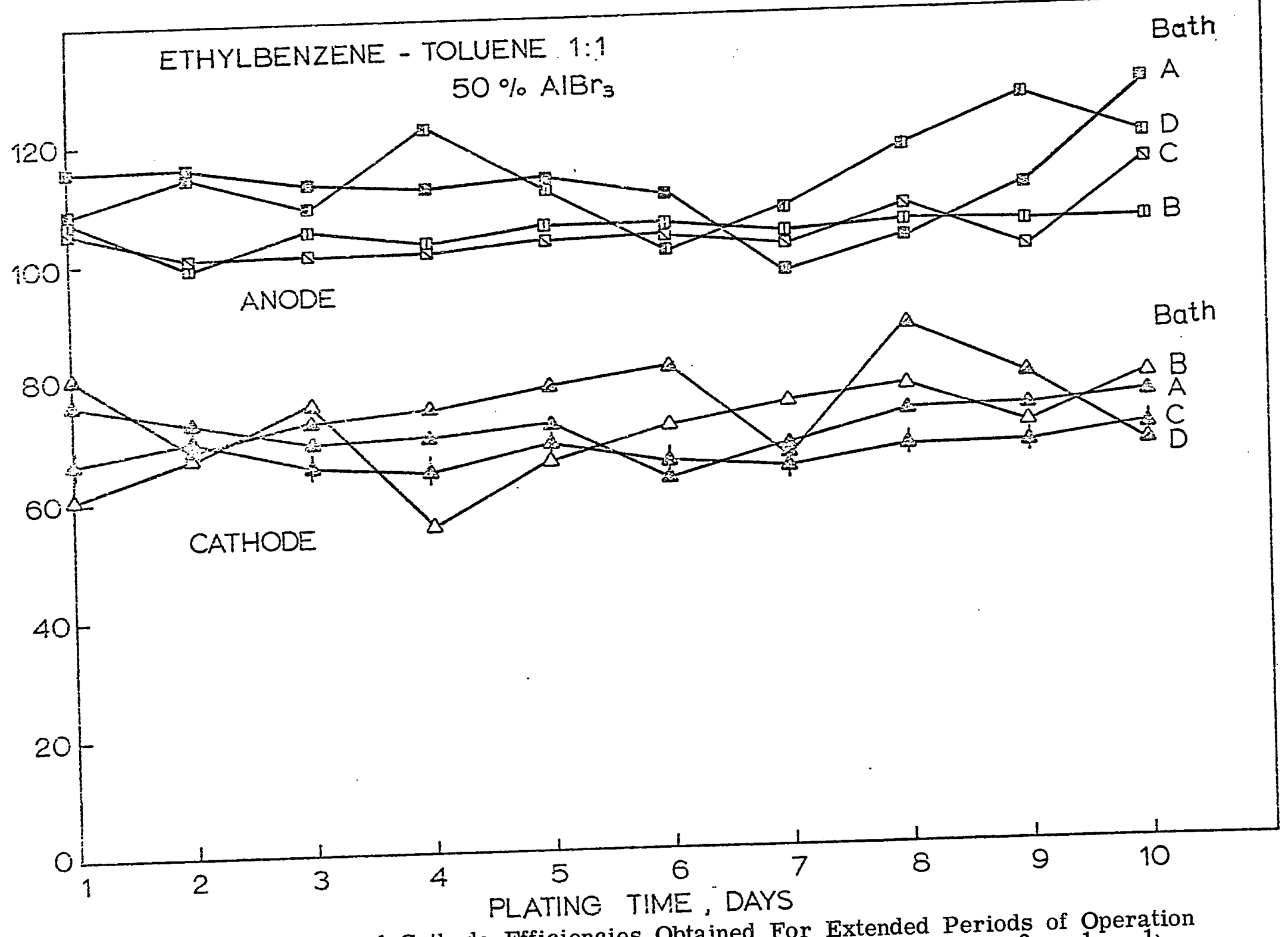


These tests (Fig. 5-8) showed that the electrolytes could be used for extended periods of time and that maintenance of the electrolyte conductance at $3 \times 10^{-3}$ to $4 \times 10^{-3} \Omega{ }^{-1} \mathrm{~cm}^{-1}$ would ensure a good plating quality and a high level of cathode efficiency $(=70 \%)$. It became evident that for best performance the electrolytes should not be permitted to build up a large aluminum ion excess before $\mathrm{HBr}$ is added.

\subsection{Electrolyte Performance at Higher Current Densities}

One of the drawbacks of electrolyte performance has been the decrease in cathode efficiency with increasing current density which effectively restricts the rate at which plating can be carried out. Since the early examination of this effect had been restricted to only one batch of electrolyte (Fig. 4-3), it was decided to re-examine the effect with 3 simultaneous tests, using three of the baths (A, B, C, Fig. 5-3) used in previous tests.

The conditions for the experiments were:

Anode shape: Flat (the anodes were removed when the bath was not being used)

Current density: 5 to $40 \mathrm{~mA} / \mathrm{cm}^{2}$

The electrolyte was well stirred so as to unify the two layers present. The conductivity was adjusted with $\mathrm{HBr}$ gas in the same way as described in the previous experiments (Section 5.4). Copper cathodes were used throughout this investigation.

Observations and Results: Table A. VI-4 (Appendix VI), Figure 5-9. 


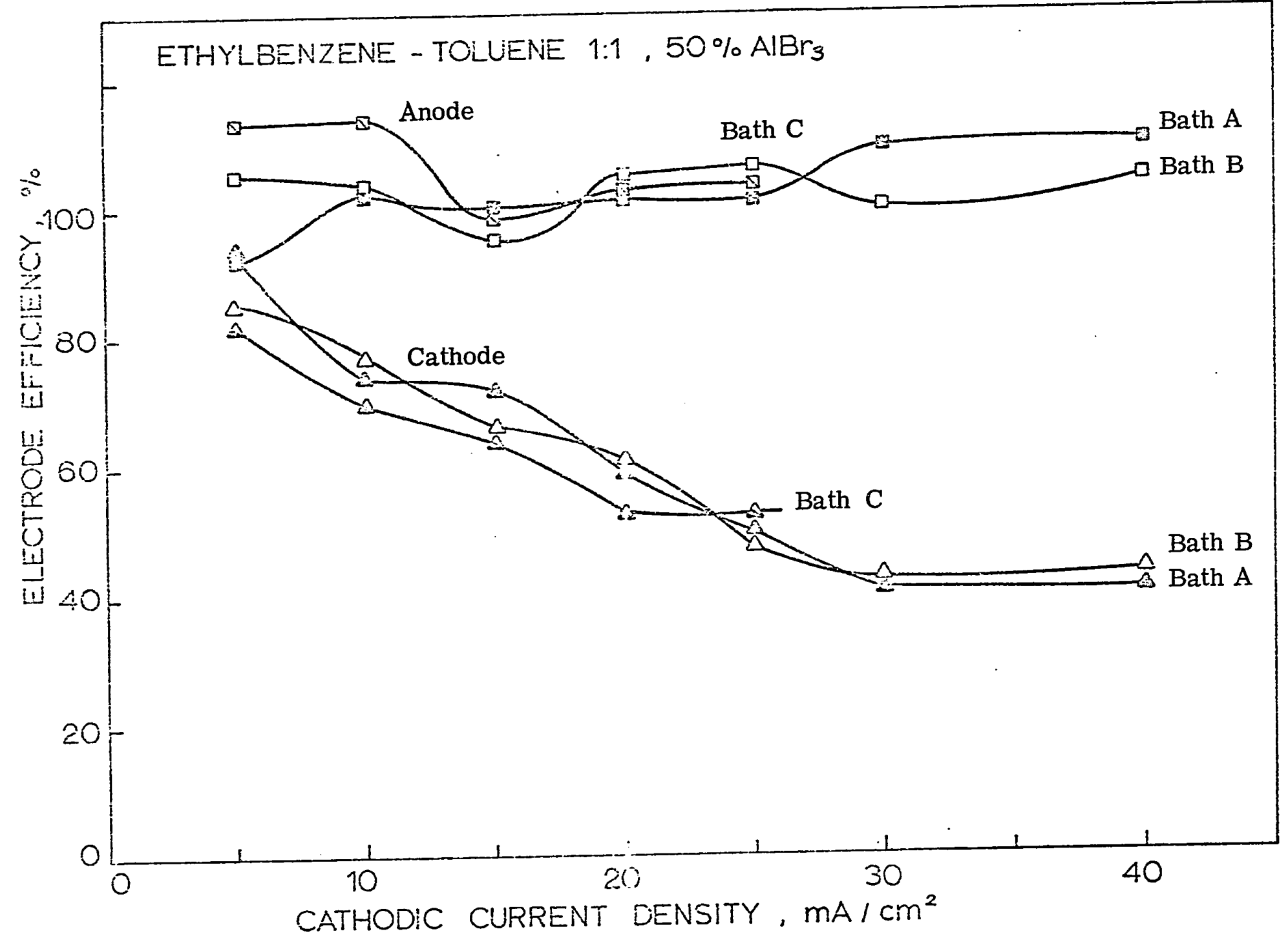

Figure 5-9. Anode and Cathode Efficiencies as a Function of Cathode Current Density. Each Point Represents $71 / 2$ Hours of Plating. 
It was noted, in confirmation of Figure 4-3, that the current efficiency did, in fact, drop at increasing current density. Thus this performance characteristic does not change with time or with $\mathrm{HBr}$ additions to the electrolyte.

It was also noticed that at higher current densities the specific conductance of the electrolyte decreased more rapidly, which would be expected with the observed greater imbalance between anode and cathode efficiencies (Fig. 5-9). No problem was encountered, however, in restoring the electrolyte performance (conductance) by additions of $\mathrm{HBr}$.

\subsection{Electrolyte Performance Over a Long Period of Time}

The electrolytes described in Sections 5.4 and 5.5 were prepared and used extensively during a year prior to the Section 5.4 and 5.5 experiments. Subsequent tests under more normal operating conditions $\left(10 \mathrm{~mA} / \mathrm{cm}^{2}\right)$ showed that the performance of the electrolytes had not deteriorated in any sense after a year of intermittent operation.

\subsection{Control of the Electrolyte}

It became evident during the $\mathrm{HBr}$ addition tests that specific conductance was an excellent indication of the operating state of the electrolytes. Specific conductance is not only an important operating parameter for its own sake, in that it determines the level of operating voltage, but there is a definite relationship between cathode efficiency and specific conductance. 
In this section of the work chemical analysis was examined as an indication of the state of the electrolyte and the relationship between specific conductance and cathode efficiency was further examined.

A. Chemical analysis as an indication of electrolyte performance Electrolyte: ethylbenzene-toluene $1: 1,50 \%$ wt. $\mathrm{AlBr}_{3}$ plating conditions: standard, plating tests of $11 / 2$ hours on copper sheets.

The electrolyte was chemically analyzed for bromide and aluminum concentration (the chemical procedures are described in Appendix $\mathrm{V}$ of this thesis) a) shortly after preparation and, b) after 300 to 500 hours of plating use.

Observations and Results: Table 5-1

The results of the chemical analyses of the electrolytes are shown in Table 5-1, which indicates that an increase in specific conductance is accompanied by a slight increase in $\mathrm{Br}^{-}$ion concentration. More importantly Table 5-1 shows that chemical analysis is not sufficiently sensitive ( $\pm 10 \mathrm{gram} / \mathrm{litre})$ to give a clear indication of performance.

It is interesting to note (Table 5-1) that after differing times of plating (hence different quantities of excess aluminum dissolved from the anode), the concentrations of aluminum and bromine ions are virtually the same for all three baths. This is due to the formation of an aluminum complex of constant composition, i.e., the excess aluminum going into solution is converted to the constant composition complex by reacting with the added $\mathrm{HBr}$ and the excess solvent which is always present in the system. 
TABLE 5-1

Analysis of Electrolyte as Prepared

$\begin{array}{cccccc}\text { Bath No. } & \begin{array}{c}\text { Specific conductance } \\ \Omega-1_{\mathrm{cm}^{-1}}\end{array} & \begin{array}{c}\mathrm{Br}^{-} \\ \text {gram/liter }\end{array} & & \begin{array}{c}\text { Date } \\ \text { prepared }\end{array} & \begin{array}{c}\text { Date } \\ \text { analyzed }\end{array} \\ \text { 3A } & 2.5 \times 10^{-3} & 584 \pm 10 & \text { June 26/71 } & \text { June 27/71 } \\ \text { 4A } & 2.5 \times 10^{-3} & 584 \pm 10 & \text { Aug 3/71 } & \text { Aug 5/71 } \\ \text { 4L } & 2.5 \times 10^{-3} & 584 \pm 10 & \text { June 17/71 } & \text { June 20/71 }\end{array}$

Analysis of Electrolyte after Being Used for Some Time

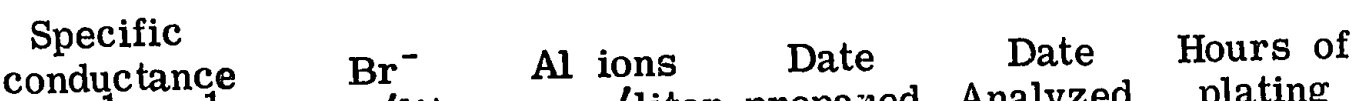

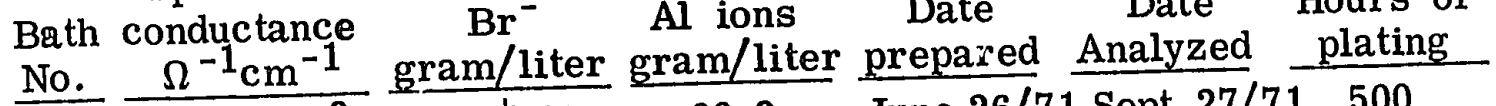

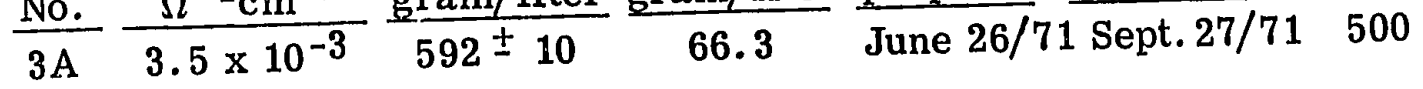

$4 \mathrm{~A} \quad 3.5 \times 10^{-3} \quad 592 \pm 10 \quad 68.1 \quad$ Aug. 3/71 Jan. 20/72 300

$4 \mathrm{~L} \quad 3.5 \times 10^{-3} \quad 592 \pm 10 \quad 66.7 \quad$ June $17 / 71$ Sept. $27 / 71 \quad 500$ 
B. Conductivity as an indication of electrolyte performance

Electrolyte: ethylbenzene-toluene 1:1, 50\% wt. $\mathrm{AlBr}_{3}$

Plating conditions: standard plating tests of $11 / 2$ hour on copper sheets.

Observations and Results: Table A.VI-5 and A.VI-6 (Appendix

VI), Figures 5-10 and 5-11.

Control of the electrolyte by a conductivity method was found to be simpler, faster and more accurate than chemical analysis. It was found that as long as specific conductance was between 2 and $4 \times 10^{-3}$ $\Omega^{-1} \mathrm{~cm}^{-1}$ the electrolyte operated uniformly and reproducibly. As Figure 5-10 shows, the cathode efficiency maximizes in this specific conductance range while chemical attack on the anode (as indicated by the amount which the anode efficiency exceeds 100\%) still remains low. The deleterious effect of raising the specific conductance too high (say greater than 4.5 by adding too much $\mathrm{HBr}$ ) is indicated by an excessive amount of aluminum dissolution from the anode. However, as Figure 5-11 shows the system reequilibrates itself to a specific conductance of 3 to $4 \times 10^{-3} \Omega^{-1} \mathrm{~cm}^{-1}$ with time.

A typical operating curve which shows the beneficial effect of the $\mathrm{HBr}$ additions on specific conductance and cathode efficiency is shown in Figure 5-11. 


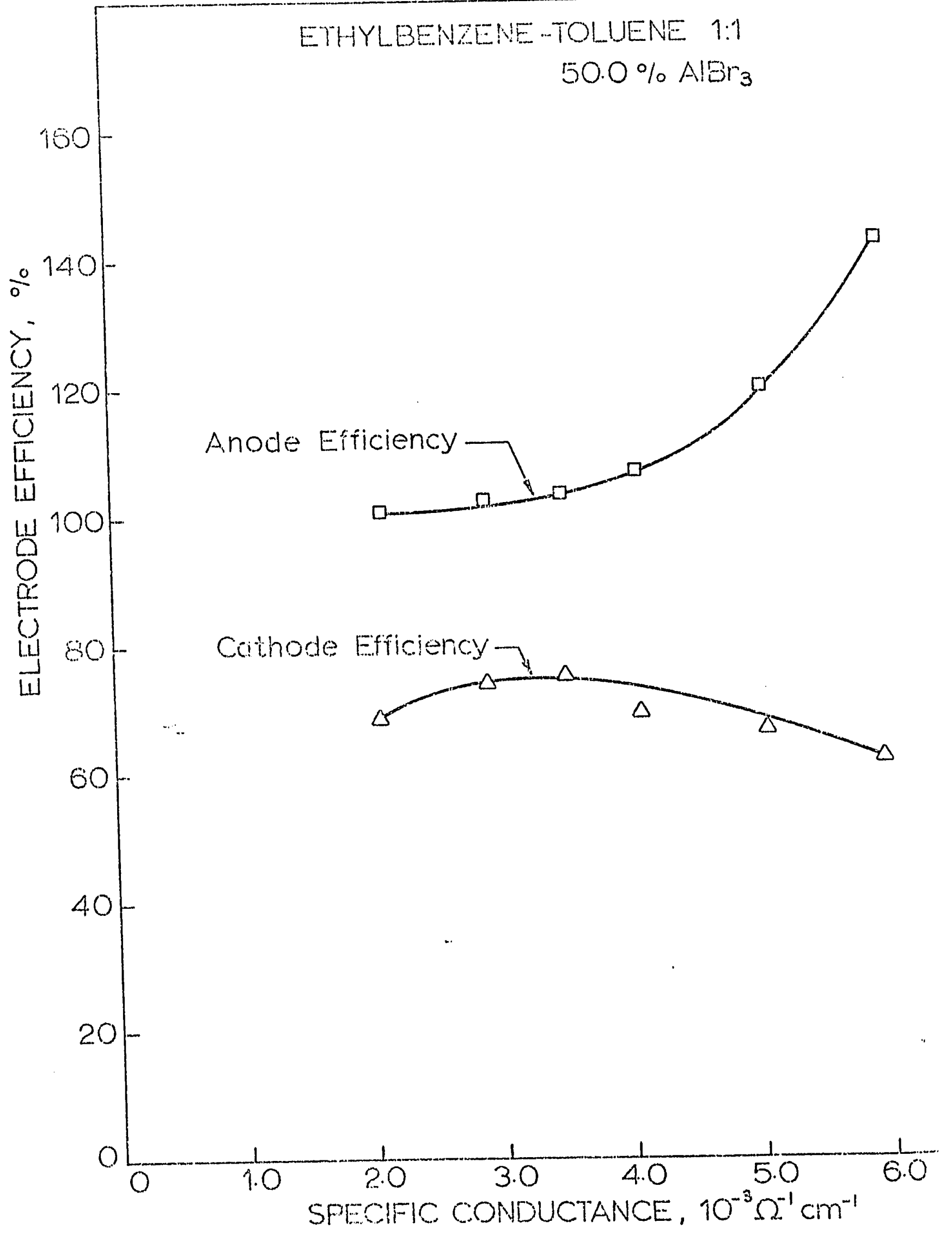

$\frac{\text { Figure 5-10. Electrode Efficiencies as a Function of Specific }}{\text { Conductance of the Electrolyte, Cathode Current Density } 10 \mathrm{~mA} / \mathrm{cm}^{-2} \text {. }}$ 


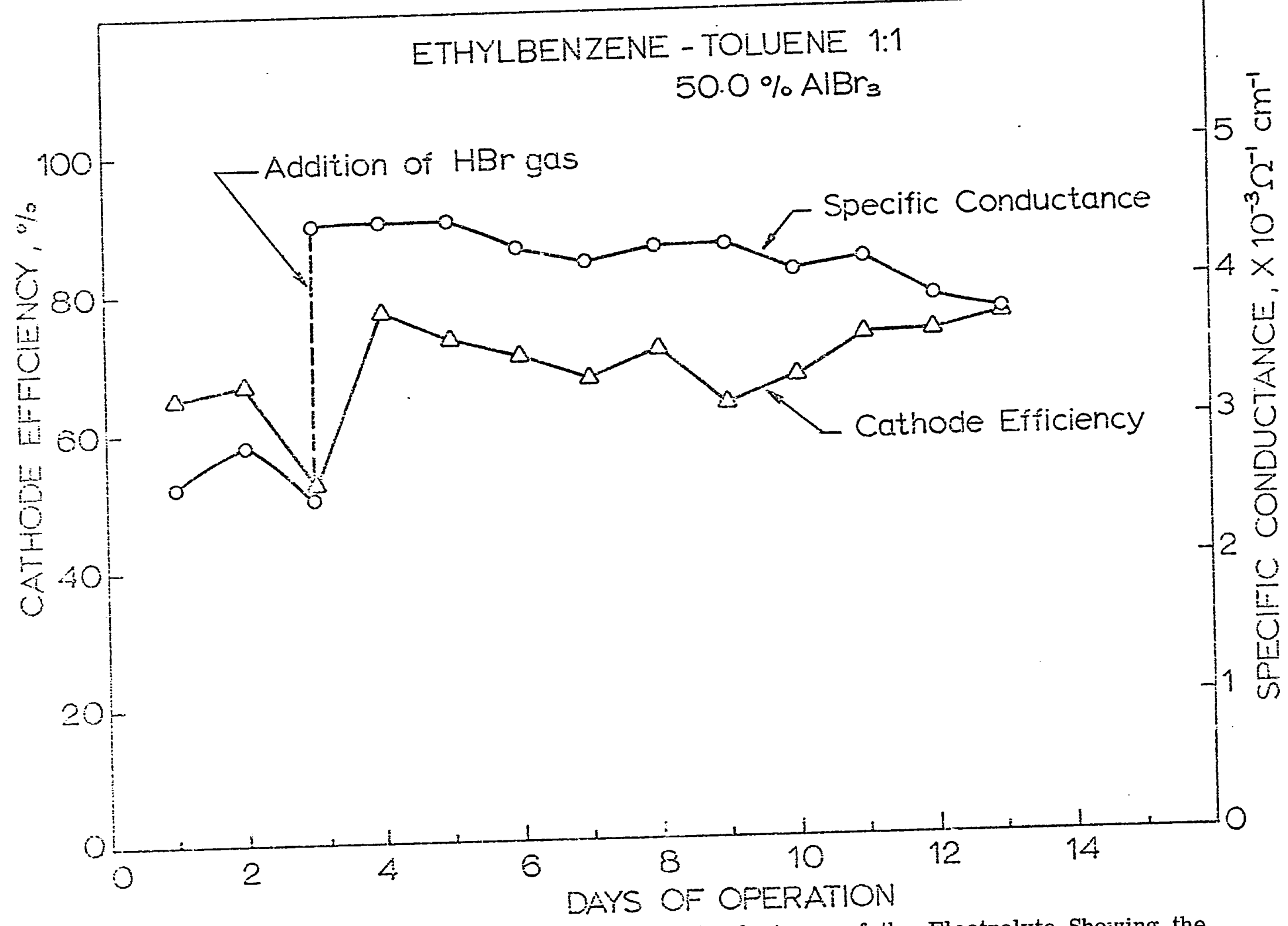

Figure 5-11. Cathode Efficiencies and Specific Conductance of the Electrolyte Showing the Effect of Adding HBr Gas to the Electrolyte. Cathode Current Density $10 \mathrm{~mA} / \mathrm{cm}^{-2}$. 


\subsection{Summary}

This section has shown that the ethylbenzene-toluene electrolyte can be operated for long periods of time without appreciable deterioration of electrolyte performance. It is, however, necessary to offset the dissolution of excess aluminum from the anode into the electrolyte by periodically adding small amounts of $\mathrm{HBr}$. It has also been shown that the aluminum anodes should be removed from the electrolytes during idle periods in order to avoid the dissolution of large quantities of aluminum from the anode.

The specific conductance of the electrolyte has been shown to be an excellent indication of electrolyte performance. 


\subsection{CATHODIC POLARIZATION IN THE ETHYLBENZENE- TOLUENE SYSTEM}

In the preceding sections optimum conditions concerning the solvent type, solute/solvent concentration, and specific conductance of the electrolyte were established. However, little information concerning the effect of temperature or the electrochemical mechanisms of the system was gathered.

It was the object of this part of the investigation to determine the charge-transfer overvoltages and the heats of activation of the cathodic process for the ethylbenzene-toluene- $\mathrm{AlBr}_{3}$ electrolyte and to begin an electrochemical kinetic and mechanistic study of the system.

A study of cathodic charge-transfer overvoltage is the starting point of such an investigation and the effect of temperature on current vs. overvoltage plots serves to establish heats of activation. However, the determination of the dynamic potential of a single electrode (electrode charge-transf er overvoltage) for organic electrolytes presents some difficulties which are mentioned in the experimental sections (6. 2 onward).

\section{1 Theoretical Concepts}

The following presentation on electrode behaviour is essentially a simplification of the detailed treatments presented by Bockris, 99 Vetter $^{101}$ and Kortum. 102 
A. Electrode Potential

Metal electrodes in aqueous solutions usually follow the Nernst relationship. When Nernstian behaviour is exhibited by an electrode, a definite potential is established between the electrode and solution. This potential is predictable from a knowledge of the activities and free energies of the electrode and solution constituents.

Quite often this potential is called the reversible potential, but this term should be used only. when the electrode reaction in question is truly reversible, i.e., when a small change in potential from one side of the reversible potential to the other will reverse the direction of the electrode reaction.

A more general term for the potential established between an electrode and a solution is the "rest" or "static" potential.

\section{B. Electrode-Solution Interface}

When an electrode is placed in an electrolyte, there is a redistribution of the electrical charge associated with the particles which come from the bulk of the two phases (electrode and solution) to form the interface or interfacial layer. This redistribution of charge forms a region which is called the double layer.

The species which are involved in electrochemical reaction across the double layer exist in energy wells: in the electrode, the well is produced by the influence of the other atoms and ions in the metal lattice; in the solution, the well is produced by the influence of solvent molecules or of other ions (complexed species). It is useful to picture 
an energy well in the electrode moving close enough to an energy well in the solution so that the energy barrier between the two wells is small enough to permit a transfer of species between the two wells.

Depending on the relative depth of the two energy wells, the transfer can be either anodic or cathodic, but there is a tendency for the two transfers to move towards a balanced state where the anodic and cathodic processes are virtually balanced. The potential and the current flow across the energy barrier in this balanced state are called the rest potential and the exchange current respectively.

Butler ${ }^{103}$ calculated that several hundreds electron volts are required to lift bare unsolvated cations from their energy wells in the metal lattice, or to lift a bare cation out of its hydration sheet. However, the transfer of a cation from a metal latice to the solution requires only about 5-10 mV potential. Thus, the energy wells in the two phases must be very close together.

\section{Overvoltage}

When a second electrode is placed in the electrolyte to complete the galvanic cell, and an external potential is applied, the rest condition is altered to a net cathodic or anodic condition depending on the direction of the applied potential. The additional potential across the double layer constitutes a driving force for electrochemical reactions at the electrode, and tends to increase the current flow through the cell. A new term, the overvoltage, is defined. 
The overvoltage at a certain current density is the difference between the measured potential and the previously established rest potential for the particular electrode. If the overvoltage is represented by $\eta$, then

$$
\eta=\phi_{i}-\phi_{0}
$$

where $\phi_{i}$ and $\phi_{0}$ are the half-cell potentials at net current density $i$ and zero respectively. It must be emphasized at this point that $\phi_{i}$ is the potential which must be met to maintain the current density level at $i$ and hence it is identical to the potential $(\Delta \phi)$ which must be applied at the electrode to maintain the current density at i, i.e.,

$$
\phi_{\mathrm{i}}=\Delta \phi
$$

Similarly $\phi_{0}$ is the rest potential at which there is no net current flow and which is identical to the potential which must be applied and slightly exceeded at the electrode $\left(\Delta \phi_{0}\right)$ to initiate net current flow, i.e.,

$$
\phi_{0}=\Delta \phi_{0}
$$

which under reversible conditions is $\Delta \phi_{\mathrm{r}}$. Various types of overvoltage have been distinguished 101,102 but the four most important types are ohmic $\left(\eta_{R}\right)$, concentration $\left(\eta_{c}\right)$, crystallization $\left(\eta_{c r}\right)$ and charge transfer $\left(\eta_{t}\right)$ overvoltages. Thus

$$
\eta_{\text {total }}=\eta_{\mathrm{R}}+\eta_{\mathrm{c}}+\eta_{\mathrm{cr}}+\eta_{\mathrm{t}}
$$

An ohmic overvoltage $\left(\eta_{R}\right)$ is developed when a film is formed on the electrode which sets up a resistance to the passage of current across it. If the current density is $i$ and the film resistance $R$, then 
the ohmic overvoltage will be iR. Values of several volts are possible for the ohmic overvoltage depending on the nature of the film formed. Concentration overvoltage $\left(\eta_{c}\right)$ is caused by the existence of a difference in concentration of ions between the electrode-solution interface or double layer and the bulk of the solution. Since the potential of the electrode is related to the ionic concentration (activity) in the double layer, and the potential measured by a reference electrode is related to the ionic concentration (activity) in the bulk solution, serious errors can be introduced in charge-transfer overvoltage measurements if the concentration overvoltage is not recognized and either allowed for or removed. The phenomenon of concentration overvoltage forms the basis of polarography. The concentration overvoltage can further be divided into diffusion and reaction overvoltage. 102

Little is known about the properties of the crystallization overvoltage $\left(\eta_{\mathrm{cr}}\right)$. It appears, however, that a reaction hin drance is created by the necessity of incorporating metallic ions into the crystal lattice of the electrode. According to Stranski's theory of crystal growth, ${ }^{108}$ each metallic ion deposited must first find its way to a suitable site at the edge of a lattice. If additional overvoltage is observed when this reaction is thus inhibited, it is known as the crystallization overvoltage $\left(\eta_{\mathrm{cr}}\right)$. Crystallization overvoltage does not follow the normal Tafel (overvoltage vs. log current density) relationship so that the appearance of a straight Tafel line indicates that the crystallation overvoltage $\left(\eta_{\mathrm{cr}}\right)$ is insignificant with respect to the charge-transfer overvoltage. 101 
The fourth overvoltage type, charge-transfer overvoltage $\left(\eta_{t}\right)$ is developed when a reacting species encounters an energy barrier against transfer of electrons which it must climb before it can proceed along the reaction path. Thus the charge-transfer overvoltage is related to the energy of activation (i.e., the energy "height" of the barrier) and if carefully determined, it can provide both the identification of the rate determining step and the rate of reaction in a charge-transfer controlled electrochemical reaction.

For the simplest case, the activation barrier exists between two adjacent energy wells, one in the electrode and the other in the solution. If a simple physical description is to be attached to the activation barrier in this case, one can picture the barrier as being the electrical charge barrier of the double layer (Fig. A.VII-1) which is established between the bulk phase species when the two phases (metal and solution) are brought in contact with each other.

The success of experiments to determine the charge-transfer overvoltage depends on the minimization of ohmic and concentration overvoltage. The procedures and equipment necessary to minimize these unwanted overvoltages are described after a brief treatment of electrode kinetics.

\section{Electrode Kinetics}

The rates of electrode reactions can most conveniently be followed by measuring the current density as a function of the electrode overvoltage. The resulting relationship, when plotted, is called polarization 
curve. If it is possible to minimize extraneous diffusion and ohmic effects, then the polarization curves can be analyzed to aid in determining the electrode reaction mechanism.

The Butler-Volmer equation for electrochemical kinetic studies, the Tafel equation, and equations to determine the heat of activation at constant current and at constant overvoltage have been derived in Appendix VII and are as follows (a complete list of symbols appears on p. 304 ):

i) Butler-Volmer Equation

The Butler-Volmer Equation (A.VII-19 of Appendix VII) is written:

$$
\mathrm{i}_{\mathrm{C}}=\mathrm{i}_{\mathrm{o}}\left[\exp -\frac{\beta \lambda \eta_{\mathrm{t}} \mathrm{F}}{\mathrm{RT}}-\exp \frac{(1-\beta) \lambda \eta_{\mathrm{t}} \mathrm{F}}{\mathrm{RT}}\right]
$$

and it shows the basic relationship between the current density ${ }^{i_{C}}$ and the charge transfer overvoltage $\eta_{t}$ in terms of several kinetic parameters. The symbols in this equation are:

$$
\begin{aligned}
& \mathfrak{i}_{C}=\text { net cathodic current density } \\
& i_{0}=\text { exchange current density } \\
& \beta=\text { activation barrier symmetry factor } \\
& \lambda=\begin{array}{l}
\text { number of electrons involved in each act of the rate } \\
\text { determining step (Equation A.VII-27) }
\end{array} \\
& \mathbf{F}=\text { the Faraday constant } \\
& \eta_{\mathrm{t}}=\text { charge transfer overvoltage defined as }\left(\phi_{\mathrm{i}}-\phi_{0}\right) \text { or } \\
& \left(\Delta \phi_{0}-\Delta \phi_{r}\right) \\
& \mathrm{R}=\text { gas constant } \\
& \mathbf{T} \quad \text { = absolute temperature }
\end{aligned}
$$


The meaning of $i_{0}$ can be understood by considering that when the electrode is at its reversible potential relative to the electrolyte, the net flow of current into or out of the electrode is zero, i.e., ${ }^{i} \mathrm{C}=0$. There is, however, an equal and opposite current flow in both directions across the electrode interface:

$$
\vec{i}=\overleftrightarrow{i}
$$

The current density in either direction under these reversible conditions is $i_{0}$, where

$$
i_{0}=\vec{i}=\stackrel{i}{i}
$$

A simple description of the exchange current is that it is a measure of the relative ability of the electrode to take part in the particular electrode reaction. For the case of hydrogen evolution on metal cathodes, Bockris ${ }^{99}$ has pointed out that there is a strong relationship between $i_{O}$, the exchange current, and $\Phi$, the thermionic work function, where $\Phi$ is a measure of the ease with which electrons leave the metal; the greater $\Phi:$, the greater $i_{0}$.

Values of $i_{o}$ for evolution of hydrogen have been found to vary from $10^{-3} \mathrm{amp} / \mathrm{cm}^{2}$ for evolution on platinum to $10^{-13} \mathrm{amp} / \mathrm{cm}^{2}$ for evolution of hydrogen on mercury ${ }^{99}$. $i_{0}$ for copper from a $1 \mathrm{M} \mathrm{CuSO}_{4}$ solution was found to be of the order of $10^{-5} \mathrm{amp} / \mathrm{cm}^{2}$ by Bockris. ${ }^{99}$ However, Hurlen 104 found values varying from 1 to $3 \times 10^{-3} \mathrm{amp} / \mathrm{cm}^{2}$ for an electrolyte having the same copper sulfate concentration.

The symmetry factor, $\beta$, indicates the portion of the applied potential which is actually operating between the initial point of the 
reaction (ions) and the peak of the energy barrier existing between the initial and final state (Fig. AVII-1). This is the important region along the reaction path, for once a reacting species passes over the peak of the energy barrier, it requires no further driving force to reach the final state.

Although it is convenient to think of the energy barrier as having a physical shape, this is not necessary for a formal development of the rate expressions; ${ }^{85}$ the term $\beta$ can be considered to be only a mathematical convenience, a number between 0 and 1 . Quite often, $\beta$ has the value of $1 / 2$ and in these cases, the energy barrier, regardless of the interpretation of its physical shape, is truly symmetrical.

For a charge-transfer controlled reaction:

$$
\begin{aligned}
& \text { when } \eta_{\mathrm{t}}>>\frac{2.303 \mathrm{RT}}{\beta \lambda \mathrm{F}} \text { (i.e., } \eta_{\mathrm{t}}>>20 \mathrm{mV} \text { for } \beta \lambda=3 \text { ) } \\
& \text { then } \mathrm{i}_{\mathrm{C}}=\mathrm{i}_{\mathrm{O}} \quad \exp -\frac{\beta \lambda \eta \mathrm{F}}{\mathrm{RT}} \\
& \text { and } \eta_{\mathrm{t}}=\frac{\mathrm{RT}}{\beta \lambda \mathrm{F}} \ln \mathrm{i}_{\mathrm{o}}-\frac{\mathrm{RT}}{\beta \lambda \mathrm{F}} \ln \mathrm{i}_{\mathrm{C}} \cdots
\end{aligned}
$$

Equation (6-4) is Equation A. VII-22 of Appendix VII.

ii) The Tafel Equation

The Tafel Equation (Equation A.VII-22) is written as

$$
\begin{aligned}
\eta_{t} & =a-b \ln i_{C} \ldots \\
\text { or } \quad \eta_{t} & =a-\frac{R T}{a F} \ln i_{C} \cdots
\end{aligned}
$$

which at high $\eta_{\mathrm{t}}$ values (equation $(6-4)$ above) has constants of 
the values:

$$
\begin{aligned}
\mathrm{a} & =\frac{\mathrm{RT}}{\beta \lambda \mathrm{F}} \ell \mathrm{n} \mathrm{i}_{\mathrm{o}} \ldots \\
\mathrm{b} & =-\frac{\mathrm{RT}}{\beta \lambda \mathrm{F}} \\
& \alpha=\beta \lambda \ldots \\
\text { also } \quad \lambda & =\frac{\mathrm{n}}{\nu} \ldots
\end{aligned}
$$

where $\mathrm{n}$ is the number of electrons involved in the overall electrode process and $\nu$ (the stoichiometric number) is the number of times the rate determining step occurs while the overall electrode process reaction occurs once. Then $\lambda$ (the stoichiometric factor) is the number of electrons involved in one act of the rate determining step.

iii) Heat of activation at constant overvoltage

Equation A. VII-34 of Appendix VII is the equation used for determining the heat of activation at constant overvoltage, i.e.,

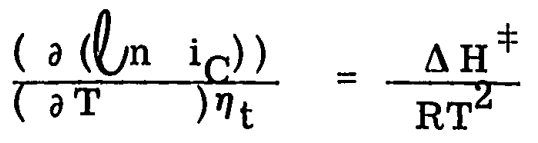

Integration of equation (6-6) and rearranging give the Arrhenius form for the electrochemical heat of activation for the charge-transfer process at constant overvoltage, i.e.,

$$
i_{C}=B \exp -\frac{\Delta H^{\neq}}{R T}
$$

and

$$
\log i_{C}=\log B-2.303 \frac{\Delta H^{\ddagger}}{R T}
$$

As shown in Equation A. VII-34

$$
\Delta \mathrm{H}^{\neq}=\Delta \stackrel{\mathrm{o}}{\mathrm{H}}^{+}+\lambda \beta \mathrm{F} \eta
$$


where:

$$
\begin{aligned}
\Delta \mathrm{H}^{\ddagger}= & \text { the electrochemical heat of activation } \\
& \text { specified charge-transfer overvoltage, and } \\
\Delta \mathrm{H}^{\ddagger}= & \text { heat of activation at the reversible potential (standard } \\
& \text { heat of activation). }
\end{aligned}
$$

iv) Heat of activation at constant current density

Equation A. VII-39 of Appendix VII was used for the determination of the heat of activation at constant current, i.e.,

$$
\frac{\left(\partial \eta_{t}\right)}{(\partial \mathrm{T})_{\mathrm{i}_{\mathrm{C}}}}=-\frac{\Delta \mathrm{H}^{\ddagger}}{\beta \lambda \mathrm{FT}}
$$

Integration of this equation gives

$$
\text { or } \begin{aligned}
\eta_{\mathrm{t}} & =-\frac{\Delta \mathrm{H}^{\ddagger}}{\beta \lambda \mathrm{F}} \ln \mathrm{T}+\mathrm{B} \\
\eta_{\mathrm{t}} & =-\frac{2.303 \Delta \mathrm{H}^{\ddagger}}{\beta \lambda \mathrm{F}} \log \mathrm{T}+\mathrm{B}
\end{aligned}
$$

and $\Delta H^{\ddagger}$ can be calculated from the slope of a plot of $\eta_{t}$ vs. $\log T$. $\Delta \mathrm{H}^{\ddagger}$ is the electrochemical heat of activation at a specified current density and differs from the heat of activation at the reversible potential (standard heat of activation $\Delta \stackrel{0}{H^{\ddagger}}$ ) by the amount $\beta \lambda \eta F$ (equation 6-6c).

It should be noted that in the present experimental investigation the reference electrodes, the anode, and the cathode are all of the same material so that they have identical reversible potentials. Thus the temperature effect on the reversible potential is not included in the calculated heat of activation and hence $\Delta H^{\ddagger}$ is considerably better than the "apparent" heat of activation as defined by Conway. 97, 98 
The electrochemical heat of activation is a function of the energy of activation and in the case of a charge-transfer controlled reaction it is actually a measure of the ease with which a reacting species climbs the free energy (or potential) barrier before it can proceed along the reaction path. The numerical values of heat or free energy of activation are considered to be the same for all practical purposes.

\subsection{Magnitude of Heat of Activation}

Gorbachev 105 has shown that in aqueous solutions the heat of activation in the case of charge-transfer polarization is of the order of 10-30 Kcal / mole, and it decreases slowly with increasing overvoltage. In the case of concentration overvoltage, on the other hand, the activation energy is of the order of only $2-4 \mathrm{Kcal} / \mathrm{mole}$ and it does not vary with the applied potential.

Simanavicius et al. ${ }^{106}$ have determined more recently the electrochemical energy of activation of an aluminum organic electrolyte (2:1 and a 1:1 molar mixtures of $\mathrm{AlBr}_{3}$ and ethyl pyridinium bromide in toluene). These workers showed that for cathodic charge-transfer overvoltage, the heat of activation was of the order of $4 \mathrm{Kcal} / \mathrm{mole}$. This low value demonstrates that the rules suggested for aqueous solutions are not necessarily valid for non-aqueous electrolytes.

\subsection{Criteria Used to Develop a Cell for Cathode Polarization Studies}

Few polarization studies on aprotic organic electrolytes have been done and thus a cell for the study of the ethylbenzene-toluene system 
had to be developed. Furthermore, since the single dynamic potential of one of the two operational electrodes during electrodeposition cannot be measured unless a third reference electrode is introduced, the specific measurement of cathode polarization (hence determination of the cathode mechanism) required that the cell be a three electrode system. The cell sought for this work had to be able to:

1. Provide direct polarization measurements without including ohmic drop due to the distance between the reference electrode and the cathode.

2. Avoid any screening effect (distortion of the electric field) due to the position of the tip of the reference electrode.

3. Give measurements free of polarization due to concentration gradients.

4. Avoid any junction potential between the electrolyte and the liquid contained in the reference electrode.

5. Insure an even distribution of current in the electrode being studied.

6. Measure the IR drop and concentration polarization.

\subsection{Possible Structures of the Reference Electrode}

As mentioned above, a third electrode (reference electrode) has to be introduced in the cell to measure the single dynamic potential (overvoltage) of one of the two operating electrodes during an electrodeposition process. This third electrode is not involved in the actual 
electrodeposition and no current passes through it. It is imperative that this reference electrode be joined in circuit with the active electrode in such a way as to minimize the problems $1,2,3$ and 4 above. One effective way of combining the reference and active electrode is by means of the so-called Luggin-Haber Capillary (Fig. 6.1). The latter is made by drawing out the connecting tube of the reference electrode to capillary dimensions, bending it through at a right angle and then placing the tip of the capillary very near the experimental electrode. Because there is no net DC current through the Luggin capillary (i.e., no concentration or ohmic polarization) the reference electrode detects the potential at the tip of the capillary. Thus the biggest advantage of the Luggin system is that potentials very close to the working electrodes can be measured.

The ohmic drop or pseudo resistance of the solution between the end of the capillary and the active electrode (cathode) can be calculated approximately ${ }^{88}$ if the capillary-electrode distance and the electrolyte conductivity are known, but it can assume very large values ${ }^{89}$ at high current density and with solutions having low conductivities.

This ohmic drop may, however, be corrected for by taking measurements at various separations of the Luggin capillary from the active electrode surface and by extrapolating the results obtained to zero separation. 90

Piontelli and his colleagues $91,92,93,94$ developed special types of capillaries to minimize the distortion of the electric field in the 


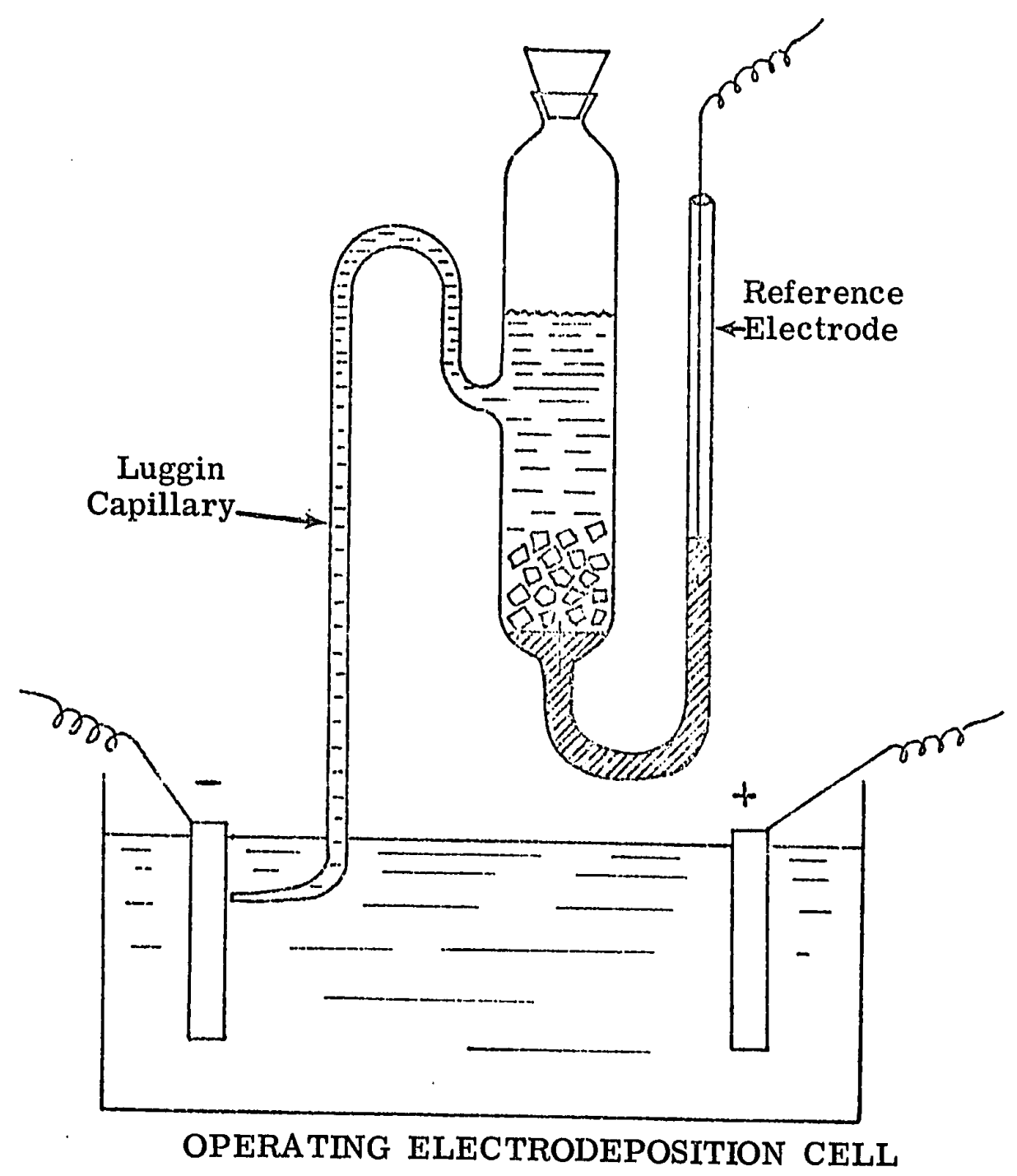

Figure 6-1. Operating Electrodeposition Cell with Reference Electrode and Luggin-Haber Capillary. 
vicinity of the test electrode (Fig. 6-2). These workers found that in the case of capillaries situated in front of the active electrode (type $a^{\prime}$, $a^{\prime \prime}, \mathrm{b}$ and c, Fig. 6-2), a distance greater than 3 times the diameter of the capillary $(\ell>3$ D) was necessary so that the electric field distortion became completely negligible. They reported, however, that a distance of $\ell>D$ is enough to render the distortion negligible for practical purposes. However, Piontelli favours the types "e" and " $f$ " back electrodes shown in Figure 6-2 and the "e" type electrode was used throughout this research. In addition, minimizing field distortion, the "e" type of capillary permits the very close placement of the capillary tip to the cathode which insures minimization of concentration differences adjacent to the active and reference electrodes.

\subsection{Cell and Reference Electrode Design}

A cylindrical cell, with the working electrodes occupying almost the entire circular section of the cell was used in order to insure the uniformity of the current (Fig. 6-5a) at the working electrodes.

Cathodic polarization was determined directly by applying the Luggin capillary to the back of the electrode (cathode) being studied (Type "e", Fig. 6-2). The reference electrode was of the same material as the anode used in the cell and the capillary contained the same electrolyte as the one under study. The latter helped to avoid junction potentials (problem 4, Section 6.3).

Reference electrodes were also placed in a lateral position on the cell (see Fig. 6-4). These were used to determine concentration polari- 

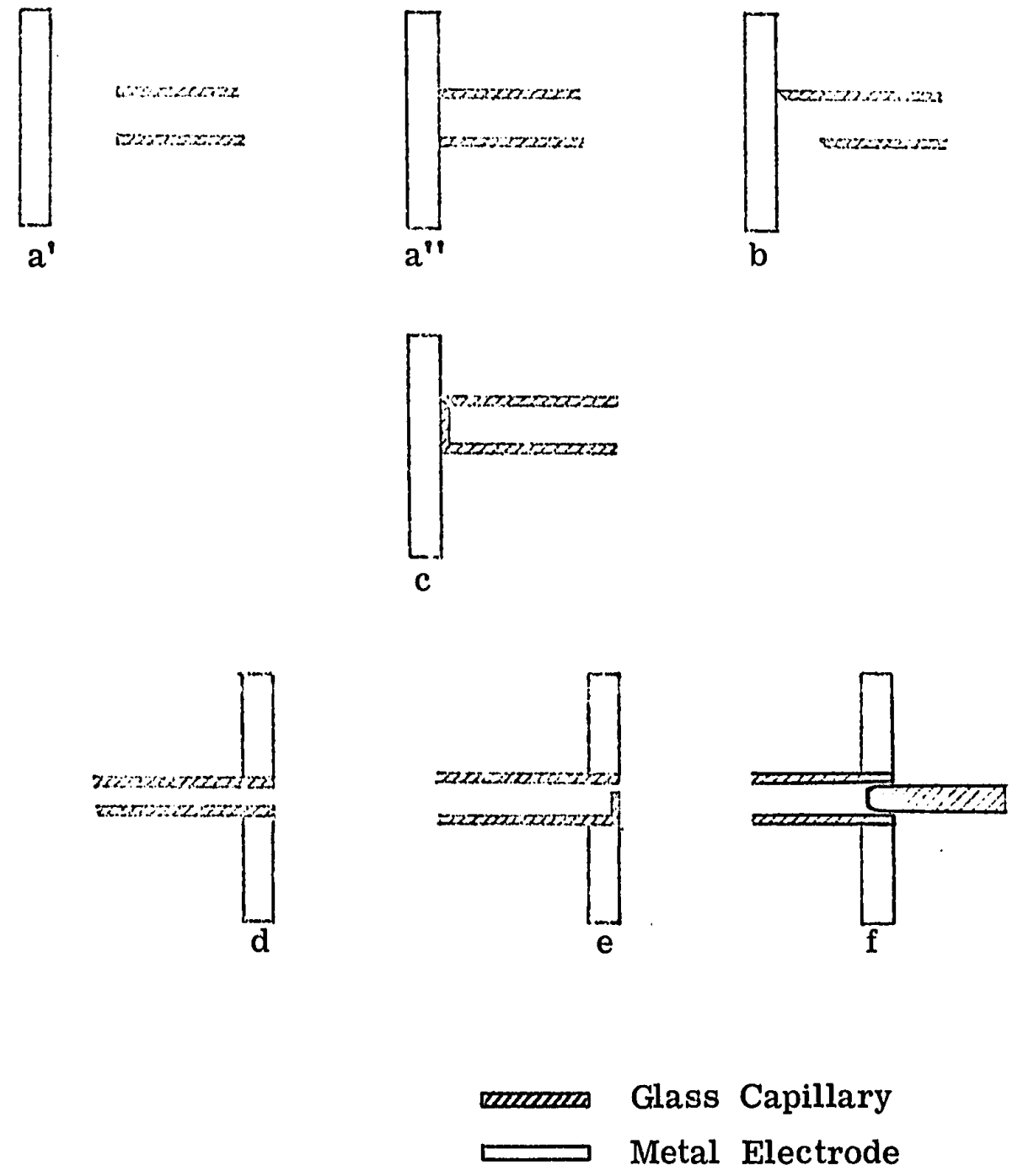

Figure 6-2. Arrangements of Luggin Capillaries Studied by Piontelli. 91, 92, 93, 94 
zation, IR drops and to verify the cathodic polarization values measured with the back reference electrode. The reference electrodes were all of the type: metal vs. metal ions and were either a wire of the anode material or a platinum rod freshly plated with the metal under study. Stirring was insured by bubbling anhydrous nitrogen or by stirring with a Teflon covered micro magnetic bar.

\subsection{Polarization Measurements in Aqueous Electrolytes}

The cell was used with an aqueous solution $1 \mathrm{~N}$ in $\mathrm{CuSO}_{4}$ and $1 \mathrm{~N}$ in $\mathrm{H}_{2} \mathrm{SO}_{4}$, prior to using it with the non-aqueous electrolyte, primarily for the purpose of verifying the applicability of using the back reference electrode (Rf3) for direct cathode overvoltage measurements.

Two additional lateral reference electrodes ( $R f 1, R f 2)$ were provided for this purpose which permitted the determination of the cathode charge-transfer overvoltage by three independent methods, as well as IR drops in the system and concentration polarization.

In the organic electrolyte experiments, however, only the cathodic charge-transfer overvoltage was studied. A few values of IR drops and concentration polarizations were determined as a matter of general interest, but were not reported here. 


\subsection{Measurements Obtainable from the Cell}

The following sketch shows the positions of the electrodes in the cell:

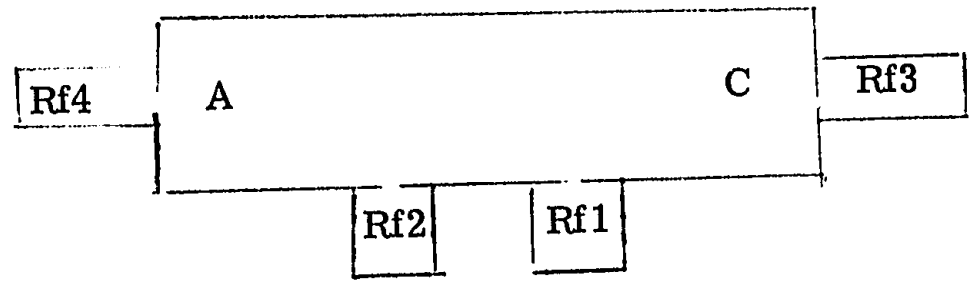

where:

C: Cathode (platinum disc welded on a $24 / 40$ glass joint)

A: Anode (aluminum rod Alcan 1s type, $99.8+\%$ minimum $\mathrm{Al}$ )

Rf3: Back reference electrode to cathode)

$\mathrm{Rf} 1$ and $\mathrm{Rf2}$ : Lateral reference electrodes

$\mathrm{Rf} 4$ : Back reference electrode to anode

Note: In this work aluminum in the form of a rod was used as an anode, therefore the reference electrode Rf4 was absent. However, it would be possible to use active and reference electrodes of the types used in the study for cathode polarization in the anode compartment; this would permit determination of anodic overvoltages.

Measurements which could be taken in the cell during the passage of current between anode and cathode, and their interpretations are outlined below:

1) $\mathrm{E}_{(\mathrm{A}-\mathrm{C})}=$ total voltage applied between anode and cathode

$$
\mathrm{E}_{(\mathrm{A}-\mathrm{C})}=\left(\mathrm{e}_{\mathrm{C}}+\eta_{\mathrm{C}}\right)-\left(\mathrm{e}_{\mathrm{A}}+\eta_{\mathrm{A}}\right)+\operatorname{IRel}(\mathrm{A}-\mathrm{C})
$$


where

$\mathbf{e}_{\mathrm{A}}=$ static or rest potential at the anode

$\eta_{\mathrm{A}}=$ overvoltage at the anode

$\mathrm{e}_{\mathrm{C}} \quad$ static cathodic potential

$\eta_{\mathrm{C}}=$ overvoltage at the cathode, which if ohmic and concentration overvoltages have been eliminated and the crystallization overvoltage is negligible, is the cathodic chargetransfer overvoltage $\eta_{\mathrm{tC}}$

$\operatorname{IRel}_{(A-C)}=\operatorname{IR}$ potential drop through the electrolyte

2) $\mathrm{E}_{(\mathrm{Rf} 1-\mathrm{C})}=$ measured voltage between reference electrode 1 and cathode

$$
=\left(e_{c}+\eta_{t C}\right)-\operatorname{eRf} 1+\operatorname{IRel}(\operatorname{Rf} 1-C)
$$

where $e_{\mathrm{Rf} 1}=\mathrm{e}_{\mathrm{C}}$ (same metal/ion electrode, well mixed electrolyte)

3) $\mathrm{E}_{(\mathrm{Rf} 2-\mathrm{Rf} 1)}=$ measured voltage between reference electrode 1 and reference electrode 2

$$
=e_{R f 2}-e_{R f 1}+\operatorname{IRel}(\operatorname{Rf} 2-\operatorname{Rf} 1)
$$

when $e_{\mathrm{Rf} 1}=e_{\mathrm{Rf} 2}$ (same metal/ion electrode, well mixed electrolyte)

4) $\mathrm{E}_{(\mathrm{A}-\mathrm{Rf} 2)}=$ measured voltage between anode and reference electrode 2

$$
=\left(e_{A}+\eta_{A}\right)-e_{R f 2}+\operatorname{IRel}(A-R f 2)
$$

where $e_{A}=e_{R f 2}$ (same metal/ion electrode, well mixed electrolyte) 
5) $\mathrm{E}_{(\mathrm{C}-\mathrm{Rf} 3)}=$ measured voltage between back reference electrode 3 and cathode

$$
=\left(\mathrm{e}_{\mathrm{C}}+\eta_{\mathrm{tC}}\right)-\mathrm{e}_{\mathrm{Rf} 3}=\eta_{\mathrm{tC}}
$$

where $e_{C}=e_{\text {Rf3 }}$ (same metal/ion electrode, well mixed electrolyte)

6) $\mathrm{E}_{(\mathrm{Rf} 1-\mathrm{Rf} 3)}=$ measured voltage between reference electrode 1 and the back reference electrode 3

$$
=e_{\mathrm{Rf} 1}-\mathrm{e}_{\mathrm{Rf} 3}+\operatorname{IRel}(\mathrm{Rf} 1-\mathrm{Rf} 3)
$$

where $e_{\mathrm{Rf} 1}=e_{\mathrm{Rf} 3}$ (same metal/ion electrode, well mixed electrolyte)

7) $\mathrm{E}_{(\mathrm{A}-\mathrm{Rf3})}=$ measured voltage between the anode and the back reference electrode 3

$$
=\left(e_{A}+\eta_{A}\right)-e_{R f 3}+I_{\text {el }}(A-R f 3)
$$

where $e_{A}=e_{R f 3}$ (same metal/ion electrode, well mixed electrolyte)

The most important measurement of this series from the point of view of cathode polarization studies is number $5\left(\mathrm{E}_{(\mathrm{C}-\mathrm{Rf} 3)}\right)$ which gives cathode overvoltage $\eta_{\mathrm{tC}}$ directly. However, it was necessary to prove that this measurement was, indeed, correct and the preliminary study using an aqueous copper sulfate solution was carried out whereby measurements 2,3 and 6 were used to verify measurement 5 .

The equations used for calculating cathode overvoltage were:

a) $\quad \eta_{\mathrm{tC}}^{*}=\mathrm{E}_{(\mathrm{C}-\mathrm{Rf} 3)}$ 
Proof of Equation 6-12a:

By equation $(6-12)$ measurement 5

$$
\begin{array}{ll} 
& \mathrm{E}_{(\mathrm{C}-\mathrm{Rf} 3)}=\left(\mathrm{e}_{\mathrm{C}}+\eta_{\mathrm{tC}}\right)-\mathrm{e}_{\mathrm{Rf} 3} \\
\text { since } & \mathrm{e}_{\mathrm{C}}=\mathrm{e}_{\mathrm{Rf} 3} \\
& \eta_{\mathrm{tC}}^{*}=\mathrm{E}_{(\mathrm{C}-\mathrm{Rf} 3)}
\end{array}
$$

b) $\quad \eta_{\mathrm{tC}}^{\neq}=\mathrm{E}_{(\operatorname{Rf} 1-\mathrm{C})}-\mathrm{E}_{(\operatorname{Rf} 1-\operatorname{Rf} 3)}$

Proof of Equation 6-15:

By equation 6-9

$$
\underset{\eta_{\mathrm{tC}}}{\neq}=\mathrm{E}_{(\mathrm{Rf} 1-\mathrm{C})}-\mathrm{IRel}_{(\mathrm{Rf} 1-\mathrm{C})}
$$

since $e_{C}=e_{R f 1}$

By equation 6-13:

$$
E_{(\operatorname{Rf} 1-\operatorname{Rf} 3)}=\operatorname{IRel}(\operatorname{Rf} 1-\operatorname{Rf} 3)
$$

since $e_{\mathrm{Rf} 1}=e_{\mathrm{Rf} 3}$

Now since IRel $($ Rf1-C) $=\operatorname{IRel}($ Rf1-Rf3)

(cathode and Rf3 virtually together)

By equations 6-15a, 6-15b, and 6-15c

$$
\eta_{\mathrm{tC}}^{\neq}=\mathrm{E}_{(\operatorname{Rf} 1-\mathrm{C})}-\mathrm{E}_{(\operatorname{Rf} 1-\operatorname{Rf} 3)}
$$

c) $\quad \eta_{\mathrm{tC}}^{+}=\mathrm{E}_{(\mathrm{Rf} 1-\mathrm{C})}-\mathrm{E}_{(\mathrm{Rf} 2-\mathrm{Rf} 1)} \cdot \mathrm{f}$

Proof of equation 6-16:

By equation (6-9), equation $(6-10)$ and $f$

where $f$ is defined as:

$$
f=\frac{I R e l(R f 1-C)}{I R e l(R f 2-R f 1)} \begin{aligned}
& \text { the determination of which is } \\
& \text { described in Section } 6-15
\end{aligned}
$$


From equation 6-9

$$
\eta_{\mathrm{tC}}^{+}=\mathrm{E}_{(\mathrm{Rf} 1-\mathrm{C})}-\mathrm{IRel}_{(\mathrm{Rf} 1-\mathrm{C})}
$$

From equation 6-17

$$
\mathrm{IRel}_{(\mathrm{Rf} 1-\mathrm{C})}=\mathrm{f} \cdot \mathrm{IRel}_{(\mathrm{Rf} 1-\mathrm{Rf} 2)}
$$

From equation 6-10

$$
\mathrm{IRel}_{(\mathrm{Rf} 1-\mathrm{Rf} 2)}=\mathrm{E}_{(\mathrm{Rf} 1-\mathrm{Rf} 2)}
$$

From equations $6-17 \mathrm{a}, 6-17 \mathrm{~b}$, and $6-17 \mathrm{c}$

$$
\eta_{\mathrm{tC}}^{+}=\mathrm{E}_{(\mathrm{Rf} 1-\mathrm{C})}-\mathrm{E}_{(\operatorname{Rf} 2-\operatorname{Rf} 1)} \cdot \mathrm{f}
$$

\subsection{Determination of Concentration Polarization}

The use of the back reference Luggin capillary electrode (Rf3) for the determination of cathode charge-transfer overvoltage virtually eliminates concentration polarization effects on the measurement.

However, if desired, the cell can be used to determine concentration polarization by making use of the two lateral electrodes ( $\mathrm{Rf} 1$, Rf2) in conjunction with the back electrode Rf3.

In equation (6-16) it was tacitly assumed that the cathodic static potential $\left(e_{C}\right)$ was equal to the potential of the reference electrode (3) $\left(e_{\mathrm{Rf3}}\right)$. This is true if the electrolyte is perfectly stirred all through the cell. However, since a micro stirrer was used in the cell it is possible that with a high applied potential a concentration gradient could be established between the reference electrode ( $R f 1)$ and the cathode, since they are $2.5 \mathrm{~cm}$ apart. In this case equation (6-16) would become:

$$
\mathrm{E}_{(\mathrm{Rf} 1-\mathrm{C}}-\mathrm{E}_{(\mathrm{Rf} 2-\mathrm{Rf} 1)} \cdot \mathrm{f}=\eta_{\mathrm{tC}}+\eta_{\mathrm{CC}}
$$


This cathodic concentration polarization $\eta_{\mathrm{c}}$ could then be determined separately from $\eta_{\mathrm{tC}}$ by using equation $(6-18)$ and equation $(6-12)$, i.e.,

$$
\eta_{c C}=E_{(\operatorname{Rf} 1-C)}-E_{(\operatorname{Rf} 2-\operatorname{Rf} 1)} \cdot f-E_{(C-R f 3)}
$$

6.9 The Principal Investigation: Organic Electrolyte

An electrolyte consisting of ethylbenzene-toluene 1:1 by volume with $50 \mathrm{wt} . \% \mathrm{AlBr}_{3}$ was used throughout the organic investigation. The electrolytes were prepared in the same way as those described in Section 5.3. The conductivity of the solution was raised by bubbling with $\mathrm{HBr}$ gas or lowered by immersing a sheet of aluminum into the electrolyte and allowing it to react until the required specific conductance was obtained.

The following three systems were studied:

a) Electrolyte with specific conductance of $4.0 \times 10^{-3} \Omega^{-1} \mathrm{~cm}^{-1}$

b) Electrolyte with specific conductance of $3.0 \times 10^{-3} \Omega^{-1} \mathrm{~cm}^{-1}$

c) Electrolyte with specific conductance of $2.0 \times 10^{-3} \Omega^{-1} \mathrm{~cm}^{-1}$

A few experiments were also carried out on an electrolyte which had a specific conductance of $1.0 \times 10^{-3} \Omega^{-1} \mathrm{~cm}^{-1}$.

The experiments were carried out at $27,40,54,67$ and $81^{\circ} \mathrm{C}$. The quantities measured were:

a) Current and cathode area (i.e., current density).

b) Potential between cathode and back reference electrode $\left(E_{(C-R f 3)}\right)$ at specified current densities.

These measurements permitted the calculation of the following parameters: 
i) Cathodic charge transfer overvoltage $\left(\eta_{\mathrm{tC}}\right)$

ii) Exchange current density $\left(i_{0}\right)$

iii) Heat of activation of the cathodic process at constant current density $\left(\Delta \mathrm{H}^{\ddagger}\right)_{\mathrm{iC}}$

iv) Heat of activation of the cathodic process at constant overvoltage $\left(\Delta \mathrm{H}^{\ddagger}\right)_{\eta_{\mathrm{tC}}}$

v) Symmetry factor $\beta$

vi) Stoichiometric factor $\lambda$ (number of electrons for one act of the rate determining step to occur).

vii) Stoichiometric number $\nu$ at low overvoltages (number of times the rate determining step occurs while the overall electrode process occurs once).

6.10 Materials

\section{A. Organic Electrolytes}

The materials used for the organic electrolytes have been described in Section 5.

i) Purity of the electrolyte

It was stated earlier that the aluminum bromide and solvent used were of technical grade. The trace of moisture contained in the solvent appears to be required for the formation of the brown hydroxy $\pi$ complex suggested later in the discussion of the mechanism of the electrolysis (p. 235 ). 
The technical grade aluminum bromide is also compulsory, since a certain amount of occluded bromine improves the conductivity of the electrolyte through the formation of $\sigma$ complexes (see Eqn. 7-14 of the mechanism discussion, p. 237 ). Previous workers ${ }^{14}$ using molten $\mathrm{AlBr}_{3}$ free from bromine required, in fact, potentials as high as 90 volts to provide a current density of $10 \mathrm{~mA} / \mathrm{cm}^{2}$, against a potential of 3-6 volts required in this study with the technical grade solute.

\section{ii) Purity of the aluminum anode used}

The anode material was Alcan $1 \mathrm{~s}$ grade aluminum $99.8+\%$ minimum $\mathrm{Al}$ and it was in fact about $99.9 \% \mathrm{Al}$. This was chosen because of the necessity of using material which was compatible with the goal of finding a practical electrolyte for industrial applications. An ultra pure aluminum could have given results which would not have been related to the actual material used in the rest of this research work.

\section{B. Aqueous Electrolytes}

The following materials were used for the aqueous electrolyte cell applicability tests.

i) Copper sulfate: reagent grade, Fisher Scientific, Montreal.

ii) Copper sulfate $1 \mathrm{~N}$ : solution prepared from Fisher reagent grade salt in triple distilled water.

iii) Sulfuric acid: reagent grade, Fisher Scientific, Montreal. iv) Sulfuric acid 1N: solution prepared from Fisher reagent grade $\mathrm{H}_{2} \mathrm{SO}_{4}$ in triple distilled water. 
v) Copper anode: electrolytic copper $99.99+\% \mathrm{Cu}$, Canadian Copper Refiners Co. Ltd., Montreal.

vi) Nitrogen: certified grade $99.99+\%$ nitrogen, Canadian Liquid Air, Montreal.

The nitrogen was further purified by passing it over a palladium catalyst (Fisher Redoxon). It was then dried through drierite and saturated with the solvent used in the particular test.

\subsection{Apparatus}

A photograph of the arrangement of the apparatus used in this experiment is shown in Figure 6-3, with the exception of the electrical equipment which was shown in Figure 5-2, Section 5.2.

\section{A. Electrolytic Cell}

The electrolytic cell used (see Fig. 6-4, Fig. 6-5 and Fig. 6-5a for details) was developed specifically for organic electrolytes from which air and moisture must be excluded. It consists of:

a) A cylindrical glass body, $2 \mathrm{~cm}$ in diameter $7.5 \mathrm{~cm}$ long, built into a thermostatically controlled water chamber which was controlled to $\pm .1^{\circ} \mathrm{C}$. The body of the cell has four tubes attached to it:

i) A tube for gas inlet.

ii) A tube for gas outlet containing a liquid seal to prevent. the contact of the electrolyte with the atmosphere.

iii) A tube for the electrolyte inlet. This can be replaced by a tube for gas outlet like ii) after the cell has been filled. 


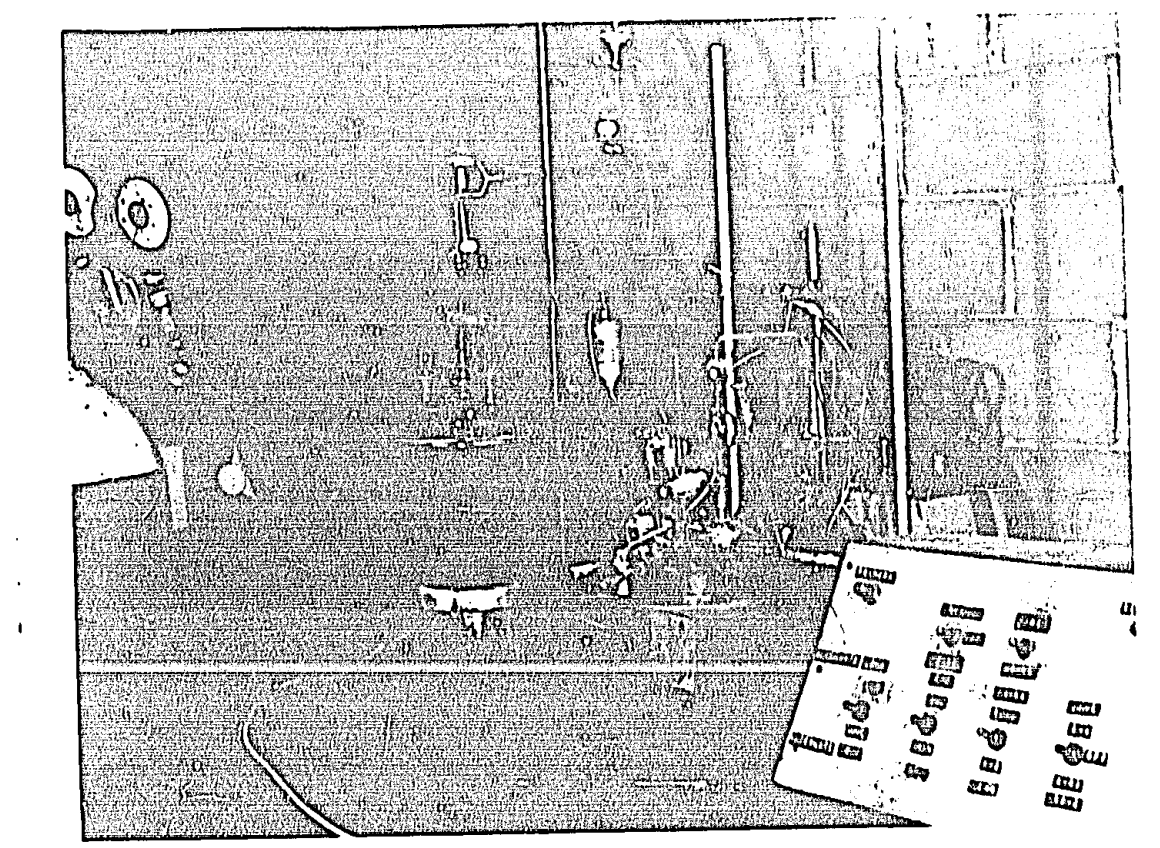

Figure 6-3. Photograph Showing Polarization Cell, Electrolyte Reservoir, Haake Constant Temperature Pump, Magnetic Stirrer, and Electrode Switch Box. 


\section{Figure 6-4}

1. Aluminum Anode

2. Cathode (Platinum, Plated with Aluminum)

3. Cell Body (Cylindrical)

4. Water Cooling Chamber

5. Water Inlet

6. Water Outlet

7. Argon Inlet (for Gas Stirring)

8. Argon Outlet (to Liquid Seal)

9. Emptying Tube (Electrolyte)

10. Filling Tube

11. Back Reference Electrode

12. Reference Electrode Electrical Connection

13. Cathode Electrical Connection

14. Gas Escape Tube to Permit Filling Reference Electrode

15. Luggin Capillary Behind Active Cathode

16. Electrolyte

17. Lateral Reference Electrodes 


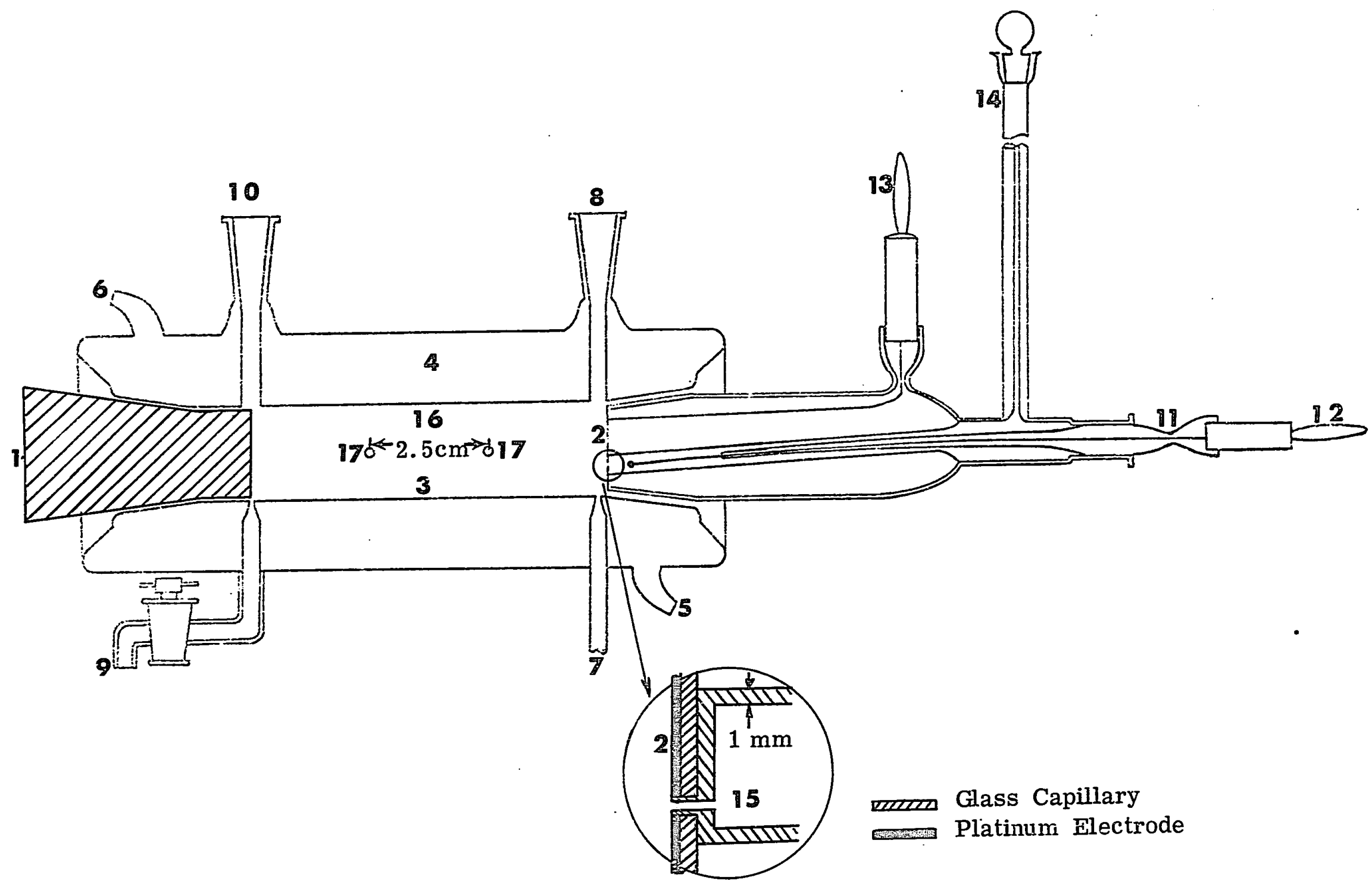




\section{Figure 6-5}

1. Aluminum Anode

2. Cathode (Platinum, Plated with Aluminum)

3. Cell Body (Cylindrical)

4. Water Cooling Chamber

5. Water Inlet

6. Water Outlet

7. Argon Inlet (for Gas Stirring)

8. Argon Outlet (to Liquid Seal)

9. Emptying Tube (Electrolyte)

10. Filling Tube

11. Back Reference Electrode

12. Reference Electrode Electrical Connection

13. Cathode Electrical Connection

14. Gas Escape Tube to Permit Filling Reference Electrode

15. Luggin Capillary Behind Active Cathode

16. Electrolyte

17. Lateral Reference Electrodes 


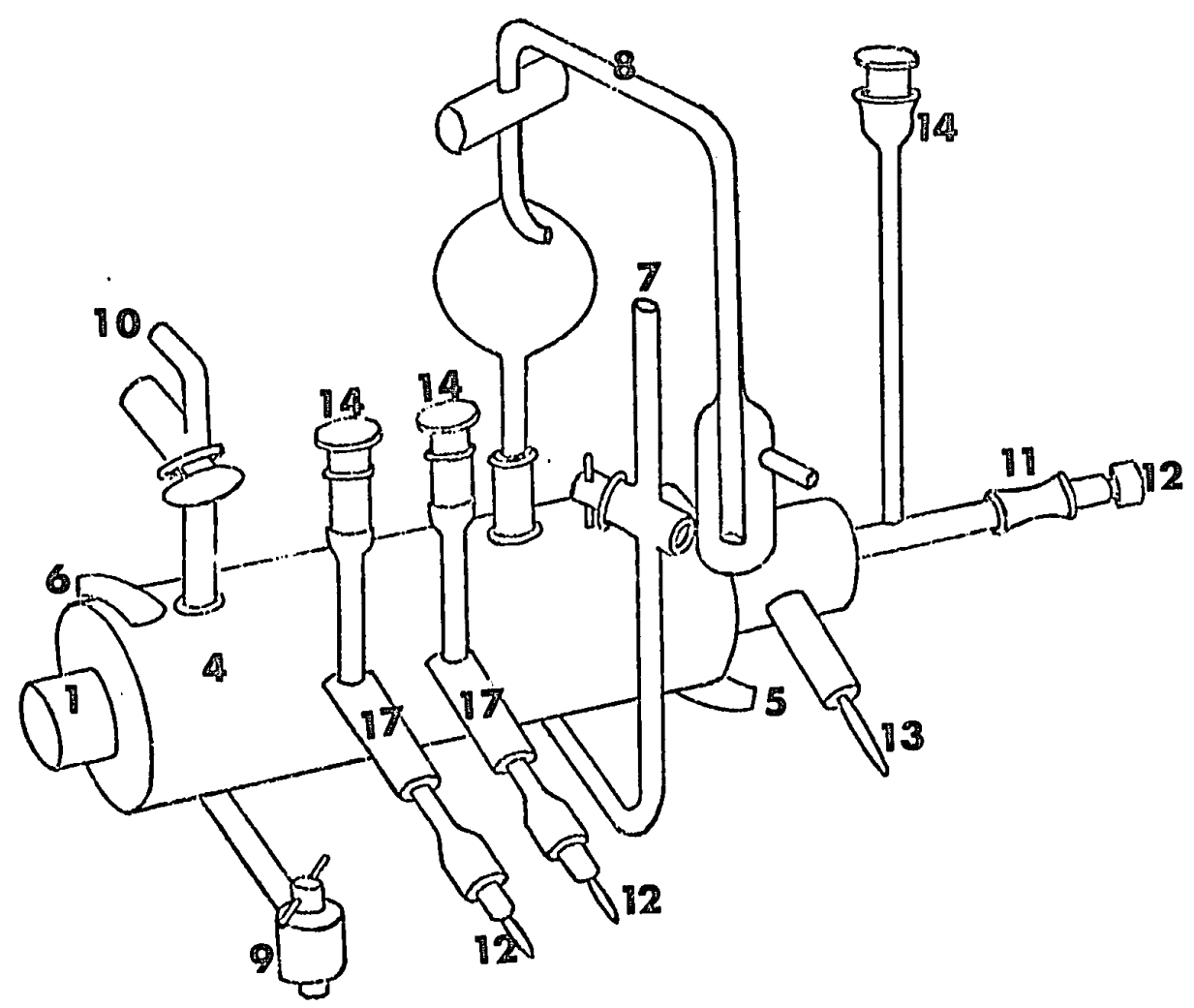




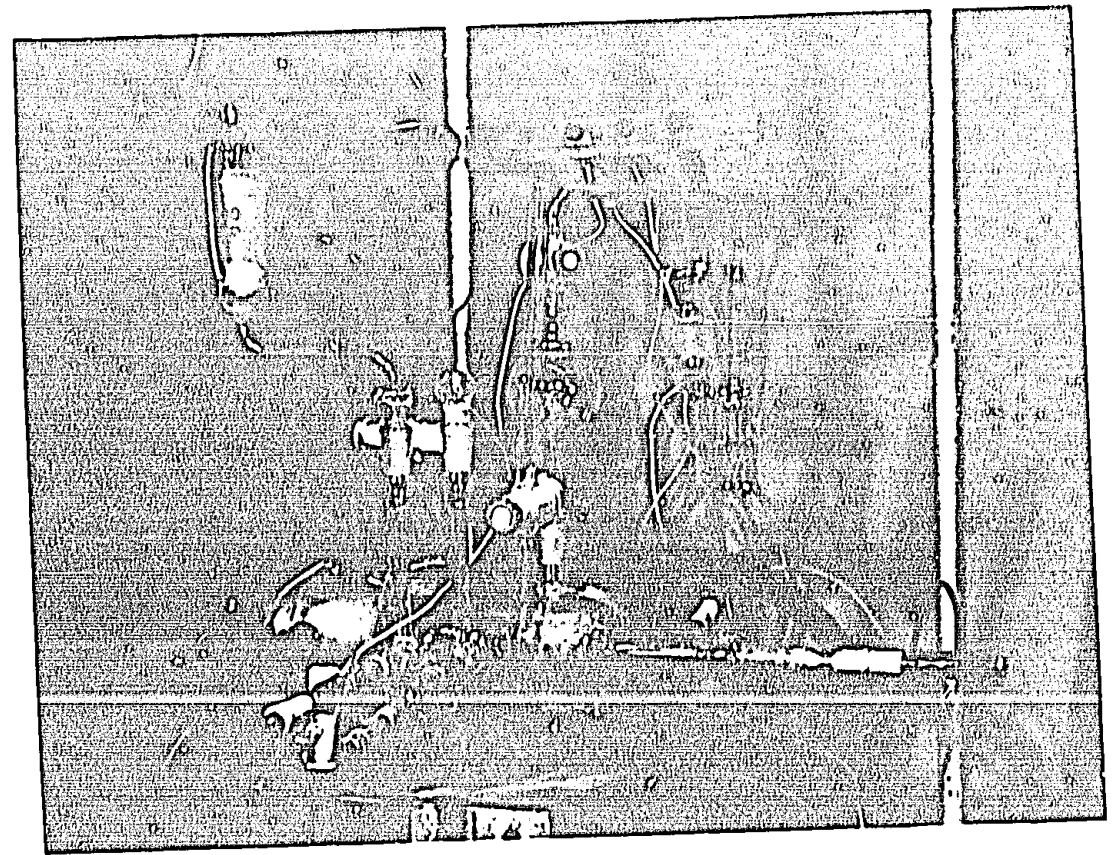

Figure 6-5a. Photograph of Polarization Cell With Electrical and Cooling Water Connections Made. 
iv) A tube for the electrolyte outlet.

b) Anode: metal rod shaped as to fit the $24 / 40$ ' ${ }^{\circ}$ glass joint of the cell. The metal rod was constructed of the anode metal under study.

c) Platinum cathode: a platinum disc $0.5 \mathrm{~mm}$ thick, and $1.8 \mathrm{~cm}$ diameter $\left(2.5 \mathrm{~cm}^{2}\right.$ of surface area) welded on a $24 / 40 \mathrm{~S}$ glass joint. A platinum wire was welded on this disc for the electrical connection. A hole $.8 \mathrm{~mm}$ diameter was drilled midway between the centre and the border of the disc, through which a glass tube $0.4 \mathrm{~mm}$ diameter, $.2 \mathrm{~mm}$ wall thickness was inserted flush with the cathode surfaces. This hole permitted the electrical contact between the front of the cathode and the back reference electrode. The entire back of the cathode was covered with glass.

d) Back reference electrode:

i) aqueous solution: a platinum wire $.5 \mathrm{~mm}$ thick freshly plated with copper from the electrolyte.

ii) organic electrolyte: a $1 \mathrm{~mm}$ diameter wire of aluminum of the same purity as the anode material.

e) Lateral reference electrodes (2), same material as the back reference electrodes. Capillaries $0.5 \mathrm{~mm}$ diameter corresponding to these electrodes were joined to the cell cylindrical body, at $2.5 \mathrm{~cm}$ from anode and cathode respectively (see Fig. 6-5), and the same distance from each other. The metal tips of the lateral and back reference electrodes were placed in the capillary at 0.75 
$\mathrm{cm}$ from the main electrolyte. It was proved experimentally that moving these tips towards or away from the main body of the electrolyte a distance of $0.5 \mathrm{~cm}$ did not affect the voltage readings taken with these reference electrodes.

f) Micromagnetic Teflon covered bar: Fisher Scientific, Montreal.

g) Greaseless joints: no grease was used for the joints in the electrolytic cell. All the joints were covered with Teflon leaves. All stopcocks were Teflon.

\section{B. Electrical Equipment}

The conductimeter, conductance cell, potentiostat, voltmeter and ammeter were the same as those described in Section 5.2 (see Fig. 5-2).

\section{Thermostatic Pump}

An Haake pump type F.E. (Fisher Scientific, Montreal) was used for controlling the temperature of the polarization cell. The water bath temperature was held within $\pm .1^{\circ} \mathrm{C}$ (see Fig. 6-3.)

\section{Remote Control Switch Box}

This box permitted contact between any two specified electrodes in the cell by simply turning one of the switches "on" or "off" (see Fig. 6-3).

\section{E. Magnetic Stirrer}

A Tekstir Type magnetic stirrer from Scientific Products, Montreal, was modified so as to reduce the diameter of the casing around the turn- 
ing magnet (see Fig. 6-3). This allowed the magnet of the stirrer to be closer to the micro magnet bar inside the electrolytic cell. The efficiency of the stirrer was thus improved considerably.

\section{F. Electrical Circuit}

The circuit for electrodeposition at constant current and measurements of cathodic polarization is shown in Figure 6-6.

All the components of this circuit have been described above with the exception of the reference resistance which was a Leeds and Northrup resistance box. The resistance was chosen according to the manufacturer's instructions to ensure that there was always an IR drop of approximately 2 volts across the reference resistance in the circuit. The reference resistance is included so that the potentiostat can detect any change in current (measured as an I R voltage drop) through the electrolytic cell.

\subsection{Experimental Procedure}

The preparation of the electrolyte used $\left(50 \mathrm{wt} . \% \mathrm{AlBr}_{3}\right.$ in ethylbenzene-toluene 1:1) has been described in Section 5.2. The conductivity of the electrolyte was adjusted to its selected value by the addition of $\mathrm{HBr}$ gas. The electrolyte was used for plating aluminum on copper sheets for $71 / 2$ hours (i.e., 5 tests of $11 / 2$ hour each as described in Section 5) before being used for the polarization study. 


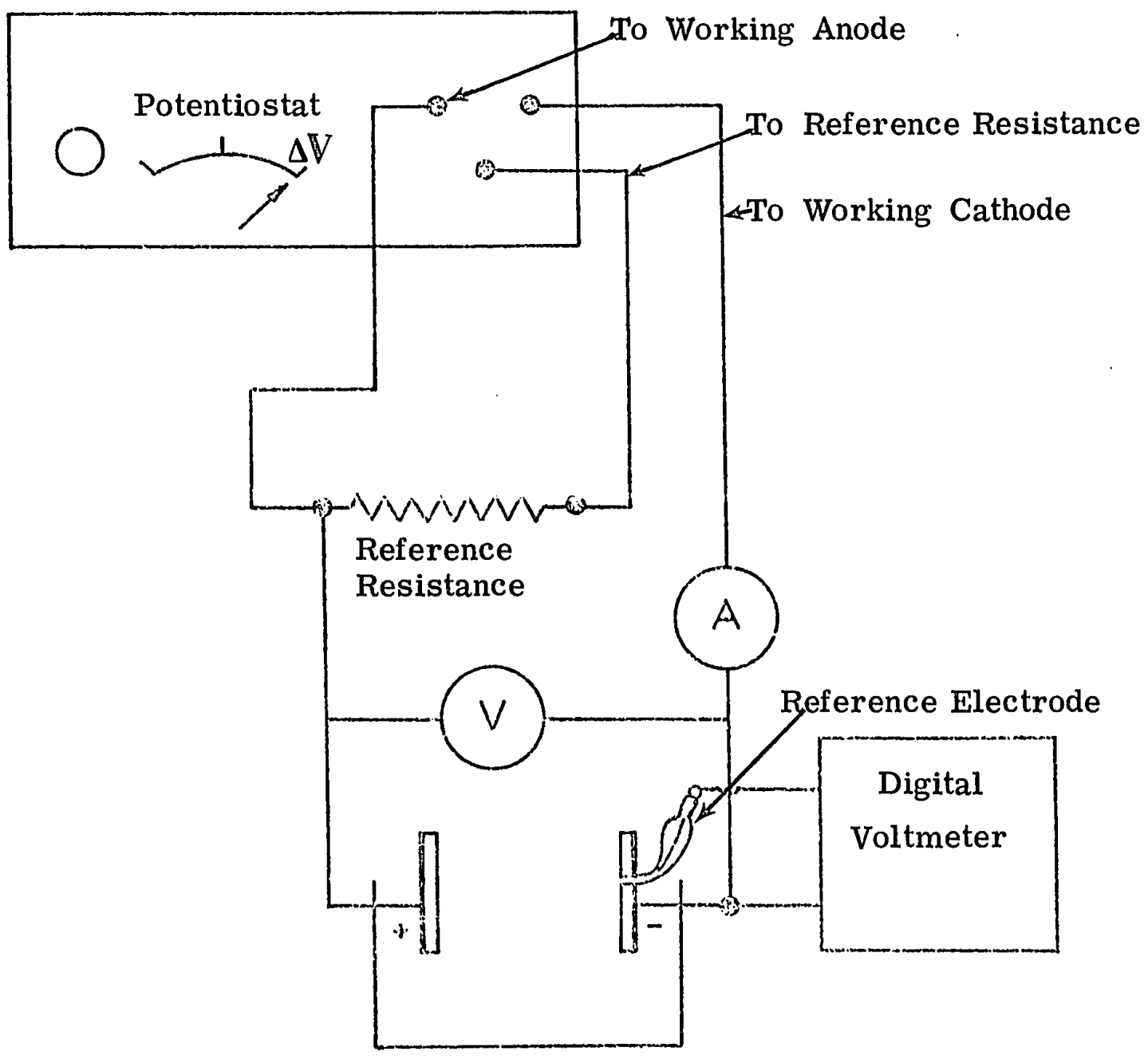

Figure 6-6. Circuit for Electrodeposition at Constant Current and Measurements of Cathodic Polarization. 
A. Preparation and Filling Up of the Polarization Cell

The electrolytic cell was dried by passing dry nitrogen through it for 10 minutes. The electrolyte was then transferred into the dry cell via the connecting glass inlet tube through a glass wool or fritted glass filter, by applying a small positive pressure of dry nitrogen.

\section{B. Pre-electrolysis}

The cell was operated at $10 \mathrm{~mA} / \mathrm{cm}^{2}$ for 1 hour before starting the polarization study. This step provided a) aluminum plating of the platinum cathode, b) purification of the electrolyte (removal of traces of foreign metals and possibly traces of moisture), c) equilibration of the reference electrode (chemical dissolution of any passive film of aluminum oxide).

\subsection{Preliminary Tests: Aqueous Electrolytes}

A. Determination of Relative IR Drops Between Electrodes

Data on the relative IR drops between reference electrode 1 and the cathode (IRel (Rf1-C) and between the two lateral reference electrodes (IRel (Rf2-Rf1) ) permitted the calculation of the cathode overvoltage $\eta_{\mathrm{tC}}$ (aqueous system) by means of a third (independent) method (Eqn. 6-16). Since the principal purpose of the aqueous tests was to verify the applicability of the back reference (Rf3) for direct determination of $\dot{\eta}_{t C}$ ' this extra independent method of calculation was of considerable importance. 
The IR drops were determined by passing a few milliamps of DC current between the anode and the back reference electrode ( $\mathrm{Rf} 3)$ and by taking voltage measurements between $\mathrm{Rf} 1$ and $\mathrm{C}$, and between Rf2 and Rf1.

Under these conditions:

$$
E_{(\operatorname{Rf} 1-C)}=e_{C}-e_{R f 1}+\operatorname{IRel}(\operatorname{Rf1-C})
$$

and

$$
E_{(\operatorname{Rf} 2-\operatorname{Rf} 1)}=e_{R f 2}-e_{R f 1}+\operatorname{IRel}(\operatorname{Rf2}-\operatorname{Rf} 1)
$$

Since

$$
\begin{aligned}
& \mathrm{e}_{\mathrm{Rf} 1}=\mathrm{e}_{\mathrm{Rf} 2}=\mathrm{e}_{\mathrm{C}} \begin{array}{c}
\text { (no current flow at cathode, good } \\
\text { mixing of the electrolyte) }
\end{array} \\
& \frac{\mathrm{E}_{(\mathrm{Rf} 1-\mathrm{C})}}{\mathrm{E}_{(\mathrm{Rf} 2-\mathrm{Rf} 1)}}=\frac{\mathrm{IRel}(\mathrm{Rf} 1-\mathrm{C})}{\mathrm{IRel}(\mathrm{Rf} 2-\mathrm{Rf} 1)}=\mathrm{f}
\end{aligned}
$$

Therefore the relative IR drops between $\mathrm{Rf} 1$ and $\mathrm{C}$ and between Rf1 and Rf2 can be obtained by plotting (Fig. 6-7) $\mathrm{E}_{(\mathrm{Rf} 1-\mathrm{C})}$ vs. E(Rf2-Rf1) The slope of this plot is $f$, above, which is used directly for calculating $\eta_{\mathrm{tC}}$ in Equation 6-16.

\section{B. Cathode Overvoltage Determination: Aqueous System}

As mentioned in Section 6-6 the study with aqueous electrolyte was done primarily to verify the feasibility of using the back reference electrode ( $\mathrm{Rf} 3)$ for direct cathodic overvoltage measurements. An aqueous copper sulfate solution with $\mathrm{H}_{2} \mathrm{SO}_{4}$ was chosen because it is easier to handle than the organic electrolytes.

The solution was first deoxygenated by bubbling pure nitrogen for 15 minutes. It was then pre-electrolysed for one hour (in situ) which 
resulted in plating of the platinum cathode and then the platinum wires (connected as cathodes for this purpose) of the lateral and back reference electrodes.

The cathodic charge-transfer overvoltage was determined in three different ways from the measurements in Equations 6-8 to 6-13 and using Equations 6-12, 6-15, and 6-16 (all experiments performed at $27^{\circ} \mathrm{C}$ ). Concentration polarization was also calculated from the measurements (Eqn. 6-19).

\section{Standard Operating Conditions}

Conditions which were kept constant throughout this series of experiments were:

i) Electrodes: Identical electrodes were used in all the tests.

ii) Temperature: Thermostatic control to $\pm .1^{\circ} \mathrm{C}$.

iii) Stirring: The same stirring was ensured for all the tests by means of a modified magnetic stirrer and a micro teflon covered magnetic bar.

iv) Current density: Constant current density for all the tests was supplied by a PRT 20-10X Tacussel potentiostat (the reading being taken by a Tacussel Milliammeter Type MAR-298).

v) Steady state over potential measurements: After reaching the desired cathode current density, one minute was always allowed for attainment of steady state values of overvoltage before the potential measurements were made. 
vi) Static potential correction: Measurements of static potentials between the working electrode (cathode) and reference electrode were made before and after each dynamic (electrolysis) test. The static values were subtracted from each overvoltage measurements as described in Section 6-16i (p. 163).

\subsection{Measurements of Cathode Overvoltage: Organic System}

The principal measurement in the organic system was the potential between cathode and back reference electrode $\left(\mathrm{E}_{(\mathrm{C}-\mathrm{Rf} 3)}\right)$ at specified current densities and at several temperatures. These measurements permitted the calculation of the kinetic parameters.

An hour of pre-electrolysis in situ served to plate the platinum cathode with aluminum from the electrolyte. The D.C. voltage was then adjusted between anode and cathode until the desired current was passing. The potential $\mathrm{E}_{(\mathrm{C}-\mathrm{Rf} 3)}$ was then measured one minute after the desired current was applied. Once the polarization voltage was measured, the current was interrupted and the static potential was read one minute after the interruption. The static potential was usually less than $5 \mathrm{mV}$.

\subsection{Accuracy and Precision of the Overvoltage Measurements}

The overvoltage measurements are considered to have been accurate to within $\pm 1 \mathrm{mV}$ for most measurements due to the relatively good precision of the equipment used. No duplicate results are reported as the different polarization studies made are, in a sense, a duplication of each 
other since they were identical except for the specific conductance of the electrolyte. However, values obtained at the highest temperature (i.e., $81^{\circ} \mathrm{C}$ ) are considered to be less accurate (i.e., $\pm 5 \mathrm{mV}$ ). The latter values were indeed discarded in most cases during the plotting of curves for the calculations of the heat of activation because of their variability.

With regard to the precision of the cell and reference electrodes, one source of error is the IR drop created by the $0.2 \mathrm{~mm}$ thick capillary glass wall relating the back reference electrode (Rf3) and the front of the platinum cathode of the cell. This is, however, partly compensated by the edge effect (slight increase in potential) ${ }^{111}$ created around the $0.4 \mathrm{~mm}$ hole in the platinum cathode of the cell (see Fig. 6-5).

\section{16 Results and Observations}

The results include the IR drops and cathode overvoltage determinations for an aqueous solution of $\mathrm{CuSO}_{4} 1 \mathrm{~N}$ in $1 \mathrm{~N} \mathrm{H}_{2} \mathrm{SO}_{4}$ and cathodic overvoltage determination for the system ethylbenzene-toluene 1:1 by volume, 50 wt. $\% \mathrm{AlBr}_{3}$ at different temperatures and specific conductivities. Calculations of the apparent heat of activation at constant potential and at constant current (organic electrolyte) are also presented in this results section. 
A. Preliminary Determination of IR Drops, Aqueous Electrolyte Electrolyte: $\mathrm{CuSO}_{4} 1 \mathrm{~N}$ in $1 \mathrm{~N} \mathrm{H}_{2} \mathrm{SO}_{4}$ Anode: Copper $99.99+\%$ minimum cu Operating conditions: DC current 1, 2, 3 or $4 \mathrm{~mA}$ was passed between the anode (A) and the back reference electrode (Rf3).

Temperature: $25 \pm .1^{\circ} \mathrm{C}$.

Measurements: (Table 6.1)

Current, (A - Rf3), i

Potential between Reference Electrode 1 and the cathode,

$$
\mathrm{E}_{(\operatorname{Rf} 1-\mathrm{C})}
$$

Potential between Reference Electrode 2 and Reference Electrode 1,

$$
E_{(\operatorname{Rf} 2-\operatorname{Rf} 1)}
$$

Calculations: (Figure 6-7)

$$
\begin{aligned}
& \mathrm{f}=\frac{\mathrm{IRel}(\mathrm{Rf} 1-\mathrm{C})}{\mathrm{IRel}(\mathrm{Rf2}-\mathrm{Rf} 1)}=\frac{\mathrm{E}_{(\mathrm{Rf} 1-\mathrm{C})}}{\mathrm{E}_{(\mathrm{Rf} 2-\mathrm{Rf} 1)}} \\
& \text { (from Equation 6-22), Section 6.13) }
\end{aligned}
$$

Observations and Results: (Table 6-1, Figure 6-7).

Table 6-1 gives measured values of $\mathrm{E}_{(\mathrm{Rf} 1-\mathrm{C})}$ and $\mathrm{E}_{(\mathrm{Rf} 1-\mathrm{Rf} 2)}$ under working (electrolysis) and static conditions. It can be noted immediately that potentials which were measured under identical conditions give reproducible results. The voltages are also seen to increase with increas- 
TABLE 6-1

Experimental Data, IR Drop Experiments,

Aqueous Electrolyte

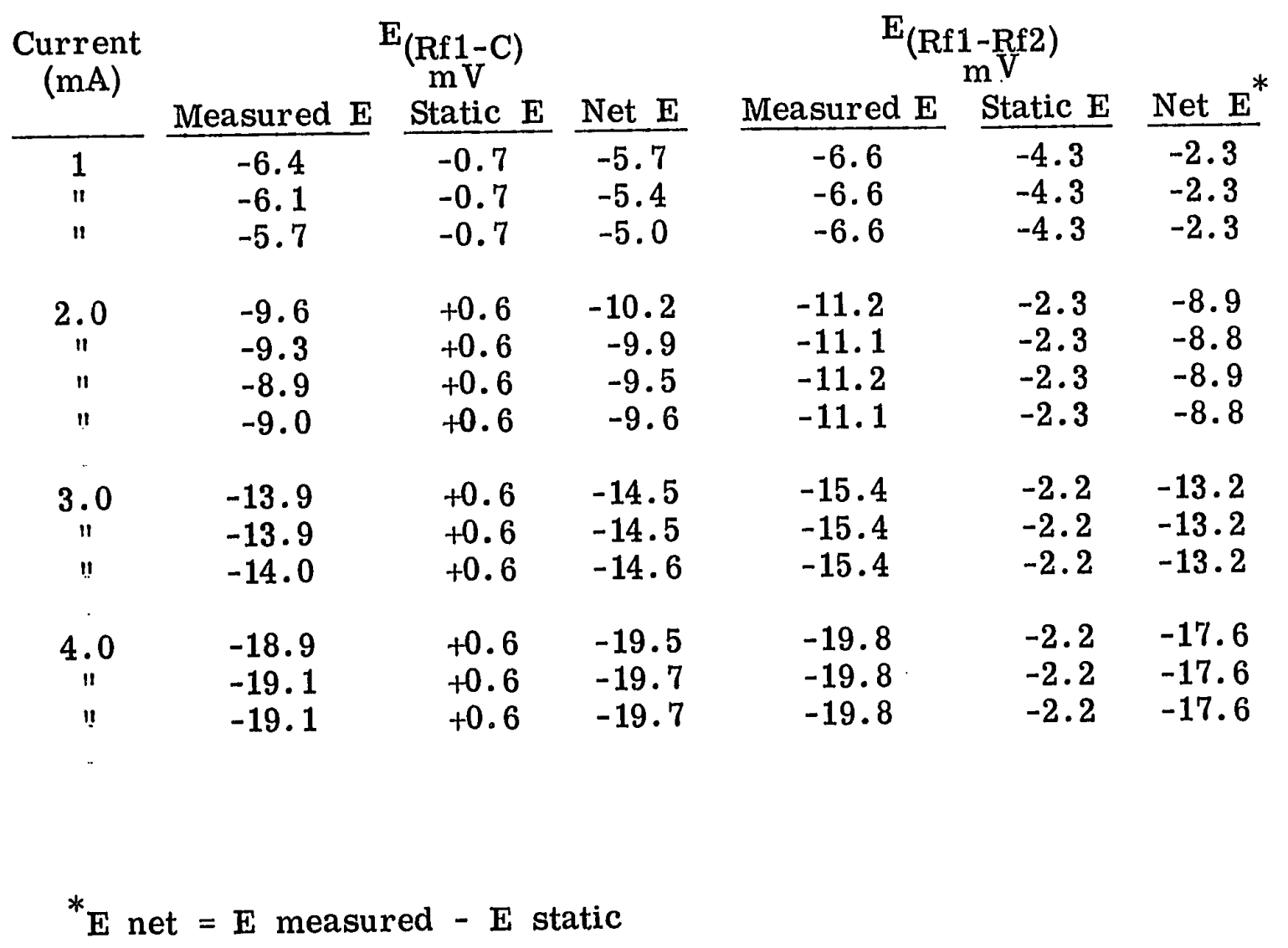




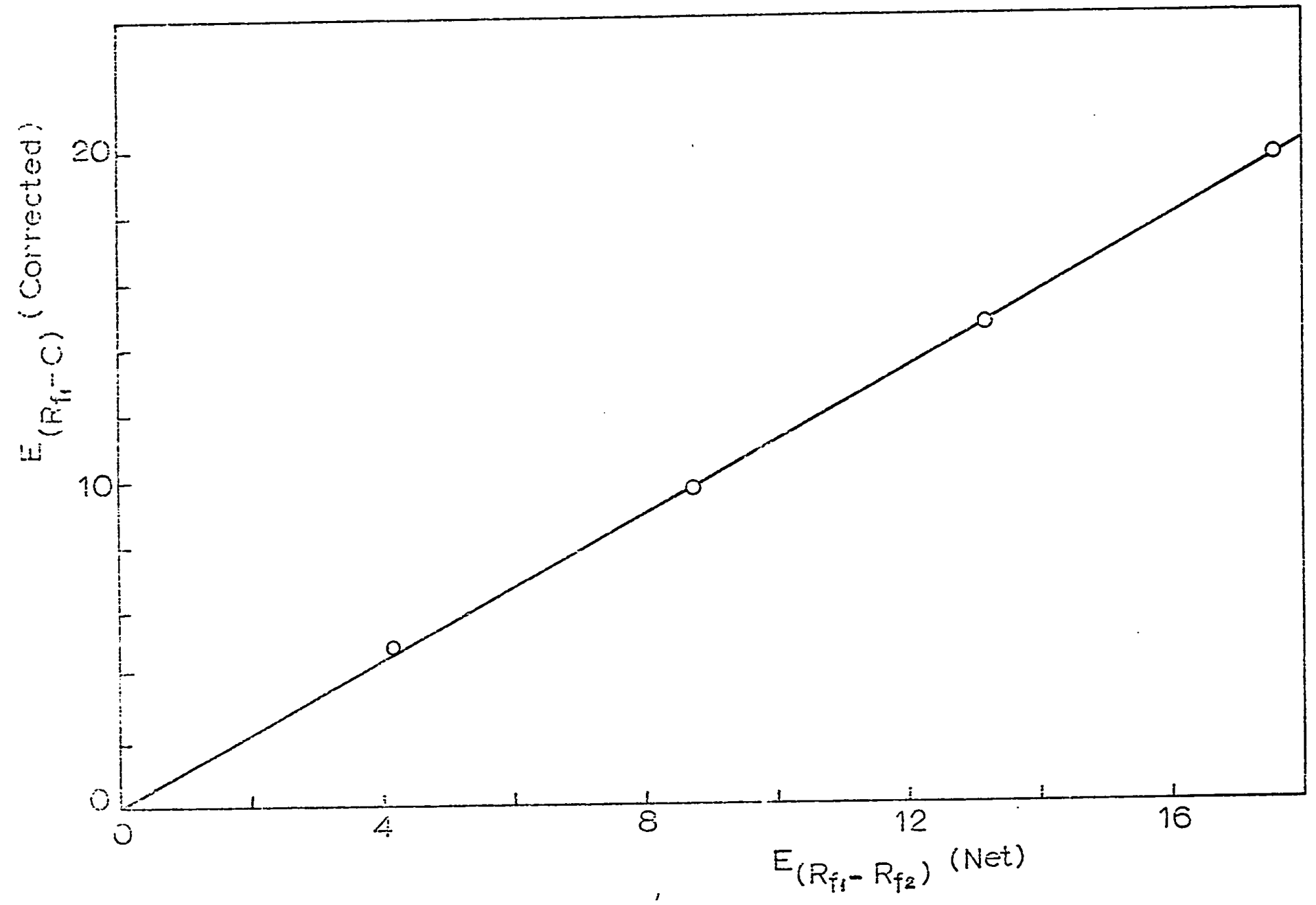

Figure 6-7. Plot of $E_{(\operatorname{Rf1}-C)}$ vs. $E_{(\mathrm{Rf1}-\mathrm{Rf} 2)}$ corrected. 
ing current (Fig. 6-7) as expected because they are a measure of the IR drop.

i) Static Potential: In all experiments (aqueous and organic) the potential measurements were repeated 1 minute after the applied voltage had been cut off. This measurement is referred to throughout the thesis as the static potential. In all calculations the measured static potential has been subtracted from its equivalent measured working potential to give a value termed the 'net potential.' The 'net potential' is the potential which would be expected under working conditions if there were no residual static potential difference between the electrodes used.

The static potential is believed to originate from slight differences in the electrode materials, i.e., slight differences in purity of the copper (or aluminum) and any thermoelectric potential component existing between the electrodes.

It can be noted that the magnitude of the static potential is important at low current densities but that at high current densities it is of considerably less importance (Tables 6-1, $6-2,6-3,6-4,6-5,6-6)$. It appears also to be reproducible in repeated tests.

ii) $f$ value: The value of $f$ defined above was calculated from the slope of the line in Figure 6-7 to be 1.1. This value was used in the subsequent calculations of $\eta_{\mathrm{tC}}^{+}$ 
B. Cathodic Polarization: Aqueous Solution

Electrolyte: $\mathrm{CuSO}_{4} 1 \mathrm{~N}$ in $1 \mathrm{~N} \mathrm{H}_{2} \mathrm{SO}_{4}$

Anode: Copper $99.99+\%$ minimum $\mathrm{Cu}$

Cathode: Platinum disc $2.5 \mathrm{~cm}^{2}$ surface area, freshly plated with copper.

Reference Electrode: Platinum wire freshly plated with copper.

Operating conditions: Standard cathode current densities up to $12 \mathrm{~mA} / \mathrm{cm}^{2}$.

Measurements:

Current between anode and cathode, and cathode area.

Applied voltage, anode to cathode, $\mathrm{E}_{(\mathrm{A}-\mathrm{C})}$

Potentials (measured during and after current flow)

Anode - Reference Electrode 2, E(A-Rf2)

Anode - Reference Electrode 3, E(A-Rf3)

Reference Electrode 1 - Reference Electrode 2, E(Rf2-Rf1)

Reference Electrode 1 - Reference Electrode 3, $\mathrm{E}_{(\mathrm{Rf} 1-\mathrm{Rf} 3)}$ (back electrode)

Reference Electrode 1 - Cathode, $\mathrm{E}_{(\mathrm{Rf} 1-\mathrm{C})}$

Reference Electrode 3 - Cathode, $\mathrm{E}_{(\mathrm{C}-\mathrm{Rf} 3)}$
(back electrode)

\section{Calculations:}

Cathode overvoltage by Equation $(6-12)\left(\eta_{\mathrm{tC}}^{*}\right)$, Equation $(6-15)$ $\left(\eta_{\mathrm{tC}}^{\neq}\right)$, and Equation $(6-16)\left(\eta_{\mathrm{tC}}^{+}\right)$

$$
\eta_{\mathrm{tC}}^{*}=\mathrm{E}_{(\mathrm{C}-\mathrm{Rf} 3)}
$$




$$
\begin{aligned}
& \eta_{\mathrm{tC}}^{\neq}=\mathrm{E}_{(\operatorname{Rf} 1-\mathrm{C})}-\mathrm{E}_{(\mathrm{Rf} 1-\mathrm{Rf} 3)} \\
& \eta_{\mathrm{tC}}^{+}=\mathrm{E}_{(\mathrm{Rf} 1-\mathrm{C})}-\mathrm{E}_{(\operatorname{Rf} 2-\operatorname{Rf} 1)} \mathrm{f}
\end{aligned}
$$

The factor $f=1.1$ calculated in Figure 6-5 was employed in the calculation of $\eta_{\mathrm{tC}}^{+}$.

Results and Observations:

The potential difference between anode and cathode $\mathrm{E}_{(\mathrm{A}-\mathrm{C})}$ was first measured. Measurements $\mathrm{E}_{(\mathrm{A}-\mathrm{Rf} 2)}, \mathrm{E}_{(\mathrm{Rf2}-\mathrm{Rf} 1)}$, and $\mathrm{E}_{(\mathrm{Rf} 1-\mathrm{C})}$, verified also that the measurements were correct, i.e., $\mathrm{E}_{(\mathrm{A}-\mathrm{C})}$ should equal $E_{(A-R f 2)}+E_{(R f 2-R f 1)}+E_{(R f 1-C)} \cdot$

The cathodic overvoltage was calculated using the three different equations given above. From Table 6-2 it can be noted that values of $\eta_{\mathrm{tC}}^{*}$ and $\eta_{\mathrm{tC}}^{\ddagger}$ calculated from Equation $(6-12)$ and Equation (6-15) respectively are similar over the complete range of current densities, i.e., up to $15 \mathrm{~mA} / \mathrm{cm}^{2}$. However, the cathodic overvoltage calculated from Equation $(6-16)$, i.e., $\eta_{t C}^{+}$, starts to differ from the other two above at current densities above $8 \mathrm{~mA} / \mathrm{cm}^{2}$.

As mentioned in Section 6-7, Equation (6-16) may contain some residual concentration polarization at high applied potentials, in spite of the fact that stirring was done near the cathode.

These differences in cathode overvoltages are reported in the column headed by the symbol $\eta_{\mathrm{cC}}$ (cathodic concentration polarization) which, as shown in Section 6-8, is given by

$$
\eta_{c C}=E_{(\operatorname{Rf} 1-C)}-E_{(\operatorname{Rf} 2-\operatorname{Rf} 1)} f-E_{(C-R f 3)}
$$


T도요 6-2

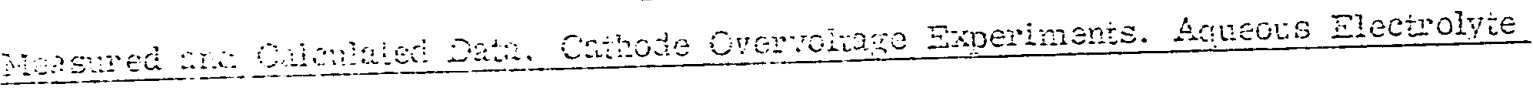

\begin{tabular}{|c|c|c|c|c|c|c|c|c|c|c|c|c|c|}
\hline$\cdots \cdots$ & 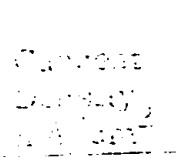 & & $\begin{array}{c}-(\mathrm{i}-\mathrm{C}) \\
\mathrm{nV} \\
\end{array}$ & 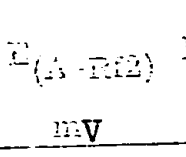 & $\begin{array}{c}-(a-R i) \\
\mathrm{aV}\end{array}$ & $\begin{array}{c}\text { Enal-c) } \\
\mathrm{miv} \\
\end{array}$ & $\begin{array}{c}E(C-E) \\
n\end{array}$ & 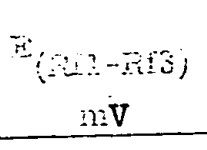 & $\begin{array}{c}E_{(A-N 3)} \\
n V \\
\end{array}$ & $\begin{array}{l}\eta_{\mathrm{CC}} \\
\mathrm{mV}\end{array}$ & $\begin{array}{l}n^{*} \\
m \mathrm{tc} \\
\mathrm{mV}\end{array}$ & 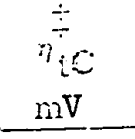 & 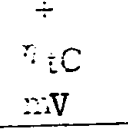 \\
\hline$\therefore$ & 0 & 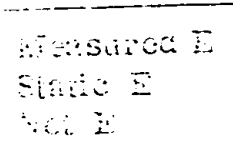 & $\begin{array}{r}53.2 \\
-3.0 \\
-20.6\end{array}$ & $\begin{array}{r}-13.3 \\
-8.0 \\
-10.3\end{array}$ & $\begin{array}{l}-6.5 \\
-2.0 \\
-2.5\end{array}$ & $\begin{array}{r}-15.5 \\
-2.5 \\
-16.5\end{array}$ & $\begin{array}{r}-4.3 \\
-4.3 \\
-6.4\end{array}$ & $\begin{array}{l}-12.5 \\
-7.5 \\
--5.1\end{array}$ & $\begin{array}{r}.32 .5 \\
-12.0 \\
-19.9\end{array}$ & $\div 0.6$ & -9.4 & $-8 . \vec{i}$ & -8.6 \\
\hline$\therefore$ & $6 . \therefore$ & 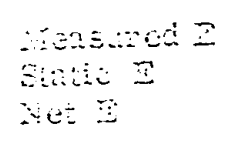 & $\begin{array}{r}-7.5 \\
-2.0 \\
60.0\end{array}$ & $\begin{array}{r}-22 . i \\
-2.5 \\
-i 9.2\end{array}$ & $\begin{array}{l}-11.1 \\
-1.9 \\
-0.2\end{array}$ & $\begin{array}{l}-4.5 \\
-3.0 \\
-1.5\end{array}$ & $\begin{array}{r}-20.0 \\
-30.7 \\
-50.7\end{array}$ & $\begin{array}{l}-15.2 \\
-\frac{5.3}{31.3}\end{array}$ & $\begin{array}{l}-51.4 \\
-\frac{11.2}{15} \\
-39.7\end{array}$ & -0.6 & 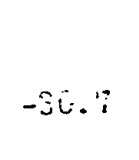 & -00.2 & -31.3 \\
\hline$\therefore$ & $\therefore .3$ & 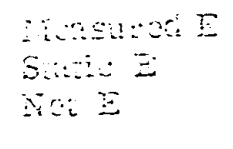 & 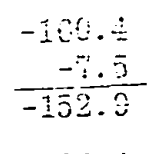 & $\begin{array}{r}-30.2 \\
-2.5 \\
-36.4\end{array}$ & $\begin{array}{l}-20.0 \\
-\frac{1.3}{-1.2}\end{array}$ & $\begin{array}{r}-101.2 \\
-3.0 \\
-05.2\end{array}$ & $\begin{aligned}-7.4 \\
-3.4 \\
-76.8\end{aligned}$ & $\begin{array}{r}-2 \div .2 \\
-5.5 \\
-20.4\end{array}$ & $\begin{array}{l}-05.3 \\
-10.6 \\
-7 \pm .7\end{array}$ & -0.2 & -77.8 & -77.8 & -70.0 \\
\hline 0.0 & 2.4 & 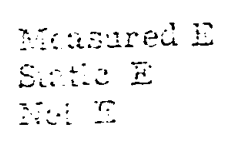 & $\begin{array}{r}-20.4 \\
-8.3 \\
-197.8\end{array}$ & $\begin{array}{r}-55.2 \\
-2.8 \\
-52.5\end{array}$ & $\begin{array}{r}-23.2 \\
-\frac{1.8}{-36.4}\end{array}$ & $\begin{array}{r}-122.7 \\
-4.0 \\
-120.7\end{array}$ & $\begin{array}{r}-89.0 \\
\div 2.4 \\
0.0 .4\end{array}$ & $\begin{array}{r}-33.9 \\
-5 . \pm \\
-2.5 .5\end{array}$ & $\begin{array}{r}-117.3 \\
-10.0 \\
-107.8\end{array}$ & $\therefore 1.0$ & $-90 . \stackrel{4}{=}$ & -90.2 & $-80 . \frac{A}{-}$ \\
\hline$\therefore \vdots$ & $\therefore=$ & 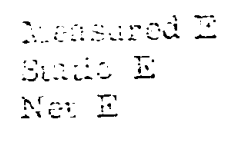 & $\begin{array}{r}-25 \% .0 \\
-1.5 \\
-247.4\end{array}$ & $\begin{array}{l}-7.2 \\
-2.8 \\
-70.4\end{array}$ & $\begin{array}{l}-35.0 \\
-1.6 \\
-36.4\end{array}$ & $\begin{array}{r}-1+2.0 \\
-3.2 \\
-141.2\end{array}$ & $\begin{array}{r}-1.0 .2 \\
-2.2 .4 \\
-1.02 .6\end{array}$ & $\begin{array}{r}-18.7 \\
-\frac{-5.4}{40.3} \\
-30.3\end{array}$ & $\begin{array}{l}-150.0 \\
-10.0 \\
-140.0\end{array}$ & $\therefore 1.7$ & -102.6 & -103.0 & -101.9 \\
\hline$\vdots \ldots$ & $\therefore$ & 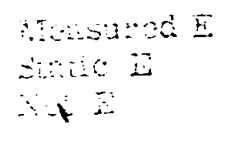 & $\begin{array}{r}253.2 \\
-20.0 \\
-203.0\end{array}$ & $\begin{array}{r}.85 .2 \\
-5.0 \\
-5.2\end{array}$ & $\begin{array}{r}-4 \overline{0} .0 \\
-\overline{1} . \overline{0} \\
-43 . \overline{2}\end{array}$ & $\begin{array}{r}-15 c .2 \\
-\frac{-6.0}{-32.2}\end{array}$ & $\begin{array}{r}-103.0 \\
+9.3 \\
-100.2\end{array}$ & $\begin{array}{r}-51.9 \\
-5.2 \\
-4.3 .7\end{array}$ & $\begin{array}{l}-107.0 \\
-10.0 \\
-177.0\end{array}$ & $\div 1.6$ & -1030.2 & -105.5 & $-10 \div . \hat{3}$ \\
\hline$\because \because 8$ & $\therefore$. & 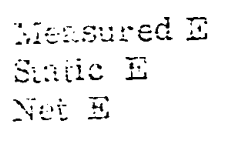 & $\begin{array}{r}-223.6 \\
-11.0 \\
-222.4\end{array}$ & $\begin{array}{r}-105.7 \\
-2.3 \\
-100.5\end{array}$ & $\begin{array}{l}-\overline{53.1} \\
-\frac{-3.9}{-53.2}\end{array}$ & $\begin{array}{r}-17.0 \\
-6.2 \\
-100.3\end{array}$ & $\begin{array}{r}-10.5 \\
-10.1 \\
-10.15\end{array}$ & $\begin{array}{r}-62.3 \\
-5.2 \\
-5.1\end{array}$ & $\begin{array}{r}-222.7 \\
\frac{-9.9}{-212.8}\end{array}$ & 4.8 & -110.6 & -109.7 & -102.8 \\
\hline$\because \therefore$ & 5.2 & 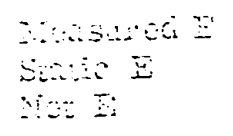 & $\begin{array}{r}-8: 1.6 \\
-11.0 \\
-30.06\end{array}$ & $\begin{array}{r}-2 \div 2 \\
-20 \\
12 \div 0\end{array}$ & 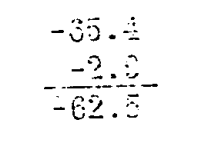 & $\begin{array}{r}2 \% .2 \\
-3.3 \\
160.5\end{array}$ & $\begin{array}{r}-112.3 \\
\div 0.2 \\
-113.8\end{array}$ & $\begin{array}{r}-7.7 \\
-\frac{2}{-2.9} \\
-8 . .8\end{array}$ & $\begin{array}{r}-25 \% .0 \\
--9.0 \\
-24.1\end{array}$ & $\div 2.3$ & 6. & ¿13.1 & -111.5 \\
\hline
\end{tabular}


TABLE 6-2 (Cont'd)

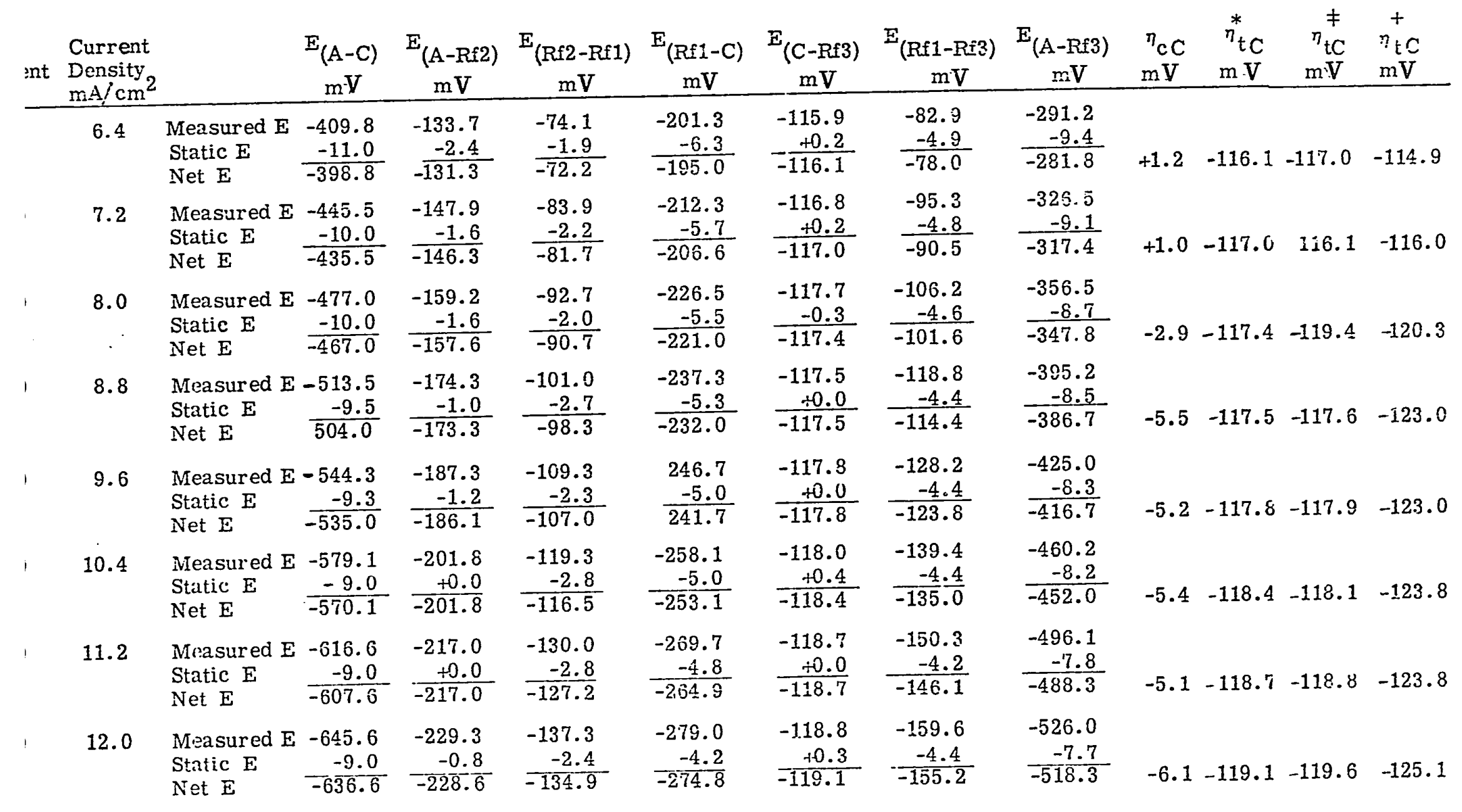


which by reference to Equation $(6-12)$ and $(6-16)$ is equivalent to:

$$
\eta_{\mathrm{CC}}=\eta_{\mathrm{tC}}^{+}-\eta_{\mathrm{tC}}^{*}
$$

It should be noted that since the system was stirred, this is a residual concentration polarization only and that $\eta_{\mathrm{CC}}$ is never more than a few percent of the charge transfer overvoltage. It would be possible, however, to measure the total concentration polarization for the system, i. e., in the complete absence of stirring by the same method.

It is interesting to note that measurements produced for the use of Equation (6-16) could also be obtained from a Haring cell, i.e., a similar cell to the one used here but without the back reference electrode. However, the use of the back reference electrode provides a direct determination of a concentration polarization free and IR drop free, cathodic charge-transfer overvoltage. It should be added here that another measurement $\mathrm{E}_{(\mathrm{A}-\mathrm{Rf} 3)}$ was made and that cathodic chargetransfer overvoltage could also be calculated from this measurement by subtracting $E_{(A-R f 3)}$ from $E_{(A-C)}$. However, the magnitude of the voltage involved in this measurement is very high, since it includes the total IR drop of the electrolyte. Since the accuracy of the voltmeter used decreases with increasing voltage measured, this method was not used for calculating $\eta_{\mathrm{tC}}$.

To summarize, this investigation indicated that the experimental cell could be used for the determination of total or partial IR drop, total or partial concentration polarization, and the charge-transfer overvoltage. The charge-transfer overvoltage is most accurately and directly determined by the back reference electrode, Rf3. 
C. Cathodic Polarization - Organic Electrolyte,

Specific Conductance: $4.0 \times 10^{-3} \Omega^{-1} \mathrm{~cm}^{-1}$

Electrolyte: Ethylbenzene-toluene $1: 1$ by volume, 50 wt. $\% \mathrm{AlBr}_{3}$. Anode: Aluminum (1S) $99.8+\%$ minimum Al.

Reference Electrodes: Aluminum (1S) $99.8+\%$ minimum Al.

Cathode: Platinum disc $.5 \mathrm{~mm}$ thick $2.5 \mathrm{~cm}^{2}$ of surface area, plated with aluminum from the electrolyte.

Operating Conditions: Standard.

Measurements: (Table 6-3).

a) Current and area of cathode.

b) Potential between cathode and $\mathrm{Rf3}\left(\mathrm{E}_{(\mathrm{C}-\mathrm{Rf} 3)}\right)$ at specified current densities.

c) Temperatures: $27,41,54,67,81^{\circ} \mathrm{C}$.

Calculations:

a) $\eta_{\mathrm{tC}}^{*}=\mathrm{E}_{(\mathrm{C}-\mathrm{Rf} 3)}$ (Equation 6-12).

$\eta_{\mathrm{tC}}^{*}$ was plotted as a function of current density (Fig. 6-8)

and as a logarithmic function of current density (Fig. 6-9)

which represents the standard Tafel line.

b) Heat of activation of the cathode process (at constant

cathode overvoltage $\left(\eta_{\text {tC }}^{*}\right)$ (Fig. 6-10)):

$$
\log i_{C}=\log B-\frac{2.303 \Delta \mathrm{H}^{\ddagger}\left(\eta_{\mathrm{tC}}^{*}\right)}{\mathrm{RT}} \quad(\text { Eqn. 6-6b) }
$$

where $B=a$ constant

This equation shows that a plot of $\log \mathrm{i}_{\mathrm{C}}$ (at constant $\left.\eta_{\mathrm{tC}}\right)$ 
vs. $\frac{1}{\mathrm{~T}}$ Figure 6.10 gives the slope

$$
\frac{2.303 \Delta \mathrm{H}^{\neq}\left(\eta_{\mathrm{tC}}\right)}{\mathrm{R}}
$$

from which $\Delta \mathrm{H}^{\ddagger}\left(\eta_{\mathrm{tC}}\right)$ has been calculated. The values of $\mathrm{i}_{\mathrm{C}}$ at constant $\eta_{\mathrm{tC}}$ are taken from Figure 6-8.

c) Heat of activation of the cathode process (constant $\mathrm{i}_{\mathrm{C}}$ ) (Fig. 6-11)

$$
\begin{aligned}
& \eta_{\mathrm{tC}}^{*}=\frac{2.303 \Delta_{\left(\mathrm{H}^{+}\right.}^{\ddagger}\left(\mathrm{i}_{\mathrm{C}}\right)}{\beta \lambda \mathrm{F}} \log \mathrm{T}+\mathrm{B} \quad \text { (Eqn. 6-7b) } \\
& \mathrm{B}=\mathrm{a} \text { constant }
\end{aligned}
$$

$\eta_{\text {tC }}^{*}$ values at constant current densities of $8,10,12 \mathrm{~mA} / \mathrm{cm}^{2}$ were taken from Figure 6.8 and were plotted against $\log T$. This gives the slope $\frac{2.303 \Delta \mathrm{H}^{\ddagger}\left(\mathrm{i}_{\mathrm{C}}\right)}{\beta \lambda \mathrm{F}}$ from which $\Delta \mathrm{H}_{\left(\mathrm{i}_{\mathrm{C}}\right)}^{\ddagger}$ can be calculated (Fig. 6-11).

\section{$\underline{\text { Results }}$}
a) Measurements and $\eta_{\mathrm{tC}}^{*}$
Table 6-3.
b) Plot of $\eta_{\text {tC }}^{*}$ ys. $i_{C}$ Figure 6-8.
c) Plot of $\eta_{\mathrm{tC}}^{*}$ vs. $\log \mathrm{i}_{\mathrm{C}}$ Figure 6-9.
d) Plot of ${ }^{i_{C}}$ (constant $\eta_{t}{ }^{*}$ ) vs. $\frac{1}{T}{ }^{o} \mathrm{~K}$
Figure 6-10.
e) Plot of $\eta_{\mathrm{tC}}^{*}$ vs. $\log \mathrm{T}^{\mathrm{o}} \mathrm{K}$
Figure 6-11.

The values of heat of activation for the cathodic process as calculated from Figures 6-10 and 6-11 are given in Table 6-4. 


\section{TABLE $6-3$}

Cathodic Polarization Measurements, Organic System, Specific Conductance $4.0 \times 10^{-3} \Omega^{-1} \mathrm{~cm}^{-1}$

Electrolyte: Ethylbenzene-Toluene 1:1, 50 wt. $\% \mathrm{AlBr}_{3}$

Anode: Aluminum (1S) 99.8+\% Al minimum

Cathode: $2.5 \mathrm{~cm}^{2}$ Platinum disc, Aluminum plated

Reference Electrode: Aluminum (1S) $99.8+\% \mathrm{Al}$ minimum

Operating Conditions: Standard

$$
E_{(C-R f 3)}
$$

Current

Current Density, $\mathrm{mA} \mathrm{mA} / \mathrm{cm}^{2}$

\begin{tabular}{|c|c|c|c|c|c|c|c|}
\hline $\begin{array}{c}\text { urrent } \\
\mathrm{mA}\end{array}$ & $\begin{array}{l}\text { sity } \\
/ \mathrm{cm}^{2}\end{array}$ & & $300^{\circ} \mathrm{K}$ & $313^{\circ} \mathrm{K}$ & $327^{\circ} \mathrm{K}$ & $340^{\circ} \mathrm{K}$ & $354^{\circ} \mathrm{K}$ \\
\hline 1.0 & 0.4 & $\begin{array}{l}\text { Measured E } \\
\text { Static E } \\
\text { Net E }\end{array}$ & $\begin{array}{l}-8.0 \\
-3.0 \\
-5.0\end{array}$ & $\begin{array}{l}-6.5 \\
-2.5 \\
-4.0\end{array}$ & $\begin{array}{l}-3.4 \\
-2.4 \\
-1.0\end{array}$ & $\begin{array}{r}+2.6 \\
+3.2 \\
-0.6\end{array}$ & \\
\hline 2.0 & 0.8 & $\begin{array}{l}\text { Measured E } \\
\text { Static E } \\
\text { Net E }\end{array}$ & $\begin{array}{l}-12.0 \\
-3.4 \\
-8.6\end{array}$ & $\begin{array}{l}-8.5 \\
-2.5 \\
-6.0\end{array}$ & $\begin{array}{l}-3.2 \\
-1.4 \\
-1.8\end{array}$ & $\begin{array}{r}+1.5 \\
+3.5 \\
-2.0\end{array}$ & $\begin{array}{r}+3.0 \\
+3.6 \\
-0.6\end{array}$ \\
\hline 4.0 & 1.6 & $\begin{array}{l}\text { Measured } \mathbf{E} \\
\text { Static E } \\
\text { Net } \mathbf{E}\end{array}$ & $\begin{array}{r}-19.0 \\
-2.4 \\
-16.6\end{array}$ & $\begin{array}{r}-14.4 \\
-2.4 \\
-12.0\end{array}$ & $\begin{array}{l}-4.0 \\
-0.2 \\
-3.8\end{array}$ & $\begin{array}{r}+0.5 \\
+3.5 \\
-3.0\end{array}$ & \\
\hline 6.0 & 2.4 & $\begin{array}{l}\text { Measured E } \\
\text { Static E } \\
\text { Net E }\end{array}$ & $\begin{array}{r}-23.0 \\
-2.8 \\
-20.2\end{array}$ & $\begin{array}{r}-18.0 \\
-2.4 \\
-15.6\end{array}$ & $\begin{array}{l}-8.2 \\
+0.4 \\
-8.6\end{array}$ & $\begin{array}{r}-2.0 \\
3.5 \\
-5.5\end{array}$ & $\begin{array}{l}+3.5 \\
+6.1 \\
-2.6\end{array}$ \\
\hline 8.0 & 3.2 & $\begin{array}{l}\text { Measured E } \\
\text { Static E } \\
\text { Net E }\end{array}$ & $\begin{array}{r}-28.6 \\
-5.0 \\
-23.6\end{array}$ & $\begin{array}{r}-20.6 \\
-2.6 \\
-18.0\end{array}$ & $\begin{array}{r}-9.6 \\
+1.0 \\
-10.6\end{array}$ & & $\begin{array}{r}+3.5 \\
+8.0 \\
-4.5\end{array}$ \\
\hline 10.0 & 4.0 & $\begin{array}{l}\text { Measured E } \\
\text { Static E } \\
\text { Net E }\end{array}$ & $\begin{array}{r}E-31.0 \\
-6.0 \\
-25.0\end{array}$ & $\begin{array}{l}-23.0 \\
-2.4 \\
-20.6\end{array}$ & $\begin{array}{r}-10.5 \\
+2.0 \\
-12.5\end{array}$ & $\begin{array}{r}-5.5 \\
+4.0 \\
-9.5\end{array}$ & $\begin{array}{r}+3.5 \\
+8.5 \\
-5.0\end{array}$ \\
\hline 12.0 & 4.8 & $\begin{array}{l}\text { Measured E } \\
\text { Static E } \\
\text { Net E }\end{array}$ & $\begin{array}{r}\text { E }-31.6 \\
\frac{-5.2}{-26.4}\end{array}$ & $\begin{array}{r}-24.8 \\
-2.6 \\
-22.2\end{array}$ & $\begin{array}{r}-14.3 \\
+2.0 \\
-16.3\end{array}$ & & $\begin{array}{r}+0.0 \\
+8.0 \\
-8.0\end{array}$ \\
\hline 14.0 & 5.6 & $\begin{array}{l}\text { Measured E } \\
\text { Static E } \\
\text { Net E }\end{array}$ & $\begin{array}{r}E-33.5 \\
-5.0 \\
-28.5\end{array}$ & $\begin{array}{r}-27.0 \\
-3.4 \\
-23.6\end{array}$ & $\begin{array}{r}-15.2 \\
+3.5 \\
-18.7\end{array}$ & $\begin{array}{r}-9.0 \\
+5.0 \\
-14.0\end{array}$ & $\begin{array}{r}+12.0 \\
+22.0 \\
-10.0\end{array}$ \\
\hline
\end{tabular}


TABLE 6-3 (Cont'd)

Current

Current Density

\begin{tabular}{|c|c|c|c|c|c|c|c|}
\hline $\begin{array}{c}\text { urrent } \\
\text { mA }\end{array}$ & $\begin{array}{l}\text { Density } \\
\mathrm{mA} / \mathrm{cm}\end{array}$ & & $\underline{300^{\circ} \mathrm{K}}$ & $\underline{313^{\circ} \mathrm{K}}$ & $327^{\circ} \mathrm{K}$ & $340^{\circ} \mathrm{K}$ & $354^{\circ} \mathrm{K}$ \\
\hline 16.0 & 6.4 & $\begin{array}{l}\text { Measured E } \\
\text { Static E } \\
\text { Net E }\end{array}$ & $\begin{array}{l}-36.0 \\
-6.0 \\
-30.0\end{array}$ & $\begin{array}{r}-29.0 \\
-3.0 \\
-26.0\end{array}$ & $\begin{array}{r}-17.0 \\
+3.0 \\
-20.0\end{array}$ & & \\
\hline 18.0 & 7.2 & $\begin{array}{l}\text { Measured E } \\
\text { Static E } \\
\text { Net E }\end{array}$ & $\begin{array}{r}-39.0 \\
-6.0 \\
-33.0\end{array}$ & $\begin{array}{r}-30.2 \\
-2.8 \\
-27.4\end{array}$ & $\begin{array}{r}-18.3 \\
+4.0 \\
-22.3\end{array}$ & $\begin{array}{r}-12.3 \\
+5.5 \\
-17.8\end{array}$ & $\begin{array}{r}+9.0 \\
+22.0 \\
-13.0\end{array}$ \\
\hline 20.0 & 8.0 & $\begin{array}{l}\text { Measured E } \\
\text { Static E } \\
\text { Net E }\end{array}$ & $\begin{array}{r}-39.4 \\
-5.6 \\
-33.8\end{array}$ & $\begin{array}{l}-32.0 \\
-3.0 \\
-29.0\end{array}$ & $\begin{array}{r}-20.1 \\
+4.7 \\
-24.8\end{array}$ & & \\
\hline 22.0 & 8.8 & $\begin{array}{l}\text { Measured E } \\
\text { Static E } \\
\text { Net E }\end{array}$ & $\begin{array}{r}-41.0 \\
-\frac{-5.6}{-35.4}\end{array}$ & $\begin{array}{r}-35.0 \\
-3.4 \\
-31.6\end{array}$ & $\begin{array}{r}-21.0 \\
+5.0 \\
-26.0\end{array}$ & $\begin{array}{r}-16.0 \\
+5.5 \\
-21.5\end{array}$ & $\begin{array}{r}+4.0 \\
+20.0 \\
-16.0\end{array}$ \\
\hline 24.0 & 9.6 & $\begin{array}{l}\text { Measured E } \\
\text { Static E } \\
\text { Net E }\end{array}$ & $\begin{array}{r}-43.6 \\
-5.8 \\
-37.8\end{array}$ & $\begin{array}{r}-36.8 \\
-3.4 \\
-33.4\end{array}$ & & & \\
\hline 26.0 & 10.4 & $\begin{array}{l}\text { Measured E } \\
\text { Static E } \\
\text { Net E }\end{array}$ & $\begin{array}{r}-44.4 \\
-6.0 \\
-38.4\end{array}$ & $\begin{array}{r}-38.4 \\
\frac{-3.4}{-35.0}\end{array}$ & $\begin{array}{r}-22.6 \\
+5.8 \\
-28.4\end{array}$ & $\begin{array}{r}-19.6 \\
+5.2 \\
-24.8\end{array}$ & $\begin{array}{r}+2.0 \\
+22.0 \\
-20.0\end{array}$ \\
\hline 28.0 & 11.2 & $\begin{array}{l}\text { Measured E } \\
\text { Static E } \\
\text { Net E }\end{array}$ & $\begin{array}{r}-45.0 \\
-5.0 \\
-40.0\end{array}$ & $\begin{array}{r}-39.8 \\
-3.4 \\
-36.4\end{array}$ & & & \\
\hline 30.0 & 12.0 & $\begin{array}{l}\text { Measured E } \\
\text { Static E } \\
\text { Net E }\end{array}$ & $\begin{array}{r}-47.8 \\
-5.6 \\
-42.2\end{array}$ & $\begin{array}{r}-41.0 \\
-3.5 \\
-37.5\end{array}$ & $\begin{array}{r}-26.0 \\
+5.5 \\
-31.5\end{array}$ & $\begin{array}{r}-22.9 \\
+5.4 \\
-28.3\end{array}$ & $\begin{array}{r}-1.5 \\
+22.0 \\
23.5\end{array}$ \\
\hline 32.0 & 12.8 & $\begin{array}{l}\text { Measured E } \\
\text { Static E } \\
\text { Net E }\end{array}$ & $\begin{array}{r}-49.0 \\
-5.5 \\
-43.5\end{array}$ & $\begin{array}{r}-42.1 \\
-\frac{3.6}{-38.5}\end{array}$ & $\begin{array}{r}-39.0 \\
-5.5 \\
-33.5\end{array}$ & & \\
\hline 34.0 & 13.6 & $\begin{array}{l}\text { Measured E } \\
\text { Static E } \\
\text { Net E }\end{array}$ & $\begin{array}{r}-50.0 \\
-5.0 \\
-45.0\end{array}$ & $\begin{array}{r}-44.1 \\
-3.6 \\
-40.5\end{array}$ & & $\begin{array}{r}-24.5 \\
+5.5 \\
30.0\end{array}$ & $\begin{array}{r}-4.5 \\
+22.0 \\
-26.5\end{array}$ \\
\hline 36.0 & 14.4 & $\begin{array}{l}\text { Measured E } \\
\text { Static E } \\
\text { Net E }\end{array}$ & $\begin{array}{l}-52.0 \\
-5.0 \\
-47.0\end{array}$ & $\begin{array}{l}-46.0 \\
-4.2 \\
-41.8\end{array}$ & $\begin{array}{r}-41.0 \\
+5.0 \\
-36.0\end{array}$ & $\begin{array}{r}-27.0 \\
+5.5 \\
-32.5\end{array}$ & \\
\hline 38.0 & 15.2 & $\begin{array}{l}\text { Measured E } \\
\text { Static E } \\
\text { Net E }\end{array}$ & $\begin{array}{r}-53.5 \\
-5.0 \\
-48.5\end{array}$ & $\begin{array}{r}-48.0 \\
-5.0 \\
-43.0\end{array}$ & $\begin{array}{r}-42.5 \\
-5.5 \\
-37.0\end{array}$ & $\begin{array}{r}-28.0 \\
+5.4 \\
-33.9\end{array}$ & $\begin{array}{r}-7.0 \\
+22.0 \\
-29.0\end{array}$ \\
\hline
\end{tabular}




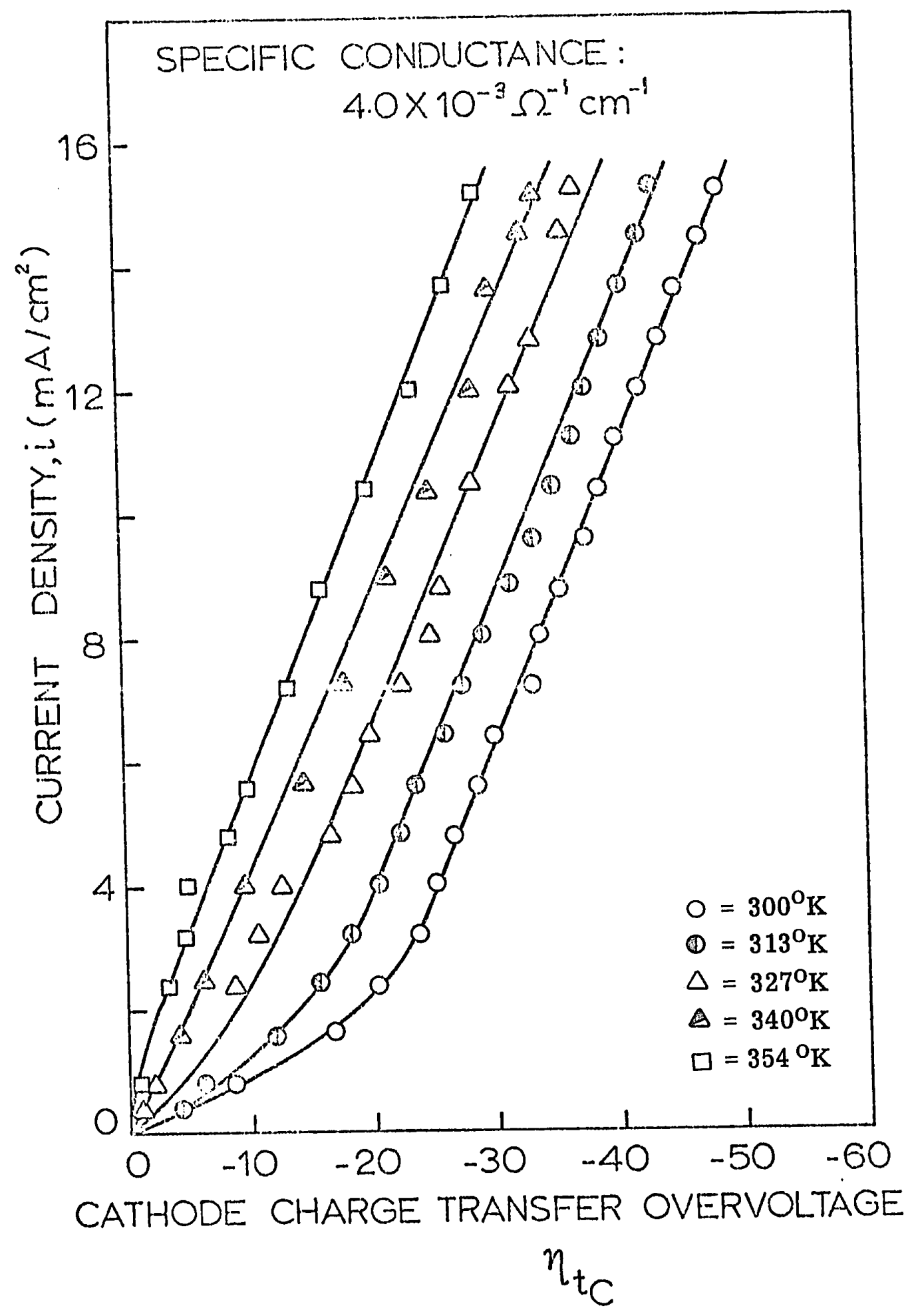

Figure 6-8. Plot of Cathode Charge Transfer Overvoltage as a Function of Cathode Current Density. 


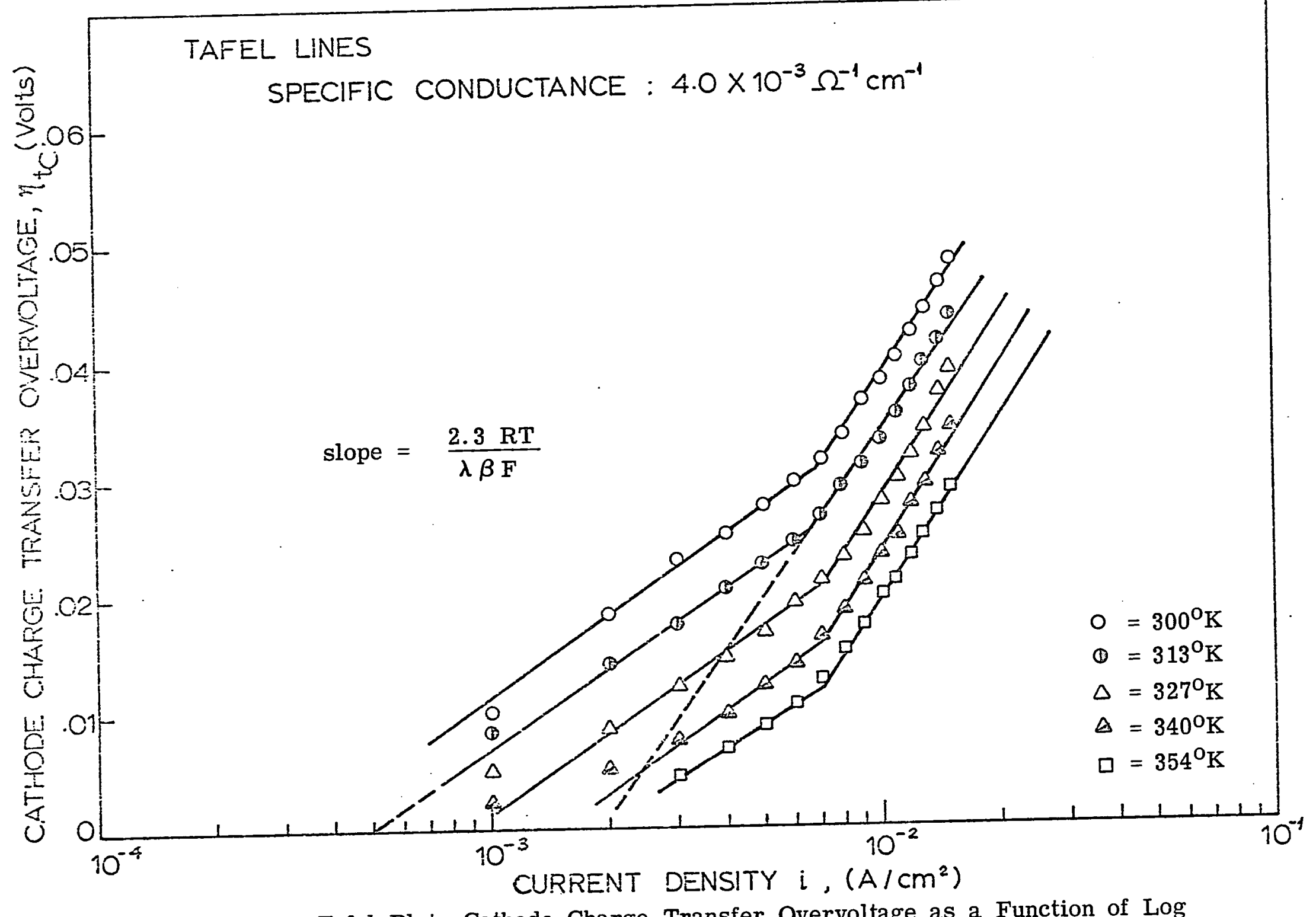

Figure 6-9. Tafel Plot, Cathode Charge Transfer Overvoltage as a Function of Log Cathode Current Density. 


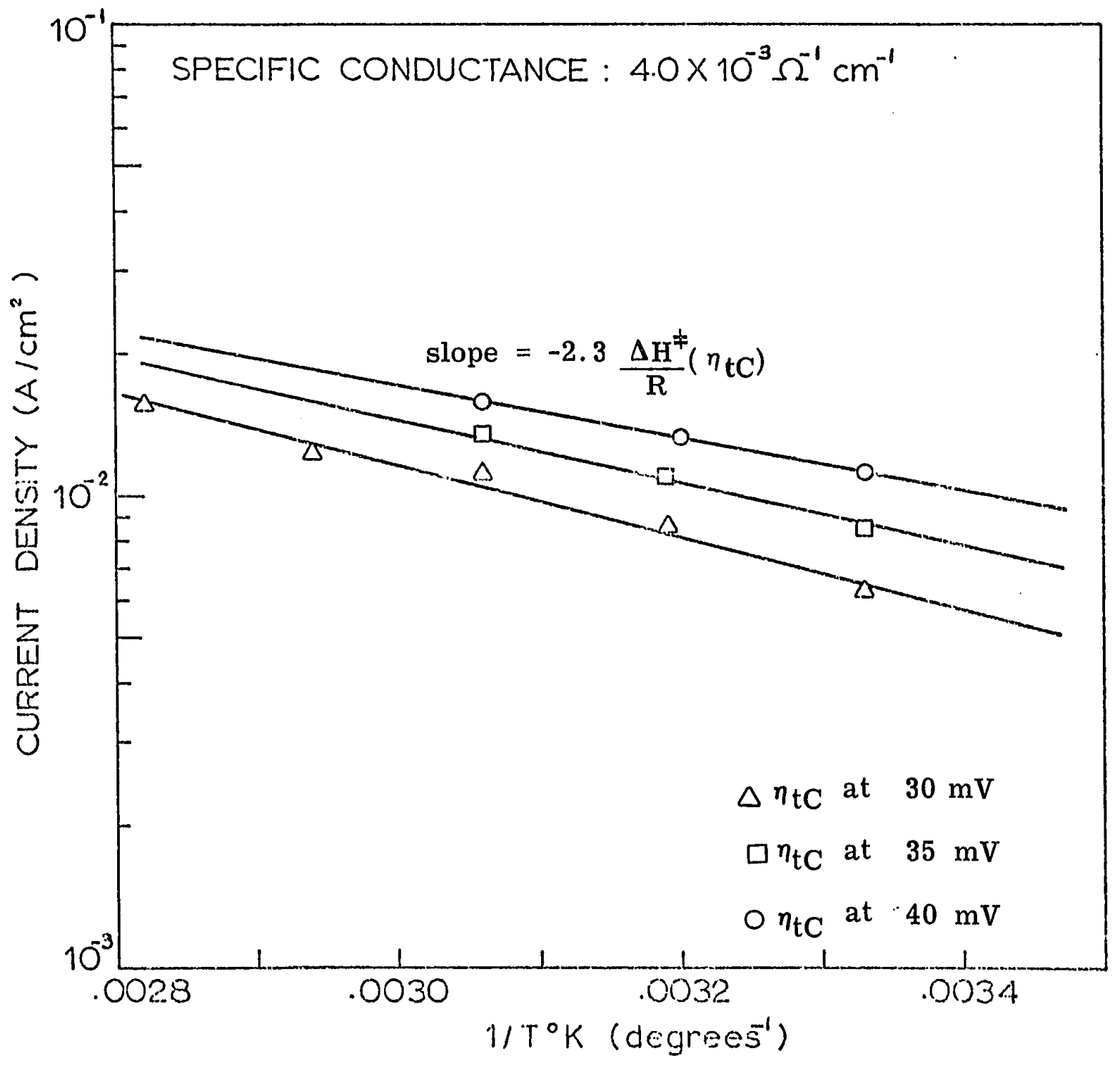

Figure 6-10. Arrhenius Plot for the Calculation of Heat of Activation $\left(\Delta \mathrm{H}^{\neq}\left(\eta_{\mathrm{tC}}\right)\right.$. 


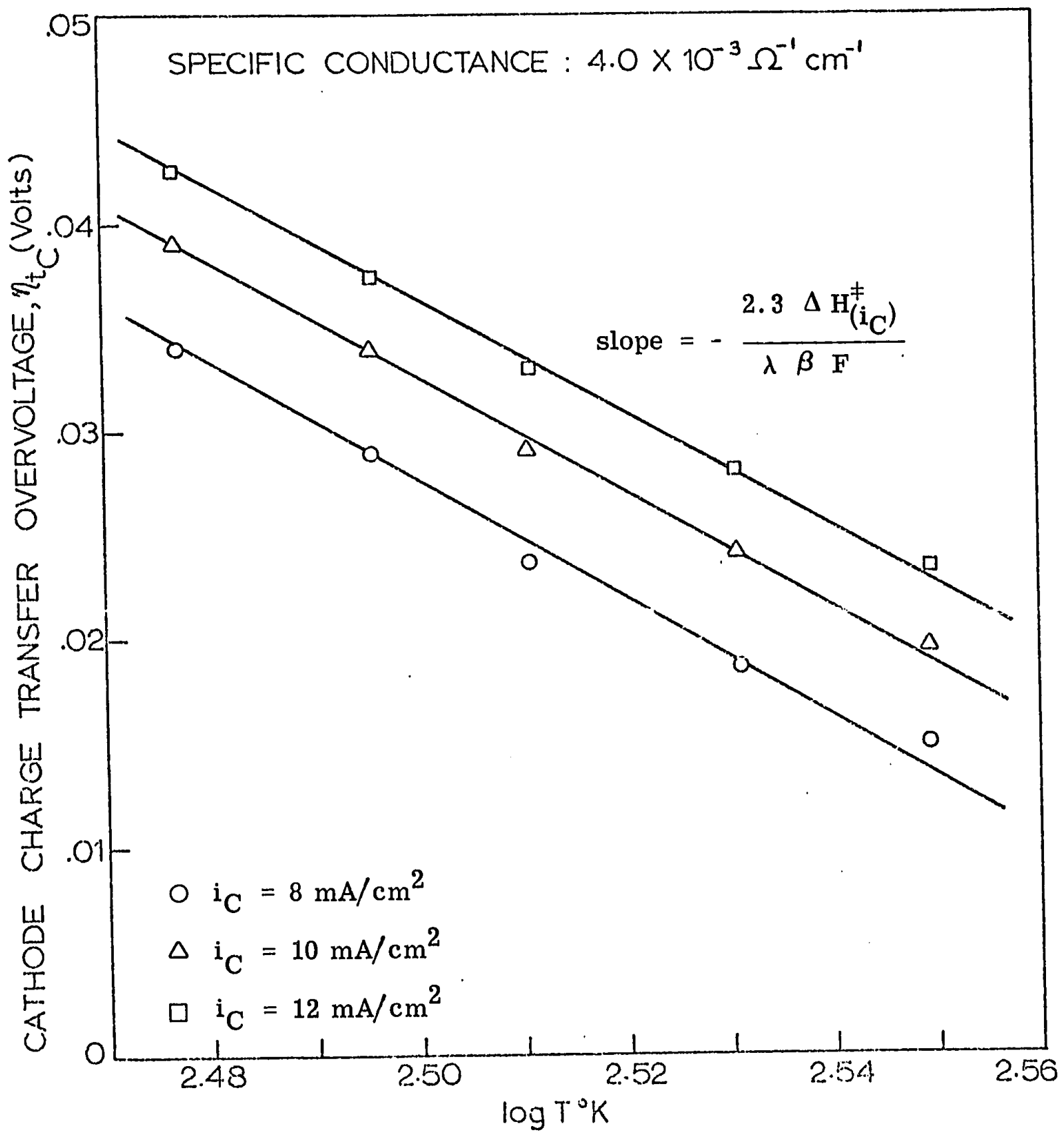

Figure 6-11. Heat of Activation $\left(\Delta \dot{H}_{\mathrm{i}_{\mathrm{C}}}^{\neq}\right)$Calculation, $\eta_{\mathrm{tC}}$ as a Function of $\log \mathrm{T}^{0} \mathrm{~K}$. 
Table 6-4

Heats of Activation, Ethylbenzene-Toluene 1:1, $\underline{50 \% \mathrm{AlBr}_{3}}$ System (Specific Conductance $4.0 \times 10^{-3} \Omega^{-1} \mathrm{~cm}^{-1}$

$\Delta \mathrm{H}^{+}$, heat of activation at constant cathode overvoltage

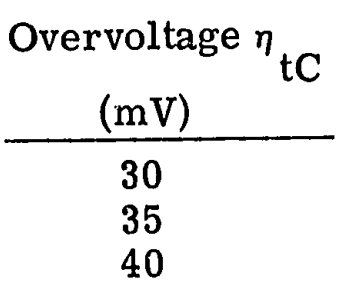

$$
\begin{gathered}
\begin{array}{c}
\Delta \mathrm{H}^{\ddagger}\left(\eta_{\mathrm{tC}}^{*}\right) \\
\text { Kcals } / \text { moles }
\end{array} \\
\hline 3.5 \\
3.1 \\
2.6
\end{gathered}
$$

$\Delta \mathrm{H}^{\ddagger}$, heat of activation at constant current density

\begin{tabular}{c}
$\begin{array}{c}\text { Current density } \\
\mathrm{mA} / \mathrm{cm}^{2}\end{array}$ \\
\hline 8 \\
10 \\
12
\end{tabular}

$$
\begin{gathered}
\Delta \mathrm{H}^{\ddagger}\left(\mathrm{i}_{\mathrm{C}}\right) \\
\text { Kcals/moles } \\
\hline 4.2 \\
4.1 \\
4.1
\end{gathered}
$$

Observations: Tables 6-3, 6-4, Figures 6-8, 6-9, 6-10, 6-11.

Steady and reproducible measurements were obtained from this system at $300^{\circ} \mathrm{K}, 313^{\circ} \mathrm{K}$, and $327^{\circ} \mathrm{K}$, but measurements at $340^{\circ} \mathrm{K}$ and $354^{\circ} \mathrm{K}$ tended to give variable results, most likely due to redissolution of the plated aluminum from the cathode surface. However, when plotted in the Tafel form (Fig. 6-9), the $\eta_{\text {tC }}^{*}$ vs. $\log i_{C}$ curves were of consistent form at all temperatures.

It can be noted, however, that the Tafel lines have two distinct slopes which indicates that there are two operative mechanisms in the cathodic process. This observation will be discussed further in the discussion section. 
D. Cathodic Polarization - Organic Electrolyte, Specific Conductance: $3.0 \times 10^{-3} \Omega^{-1} \mathrm{~cm}^{-1}$

Electrolyte: Ethylbenzene-toluene 1:1, 50 wt. $\% \mathrm{AlBr}_{3}$.

Anode: Aluminum (1S) $99.8+\%$ minimum Al.

Cathode: Platinum disc $.5 \mathrm{~mm}$ thick $2.5 \mathrm{~cm}^{2}$ surface area.

Operating conditions: Standard.

Measurements: Same as in Section 6-16 (C) above.

Calculations: Same as in Section 6-16 (C) above.

Results:
a) Measurements and $\eta_{\text {tC }}^{*}$
Table 6-5
b) Plot of $\eta^{*}$ tC vs. ${ }^{i_{C}}$
Figure 6-12
c) Plot of $\eta_{\text {tC }}^{*}$ vs. $\log { }^{i_{C}}$
Figure 6-13
d) Plot of $\mathrm{i}_{\mathrm{C}}$ (constant $\eta_{\mathrm{tC}}^{*}$ ) vs. $1 / \mathrm{T}^{\mathrm{o}} \mathrm{K}$
Figure 6-14
e) Plot of $\eta_{\mathrm{tC}}^{*}$ vs. $\log \mathrm{T}^{\mathrm{O}} \mathrm{K}$
Figure 6-15

The values of heat of activation for the cathodic process as calculated from Figure 6-14 and Figure 6-15 are given in Table 6-6. 
TABLE 6-5

Cathodic Polarization Measurements, Organic System,

Specific Conductance $3.0 \times 10^{-3} \Omega^{-1} \mathrm{~cm}^{-1}$

Electrolyte: Ethylbenzene Toluene 1:1, $50 \%$ wt. $\mathrm{AlBr}_{3}$.

Anode: Al (1S)

Cathode: $2.5 \mathrm{~cm}^{2}$ Platinum, aluminum plated.

Reference Electrode: Aluminum (1S)

Operating conditions: Standard

\begin{tabular}{|c|c|c|c|c|c|c|c|}
\hline \multirow[b]{2}{*}{$\begin{array}{c}\text { Current } \\
\mathrm{mA} \\
\end{array}$} & \multirow{2}{*}{$\begin{array}{l}\text { Current } \\
\text { Density } \\
\mathrm{mA} / \mathrm{cm}^{2}\end{array}$} & \multirow{2}{*}{\multicolumn{2}{|c|}{$300^{\circ} \mathrm{K}$}} & \multicolumn{2}{|c|}{$\begin{array}{c}\mathrm{E}_{(\mathrm{C}-\mathrm{Rf} 3)} \\
\mathrm{mV} \\
\end{array}$} & \multirow[b]{2}{*}{$340^{\circ} \mathrm{K}$} & \multirow[b]{2}{*}{$354^{\circ} \mathrm{K}$} \\
\hline & & & & $313^{\circ} \mathrm{K}$ & $\underline{327^{\circ} \mathrm{K}}$ & & \\
\hline 1.0 & 0.4 & $\begin{array}{l}\text { Measured E } \\
\text { Static E } \\
\text { Net E }\end{array}$ & $\begin{array}{r}-14.0 \\
\frac{-1.4}{-12.6}\end{array}$ & $\begin{array}{l}-7.5 \\
-1.5 \\
-6.0\end{array}$ & $\begin{array}{l}+1.6 \\
+2.8 \\
-1.2\end{array}$ & & \\
\hline 2.0 & 0.8 & $\begin{array}{l}\text { Measured E } \\
\text { Static E } \\
\text { Net } E\end{array}$ & $\begin{array}{r}-17.8 \\
-1.6 \\
-16.2\end{array}$ & $\begin{array}{l}-9.6 \\
-1.6 \\
-8.0\end{array}$ & $\begin{array}{r}+1.4 \\
+4.0 \\
-2.6\end{array}$ & $\begin{array}{r}+0.5 \\
+3.0 \\
-2.5\end{array}$ & $\begin{array}{r}+4.2 \\
+2.8 \\
-1.4\end{array}$ \\
\hline 4.0 & 1.6 & $\begin{array}{l}\text { Measured E } \\
\text { Static E } \\
\text { Net E }\end{array}$ & $\begin{array}{r}-24.7 \\
-2.7 \\
-22.0\end{array}$ & $\begin{array}{r}-16.0 \\
-2.5 \\
-13.5\end{array}$ & $\begin{array}{r}-2.0 \\
+4.8 \\
-6.8\end{array}$ & & \\
\hline 6.0 & 2.4 & $\begin{array}{l}\text { Measured E } \\
\text { Static E } \\
\text { Net E }\end{array}$ & $\begin{array}{r}26.3 \\
3.1 \\
23.2\end{array}$ & $\begin{array}{r}-20.6 \\
-2.6 \\
-18.0\end{array}$ & $\begin{array}{r}-4.9 \\
+6.0 \\
-10.9\end{array}$ & $\begin{array}{r}-4.0 \\
+4.0 \\
-8.0\end{array}$ & $\begin{array}{r}-3.0 \\
+3.0 \\
-6.0\end{array}$ \\
\hline 8.0 & 3.2 & $\begin{array}{l}\text { Measured E } \\
\text { Static E } \\
\text { Net E }\end{array}$ & $\begin{array}{r}-28.0 \\
-3.2 \\
24.8\end{array}$ & $\begin{array}{r}-24.5 \\
-3.0 \\
-21.5\end{array}$ & $\begin{array}{r}-9.0 \\
+6.0 \\
-15.0\end{array}$ & & \\
\hline 10.0 & 4.0 & $\begin{array}{l}\text { Measured E } \\
\text { Static E } \\
\text { Net E }\end{array}$ & $\begin{array}{r}-30.0 \\
-3.6 \\
-26.4\end{array}$ & $\begin{array}{r}-26.9 \\
-3.4 \\
-23.5\end{array}$ & $\begin{array}{r}-12.9 \\
+6.0 \\
18.9\end{array}$ & $\begin{array}{r}-9.0 \\
+4.5 \\
-13.5\end{array}$ & $\begin{array}{r}-7.0 \\
+3.0 \\
-10.0\end{array}$ \\
\hline 12.0 & 4.8 & $\begin{array}{l}\text { Measured E } \\
\text { Static E } \\
\text { Net E }\end{array}$ & $\begin{array}{r}-32.0 \\
-3.6 \\
-28.4\end{array}$ & $\begin{array}{r}-29.1 \\
-3.6 \\
-25.5\end{array}$ & $\begin{array}{r}-15.5 \\
+6.0 \\
-21.5\end{array}$ & & \\
\hline 14.0 & 5.6 & $\begin{array}{l}\text { IMeasured E } \\
\text { Static E } \\
\text { Net E }\end{array}$ & $\begin{array}{r}-34.4 \\
-3.8 \\
-30.6\end{array}$ & $\begin{array}{r}-30.4 \\
-3.4 \\
-27.0\end{array}$ & $\begin{array}{r}-17.0 \\
+6.0 \\
-23.0\end{array}$ & $\begin{array}{r}-14.0 \\
+4.0 \\
-18.0\end{array}$ & $\begin{array}{r}-9.0 \\
+4.5 \\
-13.5\end{array}$ \\
\hline
\end{tabular}


TABLE 6-5 (Cont'd)

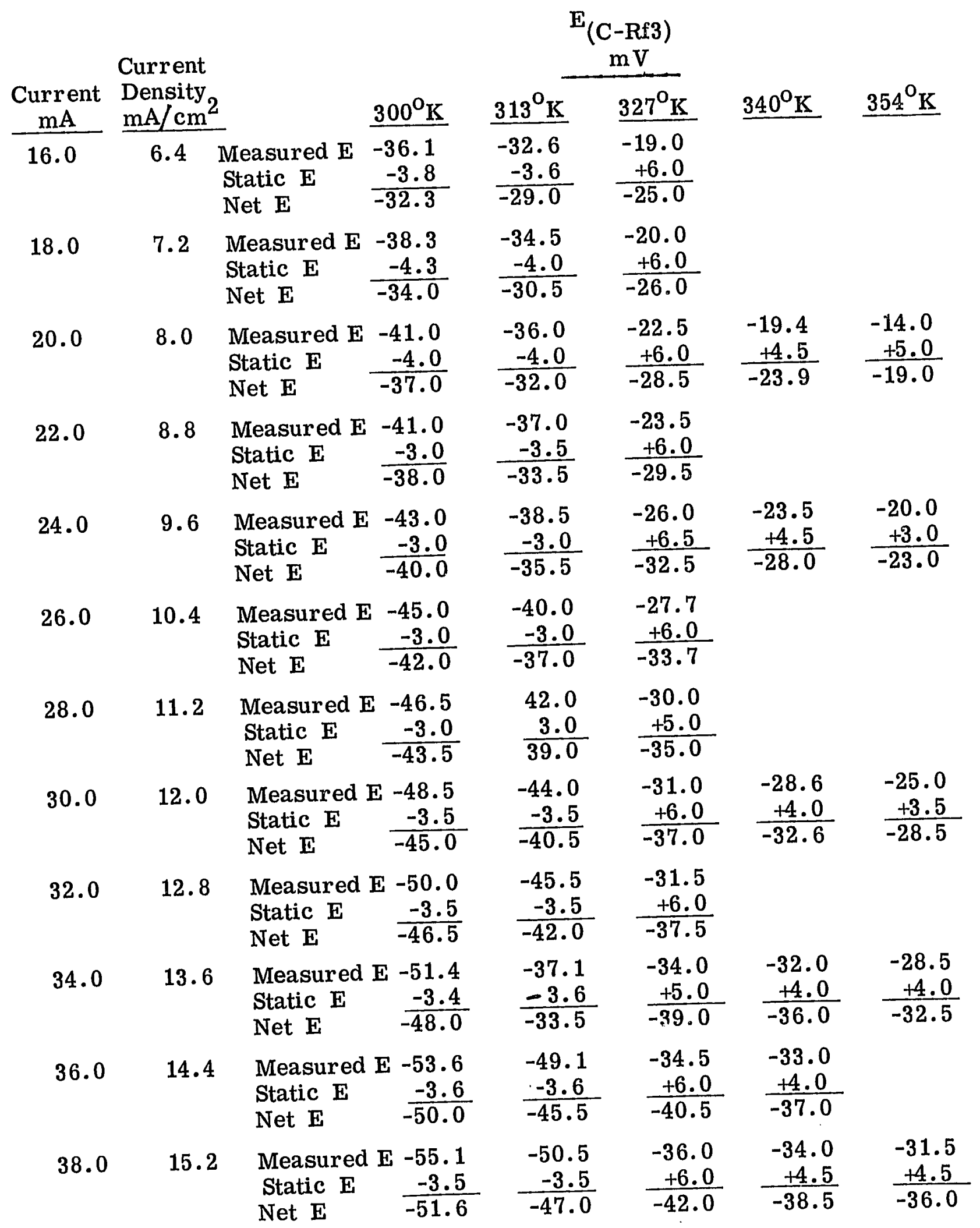




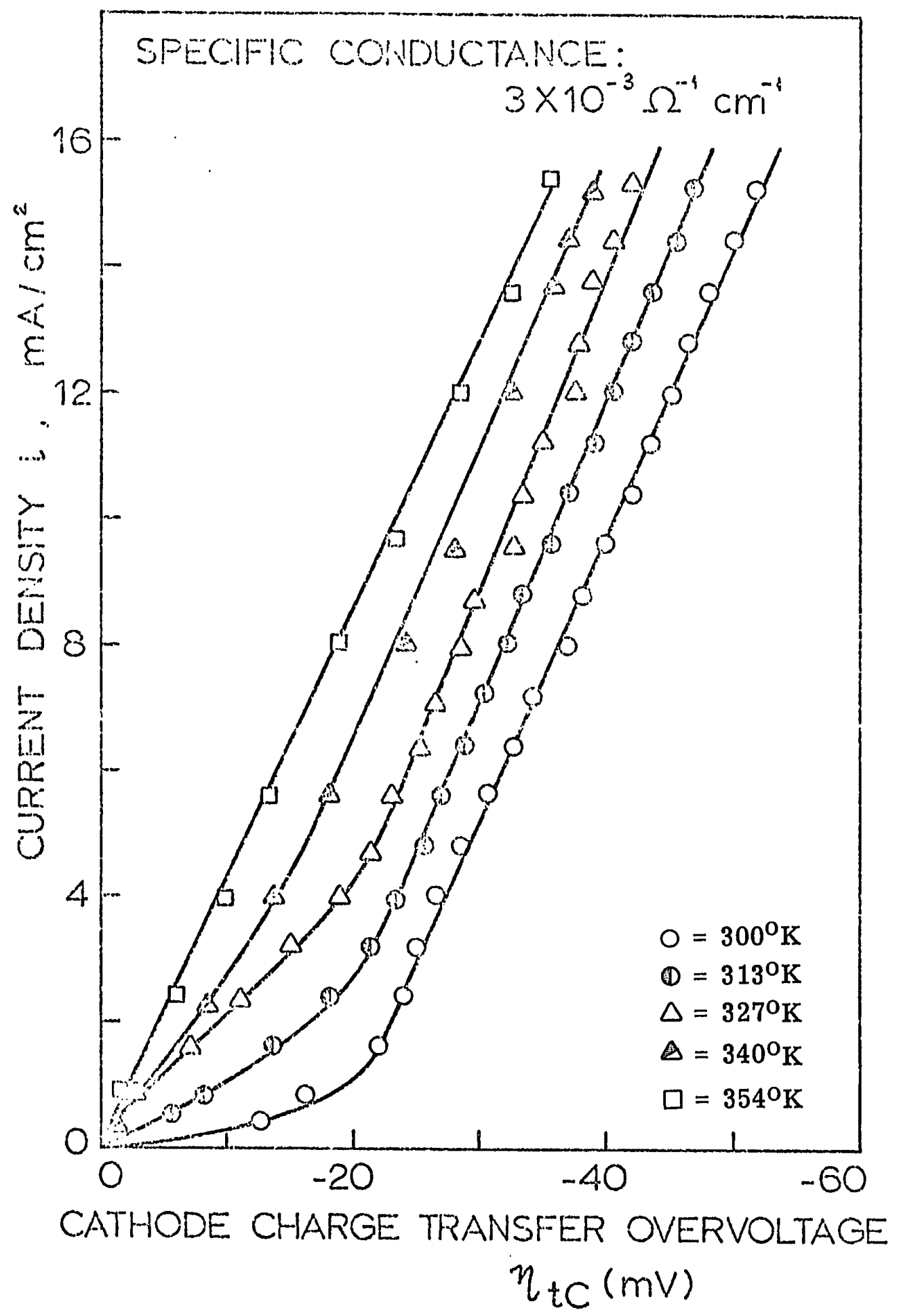

Figure 6-12. Plot of Cathode Charge Transfer Overvoltage as a Function of Cathode Current Density. 


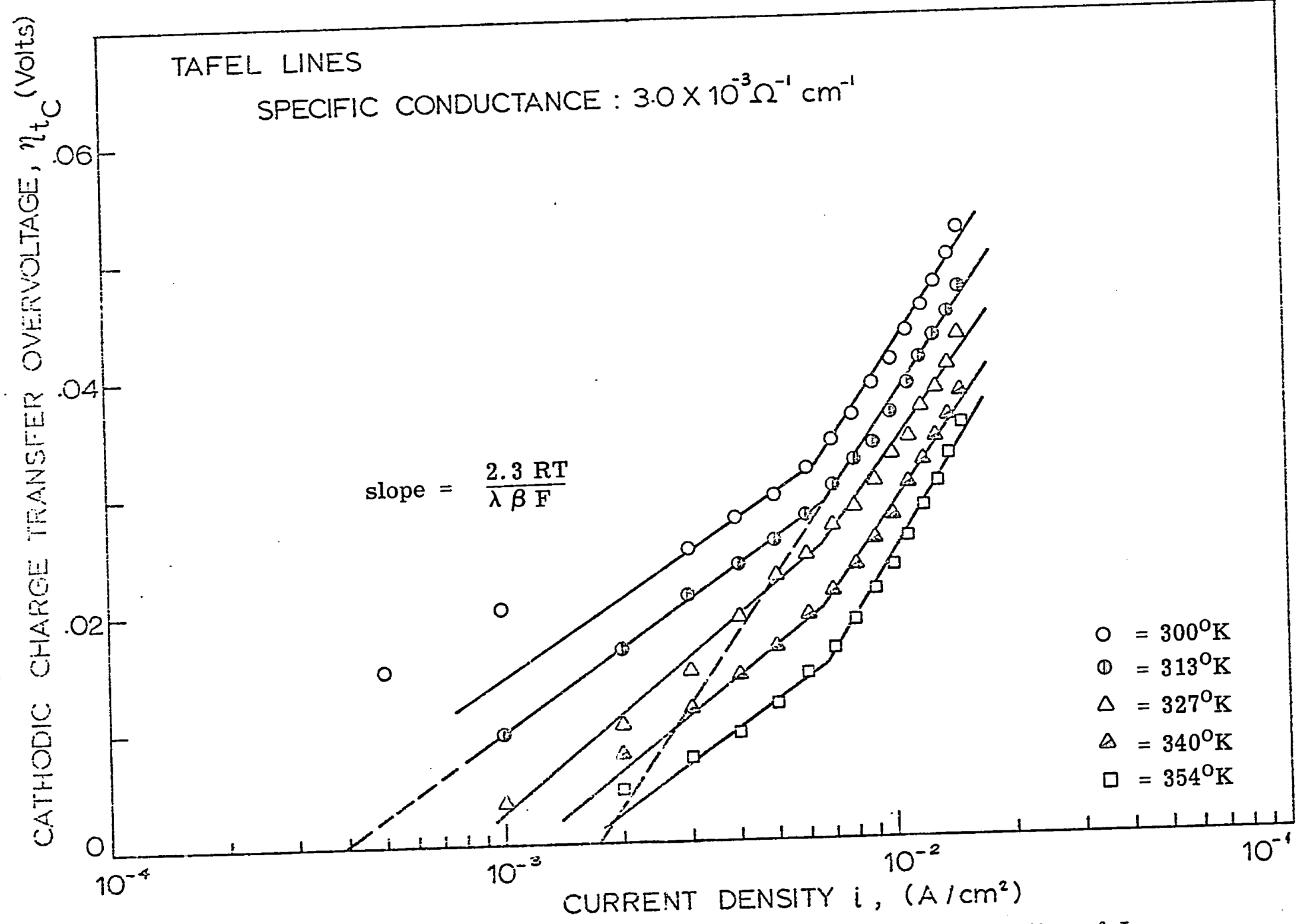

$\underset{\substack{\infty \\ 心}}{\vec{\infty}}$

Figure 6-13. Tafel Plot, Cathode Charge Transfer Overvoltage as a Function of Log Cathode Current Density. 


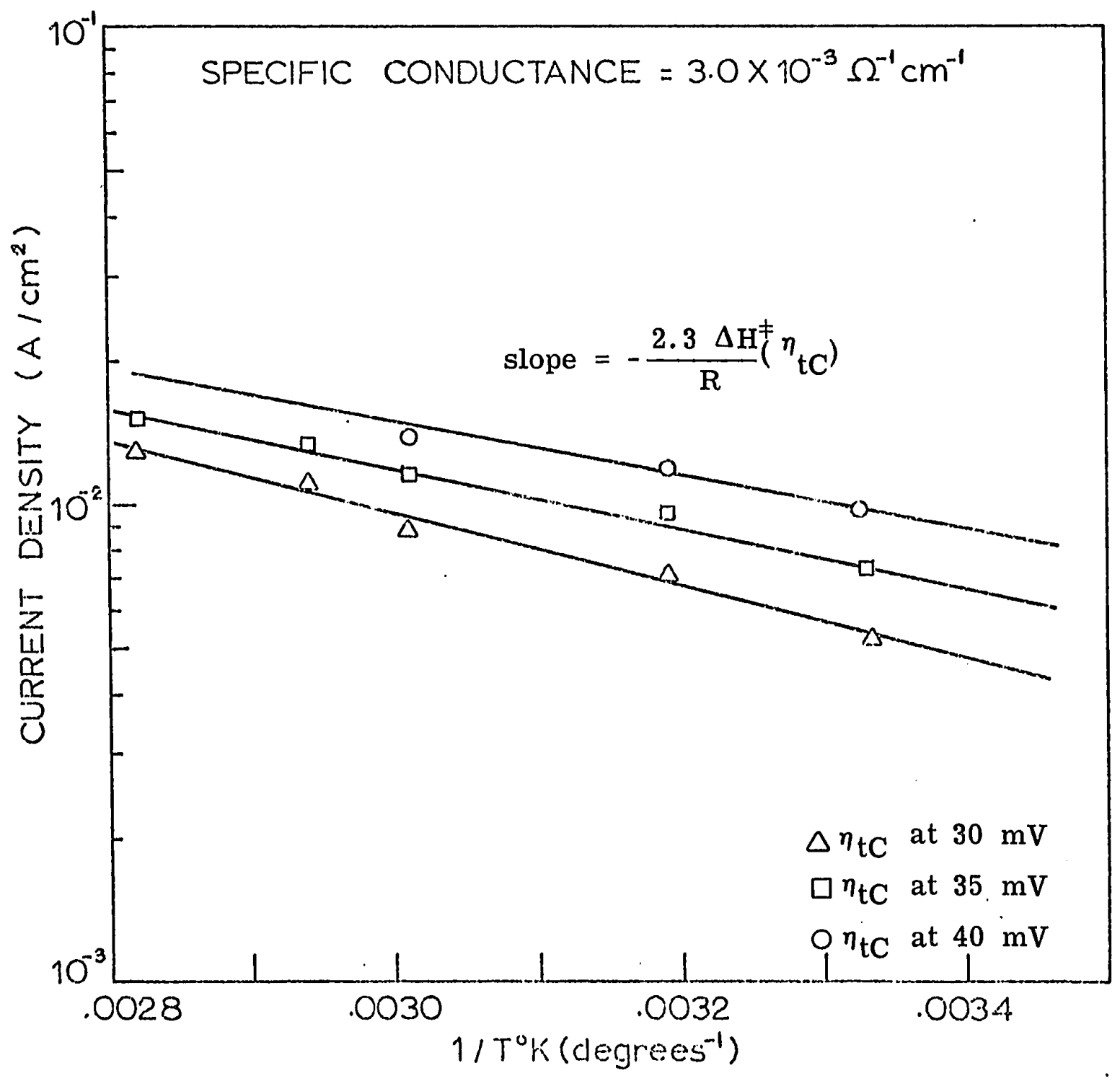

Figure 6-14. Arrhenius Plot for the Calculation of Heat of Activation $\left(\Delta \mathrm{H}^{\ddagger}\left(\eta_{\mathrm{tC}}\right)\right.$ 


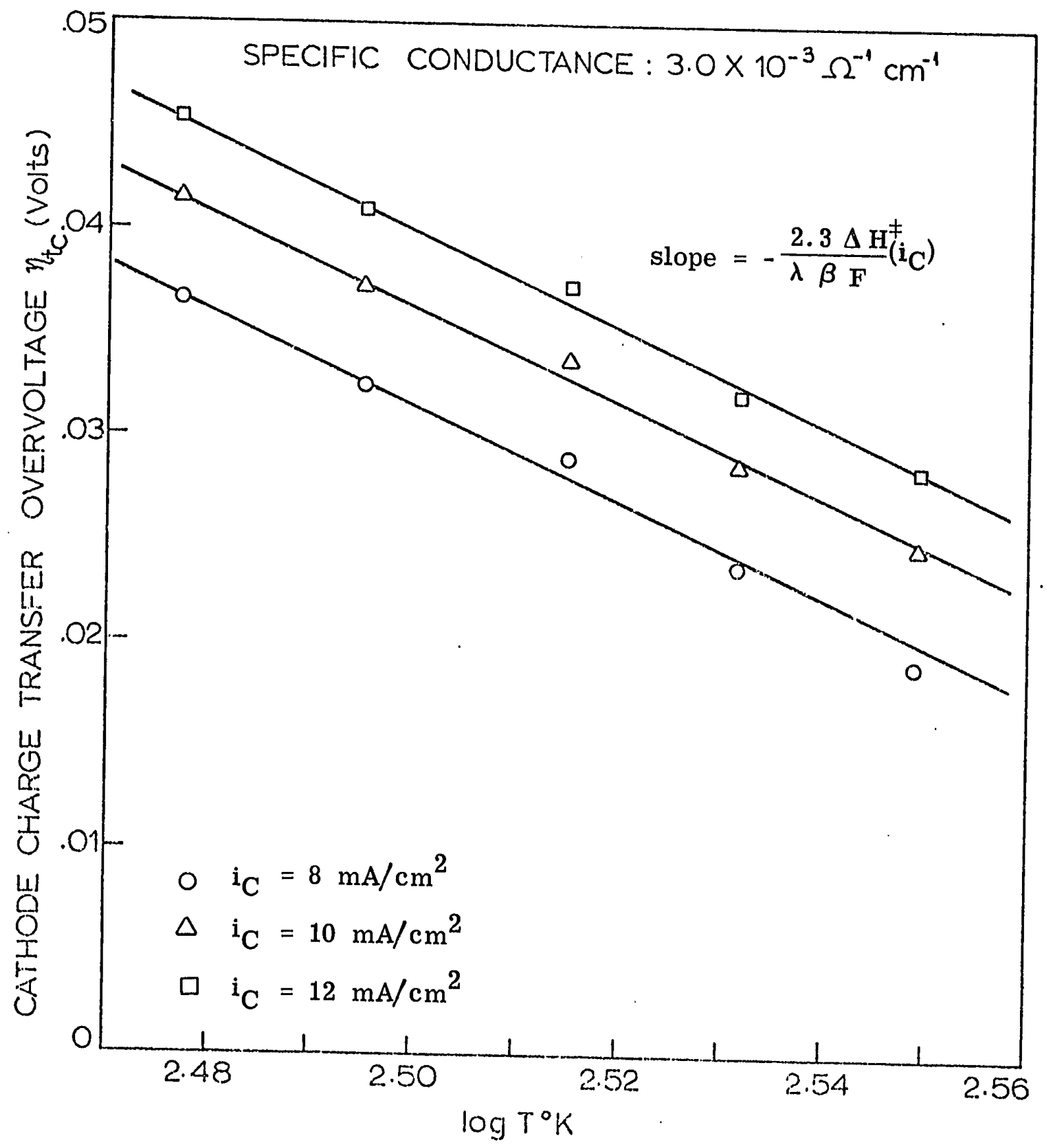

Figure 6-15. Heat of Activation $\left(\Delta \mathrm{H}_{\mathrm{i}_{\mathrm{C}}}^{\ddagger}\right)$ Calculation, $\eta_{\mathrm{tC}}$ as a Function of $\log \mathrm{T}^{\mathrm{O}} \mathrm{K}$. 
Table 6-6

Heats of Activation, Ethylbenzene-Toluene 1:1, $\underline{50 \% \mathrm{AlBr}_{3}} 3$ System (Specific Conductance $3.0 \times 10^{-3} \Omega^{-1} \mathrm{~cm}^{-1}$

$\Delta \mathrm{H}^{\ddagger}$, heat of activation at constant cathode overvoltage

\begin{tabular}{l} 
Overvoltage $\eta *$ \\
$\begin{array}{l}\text { tC } \\
(\mathrm{mV})\end{array}$ \\
\hline 30 \\
35 \\
40
\end{tabular}

$$
\begin{gathered}
\Delta \mathrm{H}^{\ddagger}\left(\eta_{\mathrm{tC}}^{*}\right) \\
\text { Kcals } / \text { moles }
\end{gathered}
$$

$\Delta \mathrm{H}^{\ddagger}$, heat of activation at constant current density

\begin{tabular}{cc}
$\begin{array}{c}\text { Current density } \\
\mathrm{mA} / \mathrm{cm}^{2}\end{array}$ & $\begin{array}{c}\Delta \mathrm{H}_{\left(\mathrm{i}_{\mathrm{C}}\right)}^{\neq} \\
\text {Kcals } / \text { moles }\end{array}$ \\
\hline 8 & 3.4 \\
10 & 3.4 \\
12 & 3.3
\end{tabular}

Observations: Tables 6-5, 6-6, Figures 6-12, 6-13, 6-14, 6-15.

Overvoltage values were not too reproducible at temperatures above $330^{\circ} \mathrm{K}$, the reason probably being, as in the previous case, an increased dissolving action at high temperature.

Polarization values for this electrolyte were higher than values obtained for the previous electrolyte $\left(\mathrm{K}_{25}=4.0 \times 10^{-3} \Omega^{-1} \mathrm{~cm}^{-1}\right)$, indicating that a decrease in specific conductance of the electrolyte causes an increase in polarization values. This point will be considered further in the Discussion Section. However, the Tafel lines and the heat of activation curves were similar to those described for the previous electrolyte. 
E. Cathodic Polarization - Organic Electrolyte, Specific Conductance $: 2.0 \times 10^{-3} \Omega^{-1} \mathrm{~cm}^{-1}$.

Electrolyte: Ethylbenzene-toluene 1:1 50 wt. $\% \mathrm{AlBr}_{3}$. Anode: Aluminum (1S) $99.8+\%$ minimum Al.

Cathode: Platinum disc, $.5 \mathrm{~mm}$ thick $2.5 \mathrm{~cm}^{2}$ surface area. Operating conditions: Standard.

Measurements: As in Section 6-16 (C) above.

Calculations: As in Section 6-16 (C) above.

Results:
a) Measurements and $\eta^{*}$ tC
Table 6-7.
b) Plot of $\eta_{\text {tC }}^{*}$ vs. $i_{C}$
Figure 6-16.
c) Plot of $i_{\mathrm{tC}}^{*}$ vs. $\log \mathrm{i}_{\mathrm{C}}$
Figure 6-17.
d) Plot of $i_{C}$ (constant $\eta_{\text {tC }}^{*}$ ) vs. $1 / \mathrm{T}^{0} \mathrm{~K}$
Figure 6-18.
e) Plot of $\eta_{\text {tC }}^{*}$ vs. $\log \mathrm{T}^{0} \mathrm{~K}$
Figure 6-19.

The value of heat of activation for the cathodic process as calculated from Figure 6-18 and Figure 6-19 are given in the table below (Table 6-8). 
TABLE 6-7

Cathodic Polarization Measurements, Organic System, Specific Conductance $2.0 \times 10^{-3} \Omega^{-1} \mathrm{~cm}^{-1}$

Electrolyte: Ethylbenzene-Toluene 1:1, 50 wt. $\% \mathrm{AlBr}_{3}$ Anode: $\mathrm{Al}$ (1S)

Cathode: $2.5 \mathrm{~cm}^{2}$ Platinum, Aluminum plated

Reference Electrode: Aluminum (1S)

Operating Conditions: Standard

\begin{tabular}{|c|c|c|c|c|c|c|c|}
\hline \multirow{2}{*}{$\begin{array}{c}\text { Current } \\
\mathrm{mA} \\
\end{array}$} & \multirow{2}{*}{$\begin{array}{l}\text { Current } \\
\text { Density } \\
\mathrm{mA} / \mathrm{cm}^{2} \\
\end{array}$} & & \multicolumn{3}{|c|}{$\mathrm{m}$ V } & & \multirow[b]{2}{*}{$354^{\circ} \mathrm{K}$} \\
\hline & & & $300^{\circ} \mathrm{K}$ & $313^{\circ} \mathrm{K}$ & $327^{\circ} \mathrm{K}$ & & \\
\hline 1.0 & 0.4 & $\begin{array}{l}\text { Measured E } \\
\text { Static E } \\
\text { Net E }\end{array}$ & $\begin{array}{r}-8.3 \\
+5.3 \\
-13.6\end{array}$ & $\begin{array}{l}-8.4 \\
-2.4 \\
-6.0\end{array}$ & $\begin{array}{r}+0.6 \\
+2.6 \\
-2.0\end{array}$ & $\begin{array}{l}+1.0 \\
+3.0 \\
-2.0\end{array}$ & $\begin{array}{r}+4.3 \\
+4.9 \\
-.6\end{array}$ \\
\hline 2.0 & 0.8 & $\begin{array}{l}\text { Measured E } \\
\text { Static E } \\
\text { Net E }\end{array}$ & $\begin{array}{r}-11.4 \\
+5.3 \\
-16.7\end{array}$ & $\begin{array}{r}-12.0 \\
-2.5 \\
-9.5\end{array}$ & $\begin{array}{l}-1.0 \\
+2.6 \\
-3.6\end{array}$ & $\begin{array}{r}-1.0 \\
+3.0 \\
-4.0\end{array}$ & $\begin{array}{r}+4.9 \\
+6.3 \\
-1.4\end{array}$ \\
\hline 3.0 & 1.2 & $\begin{array}{l}\text { Measured E } \\
\text { Static E } \\
\text { Net E }\end{array}$ & $\begin{array}{r}-13.5 \\
+5.3 \\
-18.8\end{array}$ & $\begin{array}{r}-15.9 \\
-2.4 \\
-13.5\end{array}$ & & & \\
\hline 4.0 & 1.6 & $\begin{array}{l}\text { Measured E } \\
\text { Static E } \\
\text { Net E }\end{array}$ & $\begin{array}{r}-16.4 \\
+5.3 \\
-21.7\end{array}$ & $\begin{array}{r}-18.9 \\
-2.4 \\
-16.5\end{array}$ & $\begin{array}{r}-9.1 \\
+2.6 \\
-11.7\end{array}$ & $\begin{array}{r}-2.8 \\
+3.2 \\
-6.0\end{array}$ & $\begin{array}{l}+3.9 \\
+6.3 \\
-2.4\end{array}$ \\
\hline 6.0 & 2.4 & $\begin{array}{l}\text { Measured E } \\
\text { Static E } \\
\text { Net E }\end{array}$ & $\begin{array}{r}-21.0 \\
+2.5 \\
-23.5\end{array}$ & $\begin{array}{r}22.1 \\
2.6 \\
19.5\end{array}$ & $\begin{array}{r}-12.9 \\
+3.0 \\
-15.9\end{array}$ & & $\begin{array}{r}+2.9 \\
+6.9 \\
-4.0\end{array}$ \\
\hline 8.0 & 3.2 & $\begin{array}{l}\text { Measured E } \\
\text { Static E } \\
\text { Net E }\end{array}$ & $\begin{array}{r}-24.3 \\
+2.5 \\
-26.8\end{array}$ & $\begin{array}{r}24.4 \\
2.4 \\
-22.0\end{array}$ & $\begin{array}{r}-14.4 \\
+4.0 \\
-18.4\end{array}$ & $\begin{array}{r}-8.0 \\
+3.5 \\
-11.5\end{array}$ & $\begin{array}{r}+2.8 \\
+7.9 \\
-5.1\end{array}$ \\
\hline 10.0 & 4.0 & $\begin{array}{l}\text { Measured E } \\
\text { Static E } \\
\text { Net E }\end{array}$ & $\begin{array}{r}-26.1 \\
+2.0 \\
-28.1\end{array}$ & $\begin{array}{r}-26.4 \\
-2.4 \\
-24.0\end{array}$ & $\begin{array}{r}-16.5 \\
+3.0 \\
-19.5\end{array}$ & $\begin{array}{r}-9.4 \\
+3.6 \\
-13.0\end{array}$ & $\begin{array}{r}+0.7 \\
+8.2 \\
-7.5\end{array}$ \\
\hline 12.0 & 4.8 & $\begin{array}{l}\text { Measured E } \\
\text { Static E } \\
\text { Net } \mathbf{E}\end{array}$ & $\begin{array}{r}-28.4 \\
+2.0 \\
-30.4\end{array}$ & $\begin{array}{r}-28.6 \\
-2.6 \\
-26.0\end{array}$ & $\begin{array}{r}-17.7 \\
+2.8 \\
-20.5\end{array}$ & & $\begin{array}{r}+0.5 \\
+8.0 \\
-7.5\end{array}$ \\
\hline 14.0 & 5.6 & $\begin{array}{l}\text { Measured E } \\
\text { Static E } \\
\text { Net E }\end{array}$ & $\begin{array}{r}-32.2 \\
0.0 \\
-32.2\end{array}$ & $\begin{array}{r}-30.4 \\
-2.4 \\
-28.0\end{array}$ & $\begin{array}{r}-19.5 \\
+2.8 \\
-22.3\end{array}$ & $\begin{array}{r}-13.0 \\
+3.0 \\
-16.0\end{array}$ & $\begin{array}{r}-2.3 \\
+8.3 \\
-10.6\end{array}$ \\
\hline
\end{tabular}


TABLE 6-7 (Cont'd)

\begin{tabular}{|c|c|c|c|c|c|c|c|}
\hline \multirow{2}{*}{$\begin{array}{c}\text { Current } \\
\mathrm{mA} \\
\end{array}$} & \multirow{2}{*}{$\begin{array}{l}\text { Current } \\
\text { Density } \\
\underline{\mathrm{mA} / \mathrm{cm}^{2}} \\
\end{array}$} & & \multicolumn{3}{|c|}{$\begin{array}{c}\mathrm{E}_{(\mathrm{C}-\mathrm{Rf} 3)} \\
\mathrm{mV} \\
\end{array}$} & \multirow[b]{2}{*}{$340^{\circ} \mathrm{K}$} & \multirow[b]{2}{*}{$354^{\circ} \mathrm{K}$} \\
\hline & & & $300^{\circ} \mathrm{K}$ & $313^{\circ} \mathrm{K}$ & $327^{\circ} \mathrm{K}$ & & \\
\hline 16.0 & 6.4 & $\begin{array}{l}\text { Measured E } \\
\text { Static E } \\
\text { Net E }\end{array}$ & $\begin{array}{r}-34.0 \\
+0.0 \\
-34.0\end{array}$ & $\begin{array}{r}-31.0 \\
-2.5 \\
-28.5\end{array}$ & $\begin{array}{r}-21.3 \\
+2.7 \\
-24.0\end{array}$ & $\begin{array}{r}-14.6 \\
+3.4 \\
-18.0\end{array}$ & $\begin{array}{r}-4.8 \\
+8.5 \\
-13.3\end{array}$ \\
\hline 18.0 & 7.2 & $\begin{array}{l}\text { Measured E } \\
\text { Static } \mathrm{E} \\
\text { Net } \mathrm{E}\end{array}$ & $\begin{array}{r}-36.3 \\
-0.0 \\
-36.3\end{array}$ & $\begin{array}{r}-34.4 \\
-2.4 \\
-32.0\end{array}$ & $\begin{array}{r}-22.5 \\
+3.2 \\
-25.7\end{array}$ & & \\
\hline 20.0 & 8.0 & $\begin{array}{l}\text { Measured E } \\
\text { Static E } \\
\text { Net E }\end{array}$ & $\begin{array}{r}-39.0 \\
0.0 \\
-39.0\end{array}$ & $\begin{array}{r}-36.0 \\
-2.5 \\
-33.5\end{array}$ & $\begin{array}{l}-24.6 \\
+3.4 \\
-28.0\end{array}$ & $\begin{array}{r}-17.9 \\
+3.6 \\
-21.5\end{array}$ & $\begin{array}{r}-8.8 \\
+8.0 \\
-16.8\end{array}$ \\
\hline 22.0 & 8.8 & $\begin{array}{l}\text { Measured E } \\
\text { Static E } \\
\text { Net E }\end{array}$ & $\begin{array}{r}-40.5 \\
0.0 \\
-40.5\end{array}$ & $\begin{array}{l}-38.1 \\
-2.6 \\
-35.5\end{array}$ & & & \\
\hline 24.0 & 9.6 & $\begin{array}{l}\text { Measured E } \\
\text { Static E } \\
\text { Net E }\end{array}$ & $\begin{array}{r}-42.5 \\
0.0 \\
-42.5\end{array}$ & $\begin{array}{r}-38.6 \\
-2.6 \\
-36.0\end{array}$ & $\begin{array}{r}-26.2 \\
+3.4 \\
-29.6\end{array}$ & $\begin{array}{r}-22.5 \\
+3.5 \\
-25.0\end{array}$ & $\begin{array}{r}-13.0 \\
+8.0 \\
-21.0\end{array}$ \\
\hline 26.0 & 10.4 & $\begin{array}{l}\text { Measured E } \\
\text { Static E } \\
\text { Net E }\end{array}$ & $\begin{array}{r}-44.0 \\
-0.0 \\
-44.0\end{array}$ & $\begin{array}{r}-39.9 \\
-2.4 \\
-37.5\end{array}$ & $\begin{array}{r}-27.7 \\
+3.4 \\
-31.1\end{array}$ & & \\
\hline 28.0 & 11.2 & $\begin{array}{l}\text { Measured E } \\
\text { Static E } \\
\text { Net E }\end{array}$ & $\begin{array}{r}-46.0 \\
-0.0 \\
-46.0\end{array}$ & $\begin{array}{r}-41.6 \\
-2.6 \\
-39.0\end{array}$ & $\begin{array}{r}-30.0 \\
+3.0 \\
-33.0\end{array}$ & $\begin{array}{r}-24.6 \\
+3.6 \\
-28.2\end{array}$ & $\begin{array}{r}-16.5 \\
+8.0 \\
-24.5\end{array}$ \\
\hline 30.0 & 12.0 & $\begin{array}{l}\text { Measured E } \\
\text { Static E } \\
\text { Net E }\end{array}$ & $\begin{array}{r}-48.0 \\
-0.0 \\
-48.0\end{array}$ & $\begin{array}{r}-43.5 \\
-2.5 \\
-41.0\end{array}$ & $\begin{array}{r}-32.3 \\
+3.7 \\
-36.0\end{array}$ & & \\
\hline 32.0 & 12.8 & $\begin{array}{l}\text { Measured E } \\
\text { Static E } \\
\text { Net E }\end{array}$ & $\begin{array}{r}-50.0 \\
-0.0 \\
-50.0\end{array}$ & $\begin{array}{l}-46.1 \\
-2.6 \\
-43.5\end{array}$ & $\begin{array}{r}-34.0 \\
+3.5 \\
-37.5\end{array}$ & $\begin{array}{r}-28.3 \\
+3.5 \\
-32.0\end{array}$ & $\begin{array}{r}-20.0 \\
+8.5 \\
-28.5\end{array}$ \\
\hline 34.0 & 13.6 & $\begin{array}{l}\text { Measured E } \\
\text { Static E } \\
\text { Net E }\end{array}$ & $\begin{array}{r}-51.5 \\
0.0 \\
-51.5\end{array}$ & $\begin{array}{r}-45.0 \\
-0.0 \\
-45.0\end{array}$ & $\begin{array}{r}-35.0 \\
+3.5 \\
-38.5\end{array}$ & & \\
\hline 36.0 & 14.4 & $\begin{array}{l}\text { Measured E } \\
\text { Static E } \\
\text { Net E }\end{array}$ & $\begin{array}{r}-52.5 \\
0.0 \\
-52.5\end{array}$ & $\begin{array}{r}-48.0 \\
-1.0 \\
-47.0\end{array}$ & $\begin{array}{r}-35.0 \\
+3.5 \\
-38.5\end{array}$ & $\begin{array}{r}-32.0 \\
+3.5 \\
-35.5\end{array}$ & $\begin{array}{r}-23.0 \\
+8.5 \\
-31.5\end{array}$ \\
\hline 38.0 & 15.2 & $\begin{array}{l}\text { Measured E } \\
\text { Static E } \\
\text { Net E }\end{array}$ & $\begin{array}{r}-54.0 \\
-0.0 \\
-54.0\end{array}$ & $\begin{array}{r}-50.0 \\
-1.0 \\
-49.0\end{array}$ & $\begin{array}{r}-38.4 \\
+3.6 \\
-42.0\end{array}$ & $\begin{array}{r}-33.4 \\
+5.6 \\
-37.0\end{array}$ & $\begin{array}{r}-25.0 \\
+8.0 \\
-33.0\end{array}$ \\
\hline
\end{tabular}




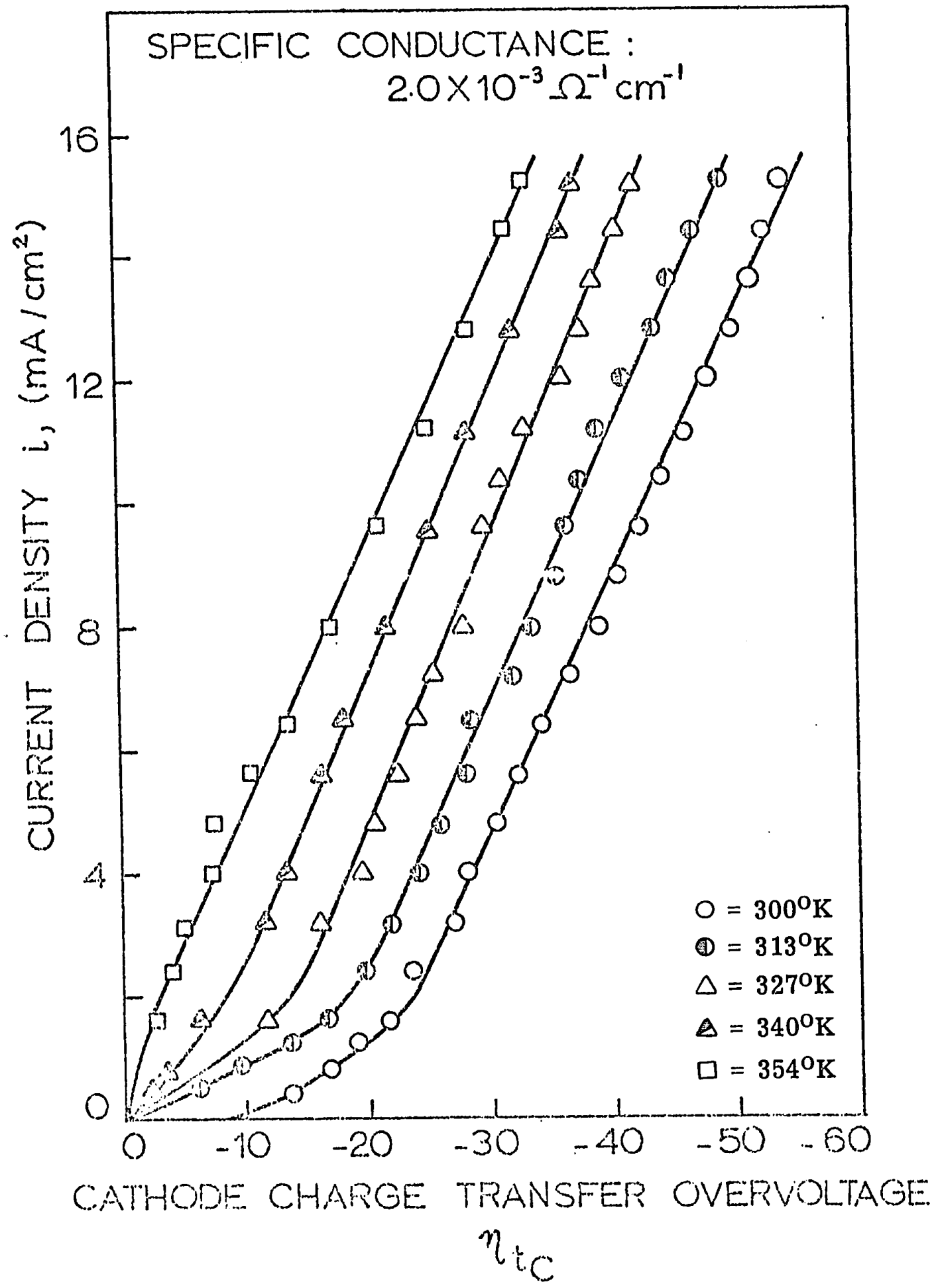

Figure 6-16. Plot of Cathode Charge Transfer Overvoltage as a Function of Cathode Current Density. 


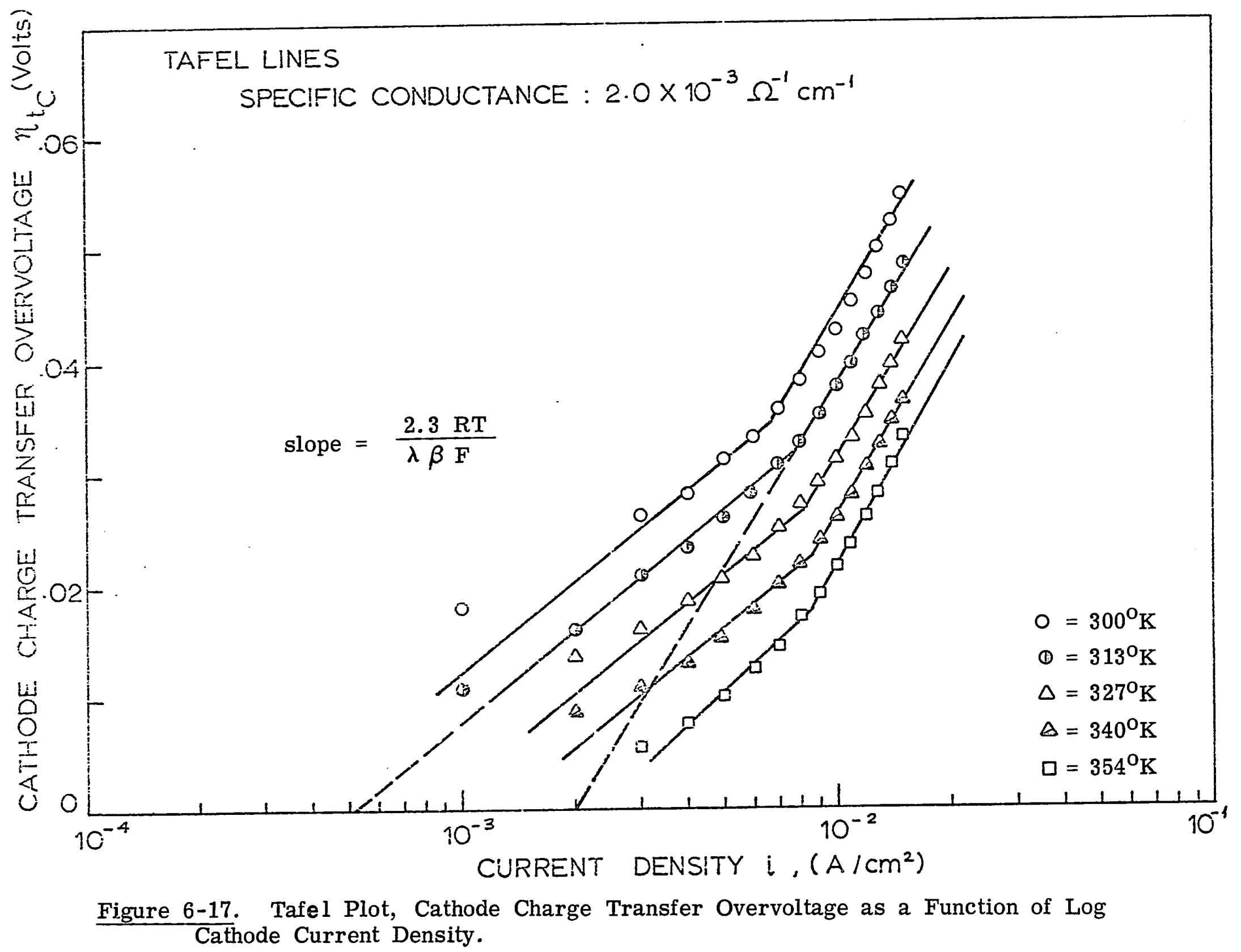

$\ddot{8}$ Cathode Current Density. 


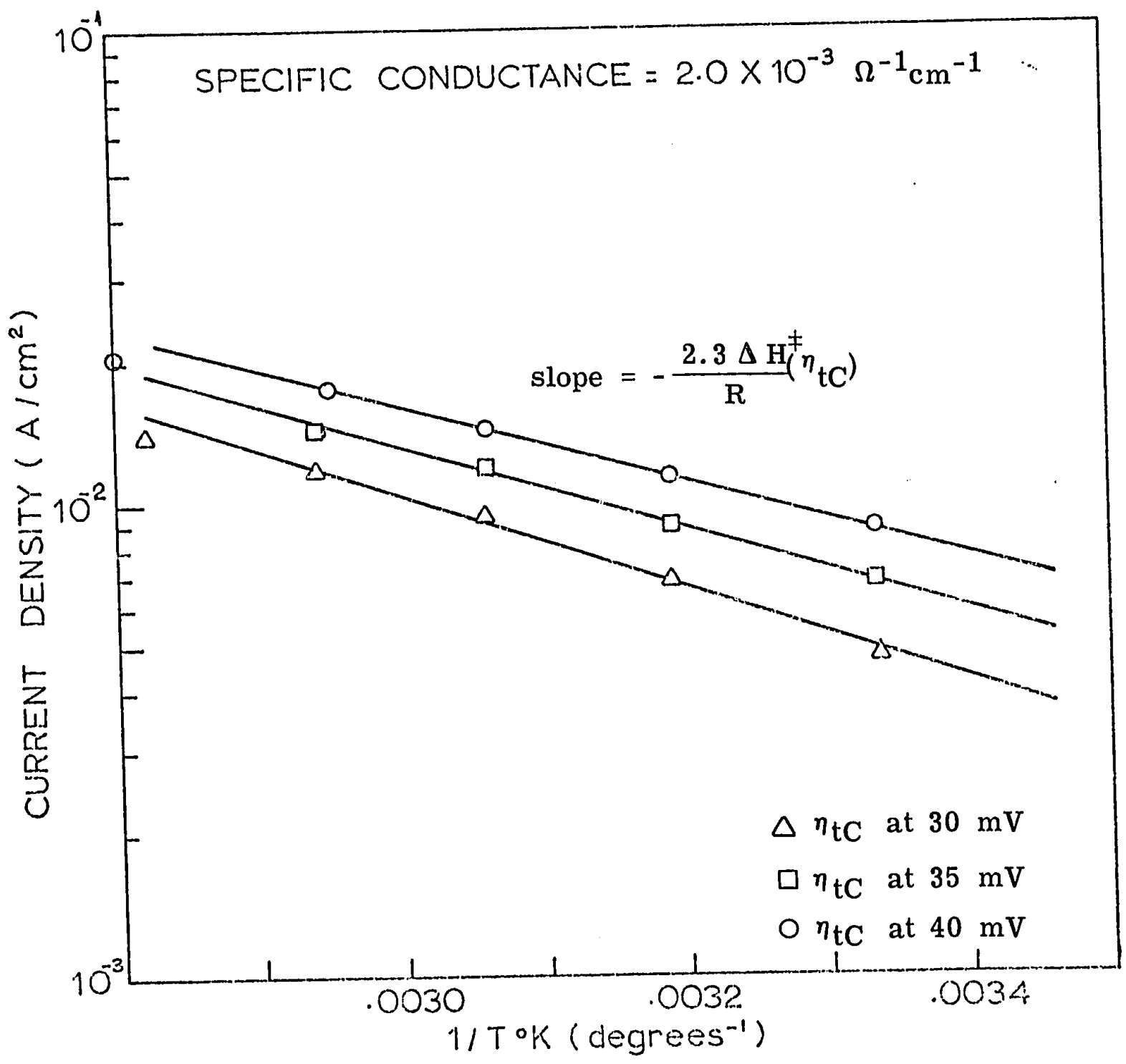

Figure 6-18. Arrhenius Plot for the Calculation of Heat of Activation $\left(\Delta \mathrm{H}^{\ddagger}\left(\eta_{\mathrm{tC}}\right)^{\circ}\right.$ 


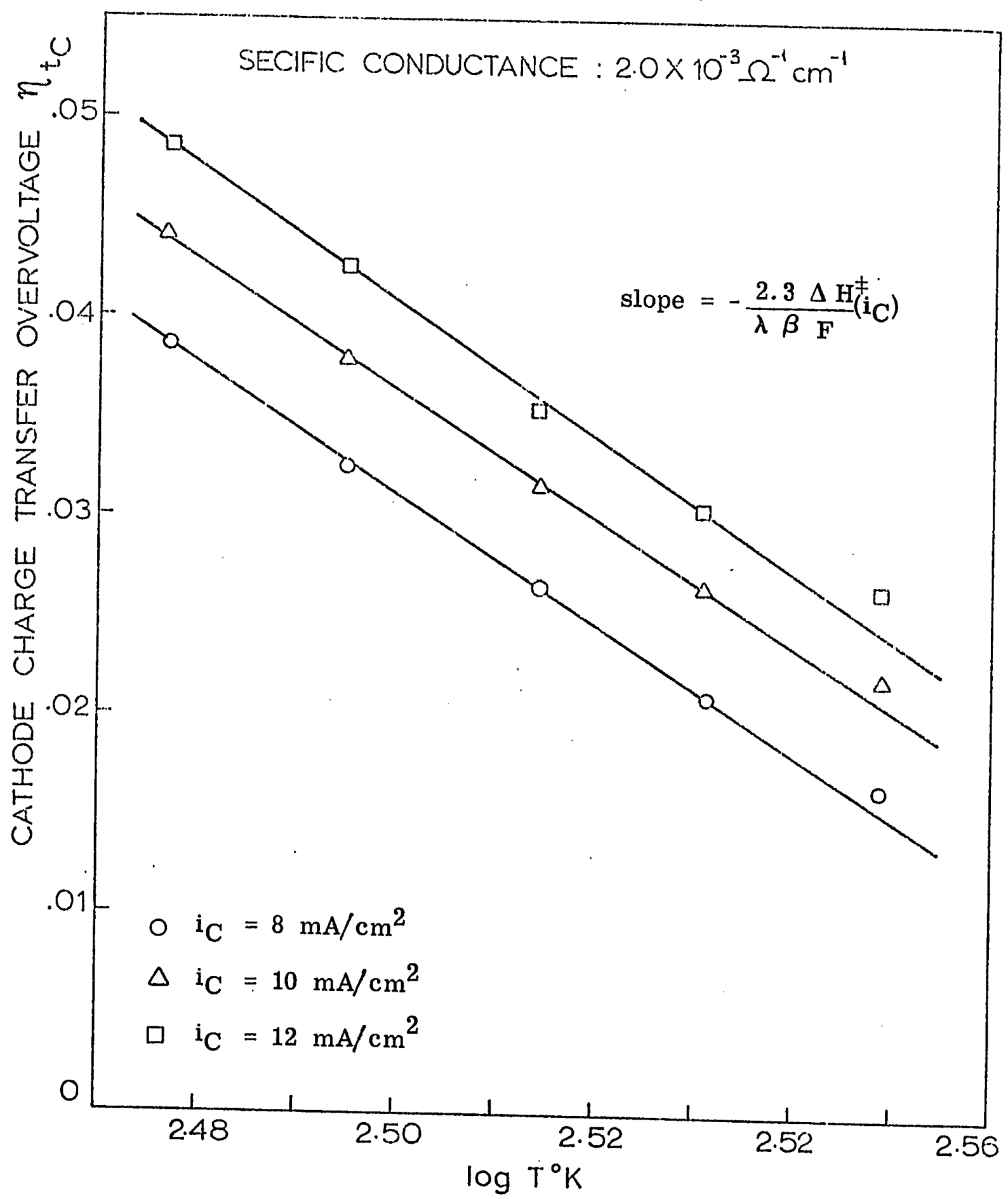

Figure 6-19. Heat of Activation $\left(\Delta \mathrm{H}_{\mathrm{i}_{\mathrm{C}}}^{\ddagger}\right)$ Calculation, $\eta_{\mathrm{tC}}$ as a Function of $\log \mathrm{T}^{\mathrm{O}} \mathrm{K}$. 
Table 6-8

Heats of Activation, Ethylbenzene-Toluene 1:1,

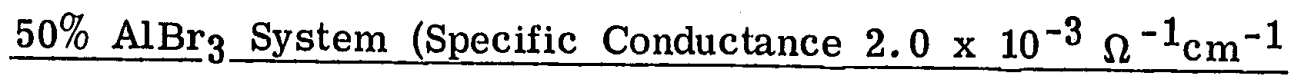

$\Delta \mathrm{H}^{\ddagger}$, heats of activation at constant cathode overvoltage

\begin{tabular}{cc} 
Overvoltage $\left({ }^{*}{ }_{\mathrm{tC}}\right)$ & $\begin{array}{c}\Delta \mathrm{H}^{\ddagger}\left(\eta^{*}{ }_{\mathrm{tC}}\right) \\
\mathrm{mV}\end{array}$ \\
\hline 30 & Kcals $/$ moles \\
35 & 4.5 \\
40 & 4.2 \\
& 3.5
\end{tabular}

$\Delta \mathrm{H}^{\ddagger}$, heats of activation at constant current density Current density

\begin{tabular}{c}
$\mathrm{mA}$ \\
\hline 8 \\
10 \\
12
\end{tabular}

Observations: Tables 6-7, 6-8, Figures 6-16, 6-17, 6-18, 6-19. As in the previous cases the overvoltages were not too reproducible at high temperature. However, instability was noticed here only at above $340^{\circ} \mathrm{K}$.

Polarization values for this electrolyte were higher than value obtained from the previous electrolytes, indicating again that a decrease in specific conductance of the electrolyte causes an increase in overvoltage. The Tafel line shape and the behaviour of heat of activation curves were similar to the two previous electrolytes. 
F. Cathodic Polarization - Organic Electrolyte, Specific Conductance: $1.0 \times 10^{-3} \Omega^{1} \mathrm{~cm}^{-1}$

Electrolyte: Ethylbenzene-Toluene 1:1, $50 \mathrm{wt} . \% \mathrm{AlBr}_{3}$

Anode: Aluminum (1S) $99.8+\%$ minimum Al

Cathode: Platinum disc, $.5 \mathrm{~mm}$ thick, $2.5 \mathrm{~cm}^{2}$ surface area

Operating Conditions: Standard

Measurements: Same as Section 6-16 (C) above except that the measurements were limited to one temperature only $\left(27^{\circ} \mathrm{C}\right)$.

Calculations: As in Section 6-16(C) above, except that no heat of activation was calculated.

Observations and Results: Table 6-9, Figure 6-20.

Only a limited number of measurements were made with this electrolyte. Due to the low specific conductance of the electrolyte, it was impossible to reach the $15 \mathrm{~mA} / \mathrm{cm}^{2}$ current density because the potentiostat maximum output of 20 volts was not sufficient to maintain the current density. A study of this electrolyte is not likely to be too important since it is not of practical use in plating aluminum. 
TABLE 6-9

Cathodic Polarization Measurements, Organic System, Specific Conductance $1.0 \times 10^{-3} \Omega^{-1} \mathrm{~cm}^{-1}$

Electrolyte: Ethylbenzene-Toluene 1:1, 50 wt. $\% \mathrm{AlBr}_{3}$

Anode: Al (IS)

Cathode: $2.5 \mathrm{~cm}^{2}$ Plat inum, Aluminum plated

Reference Electrode: Aluminum (1S)

Operating Conditions: Standard

\begin{tabular}{|c|c|c|c|}
\hline \multirow{2}{*}{$\begin{array}{c}\begin{array}{c}\text { Current } \\
\mathrm{mA}\end{array} \\
\end{array}$} & \multirow{2}{*}{$\begin{array}{l}\text { Current } \\
\text { Density } \\
\mathrm{mA} / \mathrm{cm}^{2} \\
\end{array}$} & & \multirow{2}{*}{$\frac{\begin{array}{c}\mathrm{E}(\mathrm{C}-\mathrm{Rf} 3) \\
\mathrm{m} \cdot \mathrm{V}\end{array}}{300^{\circ} \mathrm{KK}}$} \\
\hline & & & \\
\hline 1.0 & 0.4 & $\begin{array}{l}\text { Measured E } \\
\text { Static } \mathbf{E} \\
\text { Net } \mathbf{E}\end{array}$ & $\begin{array}{r}+2.0 \\
+7.9 \\
-5.9\end{array}$ \\
\hline 2.0 & 0.8 & $\begin{array}{l}\text { Measured E } \\
\text { Static E } \\
\text { Net E }\end{array}$ & $\begin{array}{r}-3.0 \\
+7.0 \\
-10.0\end{array}$ \\
\hline 3.0 & 1.2 & $\begin{array}{l}\text { Measured E } \\
\text { Static E } \\
\text { Net } E\end{array}$ & $\begin{array}{l}- \\
-\end{array}$ \\
\hline 4.0 & 1.6 & $\begin{array}{l}\text { Measured E } \\
\text { Static E } \\
\text { Net E }\end{array}$ & $\begin{array}{r}-11.0 \\
+8.0 \\
-19.0\end{array}$ \\
\hline 6.0 & 2.4 & $\begin{array}{l}\text { Measured E } \\
\text { Static E } \\
\text { Net E }\end{array}$ & $\begin{array}{r}-17.5 \\
+9.0 \\
-26.5\end{array}$ \\
\hline 8.0 & 3.2 & $\begin{array}{l}\text { Measured E } \\
\text { Static E } \\
\text { Net E }\end{array}$ & $\begin{array}{r}-21.4 \\
+10.6 \\
-32.0\end{array}$ \\
\hline 10.0 & 4.0 & $\begin{array}{l}\text { Measured E } \\
\text { Static E } \\
\text { Net E }\end{array}$ & $\begin{array}{r}-22.5 \\
+12.5 \\
-35.0\end{array}$ \\
\hline
\end{tabular}


TABLE 6-9 (Cont'd)

\begin{tabular}{|c|c|c|c|}
\hline \multirow{2}{*}{$\begin{array}{c}\text { Current } \\
\mathrm{mA} \\
\end{array}$} & \multirow{2}{*}{$\begin{array}{l}\text { Current } \\
\text { Density } \\
\text { mA } / \mathrm{cm}^{2} \\
\end{array}$} & \multirow[b]{3}{*}{$\begin{array}{l}\text { Measured E } \\
\text { Static E } \\
\text { Net E }\end{array}$} & \multirow{2}{*}{$\begin{array}{c}\begin{array}{c}\mathrm{E}_{(\mathrm{C}-\mathrm{Rf} 3)} \\
\mathrm{mV}\end{array} \\
300^{\circ} \mathrm{K}\end{array}$} \\
\hline & & & \\
\hline 12.0 & 4.8 & & $\begin{array}{l}-25.0 \\
+13.0 \\
-38.0\end{array}$ \\
\hline 14.0 & 5.6 & $\begin{array}{l}\text { Measured E } \\
\text { Static E } \\
\text { Net E }\end{array}$ & $\begin{array}{r}-29.0 \\
+12.0 \\
-41.0\end{array}$ \\
\hline 16.0 & 6.4 & $\begin{array}{l}\text { Measured } E \\
\text { Static E } \\
\text { Net E }\end{array}$ & $\begin{array}{r}-32.0 \\
+11.0 \\
-43.0\end{array}$ \\
\hline 18.0 & 7.2 & $\begin{array}{l}\text { Measured E } \\
\text { Static E } \\
\text { Net E }\end{array}$ & $\begin{array}{r}-36.0 \\
+9.0 \\
-45.0\end{array}$ \\
\hline 20.0 & 8.0 & $\begin{array}{l}\text { Measured E } \\
\text { Static E } \\
\text { Net E }\end{array}$ & $\begin{array}{r}-38.0 \\
+9.0 \\
-47.0\end{array}$ \\
\hline 22.0 & 8.0 & $\begin{array}{l}\text { Measured E } \\
\text { Static E } \\
\text { Net E }\end{array}$ & $\begin{array}{r}-39.5 \\
+9.0 \\
-48.5\end{array}$ \\
\hline 24.0 & 9.6 & $\begin{array}{l}\text { Measured E } \\
\text { Static E } \\
\text { Net E }\end{array}$ & $\begin{array}{r}-41.0 \\
+9.0 \\
-50.0\end{array}$ \\
\hline 26.0 & 10.4 & $\begin{array}{l}\text { Measured E } \\
\text { Static E } \\
\text { Net E }\end{array}$ & $\begin{array}{r}-42.5 \\
+9.0 \\
-51.5\end{array}$ \\
\hline
\end{tabular}




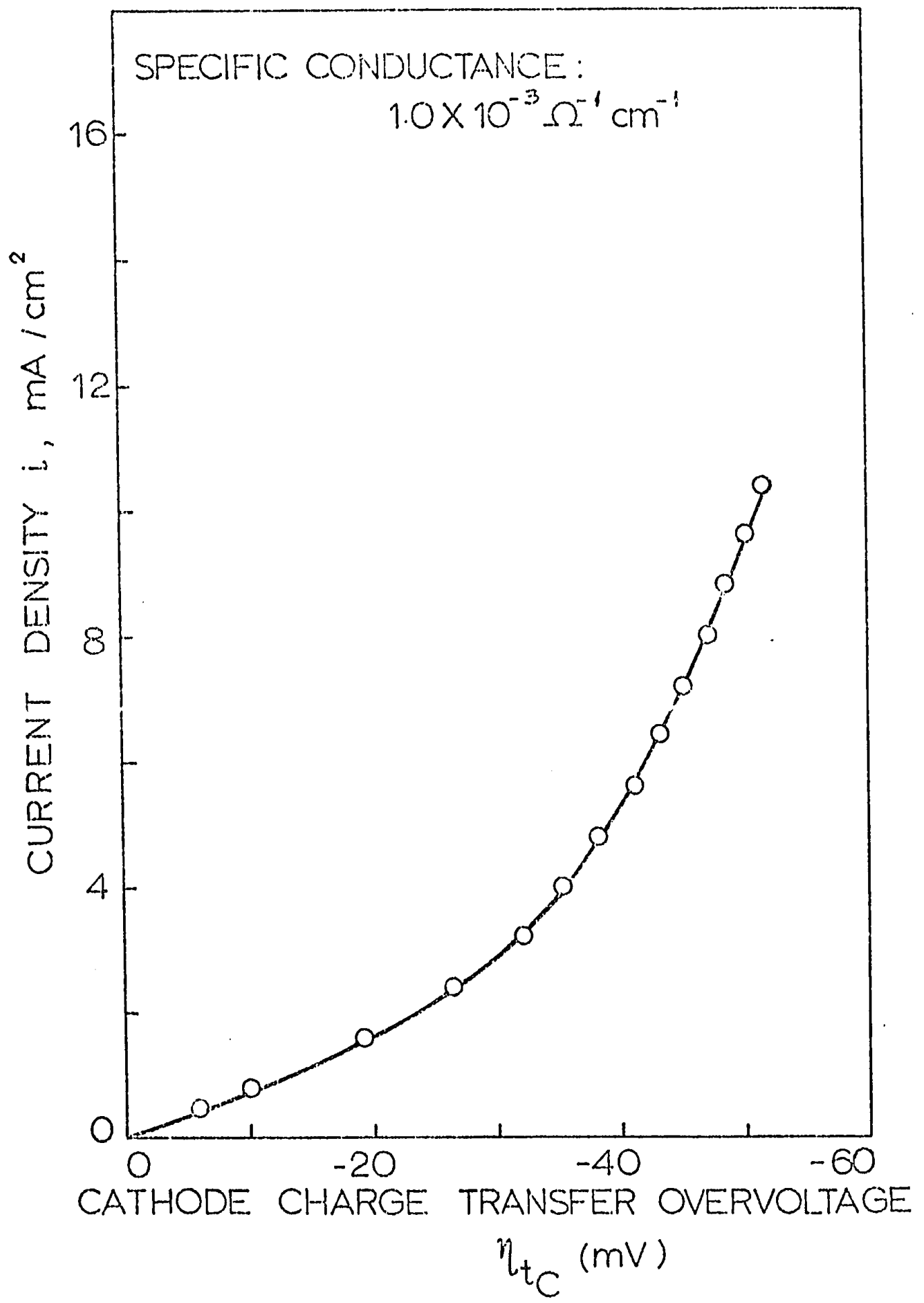

Figure 6-20. Current Density vs. Cathode Charge Transfer Overvoltage. 
The experimental aspect of the polarization study can be summarized as follows:

1. A cell for polarization studies of electrolytes based upon organic solvents was developed. The cell can be operated at constant temperature and in a closed system free from atmospheric moisture.

2. Simple metal vs. ion reference electrodes were used because little is known about stable aprotic reference electrodes.

3. In a study on an aqueous electrolyte it was demonstrated that the cell could be successfully used for the determination of IR drops, cathodic concentration polarization and cathodic chargetransfer overvoltages. It is feit that these measurements could be extended to include the determination of anodic overvoltages and anodic concentration polarization with organic electrolytes.

4. A study of cathodic overvoltages of the ethylbenzene-toluene 1:1 (by volume), 50 wt. $\% \mathrm{AlBr}_{3}$ electrolyte showed that chargetransfer overvoltages are of the order of $40 \mathrm{mV}$, at a current density of $10 \mathrm{~mA} / \mathrm{cm}^{2}$. The overvoltage increases with increasing current density and decreases with increasing specific conductance and increasing temperature of the electrolyte.

5. Straight Tafel lines were obtained up to $15 \mathrm{~mA} / \mathrm{cm}^{2}$ though two different slopes were obtained. The two slopes indicate a change in the rate controlling process at the cathode. 
6. Experiments were unsatisfactory above $70^{\circ} \mathrm{C}$ due to the slow re-dissolution of the plated aluminum.

7. Charge-transfer overvoltages of aluminum in organic electrolytes were found to be of the same order of magnitude as those usually found for metals in aqueous electrolytes.

8. Heats of activation were calculated from polarization curves obtained between 27 and $67^{\circ} \mathrm{C}$. The values are of the order of $4 \mathrm{Kcals} / \mathrm{mole}$, which are considerably less than the values for metals in aqueous solution. 


\section{PART THREE}

\section{DISCUSSION AND CONCLUSIONS}




\section{PART THREE - DISCUSSION AND CONCLUSIONS}

\subsection{DISCUSSION}

Research on aluminum deposition from organic electrolytes began at the turn of the century ${ }^{1}$ and since that time a considerable variety of electrolytes has been proposed. However, as the literature review in Part One of this thesis has shown, none has attained any large degree of industrial success. The reason for this lack of success appears to be cost, electrolyte inflammability and difficulty in the preparation of the electrolyte. Ether electrolytes, for example, produce excellent coatings, but the inflammability of ether and the difficulty encountered in preparing the plating bath have restricted the plating from ether electrolytes to very specialized space applications. 43,44

It was seen in the exploratory section of this thesis (Section 3) that a number of alkyl benzenes are suitable for use in electrolytes for electroplating aluminum. Ethylbenzene, diethylbenzene and mixtures of these two solvents with toluene are definitely the best of the experimental systems in terms of plating quality, cathodic efficiency and gas evolution.

7.1 Comparison of Cathode Efficiencies: Ethylbenzene-Toluene and Diethylbenzene-Toluene Systems Figure $7-1^{83}$ shows the average cathodic efficiencies of all tests performed with toluene, ethylbenzene and ethylbenzene-toluene 


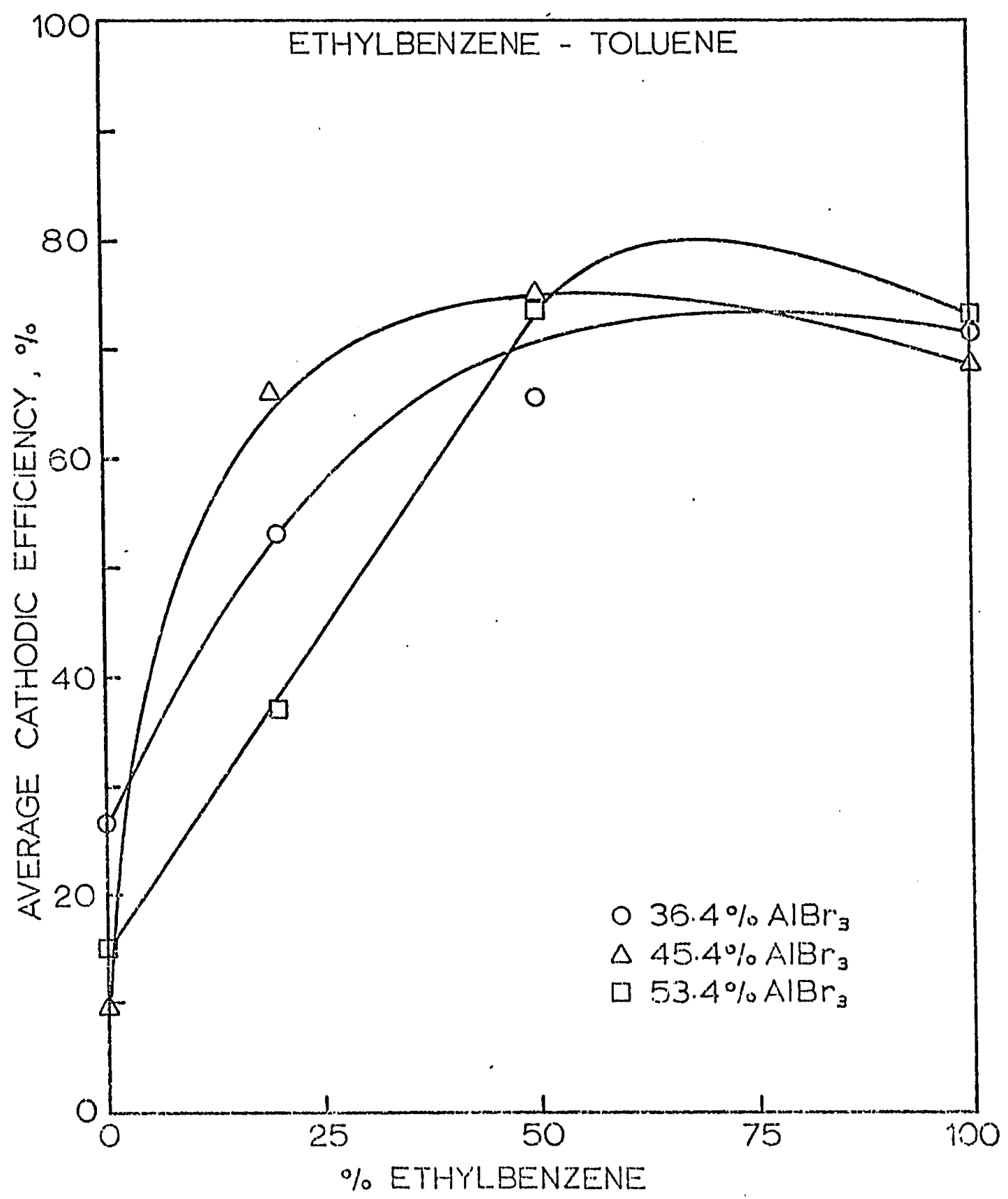

Figure 7-1. Average Cathodic Efficiency as a Function of percent Ethylbenzene in Ethylbenzene-Toluene Electrolytes at Several $\mathrm{AlBr}_{3}$ Concentrations. Average Cathodic Current Density: $10 \mathrm{~mA} / \mathrm{cm}^{2}$. 
mixtures at various $\mathrm{AlBr}_{3}$ concent rations. This graph clearly shows that ethylbenzene improves to a great extent the cathode efficiency obtained with the $\mathrm{AlBr}_{3}$-toluene electrolyte.

It can also be noticed on the same graph that the $50 \%$ ethylbenzenetoluene electrolyte gave the best performance. The ethylbenzene-toluene system gives, in fact, cathode efficiencies greater than $60 \%$ for solvent mixtures ranging from 25 to $100 \%$ ethylbenzene (with a solute concentration of $\left.45.4 \% \mathrm{AlBr}_{3}\right)$.

Figure 7-2 shows by comparison the average cathodic efficiency of all tests performed with toluene, diethylbenzene and diethylbenzenetoluene mixtures at various $\mathrm{AlBr}_{3}$ concentrations. As for the ethylbenzene system this graph shows that diethylbenzene greatly improves the cathode efficiency obtained with the $\mathrm{AlBr}_{3}$-toluene electrolyte. The diethylbenzene-toluene system $\left(53.4 \% \mathrm{AlBr}_{3}\right)$ exhibits cathodic efficiencies greater than $60 \%$ for solvent mixtures ranging from 15 to $95 \%$ diethylbenzene.

A comparison of Figures $7-1$ and 7-2 shows in general that the cathode efficiencies in the ethylbenzene-toluene system are higher than those in the diethylbenzene-toluene system for any given solvent ratio and solute concentration. Figure 7-2 shows, however, that the diethylbenzene-based electrolytes give very good maximum performance at $25 \%$ diethylbenzene $\left(53.4 \% \mathrm{AlBr}_{3}\right)$. This composition would be the most useful electrolyte of this system, and the performance is similar to the best results from the ethylbenzene-toluene system. 


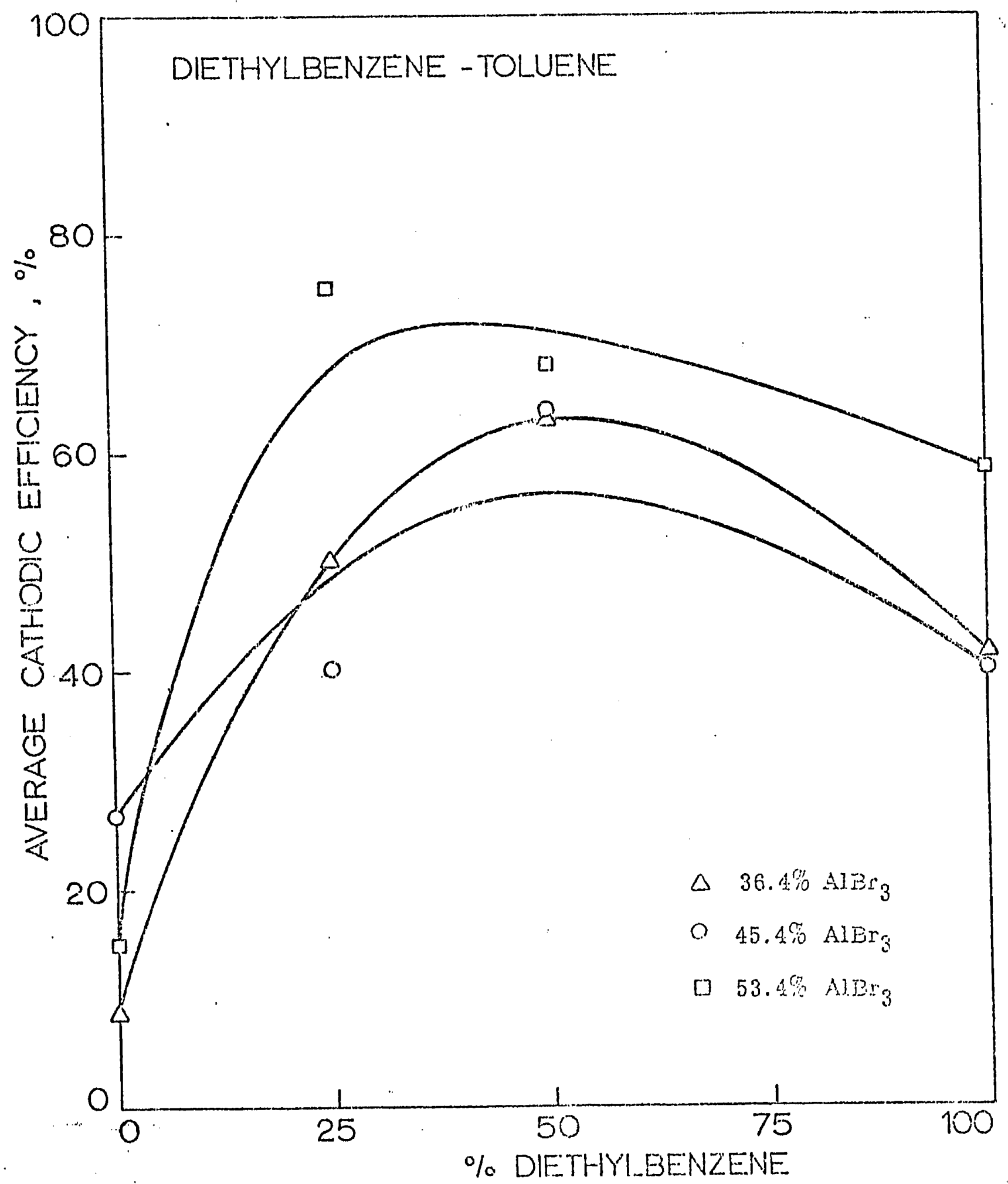

Figure 7-2. Average Cathodic Efficiency as a Function of percent Diethylbenzene in Diethylbenzene-'Toluene Electrolytes at Several
$\mathrm{AlBr}_{3}$ Concentrations. Average Cathodic Current Density: $10 \mathrm{~mA} / \mathrm{cmi}$ 
7.2 Overall Comparison of Ethylbenzene and Diethylbenzene Electrolytes Electrolytes based upon ethylbenzene and diethylbenzene (with toluene) are very similar in terms of ease of preparation, complete absence of gas evolution during electrolysis and quality of the aluminum coating. However, they do differ considerably in the properties of cathode efficiency, specific conductance and inflammability.

A. Conductivity of Ethylbenzene and Diethylbenzene Electrolytes

Figure 7-3 shows the specific conductance of benzene and four alkylbenzene electrolytes as a function of the molecular weight of the solvents. As can be expected, larger molecules (higher molecular weights) produce electrolytes with lower conductivity.

Furthermore, Figures 7-4 and 7-5 show the effects on the specific conductance of toluene electrolytes due to additions of ethylbenzene and diethylbenzene. In both cases there is a loss of electrolyte conductivity, however, the loss is much more pronounced in the case of diethylbenzene due to its large molecular structure. On the other hand, conductivity of both electrolytes can be raised by the addition of $\mathrm{HBr}$.

\section{B. Inflammability of the Electrolytes}

Table 7-1 shows the boiling point of several alkylbenzenes. As can be seen from this table, diethylbenzene has a higher boiling point $\left(183^{\circ} \mathrm{C}\right)$ than ethylbenzene $\left(136^{\circ} \mathrm{C}\right)$, hence a more elevated flash point. This is an advantage in the use of diethylbenzene in industrial baths since the danger of inflammability is greatly reduced. 


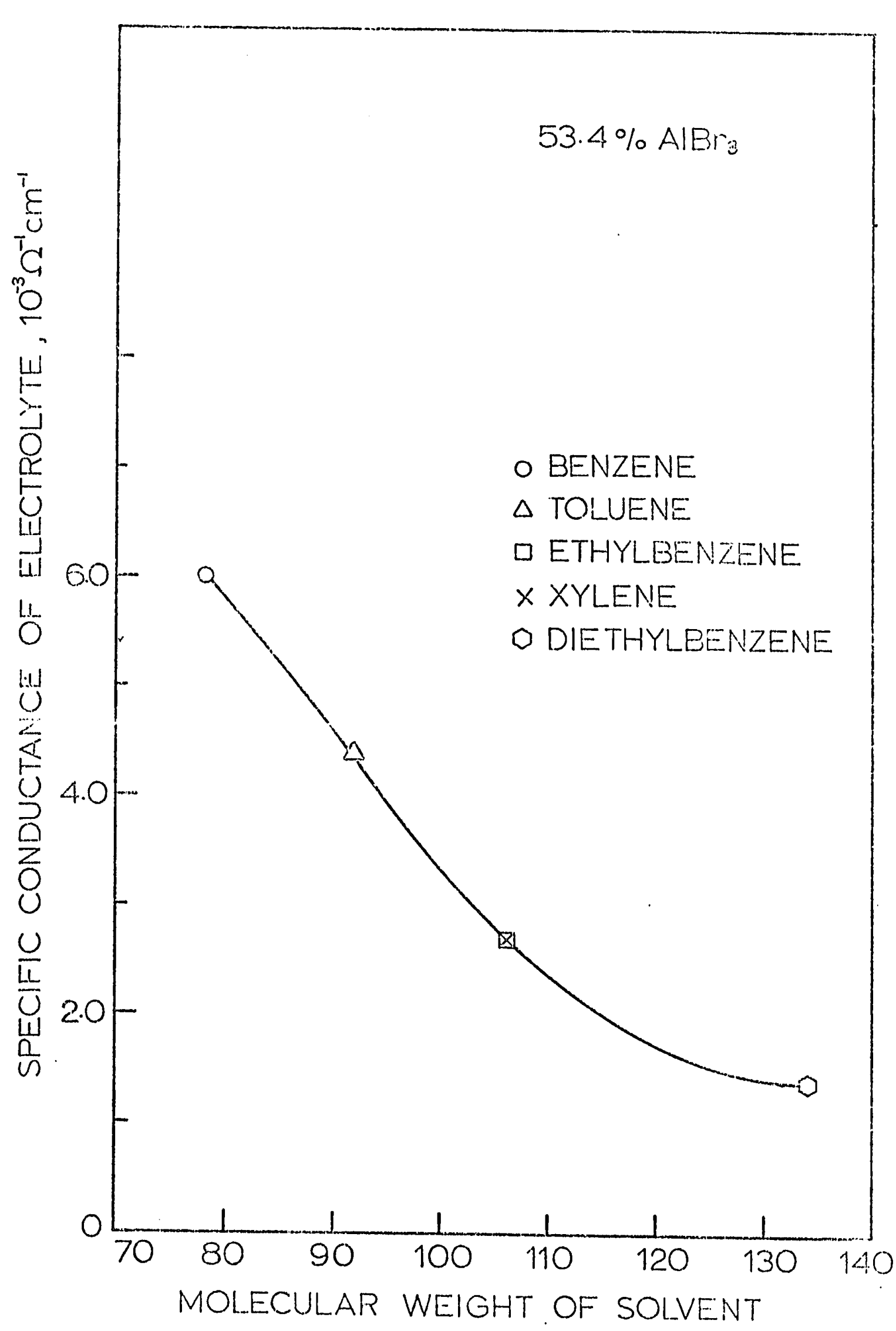

Figure 7-3. Graph Showing the Specific Conductance of Electrolytes Formed from Solvents of Various Molecular Weights. 


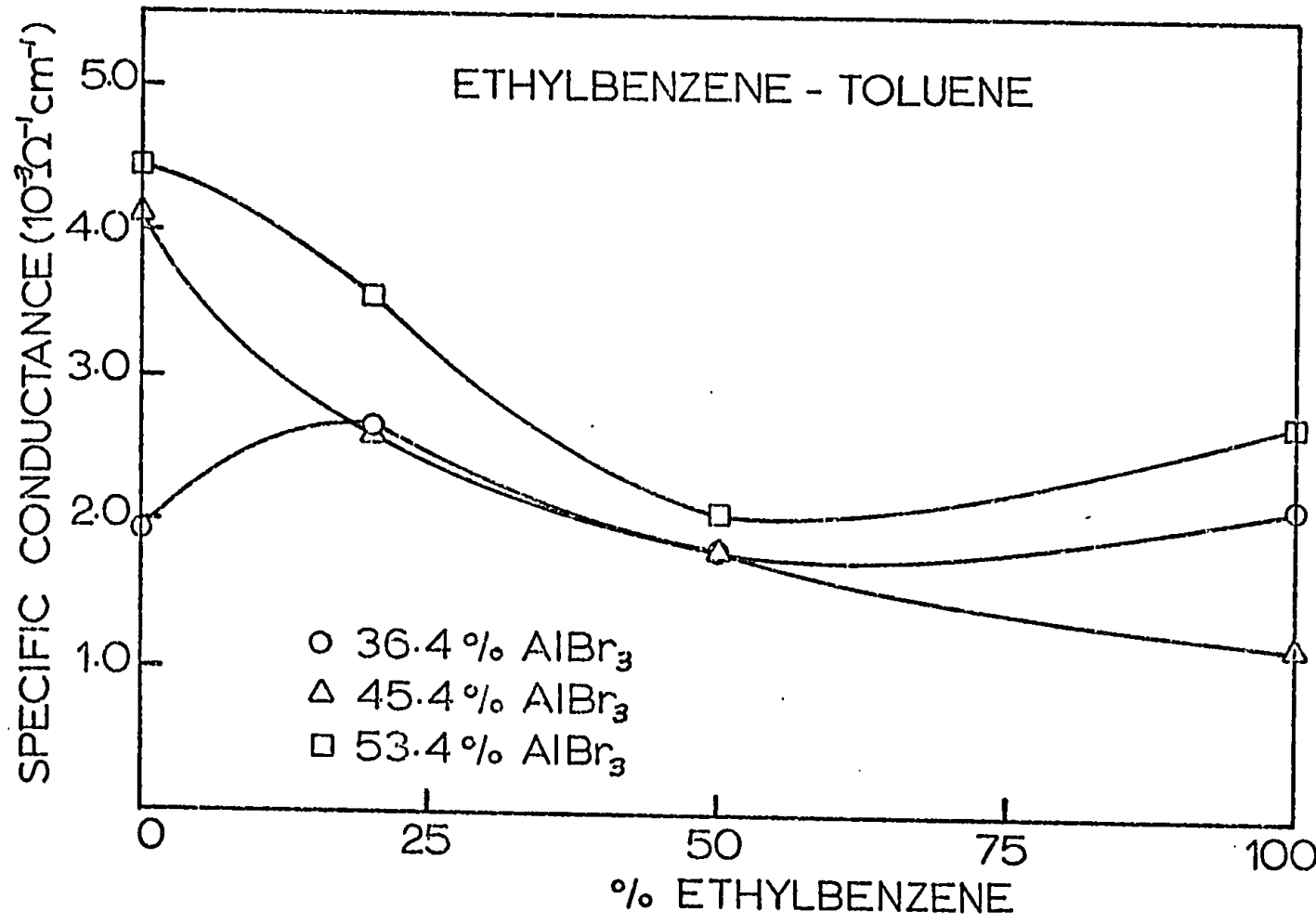

Figure 7-4. Electrolyte Conductance; Ethylbenzene-Toluene System. 


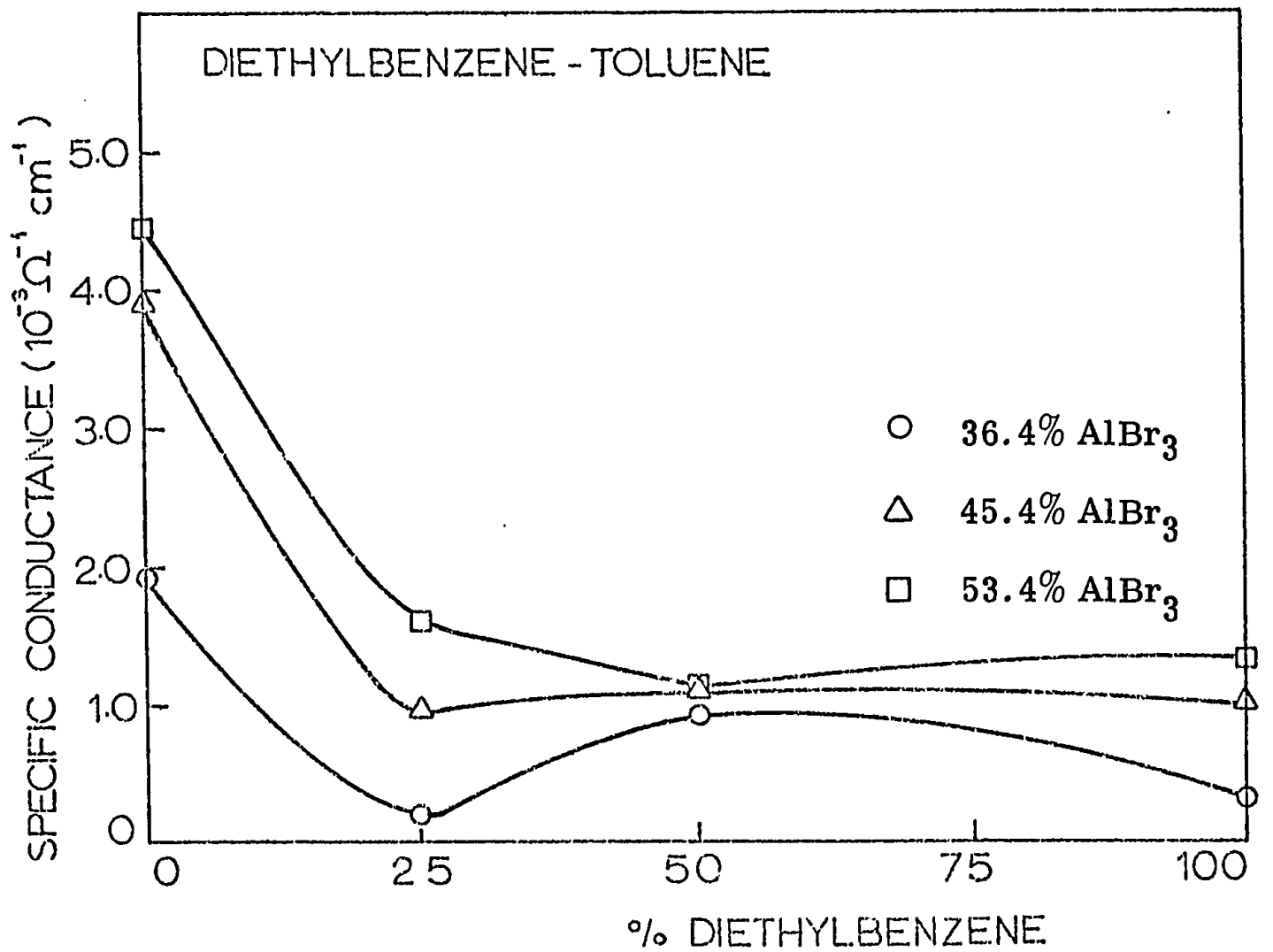

Figure 7-5. Electrolyte Conductance; Diethylbenzene- Toluene System. 
Table 7-1

Solvent Details ${ }^{109,} 110$

\begin{tabular}{|c|c|c|c|c|c|c|}
\hline Name and Formula & $\begin{array}{l}\text { Molecular } \\
\text { Weight }\end{array}$ & $\begin{array}{c}\text { Density } \\
20^{\circ} \mathrm{C} \\
\end{array}$ & 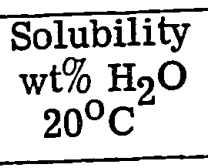 & $\begin{array}{c}\text { Solubility } \\
\text { wt } \% \mathrm{AlBr}_{3} \\
20^{\circ} \mathrm{C} \\
\end{array}$ & $\begin{array}{c}\text { Boiling } \\
\text { Point } \\
{ }^{\circ} \mathrm{C}\end{array}$ & $\begin{array}{c}\text { Dielectric } \\
\text { Constant } \\
\epsilon \\
\end{array}$ \\
\hline Benzene $-\mathrm{C}_{6} \mathrm{H}_{6}$ & 78.11 & 0.8790 & .060 & 46.5 & 80.099 & 2.28 \\
\hline Toluene $-\mathrm{C}_{6} \mathrm{H}_{5} \mathrm{CH}_{3}$ & 92.13 & 0.86694 & .034 & 42.5 & 110.626 & 2.37 \\
\hline o-Xylene $-\mathrm{C}_{6} \mathrm{H}_{4}\left(\mathrm{CH}_{3}\right)_{2}$ & 106.16 & 0.8802 & .028 & 35.7 & 144.41 & 2.57 \\
\hline m-Xylene $-\mathrm{C}_{6} \mathrm{H}_{4}\left(\mathrm{CH}_{3}\right)_{2}$ & 106.16 & 0.86417 & .028 & 35.7 & 139.10 & 2.37 \\
\hline $\mathrm{p}$-Xylene $-\mathrm{C}_{6} \mathrm{H}_{4}\left(\mathrm{CH}_{3}\right)_{2}$ & 106.16 & 0.86105 & .028 & 35.7 & 138.35 & 2.27 \\
\hline Ethyl Benzene $-\mathrm{C}_{6} \mathrm{H}_{5} \mathrm{C}_{2} \mathrm{H}_{5}$ & 106.16 & 0.8669 & .0327 & & 136.15 & 2.41 \\
\hline Aluminum Bromide $-\mathrm{AlBr}_{3}$ & 266.72 & 3.01 & soluble & - & 263.3 & \\
\hline Aluminum Chloride $-\mathrm{AlCl}_{3}$ & 133.34 & 2.44 & soluble & - & 182.7 & \\
\hline o-Diethylbenzene & 134.21 & 0.87996 & & & 183.42 & \\
\hline m-Diethylbenzene & 134.21 & 0.86394 & & & 181.10 & \\
\hline p-Diethylbenzene & 134.21 & 0.86196 & & & 183.75 & \\
\hline
\end{tabular}


This desirable property could offset, in some cases, the inconvenience encountered with diethylbenzene of producing electrolytes of generally lower cathodic current efficiencies than those of the ethylbenzene electrolytes. A life study of diethylbenzene-toluene electrolytes should supply further evidence for the use of diethylbenzene as a substitute for ethylbenzene. At present, ethylbenzene-toluene 1:1 volume $50 \%$ wt. $\mathrm{AlBr}_{3}$ is considered to be the best electrolyte.

C. Summary of Ethylbenzene vs. Diethylbenzene Comparison

To summarize, the advantages and disadvantages of diethylbenzene electrolytes with respect to ethylbenzene electrolytes are the following: Advantages:

1. Diethylbenzene is required in one half the quantity required of ethylbenzene in toluene to attain the maximum cathode efficiency level (Figs. 7-1 and 7-2), i.e., 75\% efficiency.

2. Diethylbenzene has a higher boiling point, hence a more elevated flash point. It is therefore more suitable for use in industrial plating baths.

Disadvantages

1. Diethylbenzene is more expensive than ethylbenzene (twice or three times).

2. Diethylbenzene electrolytes gave, in general, lower cathodic efficiencies than electrolytes based upon ethylbenzene.

3. Diethylbenzene electrolytes are less conductive than electrolytes based upon ethylbenzene. However, this is not a great problem 
as the conductivity can be raised by the addition of $\mathrm{HBr}$.

\subsection{Electrolyte Life}

When it was first observed that the cathode efficiency was always lower than the anode efficiency, it was feared that the build-up of an aluminum excess on the electrolyte would quickly lead to electrolyte deterioration.

The experiments of Section 5 showed clearly, however, that the excess aluminum could be combined by adding $\mathrm{HBr}$ plus solvent to the electrolyte.

On this basis the electrolytes (in particular ethylbenzene-toluene $1: 1$ by volume $50.0 \% \mathrm{wt} . \mathrm{AlBr}_{3}$ ) have been successfully used on and off for more than a complete turnover (i.e., more aluminum has been plated than was in the $\mathrm{AlBr}_{3}$ of the initial electrolyte) of aluminum.

No deterioration of the electrolytes has been observed over this period which indicates that the electrolytes should be able to maintain performance indefinitely when the $\mathrm{HBr}$ method of rejuvenation is practised.

It was found also that the aluminum anode will dissolve in the electrolyte when plating is not being carried out and that the dissolved aluminum destroys the electrolyte particularly with respect to conductivity. It is clear then that:

a) the anode must be removed when plating is not being carried out;

b) aluminum is not a suitable container material for the electrolyte. 
7.4 Control of the Electrolyte (Ethylbenzene-Toluene 1:1,50 wt. \% $\mathrm{AlBr}_{3}$ )

The most indicative property as to the operating state of the electrolyte was found to be its specific conductance. A low specific conductance is not only undesirable itself (requiring a high applied voltage for any given current density) but it also indicates a deteriorating cathode efficiency.

It has been found that a specific conductance between 3 and $4 \times 10^{-3} \Omega^{-1} \mathrm{~cm}^{-1}$ is ideal for the electrolyte to operate uniformly and reproducibly though operating values between 2 and $5 \times 10^{-3} \Omega^{-1} \mathrm{~cm}^{-1}$ are acceptable. As Figure 5-10 shows (p.117), the cathode efficiency maximizes in this specific conductance range while chemical attack on the anode (as indicated by the amount which the anode efficiency exceeds $100 \%$ ) still remains low. The deleterious effect of raising the specific conductance too high (say greater than 4.5 ) is indicated by an excessive amount of aluminum dissolution at the anode.

The standard operating procedure now is to plate aluminum from the electrolyte as long as the specific conductance is above $3 \times 10^{-3} \Omega^{-1} \mathrm{~cm}^{-1}$ and to make an $\mathrm{HBr}$ addition once the specific conductance drops below $3 \times 10^{-3} \Omega^{-1} \mathrm{~cm}^{-1}$. Enough $\mathrm{HBr}$ to bring the specific conductance up to above $3.5 \times 10^{-3} \Omega^{-1} \mathrm{~cm}^{-1}$ is added, typically 1 litre per litre of electrolyte. This appears to be the most satisfactory way of maintaining the electrolyte in its best operating state.

Control by the conductivity method eliminates the need for control by chemical analysis. 


\subsection{Throwing Power}

Although the throwing power of the ethylbenzene-toluene electrolyte was discussed in a previous research work, ${ }^{83}$ where the throwing power of ethylbenzene was found to be better than the throwing power of xylene, some additional experimental work has confirmed the good throwing power of ethylbenzene electrolytes. For instance, ethylbenzene-toluene electrolytes have been successfully used to plate objects with cavities such as bolts, screws, nails, etc. A photograph of one of the bolts plated is shown in Figure 7-6.

\subsection{Plating Quality}

Earlier experiments showed that the aluminum coatings from ethylbenzene-toluene electrolytes were well adherent, of good appearance and fine grained. This has also been true of the coatings from the diethylbenzene-toluene electrolytes and for the extended (1 year) ethylbenzene-toluene tests. A number of $1 \mathrm{mil}(0.025 \mathrm{~mm})$ aluminum coatings have been successfully given an anodizing treatment without difficulty .

Spectrographic analyses of the electroplated aluminum coatings have also been made. Table 7-2 shows that the main impurity in 2S grade aluminum, iron, is refined from the cathode during the plating and that no impurity is present at a concentration greater than . $1 \%$ in the final cathode plate. The slight increase in copper concentration is possibly due to copper diffusion into the coating from the copper 


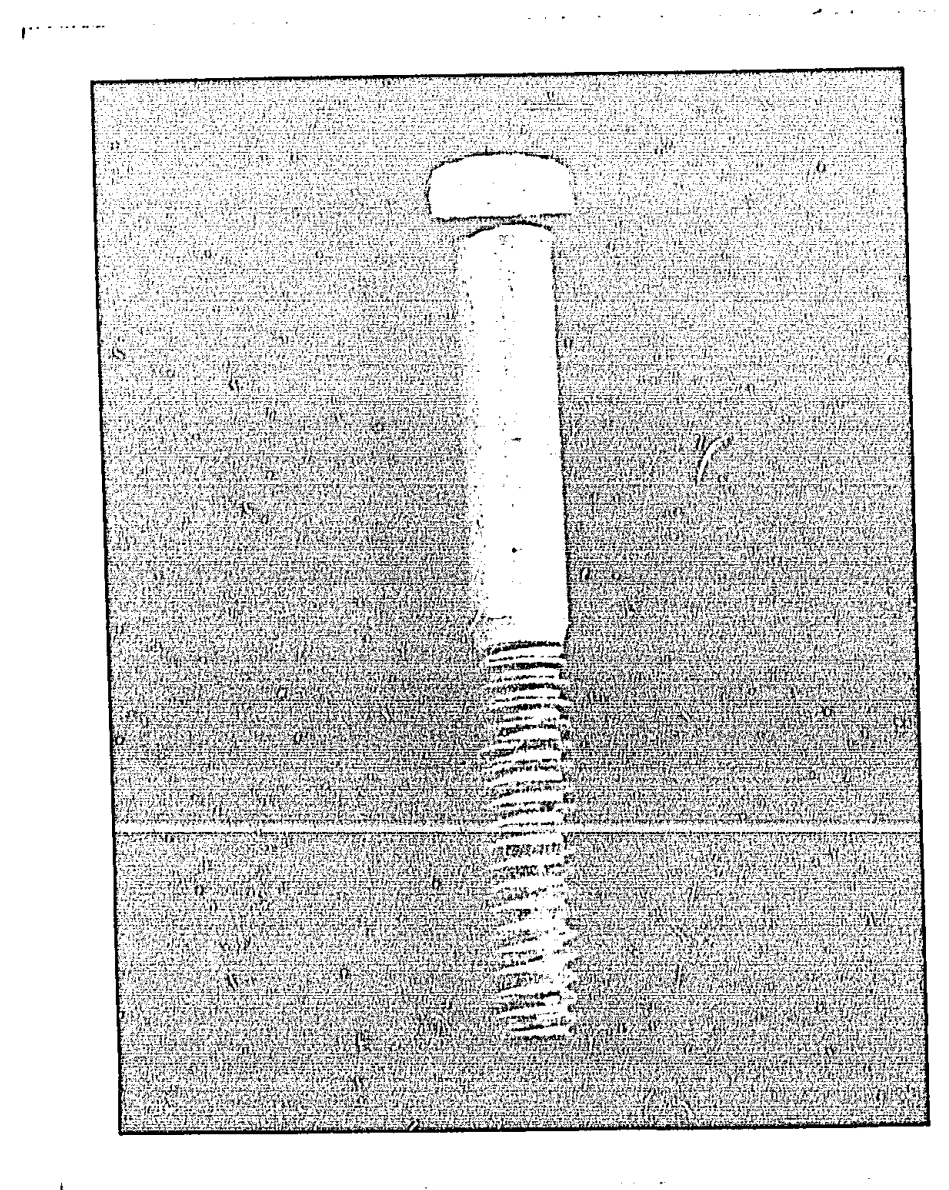

Figure 7-6. Photograph Showing an Aluminum Electroplated Steel Bolt. 
Table 7-2

Spectrographic Analysis of Anode and Cathode Aluminum

Compositions (Weight Percent)

Al Anode

$\begin{array}{llllllllllll}\mathrm{Bi} & \frac{\mathrm{Ca}}{.042} & \frac{\mathrm{Cu}}{.002} & \frac{\mathrm{Fe}}{.075} & \frac{\mathrm{Mg}}{.5} & \frac{\mathrm{Mn}}{.006} & \frac{\mathrm{Pb}}{.006} & \frac{\mathrm{Si}}{.023} & \frac{\mathrm{Sn}}{.12} & .015 & \frac{\mathrm{Ti}}{.015} & \frac{\mathrm{V}}{.01} \\ .01 & .000 & .094 & .05 & .006 & .005 & .01 & .06 & <.01 & .01 & .01\end{array}$


cathode. A summary of the spectrographic procedures followed for the chemical analysis is described in Appendix VIII.

\subsection{Value of the New Electrolytes}

It would seem that the electrolytes presented in this thesis are promising and that they warrant further investigations on a larger scale. A small-scale barrel plating system is presently being installed. The principal advantages of the electrolyte are simplicity of preparation and cheapness of the solvents (technical grade), along with good plating characteristics. In addition, the best electrolytes (for example, ethylbenzene-toluene $1: 1,50 \% \mathrm{AlBr}_{3}$ ) give a uniform operation which is largely unaffected by changes in electrolyte composition or operating conditions.

The procedures outlined in the thesis will permit the consistent plating of aluminum onto steel or copper (or other metals). The solvents for the electrolyte are readily available and the only nonstandard material is the $\mathrm{AlBr}_{3}$ which has been found to be easily prepared in the laboratory from aluminum chips and liquid bromine.

The electrolytes are safe to handle. No violent reactions occur during the preparation of the electrolytes and the flash points of the solvents are high enough so that no problem exists with electrical sparks or discharges during connection or disconnection of the electrical supply. Although the preparation of the electrolytes is normally carried out under a fume hood, the actual plating procedures are safely carried out in a ventilated room. 
All electrolytes containing aluminum ions must, however, be protected from moisture to prevent hydrolysis of the aluminum ions. This appears to be the only precaution necessary to guarantee good electrolyte performance from the alkyl benzene electrolytes.

\subsection{Discussion of Cathodic Charge Transfer Overvoltage Measurements}

The initial part of this discussion considered the more practical consequences of the investigation. The following sections are devoted to discussing the polarization study and possible electrode mechanisms. Firstly, the experimental cell developed for cathodic polarization experiments gave consistent and reproducible results. It would seem to be a good design for polarization measurements for systems from which the atmosphere (particularly $\mathrm{O}_{2}$ and $\mathrm{H}_{2} \mathrm{O}$ ) must be excluded.

Tests using a copper sulfate electrolyte confirmed that the single Luggin capillary back electrode was very satisfactory for cathode charge transfer overvoltage determinations.

\section{A. Absolute Values of Charge Transfer Overvoltage $\eta$ tC from Alkylbenzene Electrolytes, Compared with Overvoltages from Aqueous Electrolytes}

Cathodic charge transfer overvoltages for ethylbenzene-toluene electrolyte at a current density of $10 \mathrm{~mA} / \mathrm{cm}^{2}$ and $27^{\circ} \mathrm{C}$ varied from 35 to $50 \mathrm{mV}$ depending on the specific conductance. These values can be compared with the cathodic charge transfer overvoltages of 118 to $123 \mathrm{mV}$ for copper deposition from the copper sulfate solution (Table 6-2, 
Section 6) determined with the same polarization cell, at the same current density and temperature. These copper charge-transfer overvoltages are within the range $(40 \mathrm{mV}$ to $140 \mathrm{mV})$ normally measured for aqueous electrolytes.

It appears, therefore, that charge transfer overvoltages from organic electrolytes for aluminum deposition are of the same order of magnitude as those usually obtained with aqueous electrolytes for metal deposition.

\section{B. Effect of Specific Conductance on Charge Transfer}

\section{Overvoltages}

It was noted in the studies of electrolyte life (Section 5.0) that the specific conductance of the electrolyte is a good indicator of electrolyte performance. The polarization studies also showed that the cathode charge overvoltage $\left(\eta_{\mathrm{tC}}\right)$ is significantly lowered with increasing specific conductance of the electrolyte (constant current density) (Fig. 7-7).

The lowering of the cathode charge transfer overvoltage can be explained in terms of an increase in the concentration of the active aluminum bearing ions ( $\pi$ complexes). An increase in the concentration of this active plating species (the term $\mathrm{CA}^{\mathrm{n}+}$ in Eqn. A. VII-10) causes an increase in current density at any applied cathodic potential, $\Delta \phi$. Similarly, an increase in $\mathrm{CA}^{\mathrm{n}+}$ means that less applied potential $\Delta \phi$ is required to achieve any desired current density. Since

$$
\dot{\eta}_{\mathrm{tC}}=\Delta \phi-\Delta \phi \mathbf{r}
$$




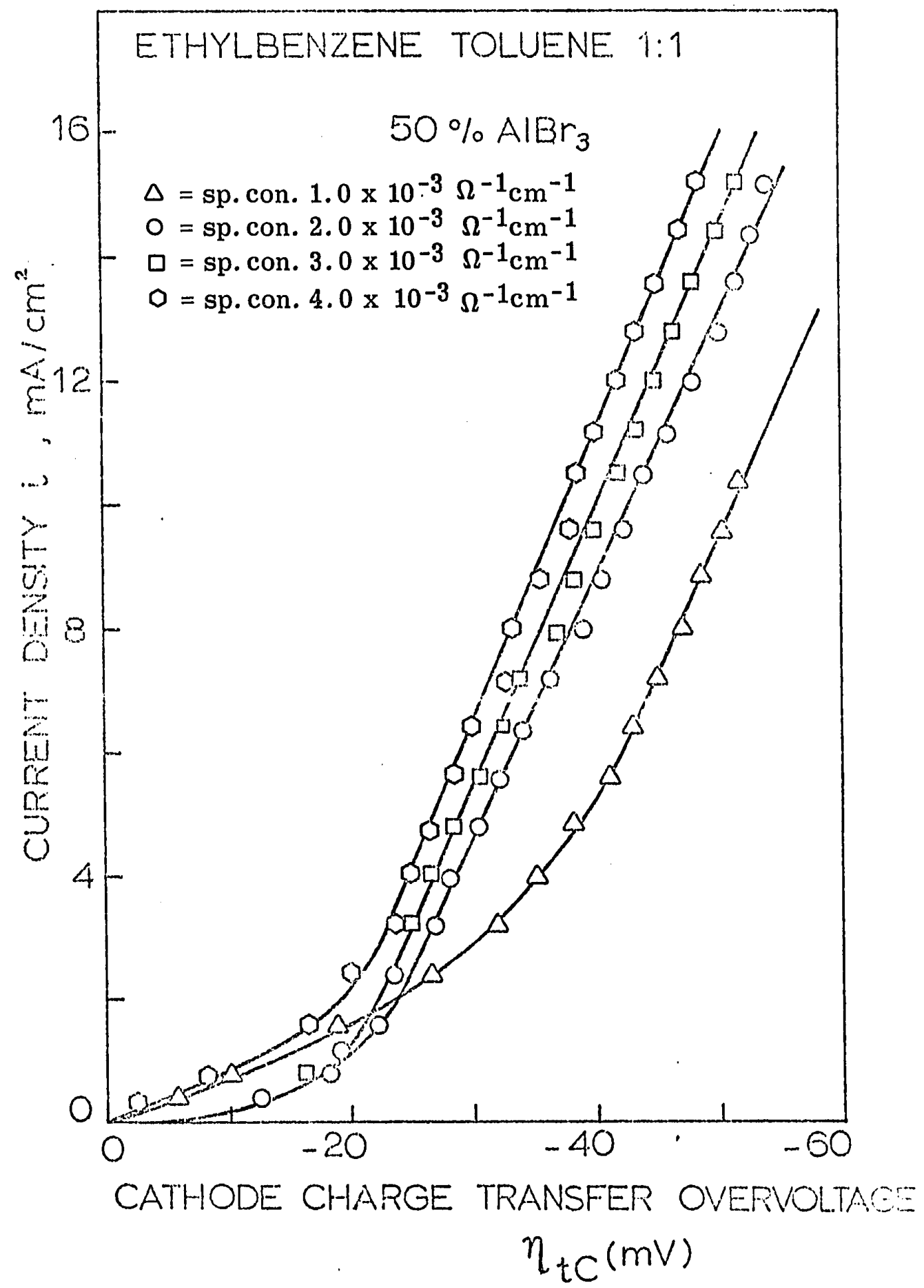

Figure 7-7. Cathode Current Density vs. Cathode Charge Transfer Overvoltage for Various Specific Conductances. Electrolyte Ethylbenzene-Toluene 1:1, 50 wt. \% $\mathrm{AlBr}_{3}$. 
the lower required applied potential (for any current density) is equivalent to the presence of a lower charge transfer overvoltage at the cathode.

As was shown earlier, the principal technique for increasing the specific conductance of the electrolyte is the addition of $\mathrm{HBr}$.

$\mathrm{HBr}$ increases the specific conductance by producing an increase in concentration of both active $(\pi)$ and non-active $(\sigma)$ complexes by the following reactions:

$$
\begin{aligned}
& \mathrm{ArH}+\mathrm{HBr}+\mathrm{AlBr}_{3} \rightarrow \mathrm{ArH}_{2}^{+}+\mathrm{AlBr}_{4}^{-} \\
& \text {(solvent) ( } \sigma \text { complex) }
\end{aligned}
$$

$$
\begin{aligned}
\mathrm{AlBr}_{3} \cdot \mathrm{nArH}+\mathrm{HBr} \rightarrow & \mathrm{ArH}_{2}^{+}+\mathrm{AlBr}_{4}^{-} \\
& (\sigma \text { complex })
\end{aligned}
$$

$$
\begin{aligned}
\mathrm{AlBr}_{4}^{-}+\mathrm{nArH} & \rightarrow \quad\left(\mathrm{AlBr}_{2} \cdot \mathrm{nArH}\right)^{+}+2 \mathrm{Br}^{-} \\
(\text {solvent }) & (\pi \text { complex })
\end{aligned}
$$

or

$$
\underset{\text { (solvent })}{\mathrm{AlBr}_{4}^{-}} \underset{(\pi \text { complex })}{\left(\mathrm{AlBr}_{2} \cdot \mathrm{nArH}\right)^{+}}+\mathrm{Br}^{-}+\mathrm{ArH}_{2}^{+}+\underset{(7-2}{\mathrm{nArH}}+\mathrm{Br}^{-}
$$

It can be noted also that reactions $7-2$ and $7-2 \mathrm{a}$ provide $\mathrm{Br}^{-}$ions to the electrolyte which will combine with any excess aluminum dissolved from the anode during the process. The aluminum bromide thus formed can then participate in the above reactions to form the desired $\pi$ complexes.

It can be concluded here that as well as lowering the resistance of the solution (hence lowering the IR drop and the electrical energy 
to plate aluminum), addition of $\mathrm{HBr}$ also reduces the cathodic polarization of the electrolyte. Thus the polarization study clearly confirms and explains the beneficial effects of $\mathrm{HBr}$ which were noted in the practical part of the investigation.

7.9 The Effect of Temperature on Cathodic Charge Transfer Overvoltages The charge transfer overvoltages for electrolytes having specific conductances between 2 to $4 \times 10^{-3} \Omega^{-1} \mathrm{~cm}^{-1}$ (see Figs. 6-6, 6-10,5-14) decreased by about $15 \mathrm{mV}$ as the temperature increased from 27 to $67^{\circ} \mathrm{C}$. This is in accord with Equation A. VII-10 and it indicates that lower applied potential (and hence a lower energy) is required for plating at higher temperatures. In terms of applying the process it would seem, therefore, that an elevated temperature of operation (say $50^{\circ} \mathrm{C}$ ) would be beneficial for the plating process.

A. Heat of Activation of Ethylbenzene-Toluene Electrolytes The heat of activation for the ethylbenzene-toluene electrolyte at constant potential varied from 2.5 to $4.5 \mathrm{Kcal} / \mathrm{mole}$ for electrolytes varying from 4 to $2 \times 10^{-3} \Omega^{-1} \mathrm{~cm}^{-1}$. The heat of activation at constant current density varied from 3.5 to $5.0 \mathrm{Kcal} / \mathrm{mole}$ for the same electrolytes.

Simanavicius et al. ${ }^{106}$ have determined recently the heat of activation of the Hurley and wier 19 type electrolyte, which consists of an aluminum bromide and an ethylpyridinium bromide in toluene. These workers reported values for the activation energies of the 
order of $4 \mathrm{Kcals} / \mathrm{mole}$.

It has been generally agreed that heat of activation in the electrodeposition of metals from aqueous solutions is of the order of 10-30 Kcals/mole. ${ }^{105}$ The values from the present work and values obtained by Simanavicius et al. 106 indicate, however, that the activation energies for plating metals from organic electrolytes are an order of magnitude less than the heats of activation for plating from aqueous electrolytes. This result suggests that the bond energy of aluminum bromide in the alkyl benzene complexes is considerably lower than the hydration energy of metal ions in aqueous solutions.

\section{B. The ffect of Applied Potential on Heat of Activation}

The heat of activation $\left(\Delta H^{\ddagger}\right)$ which is closely related to the free energy of activation, was found to decrease with an increasingly negative charge-transfer overvoltage. This can be explained in terms of Equations A.VII-6, and A. VII-15 where:

$$
\underset{\text { (actual) }}{\left(\Delta \mathrm{G}^{\ddagger}\right)_{1}}=\underset{\text { (chemical) }}{\left(\Delta \mathrm{G}_{\mathrm{c}}^{\ddagger}\right)_{1}}+\lambda \beta \mathrm{F}\left(\eta_{\mathrm{tC}}+\dot{\Delta} \phi_{\mathrm{r}}\right)
$$

This lower activation energy requirement can be understood by ${ }^{-}$ the concept that as the applied potential $\left(\Delta \phi=\eta_{\mathrm{tC}}+\Delta \phi_{\mathrm{r}}\right)$ is increased, the negative electrode (cathode) is made more and more negative and the ions being electronated require less and less electrochemical activation energy to cross the double layer barrier to become plated atoms. This lowered activation energy requirement is best seen in Figure A.VII-1, i.e., curve $3, \Delta \phi$ is negative. 


\subsection{Calculation of Kinetic Parameters}

In addition to the heats of activation, the kinetic parameters exchange current density $\left(i_{o}\right)$, stoichiometric factor $(\lambda)$, symmetry factor $(\beta)$, and stoichiometric number $(v)$ can be calculated from the experimental Tafel lines. These parameters, which are described in Section 6.1-D, have been useful in the elucidation of the electrodeposition mechanisms at the cathode.

\section{A. Exchange Current Density $\left(i_{0}\right)$}

The values of the exchange current density $\left(i_{0}\right)$ were calculated according to Tafel equation A.VII-22:

$$
\eta=\frac{R T}{\lambda \beta F} l n i_{o}-\frac{R T}{\lambda \beta F} l_{n} i_{C}
$$

by extrapolating the Tafel line to $\eta=0$.

The exchange current densities were calculated for three experimental electrolytes $\left(K_{25}=2.0,3.0\right.$ and $\left.4.0 \times 10^{-3} \Omega^{-1} \mathrm{~cm}^{-1}\right)$ from the measured data $\left(40^{\circ} \mathrm{C}\right)$ in Figures $6-8,6-10$, and 6-16. Values for the two Tafel steps $\left(\mathfrak{i}_{0}, \dot{i}_{O_{I I}}\right)$ of each electrolyte were determined (results Table 7-3).

As was mentioned in Section 6-1, exchange current density is a measure of the relative ability of the electrode to take part in the particular electrode reaction. Bockris ${ }^{99}$ found values of the order of $10^{-5} \mathrm{~A} / \mathrm{cm}^{2}$ for copper deposition on copper from $1 \mathrm{M} \mathrm{CuSO}_{4}, 10^{-9}$ for $\mathrm{Ni}$ on $\mathrm{Ni}$ deposition from $1 \mathrm{M} \mathrm{NiSO}{ }_{4}$ and $10^{-1}$ for cadmium on $\mathrm{Cd} / \mathrm{Hg}$ amalgams from $10^{-3} \mathrm{M} \mathrm{Cd}\left(\mathrm{NO}_{3}\right)_{2}$ in $1 \mathrm{M} \mathrm{KNO}_{3}$. 
Table 7-3

Calculated Kinetic Parameters $\left(40^{\circ} \mathrm{C}\right)$

\begin{tabular}{|c|c|c|c|c|c|c|c|c|c|}
\hline & \multicolumn{2}{|c|}{ Linear Plot } & \multicolumn{3}{|c|}{ STEP I (Tafel Line) } & \multicolumn{3}{|c|}{ STEP II (Tafel Line) } & \multirow[b]{2}{*}{$\lambda \neq$} \\
\hline $\begin{array}{c}\text { Specific } \\
\text { conductance } \\
\Omega^{-1} \mathrm{~cm}^{-1} \\
\end{array}$ & $\begin{array}{l}\text { Slope } \\
\frac{\mathrm{i}_{0} \lambda \mathrm{F}}{\mathrm{RT}}\end{array}$ & $\begin{array}{c}\lambda \\
\text { electrons } \\
\end{array}$ & $\begin{array}{c}{ }^{\mathrm{i}_{\mathrm{O}}} \\
\mathrm{mA} / \mathrm{cm}^{2} \\
\end{array}$ & $\begin{array}{l}\text { Tafel } \\
\text { slope } \\
2.3 \mathrm{~b} \\
\end{array}$ & $\beta * *$ & $\begin{array}{c}{\stackrel{\mathrm{I}}{\mathrm{O}_{\text {II }}}} \\
\mathrm{mA} / \mathrm{cm}^{2}\end{array}$ & $\begin{array}{c}\text { Tafel } \\
\text { slope } \\
2.3 \mathrm{~b} \\
\end{array}$ & $\begin{array}{c}\lambda+ \\
\text { electrons } \\
\end{array}$ & \\
\hline $4.0 \times 10^{-3}$ & .132 & 7.1 & 0.5 & .023 & 0.45 & 1.9 & .046 & 3.0 & 2.7 \\
\hline $3.0 \times 10^{-3}$ & .102 & 6.9 & 0.4 & .023 & 0.45 & 1.7 & .048 & 2.9 & 2.6 \\
\hline $2.0 \times 10^{-3}$ & .093 & 5.1 & 0.5 & .027 & 0.38 & 1.9 & .053 & 3.05 & 2.5 \\
\hline Averages: & & 6.3 & & .024 & 0.43 & & .049 & 2.98 & 2.6 \\
\hline
\end{tabular}

* Slope from linear plot i vs. $\eta_{t C}$ (Equation A. VII-28)

** Calculated assuming $\lambda=6$ electrons per overall reduction reaction calculated by Equation A. VII-28.

₹ Calculated assuming $\beta=0.5$

+ Calculated assuming $\beta$ found for Step I. 
The exchange current value of approximately $10^{-3} \mathrm{amps} / \mathrm{cm}^{2}$ determined for the ethylbenzene-toluene system indicates that a relatively low overvoltage must be met to achieve a significant rate of the aluminum electroplating.

\section{B. Kinetic Parameters $\lambda, \beta$ and $\nu$}

Values for the stoichiometric factor $\lambda$ (Section 6.1-D) were calculated from Equation A. VII-28 of Appendix VII:

$$
\mathrm{i}_{\mathrm{C}} \simeq \frac{\mathrm{i}_{\mathrm{o}} \lambda \mathrm{F} \boldsymbol{\eta}_{\mathrm{t}}}{\mathrm{RT}}
$$

which applies to the region of low overvoltage $\left(\eta_{\mathrm{tC}}<20 \mathrm{mV}\right)$ of the polarization curves.

Linear polarization curves of $\mathbf{i}_{\mathbf{C}}$ vs. $\eta_{\text {tC }}$ corresponding to Tafel lines at $40^{\circ} \mathrm{C}$ from Figures $6-7,6-11$ and 6-15 were replotted up to values of $16 \mathrm{mV}$ as shown in Figures 7-8, 7-9, and 7-10. $\lambda$ was calculated from the slopes of the new plots by using Equation A. -VII-28 in conjunction with the values of $i_{o}$ from the intercepts of the first step of the Tafel lines $\left(i_{\mathrm{O}_{\mathrm{I}}}\right)$.

The values of $\lambda$ are reported on Table 7-3. As can be noticed from Table 7-3, values of $\lambda$ vary from 5.1 to 7.1 electrons per act with an average of 6.3 which indicates that the electrodeposition act involves 6 electrons.

The second kinetic parameter calculated from the experimental polarization data was $\beta$, the symmetry factor, which was determined from the slopes of the first step of Tafel lines by means of Equation 


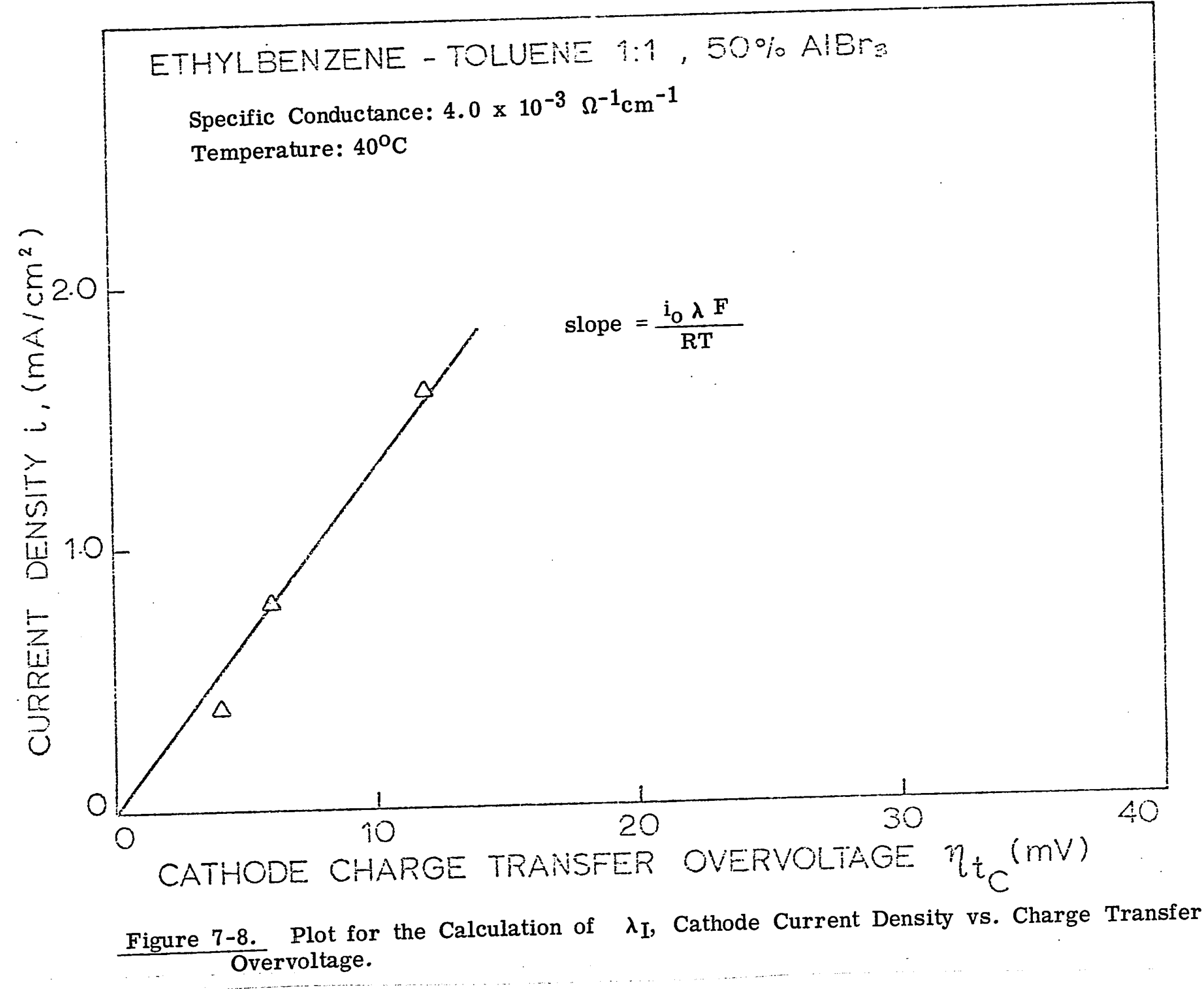




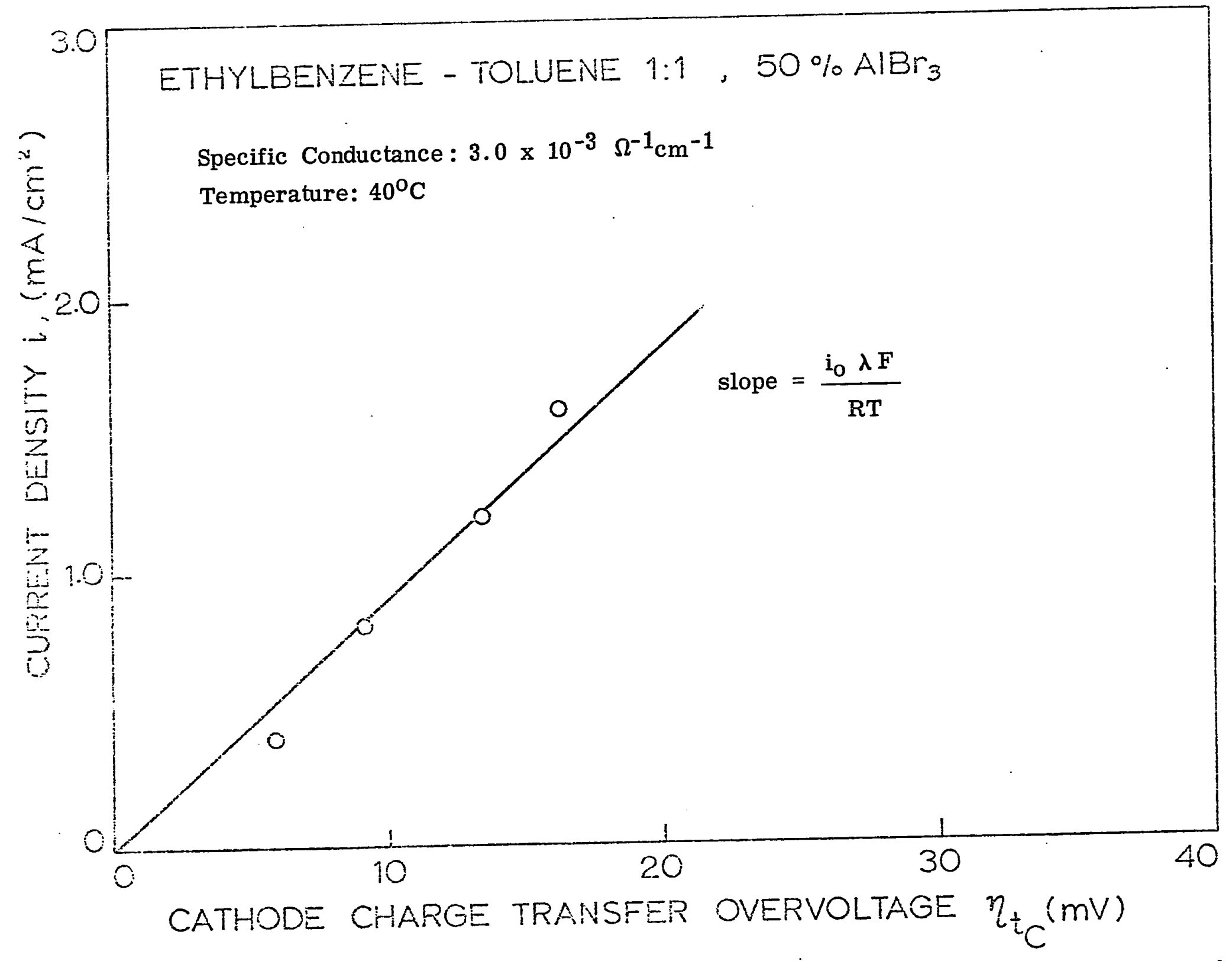

Figure 7-9. Plot for the Calculation of $\lambda I$, Cathode Current Density vs. Charge Transfer Overvoltage. 


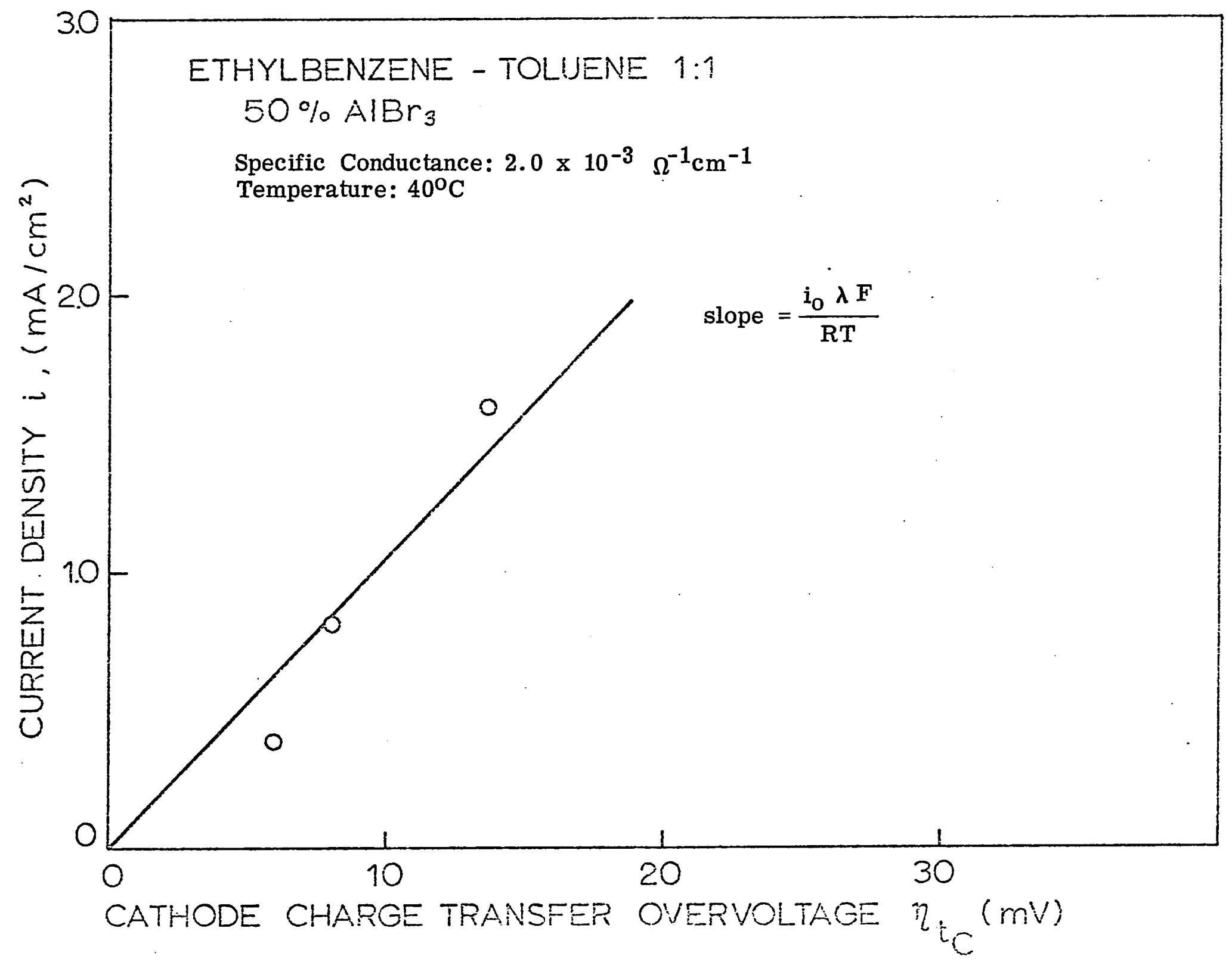

Figure 7-10. Plot for the Calculation of $\lambda_{I}$, Cathode Current Density. vs. Charge Transfer Overvoltage. 
A. VII-22. $\lambda$ was assumed to be 6 for all the calculations and the data for the slopes were obtained from Figures 6-8, 6-12 and 6-16 $\left(40^{\circ} \mathrm{C}\right)$.

The two electrolytes of main interest, i.e., those having specific conductances from 3.0 to $4.0 \times 10^{-3} \Omega^{-1} \mathrm{~cm}^{-1}$ gave values of 0.45 for $\beta$, while the lower $\left(2.0 \times 10^{-3} \Omega^{-1} \mathrm{~cm}^{-1}\right)$ specific conductance electrolyte gave $\beta=0.38$ (results Table 7-3). These values of $\beta$ are in the expected range of 0.4 to 0.6 for metal electrodeposition. ${ }^{99}$

\section{The Two Slopes of Tafel Line}

It was noted in Section 6, Figures 6-7, 6-11 and 6-15, that the experimental plots of charge transfer overvoltage vs. log current density gave Tafel lines with two slopes. This observation gives a strong indication that two electrode mechanisms are involved.

According to Conway ${ }^{98}$ two slopes in a Tafel line imply either two consecutive or two alternative electrochemical reactions. Conway further states that a line with a small slope followed by a line with a large slope (i.e., ) suggests two consecutive reactions, but that a large slope followed by a small slope $(\ulcorner)$ indicates alternative reactions.

In the case of two slopes from two consecutive reactions (I and II, Fig. 7-11 which is the observed behaviour in the present study, it can be seen that:

Reaction I is the slower at low overvoltages and hence it is the current limiting reaction at low applied potentials. 
CHANGES OF MECHANISM

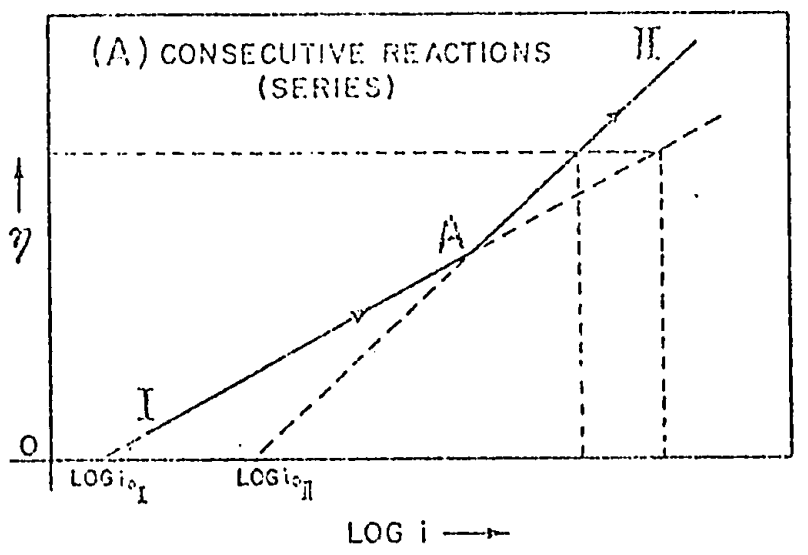

Figure 7-1\%. Current-potential relation for consecutive electrode processes with exchange current $\mathfrak{i}_{\text {oI }}$ and $i_{o r r}$ and Tafel slopes $b_{1}$ and $b_{2}$. Reaction $I$ is slower than $\mathrm{Ir}$, but its rate is more potentialdependent than that of II. II becomes ratedetermining at high potentials even though $i_{\text {OII }}>$ $>\dot{i}_{\text {o]: }} i j .2,113$ 
Reaction II has a smaller electrochemical rate constant (defined by Equation A.VII-22) and consequently a larger Tafel slope. It can be seen that as $\eta_{\text {tC }}$ increases the current is ultimately limited by this reaction (at point $\mathrm{A}$ ). Thus at high applied potentials reaction II is the current limiting reaction.

Thus for two consecutive reactions, the reaction having the larger electrochemical rate constant (small Tafel slope) is the rate controlling step at low $\eta_{\mathrm{tC}}$ values while the reaction having the smaller electrochemical rate constant (large Tafel slope) is the rate controlling step at high $\eta_{\mathrm{tC}}$ values.

In terms of kinetic parameters a change in Tafel slope implies (Equation A.VII-22) a change in $\lambda$, since $\beta$ is generally constant ${ }^{98,} 99$ as are the other factors, $\mathrm{R}, \mathrm{T}$ and $\mathrm{F}$.

Slopes of the second step (reaction II) of Tafel lines and the exchange current density ( ${ }{ }_{O}$ II' calculated by extrapolating the reaction II line to $\eta_{\mathrm{tC}}=0$ ) of this step were determined and they are repor ted in Table 7.3. Values of $\lambda$ for the second step of Tafel lines have also been calculated:

i) using values of $\beta$ found for Step I (Table 7-3)

ii) assuming $\beta=0.5$.

As can be noticed on Table $7-3$, the $\lambda$ values vary from 2.9 to 3.05 electrons per act with an average of 2.98 electrons per act in the first case ( $\beta$ from Step I), and from 2.5 to 2.7 electrons per act 
with an average of 2.6 electrons per act in the second case $(\beta=0.5)$. Both $\lambda$ ranges indicate that the second step of the Tafel lines involves a 3 electron process. However, for a precise knowledge of the mechanism of aluminum electrodeposition, values for $n$ the number of electrons for the overall deposition process, or $\nu$ the stoichiometric number need to be known, where $\nu=\frac{\mathrm{n}}{\lambda}$.

Brown and Wallace ${ }^{76}$ suggested (Section 3.2-F) a dimeric aluminum bromide complex (Equation 3-3):

$$
\begin{aligned}
\mathrm{Al}_{2} \mathrm{Br}_{6}+\mathrm{ArHI} \rightarrow & \left(\mathrm{Al}_{2} \mathrm{Br}_{5} \cdot \mathrm{ArH}\right)^{+}+\mathrm{Br}^{-} \\
& (\text {dimeric } \pi \text { complex) }
\end{aligned}
$$

which would indicate that $\mathrm{n}$ for the overall deposition process should be 6. However, other workers have suggested a complex containing monomeric aluminum bromide $(\mathrm{n}=3)$ as the active ion for the electrodeposition of aluminum (Equation 3-6):

$$
\begin{aligned}
& \mathrm{AlBr}_{2} \cdot \mathrm{n}\left(\mathrm{CH}_{4}\left(\mathrm{CH}_{3}\right)_{2}\right)^{+}+3 \mathrm{e} \rightarrow \mathrm{Al}+\mathrm{nC}_{6} \mathrm{H}_{4}\left(\mathrm{CH}_{3}\right)_{2}+2 \mathrm{Br}^{-} \\
& \text {(monomeric } \pi \text { complex) }
\end{aligned}
$$

Thus both 6 electron and 3 electron deposition processes are possible.

\subsection{Mechanisms of Dissolution and Deposition of Aluminum}

Although the polarization study made considerable headway into establishing the electrodeposition mechanism, it is difficult to postulate the precise mechanisms of aluminum dissolution and deposition as there are too many views on the structure of the complexes formed between aluminum halides and aromatic hydrocarbons. 
Menskutkin, 47 for instance, stated that complexes of aluminum halides and aromatic solvents are not found unless moisture or $\mathrm{HBr}$ is present. Brown and Wallace, ${ }^{52}$ on the other hand, deduced, from vapour pressure-composition-phase studies, the existence of solid compounds $\mathrm{Al}_{2} \mathrm{Br}_{6} \cdot \mathrm{ArH}$ with anhydrous benzene or toluene and they attributed the conductivity of the compounds to the formation of dimeric complexes.

$$
\begin{aligned}
& \mathrm{Al}_{2} \mathrm{X}_{6}+\mathrm{nArH} \rightarrow\left(\mathrm{Al}_{2} \mathrm{X}_{5} \cdot \mathrm{nArH}\right)^{+}+\mathrm{X}^{-} \\
&(\pi \text { complex })
\end{aligned}
$$

where $\mathrm{ArH}$ represents an aromatic hydrocarbon.

The existence of compounds containing monomeric aluminum bromide $\left(\mathrm{AlBr}_{3} \cdot \mathrm{ArH}\right)$ has been put forward by many workers ${ }^{48,} 49$ while many others ${ }^{50}, 51,52$ have postulated that the aluminum is dimeric $\left(\mathrm{Al}_{2} \mathrm{X}_{6} \cdot \mathrm{ArH}\right)$.

It appears to be well established, however, ${ }^{46}$ that the addition of hydrogen bromide will cause aluminum bromide to react with aromatic hydrocarbons to form $\sigma$ complexes or salts of carbonium ions $\left(\mathrm{ArH} \cdot \mathrm{H}^{+}\right)$which are formed by the following reactions:

$$
\begin{aligned}
& \mathrm{ArH}+\mathrm{HX}+\mathrm{Al}_{2} \mathrm{X}_{6} \neq \mathrm{ArH} \cdot \mathrm{H}^{+}+\mathrm{Al}_{2} \mathrm{X}_{7}^{-} \\
& \text {or } \quad \mathrm{ArH}+\mathrm{HX}+\frac{1}{2} \mathrm{Al}_{2} \mathrm{X}_{6} \rightleftarrows \mathrm{ArH} \cdot \mathrm{H}^{+}+\mathrm{AlX}_{4}^{-}
\end{aligned}
$$

Simanavicius and Levinskiene ${ }^{59}$ have measured the decomposition potential of this carbonium ion and have considered the reduction of this ion to be an inevitable process in the electrodeposition of aluminum, the process taking place before the deposition potential of $\mathrm{Al}^{+++}$is 
attained. The suggested mechanism for the reduction of a xylene $\sigma$ complex is as follows:

$$
2\left[\mathrm{C}_{6} \mathrm{H}_{4}\left(\mathrm{CH}_{3}\right)_{2} \cdot \mathrm{H}\right]^{+}+2 \mathrm{e}^{-} \rightarrow \mathrm{C}_{6} \mathrm{H}_{4}\left(\mathrm{CH}_{3}\right)_{2}+\mathrm{C}_{6} \mathrm{H}_{6}\left(\mathrm{CH}_{3}\right)_{2}
$$

These authors $\mathrm{s}^{59}$ postulate that the reduction of aluminum originates from a monomeric $\pi$ complex suggested by Lebeder and Korshak ${ }^{77,78,79}$ (Section 3.1-F), i.e.,

$$
\mathrm{AlBr}_{2} \cdot \mathrm{nC}_{6} \mathrm{H}_{4}\left(\mathrm{CH}_{3}\right)_{2}+3 \mathrm{e}^{-} \rightarrow \mathrm{Al}+\mathrm{nC}_{6} \mathrm{H}_{4}\left(\mathrm{CH}_{3}\right)_{2}+2 \mathrm{Br}^{-}
$$

In the present work it was found that moisture was necessary to obtain an electrolyte with good conductivity and capable of producing good aluminum plating. However, the same electrolyte would deteriorate if kept in contact with atmospheric moisture for long periods of time.

The following mechanisms concerning aluminum bromide complexes can, therefore, be suggested:

a) $\pi$ complexes are formed between aluminum bromide and alkyl benzenes. The conductivities are not high, however, and hydrogen bromide or water has to be added if the complex is to be used as an electrolyte for the electrodeposition of aluminum.

b) The reaction of aluninum bromide, hydrogen bromide and an alkyl benzene (such as ethylbenzene) results in a mixture of $\pi$ complexes, from which aluminum can be reduced, and a complexes which contribute to the high conductivity of the electrolyte (Eqns. 3-1 and 7-2). Excessive addition of $\mathrm{HBr}$, however, i.e., the presence of a high concentration of $\mathrm{Br}^{-}$ions, causes redissolution of aluminum 
from the cathode and the rate of aluminum dissolution is greater than the rate of aluminum plating. In the present work the termination of aluminum plating was observed to occur when the specific conductance exceeded $8 \times 10^{-3} \Omega^{-1} \mathrm{~cm}^{-1}$.

This cathode redissolution mechanism has been confirmed by Simanavicius and Levinskiene ${ }^{59}$ who found that the electrodeposition of aluminum ceases if more than 8 mole percent of hydrogen bromide is added to their $\mathrm{AlBr}_{3}$ - xylene electrolyte.

c) The mechanisms for active aluminum ion formation in the presence of moisture (i.e., aluminum bromide and a hydrocarbon each containing traces of moisture being reacted) can be considered on the basis of modified $\pi$ complexes which might be called aluminum hydroxy $\pi$ complexes.

\subsection{The Effect of Moisture}

To start with, experimental evidence has shown that in the absence of moisture or $\mathrm{HBr}$ no $\sigma$ complexes are found and the following aluminum organic compounds and $\pi$ complexes form (ethylbenzene example):

$$
\begin{aligned}
& \mathrm{Al}_{2} \mathrm{Br}_{6}+\mathrm{n}\left(6 \mathrm{H}_{5} \mathrm{C}_{2} \mathrm{H}_{5} \quad \rightarrow \quad \mathrm{Al}_{2} \mathrm{Br}_{6} \cdot \mathrm{n} \mathrm{C}_{6} \mathrm{H}_{5} \mathrm{C}_{2} \mathrm{H}_{5}\right. \\
& \text { and/or } \mathrm{Al}_{2} \mathrm{Br}_{6}+2 \mathrm{nC}_{6} \mathrm{H}_{5} \mathrm{C}_{2} \mathrm{H}_{5} \rightarrow 2 \mathrm{AlBr}_{3} \cdot \mathrm{nC}_{6} \mathrm{H}_{5} \mathrm{C}_{2} \mathrm{H}_{5} \\
& \mathrm{AlBr}_{3} \cdot \mathrm{nC}_{6} \mathrm{H}_{5} \mathrm{C}_{2} \mathrm{H}_{5} \underset{\text { dissociation }}{\stackrel{\text { weak }}{\rightarrow}} \underset{(\pi \text { complex })}{\left(\mathrm{AlBr}_{2} \cdot \mathrm{nC}_{6} \mathrm{H}_{5} \mathrm{C}_{2} \mathrm{H}_{5}\right)^{+}+\mathrm{Br}^{-}} \\
& \text {or } \mathrm{Al}_{2} \mathrm{Br}_{6} \cdot \mathrm{nC}_{6} \mathrm{H}_{5} \mathrm{C}_{2} \mathrm{H}_{5} \underset{\text { dissociation }}{\stackrel{\text { weak }}{\leftrightarrows}} \stackrel{\left(\mathrm{Al}_{2} \mathrm{Br}_{5} \cdot \mathrm{nArH}\right)^{+}+\mathrm{Br}^{-}}{(\pi \text { complex })}
\end{aligned}
$$


However, if moisture is present, it is thought to strongly displace $\mathrm{Br}^{-}$ions from the organic aluminum compound due to the high electronegativity of $\mathrm{OH}^{-}$as compared with $\mathrm{Br}^{-}$ions, according to the reactions:

$$
\begin{aligned}
& 2 \mathrm{AlBr}_{3} \cdot \mathrm{nC}_{6} \mathrm{H}_{5} \mathrm{C}_{2} \mathrm{H}_{5}+\mathrm{H}_{2} \mathrm{O} \underset{\text { dissociation }}{\stackrel{\text { strong }}{\rightarrow}}\left(\mathrm{AlBrOH}(\mathrm{n}-1) \mathrm{C}_{6} \mathrm{H}_{5} \mathrm{C}_{2} \mathrm{H}_{5}\right)^{+}+\mathrm{Br}^{-} \\
& \text {(hydroxy } \pi \text { complex) } \\
& +\mathrm{AlBr}_{4}^{-}+\left(\mathrm{C}_{6} \mathrm{H}_{5} \mathrm{C}_{2} \mathrm{H}_{5} \cdot \mathrm{H}\right)^{+} \\
& \text {( o. complex) }
\end{aligned}
$$

thereby forming a mixture of hydroxy $\pi$ and $\sigma$ complexes. The presence of water thus promotes the formation of hydroxy $\pi$ complexes and results in good plating electrolytes.

If an excess of water is added, however, all the $\mathrm{Br}^{-}$ions will be displaced and the hydroxy $\pi$ complex (Equation 7-12) will fall apart as $\mathrm{Al}(\mathrm{OH})_{3}+\mathrm{nC}_{6} \mathrm{H}_{5} \mathrm{C}_{2} \mathrm{H}_{5}$. In this case more $\sigma$ complexes will be formed (Equation 7-13) but aluminum will cease to be plated out, i.e., the electrolyte will have deteriorated, $\left(\mathrm{AlBrOH} \cdot \mathrm{nC}_{6} \mathrm{H}_{5} \mathrm{C}_{2} \mathrm{H}_{5}\right)^{+}+\mathrm{Br}^{-}+2 \mathrm{H}_{2} \mathrm{O} \rightarrow \mathrm{Al}(\mathrm{OH})_{3}+\mathrm{nC}_{6} \mathrm{H}_{5} \mathrm{C}_{2} \mathrm{H}_{5}+2 \mathrm{HBr}$

$$
\begin{gathered}
2 \mathrm{C}_{6} \mathrm{H}_{5} \mathrm{C}_{2} \mathrm{H}_{5}+2 \mathrm{HBr} \rightarrow \underset{6}{2\left(\mathrm{C}_{6} \mathrm{H}_{5} \mathrm{C}_{2} \mathrm{H}_{5} \cdot \mathrm{H}\right)^{+}+2 \mathrm{Br}^{-}}+(\text {o complex })
\end{gathered}
$$

Similar reactions can be written for the effect of moisture on the $\pi$ complex containing dimeric aluminum bromide (Eqn. 7-1). The belief that the structure of these hydroxy complexes is different from anhydrous $\pi$ complexes is emphasized by the fact 
that the colour of complexes in the present work varied from brown to black as opposed to the red colour reported for anhydrous $\pi$ complexes. $15,67,69$

\subsection{The Effect of Bromine}

It was stated that the aluminum bromide used was technical grade, or else it was prepared by reacting bromine with aluminum. Since the resulting salt is not recrystallized, the aluminum bromide used in all the experiments contains above $0.5 \%$ occluded bromine. The addition of bromine to an alkyl benzene in the presence of aluminum bromide (catalyst) causes the ortho and para bromination of the solvent. Using ethyl benzene as an example:

$$
\begin{aligned}
& 2 \mathrm{AlBr}_{3} \cdot \mathrm{nC}_{6} \mathrm{H}_{5} \mathrm{C}_{2} \mathrm{H}_{5}+\frac{1}{2} \mathrm{Br}_{2} \rightarrow\left(\mathrm{AlBr}_{2}(\mathrm{n}-1) \mathrm{C}_{6} \mathrm{H}_{4} \mathrm{BrC}_{2} \mathrm{H}_{5}\right)^{+}+\mathrm{Br}^{-} \\
& \text {(o \& } \mathrm{p} \text { brominated } \pi \text { complex) } \\
& +\mathrm{AlBr}_{4}^{-}+\left(\mathrm{C}_{6} \mathrm{H}_{5} \mathrm{C}_{2} \mathrm{H}_{5} \mathrm{H}\right)^{+} \\
& \text {( } \sigma \text { complex) }
\end{aligned}
$$

Similar to Equation 7-11, Equation 7-14 produces both $\pi$ and $\sigma$ complexes. The only difference is that in Equation 7-11 an hydroxy $\pi$ complex is formed, whereas in Equation 7-14 a brominated $\pi$ complex is obtained.

Therefore moisture and bromine cause similar effects in producing highly conductive electrolytes and altered $\pi$ complexes. 


\subsection{Effect of Both Moisture and Bromine}

It is possible that in the presence of both moisture and bromine an hydroxy bromo $\pi$ complex is formed:

$$
\begin{aligned}
& 2 \mathrm{AlBr}_{3} \cdot \mathrm{nC}_{6} \mathrm{H}_{5} \mathrm{C}_{2} \mathrm{H}_{5}+\mathrm{H}_{2} \mathrm{O}+\frac{1}{2} \mathrm{Br}_{2} \rightarrow\left(\mathrm{AlBrOH} \cdot(\mathrm{n}-2) \mathrm{C}_{6} \mathrm{H}_{4} \mathrm{BrC}_{2} \mathrm{H}_{5}\right)^{+}+\mathrm{Br}^{-} \\
& \text {(hydroxy o \& } \mathrm{p} \text { bromo } \pi \text { complex) } \\
& +\mathrm{AlBr}_{4}^{-}+2\left(\mathrm{C}_{6} \mathrm{H}_{5} \mathrm{C}_{2} \mathrm{H}_{5} \cdot \mathrm{H}\right)^{+} \\
& \text {( } \sigma \text { complex) }
\end{aligned}
$$

It can be noticed from Equation 7-15 that while the reaction of water and bromine together produced the same number of molecules of $\pi$ complex obtained by the water (Equation 7-11) or bromine (Equation 7-14:) alone, the amount of $\sigma$ complexes formed is twice the amount formed by each one of this reagent alone. Since $\sigma$ complexes promote conductivity in the electrolyte, this explains why technical grade aluminum bromide and hydrous solvents produce highly conductive electrolytes. In fact, Blue and Mathers ${ }^{14}$ required 90 volts to pass 0.1 ampere from an electrolyte prepared from anhydrous $\mathrm{AlBr}_{3}$ and anhydrous alkyl benzenes, as compared with the present work (water and free $\mathrm{Br}_{2}$ present), in which $3-6$ volts were sufficient to produce the same current density (similar cell configurations).

In summary, the ionic species from which the aluminum is plated can be any of the following (Eqns. 7-16 and 7-18, Section 7.15).

a) dimeric complexes:

1. $\left(\mathrm{Al}_{2} \mathrm{Br}_{5} \cdot \mathrm{nC}_{6} \mathrm{H}_{5} \mathrm{C}_{2} \mathrm{H}_{5}\right)^{+}$

2. $\left(\mathrm{Al}_{2} \mathrm{Br}_{4} \mathrm{OH} \cdot \mathrm{nC}_{6} \mathrm{H}_{5} \mathrm{C}_{2} \mathrm{H}_{5}\right)^{+}$ 
3. $\left(\mathrm{Al}_{2} \mathrm{Br}_{5} \cdot \mathrm{n} \cdot \mathrm{o}-\mathrm{C}_{6} \mathrm{H}_{4} \mathrm{BrC}_{2} \mathrm{H}_{5}\right)^{+}$

4. $\left(\mathrm{Al}_{2} \mathrm{Br}_{5} \cdot \mathrm{n} \mathrm{p} \mathrm{C} \mathrm{C}_{6} \mathrm{H}_{4} \mathrm{BrC}_{2} \mathrm{H}_{5}\right)^{+}$

5. $\left(\mathrm{Al}_{2} \mathrm{Br}_{4} \mathrm{OH} \cdot \mathrm{n}-\mathrm{oC}_{6} \mathrm{H}_{4} \mathrm{BrC}_{2} \mathrm{H}_{5}\right)^{+}$

6. $\left(\mathrm{Al}_{2} \mathrm{Br}_{4} \mathrm{OH} \cdot \mathrm{n}-\mathrm{p} \cdot \mathrm{C}_{6} \mathrm{H}_{4} \mathrm{BrC}_{2} \mathrm{H}_{5}\right)^{+}$

b) monomeric complexes

7. $\left(\mathrm{AlBr}_{2} \cdot \mathrm{n} \mathrm{C}_{6} \mathrm{H}_{5} \mathrm{C}_{2} \mathrm{H}_{5}\right)^{+}$

8. $\left(\mathrm{AlBrOH} \cdot \mathrm{n} \mathrm{C}_{6} \mathrm{H}_{5} \mathrm{C}_{2} \mathrm{H}_{5}\right)^{+}$

9. $\left(\mathrm{AlBr}_{2} \cdot \mathrm{no}-\mathrm{C}_{6} \mathrm{H}_{4} \mathrm{BrC}_{2} \mathrm{H}_{5}\right)^{+}$

10. $\left(\mathrm{AlBr}_{2} \cdot \mathrm{np}-\mathrm{C}_{6} \mathrm{H}_{4} \mathrm{BrC}_{2} \mathrm{H}_{5}\right)^{+}$

11. $\left(\mathrm{AlBrOH} \cdot \mathrm{no}-\mathrm{C}_{6} \mathrm{H}_{4} \mathrm{BrC}_{2} \mathrm{H}_{5}\right)^{+}$

12. $\left(\mathrm{AlBrOH} \cdot \mathrm{np}-\mathrm{C}_{6} \mathrm{H}_{4} \mathrm{BrC}_{2} \mathrm{H}_{5}\right)^{+}$

Higher bromination or hydroxylation are also possible.

To summarize, technical grade aluminum bromide and technical grade solvents are the best for the preparation of binary electrolytes, i.e., aluminum bromide plus alkyl benzenes, because they immediately produce good starting conductivity and a high concentration of aluminum bearing ions. Both of these conditions result in good aluminum plating.

\subsection{Mechanisms of Aluminum Electrodeposition}

As mentioned above, there are many views on the structure of the complexes formed between aluminum bromide and alkyl benzenes. However, the basic differences between the structures suggested are that in one case aluminum bromide would combine in a monomeric form to form a complex, e.g., $\left(\mathrm{AlBr}_{2} \cdot \mathrm{nArH}\right)^{+}$(see Eqn. 7-8) and in the other case aluminum bromide would combine in its dimeric form, 
e.g. , $\left(\mathrm{Al}_{2} \mathrm{Br}_{5} \cdot \mathrm{nArH}\right)^{+}($Eqn. $7-3)$.

It has been seen in the results section that the experimental process gives two slopes of the Tafel line which indicates that two consecutive reactions are taking place. As is discussed below, however, it is also possible that only one slope, i. e., the slope at high applied potential is valid, which would indicate a single step reaction.

\section{A. Assuming two consecutive slopes in Tafel line}

In the discussion of kinetic parameters (Section 7.11) it was shown that $\lambda$, i.e., the number of electrons necessary so that one act of the rate determining step can occur, was equal to 6 electrons at low overvoltages (see Table 7-3), but that it dropped to a value of 3 electrons at overvoltages higher than $30 \mathrm{mV}$.

a) Postulating monomeric aluminum complexes

It must be first noted that a value of $\lambda=6$ is not consistent with a monomeric complex, iwe., $\lambda$ cannot be greater than $n$. Furthermore even a $\lambda$ of 3 is not consistent with there being two consecutive reactions involved with a monomeric aluminum complex, i.e., if $\lambda=3$ and $\mathrm{n}=3$ there can be only one reaction step.

b) Postulating dimeric aluminum complexes

A deposition process having two steps, $\lambda=6$ followed by $\lambda=3$, is not possible even for electrodeposition from a dimeric aluminum complex $(n=6)$. This is because all 6 electrons will be provided by the $\lambda=6$ step, leaving the $\lambda=3$ step as being superfluous. Thus if there is in fact a $\lambda=6$ step included in the 
two consecutive reactions, the complexes must be trimeric or larger, for which there is no experimental evidence. Therefore the $\lambda=6$ result obtained at low overvoltages implies that:

i) the aluminum bromide complex are trimeric or the complexes have more than one dimeric aluminum bromide molecule;

ii) the $\lambda=6$ result is not correct, i.e., that more experimental data are required at low overvoltages to substantiate the values of the slopes obtained in Figures 7-8, 7-9 and 7-10.

B. Assuming one slope (high overvoltages) in the Tafel line

It was noted above that the second step of Tafel lines gave values of $\lambda=3$ (Fig. 7-2) and that values of $\lambda=6$ found at low overvoltage are not consistent with this second step.

In Appendix VII, the Butler-Volmer equation (Eqn. A. VII-19) was simplified by assuming operation at high overvoltage, i. e., $\quad \eta>20 \mathrm{mV}$. The Butler-Volmer equation then took' a form similar to Tafel equation (Eqn. A. VII-22). For this assumption to be valid, any points in Tafel line at overvoltages below $20 \mathrm{mV}$ should be disregarded, in which case the present results should be interpreted as being a single slope Tafel line process.

Assuming $\beta=0.5$, i. e., disregarding values of $\beta$ found in the first step, $\lambda$ was calculated to be approximately 3 electrons. Therefore:

a) Postulating monomeric aluminum bromide complexes

If a monomeric aluminum complex is postulated, i.e., $\mathrm{n}=3, v$ can be equal only to 1 (a single step) and the following reaction for 
aluminum reduction can be postulated (hydroxy $\pi$ example): $\left(\mathrm{AlBrOH} \cdot \mathrm{nC}_{6} \mathrm{H}_{5} \mathrm{C}_{2} \mathrm{H}_{5}\right)^{+}+3 \mathrm{e} \rightarrow \mathrm{Al}^{\mathrm{O}}+\mathrm{Br}^{-}+\mathrm{OH}^{-}+\mathrm{nC}_{6} \mathrm{H}_{5} \mathrm{C}_{2} \mathrm{H}_{5} \quad$ (7-16) The anodic dissolution of aluminum is given by the opposite reaction:

$$
\mathrm{Al}^{\mathrm{o}}+\mathrm{Br}^{-}+\mathrm{OH}^{-}+\mathrm{nC}_{6} \mathrm{H}_{5} \mathrm{C}_{2} \mathrm{H}_{5} \rightarrow\left(\mathrm{AlBrOH} \cdot \mathrm{nC}_{6} \mathrm{H}_{5} \mathrm{C}_{2} \mathrm{H}_{5}\right)^{+}+3 \mathrm{e}
$$

b) Postulating dimeric aluminum bromide complexes

If a dimeric aluminum bromide complex is assumed, i. e., $\mathrm{n}=6$, there must be two steps $(\nu=2)$ since $\lambda$ was found to be 3 . The following reduction reactions can be suggested (hydroxy $\pi$ example):

$$
\begin{aligned}
&\left(\mathrm{Al}_{2} \mathrm{Br}_{4} \mathrm{OH} \cdot \mathrm{nArH}\right)^{+}+3 \mathrm{e} \rightarrow\left(\mathrm{Al}_{2} \mathrm{BrOH} \cdot \mathrm{nArH}\right)^{+}+3 \mathrm{Br}^{-} \\
&(\text {Hydroxy } \pi \text { complex with } \\
& \text { monovalent and divalent } \\
& \text { aluminum) }
\end{aligned}
$$

and

$$
\left(\mathrm{Al}_{2} \mathrm{BrOH} \cdot \mathrm{nArH}\right)^{+}+3 \mathrm{e} \rightarrow 2 \mathrm{Al}^{\mathrm{O}}+\mathrm{nArH}+\mathrm{OH}^{-}
$$

Although this case could have been placed in Section $7.15-\mathrm{A}$

two consecutive slopes in the Tafel line, because it is a two step reaction, it will not display two slopes in a Tafel line since both steps have the same number of electrons per step, i.e., $\lambda=3$.

\section{16 Other Reactions at the Cathode}

The experimental electroplating. results have shown that the cathode efficiency with respect to aluminum has been a maximum of $80 \%$. It is likely that the remaining current is used in the reduction of $\sigma$ complexes (carbonium ion) to form compounds of higher molecular weights. This phenomenon has also been demonstrated by Simanavicius and 
Levinskiene ${ }^{59}$ (see Equation $3-5$, p. 40). It can be suggested that the problem of $\sigma$ complex reduction (which wastes energy) might be overcome by the addition of potential buffer compounds, i.e., compounds which will keep the applied potential in a region outside the decomposition potentials of the complexes.

\subsection{Summary}

It has not been possible to establish precisely the mechanism for the electrodeposition of aluminum because of the number of possibilities for the structure of the complexes (ions), and because the polarization curves gave results open to several interpretations.

However, it has been established that the most probable number of electrons for the electrodeposition step $(\lambda)$ is 3 . This value of $\lambda=3$ can be interpreted in terms of a single step process $(\nu=1)$ from a monomeric complex and/or a two step process $(\nu=2)$ from a dimeric complex. The two step process would imply the presence of monovalent and divalent aluminum in the intermediate ions of the reduction process.

The value of 6 electrons per electrodeposition step $(\lambda=6)$ is not consistent with monomeric ions or for two step deposition from dimeric ions.

It is most likely that the actual ions involved in aluminum plating are $\pi$, hydroxy $\pi$, and brominated $\pi$ type complexes. 


\subsection{Suggestions for Further Work}

1. A study of the structure of the aluminum complexes responsible for the plating should be undertaken to further clarify the deposition mechanisms. Suggested techniques are: $\mathrm{X}$-ray diffraction, Infrared, Raman and Mass Spectroscopy.

2. The polarization study should be extended to include anode polarization which would provide additional kinetic parameter data (particularly the stoichiometric number).

3. A life study should be undertaken with the diethylbenzene-toluene electrolytes which over a short term appeared to be as good as the ethylbenzene-toluene electrolytes.

4. In a practical sense, the most pressing studies are to determine methods of:

a) increasing current densities without lowering cathode efficiencies, i.e., to increase the speed of plating;

b) improving plating quality, particularly to permit large thicknesses of aluminum without causing treeing or other surface imperfections.

Possible techniques for realizing these goals are: current reversal, $A_{\perp}$ ripple, ult rasonic stirring, the use of addition agents, and temperature control.

5. The use of the electrolytes for other purposes (batteries, electrorefining, electrowinning, the plating of other reactive metals) should be considered. 


\subsection{CONCLUSIONS}

1. A number of electrolytes consisting essentially of an $\mathrm{AlBr}_{3}$ solute in alkylbenzene solvents or solvent mixtures were developed for the electrodeposition of aluminum onto metallic substrates. Solvents of the ethylbenzene family appear to be the most useful for the electrolytes.

2. Whitish gray, ductile, fine-grained, coherent and well-adherent aluminum coatings have been deposited on copper, steel, platinum, brass and other alloys. A number of 1 mil aluminum coatings have been successfully given an anodizing treatment.

3. Technical grade solvents and aluminum bromide of commercial purity are preferable for the electrolytes.

4. Water up to a certain level is a desirable ingredient in the electrolytes as it improves electrolyte conductivity. Technical grade solvents in equilibrium with atmospheric moisture are good starting materials for the electrolyte.

5. Cathode efficiencies of the order of $60-85 \%$ and anode efficiencies very nearly $100 \%$ were obtained for coating thickness of .5 mills $(.013 \mathrm{~mm})$.

6. Extensive studies of aluminum bromide-ethylbenzene-toluene electrolytes and aluminum bromide-diethylbenzene-toluene electroly tes have shown that both ethylbenzene and diethylbenzene improve plating performance. 
7. Anode efficiencies are always greater than cathode efficiencies in the plating process with the result that excess aluminum tends to build up in the elect rolyte. This excess aluminum can be offset by adding a small amount of $\mathrm{HBr}$ gas. The $\mathrm{HBr}$ also seems to maintain the desired specific conductance of the electrolyte.

8. The most indicative property as to the operative state of the electrolyte is the specific conductance of the electrolyte. It has been found that specific conductance between 3.0 and $4.0 \times 10^{-3} \Omega^{-1} \mathrm{~cm}^{-1}$ is ideal for the electrolyte to operate uniformly and reproducibly.

9. A cell for polarization studies of electrolytes based upon organic solvents was developed. The cell can be operated at constant temperature and in a closed system free from atmospheric moisture.

10. It was demonstrated that the cell could be successfully used for the determination of IR drops, cathodic concentration polarization and cathodic charge transfer overvoltages. It is expected that these measurements could be extended for the determination of anodic overvoltages and anodic concentration polarization with organic electrolytes.

11. A study of cathodic overvoltages of ethylbenzene-toluene- $\mathrm{AlBr}_{3}$ electrolyte showed that charge-transfer overvoltages were of the order of $40 \mathrm{mV}$ at current density of $10 \mathrm{~mA} / \mathrm{cm}^{2}$. The over- 
voltages decreased with increasing specific conductance and temperature of the electrolyte.

12. Heats of activation were calculated from polarization curves obtained between 27 and $67^{\circ} \mathrm{C}$, at both constant potential and constant current density. The values were of the order of $4 \mathrm{Kcal} / \mathrm{mole}$. The heat of activation decreases with increasing specific conductance, temperature and applied potential.

13. Both charge-transfer overvoltage and heat of activation of aluminum organic electrolytes were found to be somewhat less than those usually found for metals in aqueous electrolytes.

14. The complexes (ions) responsible for the plating of aluminum are thought to be $\pi$, hydroxy $\pi$, and bromo $\pi$ complexes.

15. The $\pi$ complexes may be monomeric or dimeric in aluminum. There is not yet sufficient evidence to establish which is the predominant species.

16. The electrodeposition process takes place in steps of 3 electrons which implies one step for monomeric $\pi$ complexes and two steps for dimeric $\pi$ complexes. 


\subsection{ORIGINAL CONTRIBUTION TO KNOWLEDGE}

1. A number of electrolytes suitable for the electroplating of aluminum have been developed. The electrolytes appear to be simpler, less costly and less hazardous than existing systems. Commercialization of the electroplating process is proceeding.

2. Techniques for maximizing the effectiveness of the electrolytes have been established. In particular, the problem of aluminum buildup in the electrolyte due to excess aluminum dissolution at the anode has been overcome by additions of $\mathrm{HBr}$ and solvent.

3. It has been established that the performance of the electrolytes is best indicated by their specific conductance which should be between 3 and $4 \times 10^{-3} \Omega^{-1} \mathrm{~cm}^{-1}$. The specific conductance can be controlled by periodic addition of $\mathrm{HBr}$.

4. A cell has been developed for studying the polarization behaviour of organic-based electrolytes from which air and moisture must be excluded. A new back reference capillary electrode has been tested and found to be effective for directly determining cathode charge transfer overvoltage.

5. Electrodeposition parameters $\mathrm{i}_{\mathrm{O}}, \lambda, \beta, \nu, \Delta \mathrm{H}_{\left(\eta \mathrm{t}_{\mathrm{C}}\right)}^{\neq}$and $\Delta \mathrm{H}_{\left(\mathrm{i}_{\mathrm{C}}\right)}^{\neq}$have been determined for the system ethylbenzene-toluene (1:1 volume), $\mathrm{AlBr}_{3}(50 \mathrm{wt}$ \%). The results indicate that the electrodeposition takes place in 3 electron steps with a relatively small energy requirement $(\approx 4 \mathrm{Kcal} / \mathrm{mole}$ ).

6. The mechanisms of electrodeposition have been examined in detail on the basis of published data and information from the experimental polarization study. It is suggested that $\pi$, hydroxy $\pi$, and bromo $\pi$ complexes are the most active aluminum bearing ions. 
249

APPENDIX I 


\section{APPENDIX I}

\section{Effect of Anode and Cathode Size}

Electrolyte: 45.4 wt. percent $\mathrm{AlBr}_{3}$ in ethylbenzene.

Cathode efficiencies were determined for various anode widths.

Cathode width was maintained at $1 \mathrm{~cm}$ and immersion depths were maintained constant at $5 \mathrm{~cm}$. The results are given in Table A.I-1 below.

\section{Table A.I-1}

Electrode width versus percent cathode efficiency

\begin{tabular}{ccc}
$\begin{array}{c}\text { Anode } \\
\text { width } \\
\text { cm }\end{array}$ & $\begin{array}{c}\text { Cathode } \\
\text { width } \\
\text { cm }\end{array}$ & $\begin{array}{c}\text { Average } \\
\text { Cathode } \\
\text { efficiency }\end{array}$ \\
\hline 1.0 & 1 & $\frac{58.5}{1.5}$ \\
& 1 & 59.0 \\
2.0 & 1 & 60.0 \\
4.0 & 1 & 51.0
\end{tabular}

Table A. I-1 shows that a variation of anode width between 1 and $2 \mathrm{~cm}$ causes only a small effect upon cathode efficiency. A further increase in width to $4 \mathrm{~cm}$ does, however, result in a decreased efficiency.

An anode width of $1.5 \mathrm{~cm}$ was used throughout the ethylbenzenexylene and ethylbenzene-toluene tests. 
251

APPENDIX II 
APPENDIX II

Calibration of Conductimeter

A solution of $0.1 \mathrm{M} \mathrm{KCl}$ was prepared by dissolving ACS grade $\mathrm{KCl}$ (heated to constant weight at $150^{\circ} \mathrm{C}$ ) in triple distilled water. The triple distilled water was prepared by redistilling three times distilled water to which $1 \mathrm{ml}$ of $0.1 \mathrm{~N} \mathrm{KMnO}_{4}$ had been added. The redistillation was carried out in a hard glass retort and resistance glass condenser.

The conductimeter used, a Tacussel Type CD7 Direct Reading Conductimeter, was adjusted to read the known specific conductance of this $\mathrm{KCl}$ electrolyte $\left(12.88 \times 10^{-3} \Omega^{-1} \mathrm{~cm}^{-1} \text { at } 25^{\circ} \mathrm{C}\right)^{85}$ by adjusting the resistance of the internal potentiometer.

This procedure established the cell constant of the instrument and all subsequent conductivities were measured directly, based upon this calibration. 
APPENDIX III 
APPENDIX III

Adjustment of Specific Conductances to $25^{\circ} \mathrm{C}$

Comparisons of the specific conductances of electrolytes used in the investigation were made on the basis of specific conductances measured at ambient temperatures and adjusted to $25^{\circ} \mathrm{C}$.

Figure A.III-1 shows the relationship between the specific conductance of a $45.4 \mathrm{wt}$. percent $\mathrm{AlBr}_{3}$-ethylbenzene electrolyte as a function of temperature. All adjustments to $25^{\circ} \mathrm{C}$ we re made on the basis of this curve by assuming a straight line relationship between 25 and $35^{\circ} \mathrm{C}$, the temperature range of the experimental conductance measurements. The equation employed was:

$$
\mathrm{K}_{\mathrm{t}}=\mathrm{K}_{25^{\circ}}\left[1+\mathrm{m}\left(\mathrm{t}-25^{\circ} \mathrm{C}\right)\right]
$$

where $\mathrm{t}$ is temperature ${ }^{\circ} \mathrm{C}$ and $\mathrm{m}$ is a constant over a limited temperature range.

The value of $\mathrm{m}$ was determined from Figure A. III-1 by rearranging equation $\mathrm{A}$. III-1 to

$$
\mathrm{K}_{\mathrm{t}}=\mathrm{K}_{25^{\mathrm{O}}}+\mathrm{K}_{25^{\mathrm{o}}} \mathrm{m}\left(\mathrm{t}-25^{\circ} \mathrm{C}\right)
$$

where $\mathrm{K}_{25^{\circ}} \mathrm{O}$ is the intercept at $\mathrm{t}-25^{\circ} \mathrm{C}$ equals 0 .

$\mathrm{K}_{25}$ o was calculated for other electrolytes from Equation A. III-1 by rearranging to:

$$
\mathrm{K}_{25^{\circ}}=\frac{\mathrm{K}_{\mathrm{t}}}{1+\mathrm{m}\left(\mathrm{t}-25^{\circ} \mathrm{C}\right)}
$$




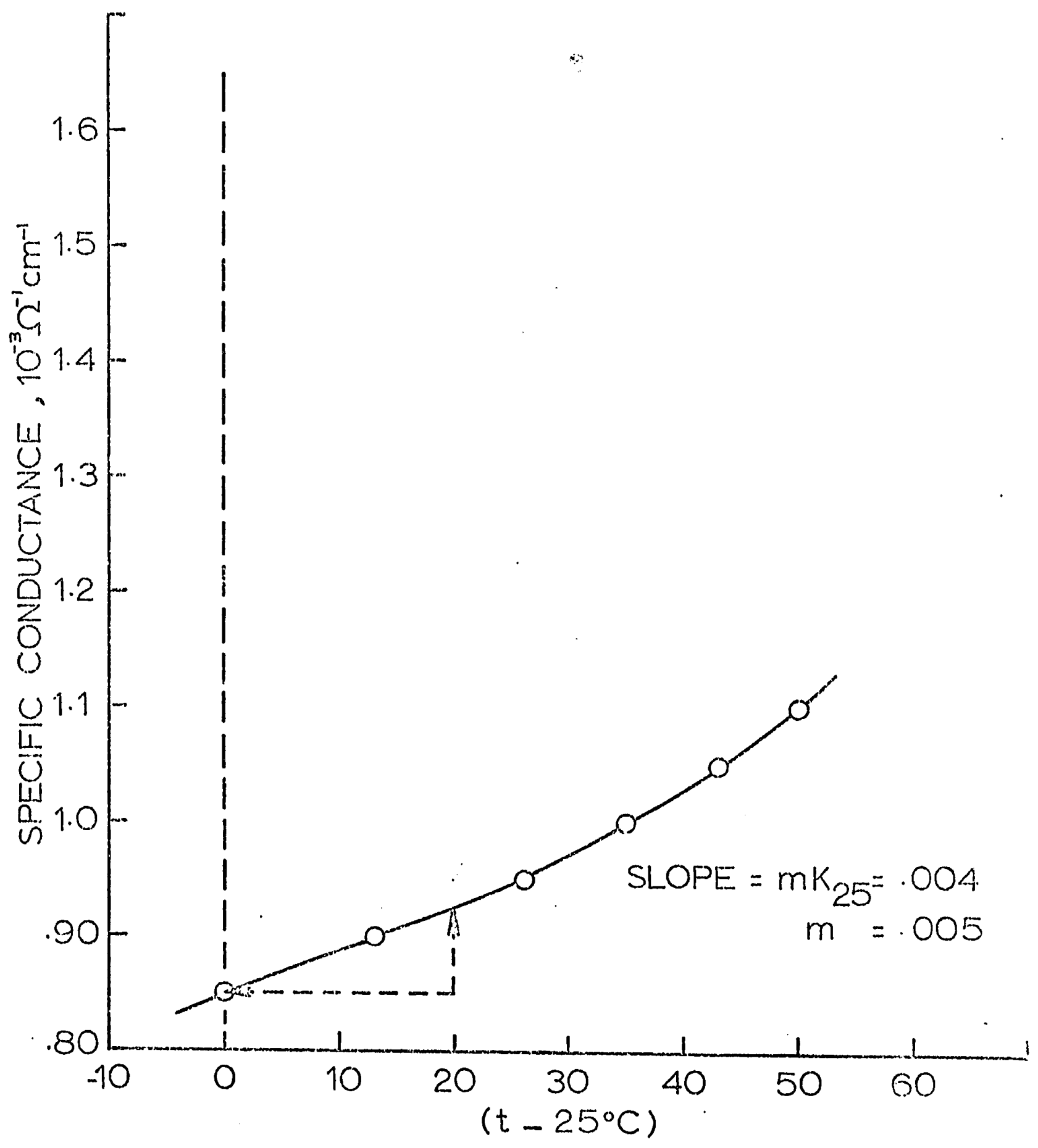

Figure A.III-1. Specirie conductnije versus (i- $-2,0 \mathrm{C})$

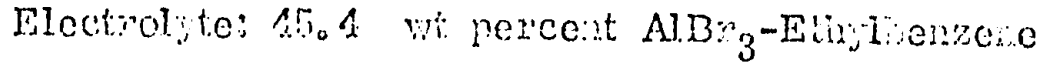


256

APPENDIX IV 
Table A. IV -1

Electrodeposition of Aluminum onto Copper

Solvent: Diethylbenzene, $174 \mathrm{~g}$. (200 ml)

Solute: $\mathrm{AlBr}_{3}, 100 \mathrm{~g}$. (36.4 wt. percent)

Current: 0.100 ampere

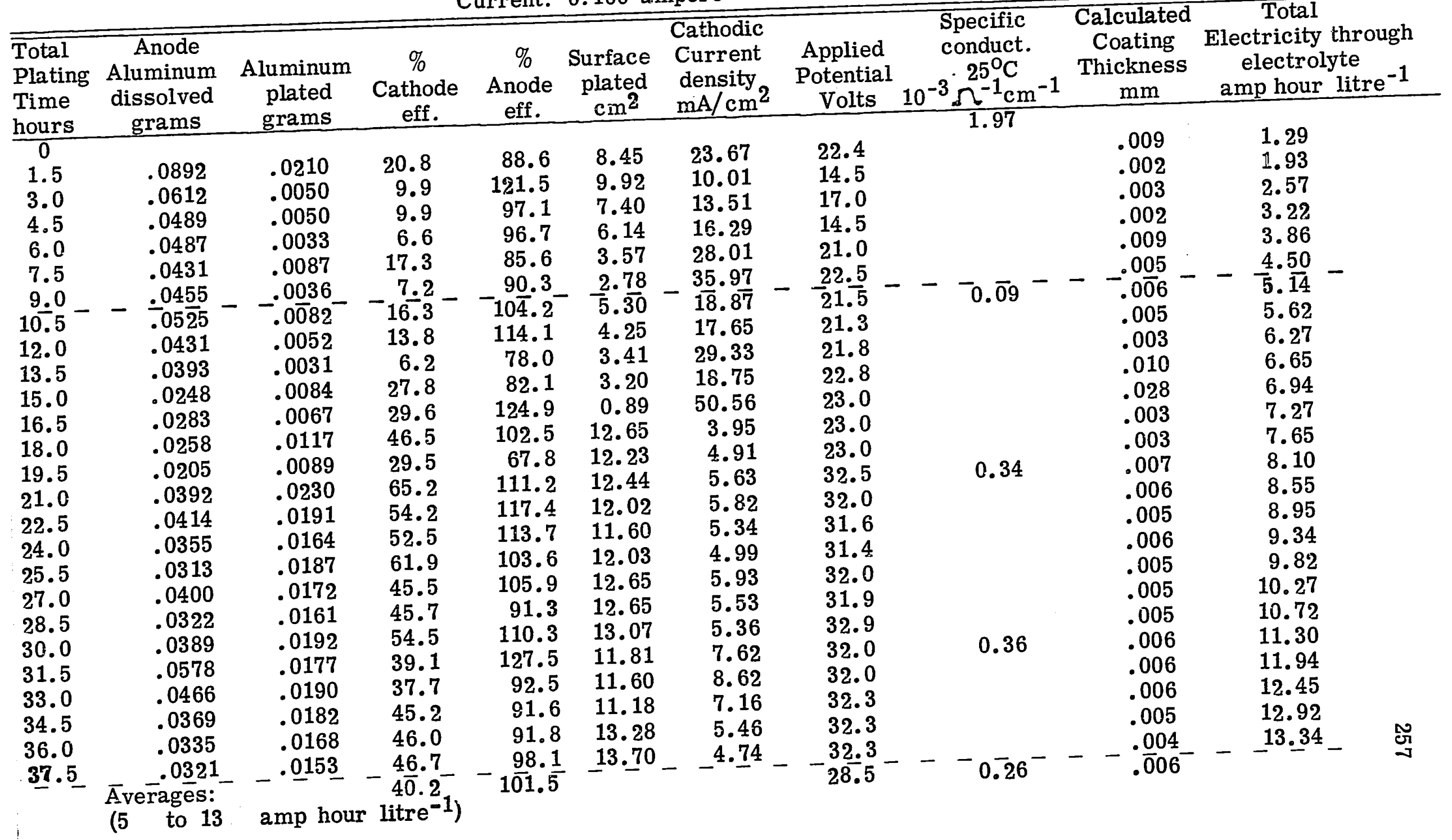


Table A.IV-2

Electrodeposition of Aluminum onto Copper Solvent: Diethylbenzene, $174 \mathrm{~g} .(200 \mathrm{ml})$ Solute: $\mathrm{AlBr}_{3}, 145 \mathrm{~g}$. (45.4 wt. percent) Current: 0.100 ampere

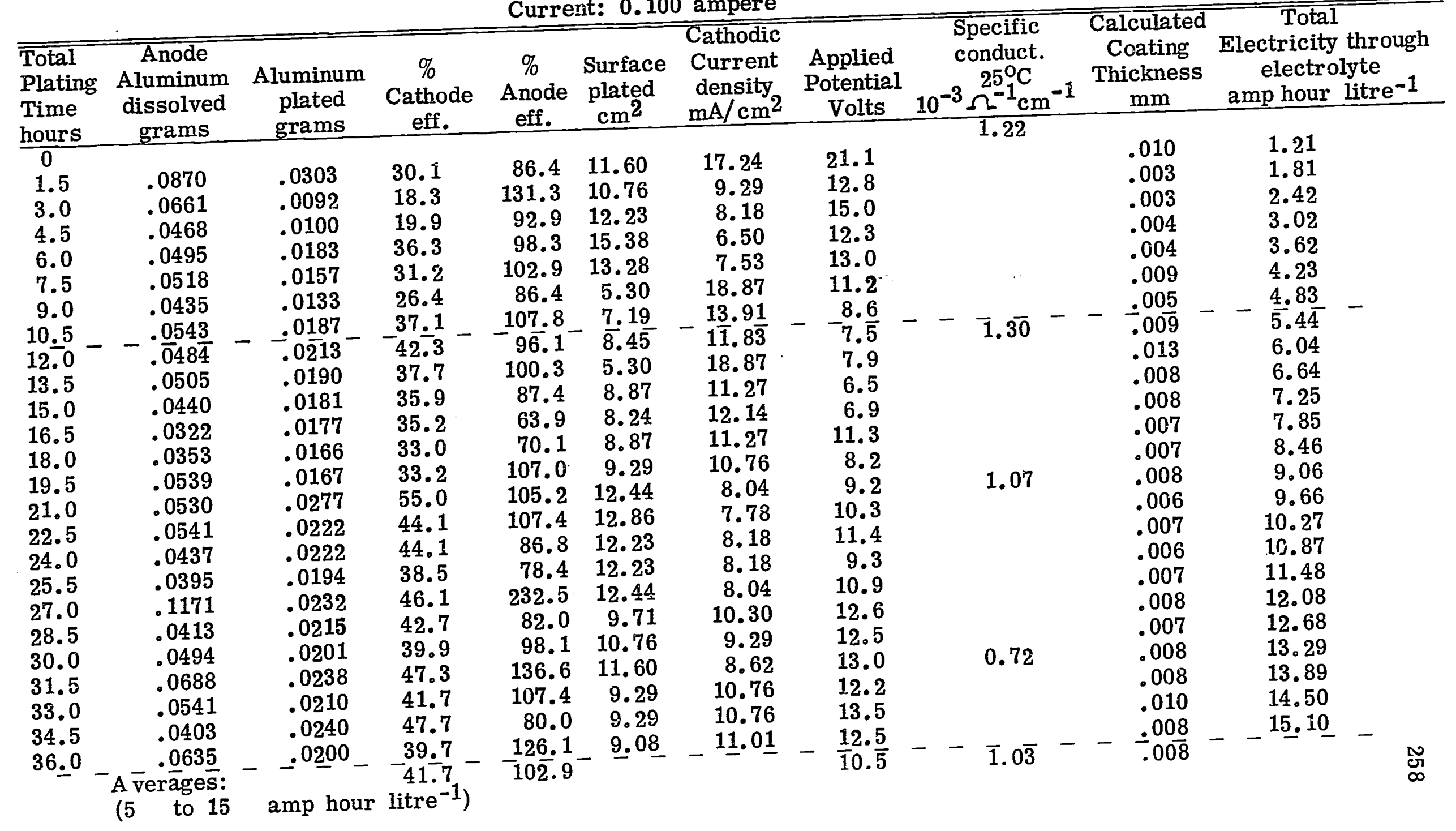


Table A.IV-3

Electrodeposition of Aluminum onto Copper Solvent: Diethylbenzene, 174g. $(200 \mathrm{ml})$

Solute: $\mathrm{AlBr}_{3}, 200 \mathrm{~g}$. (53.4 wt. percent)

Current: 0.100 ampere

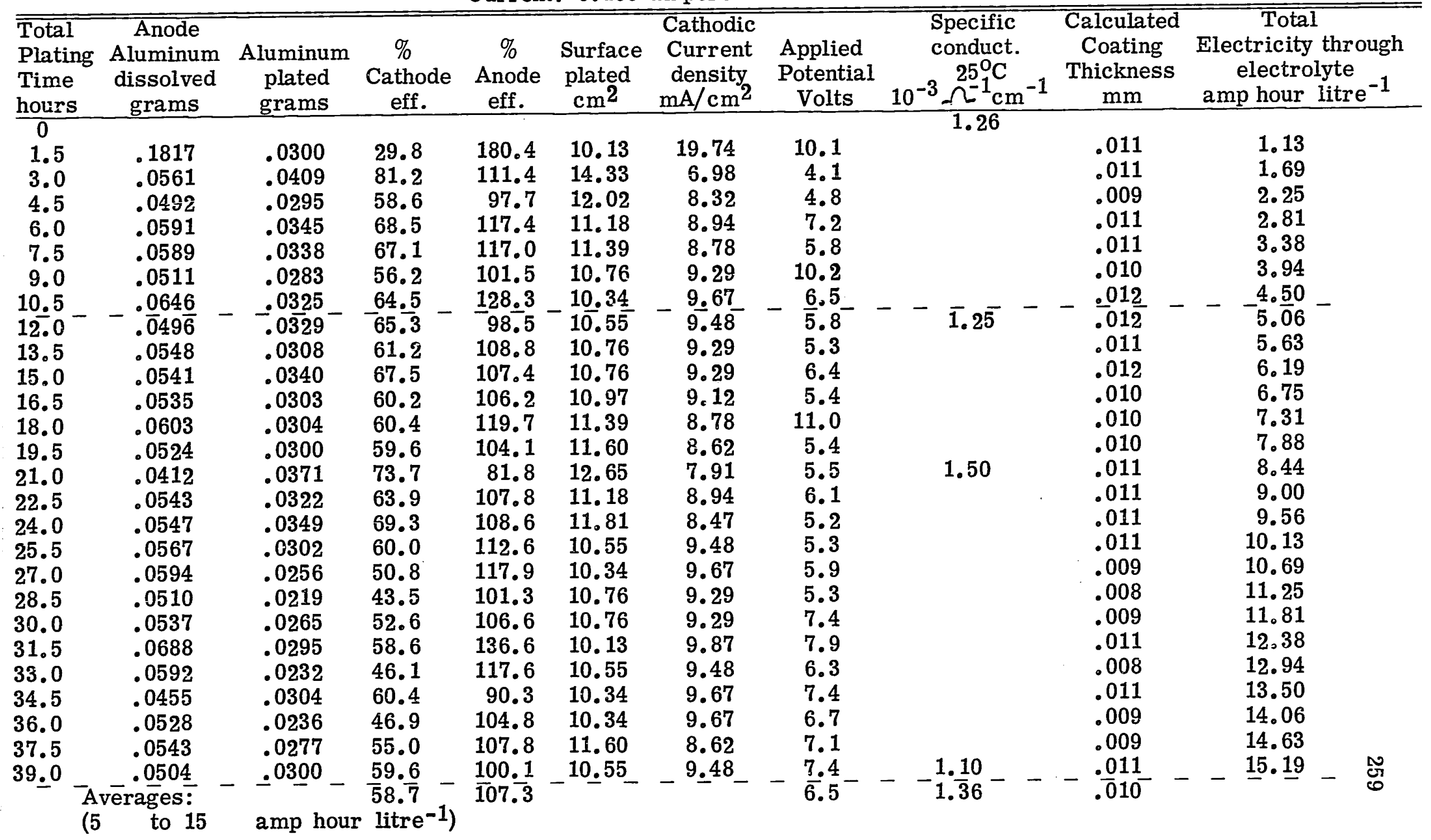


Table A.IV-4

Electrodeposition of Aluminum onto Copper Solvent: Toluene, $200 \mathrm{ml}$

Solute: $\mathrm{AlBr}_{3}, 100 \mathrm{~g}$. (36.4 wt. percent)

Current: 0.150 ampere

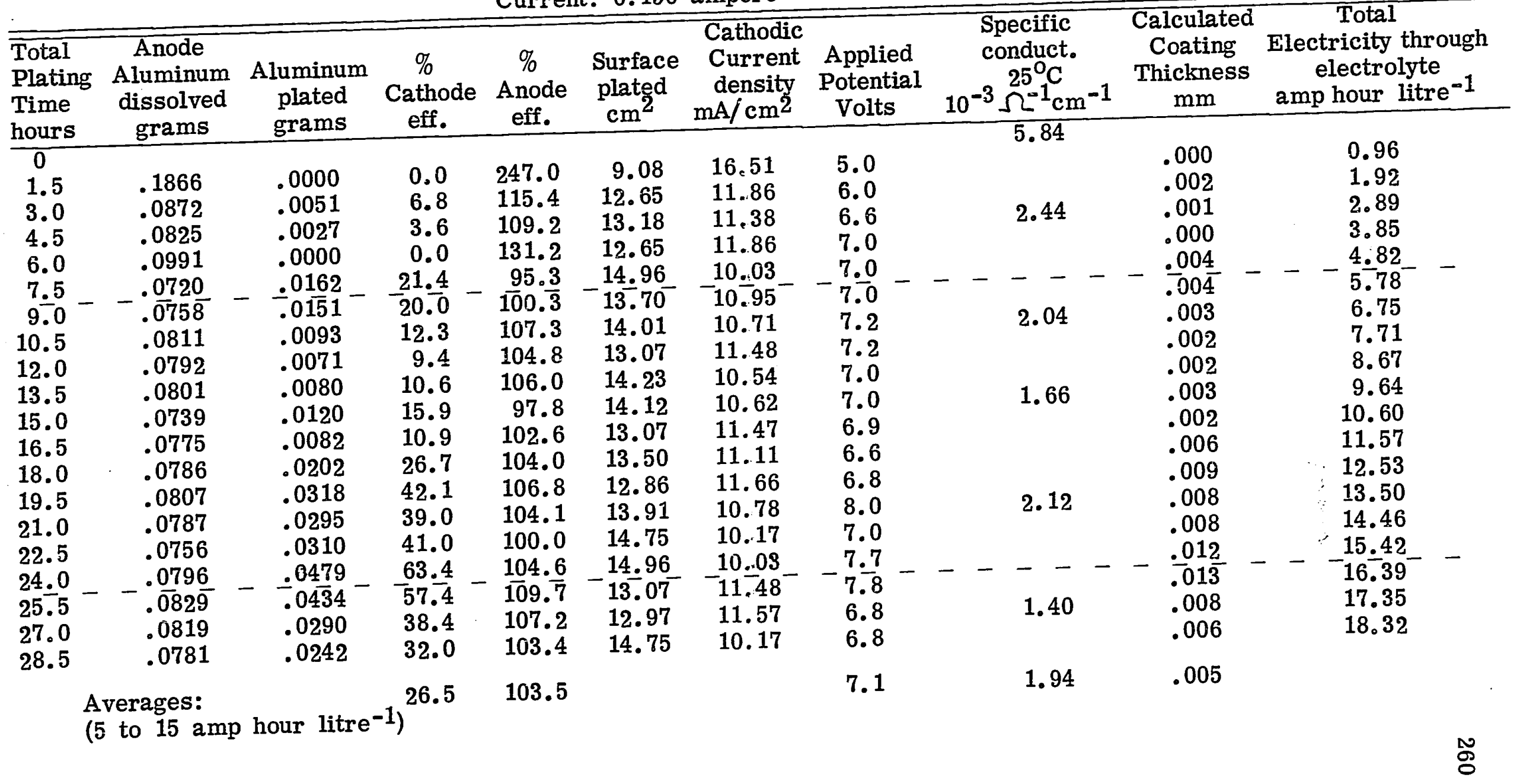


Table A. IV -5

Electrodeposition of Aluminum onto Copper

Solvent: Toluene, $200 \mathrm{ml}$

Solute: $\mathrm{AlBr}_{3}, 145 \mathrm{~g}$. (45.4 wt. percent)

Current: 0.150 ampere

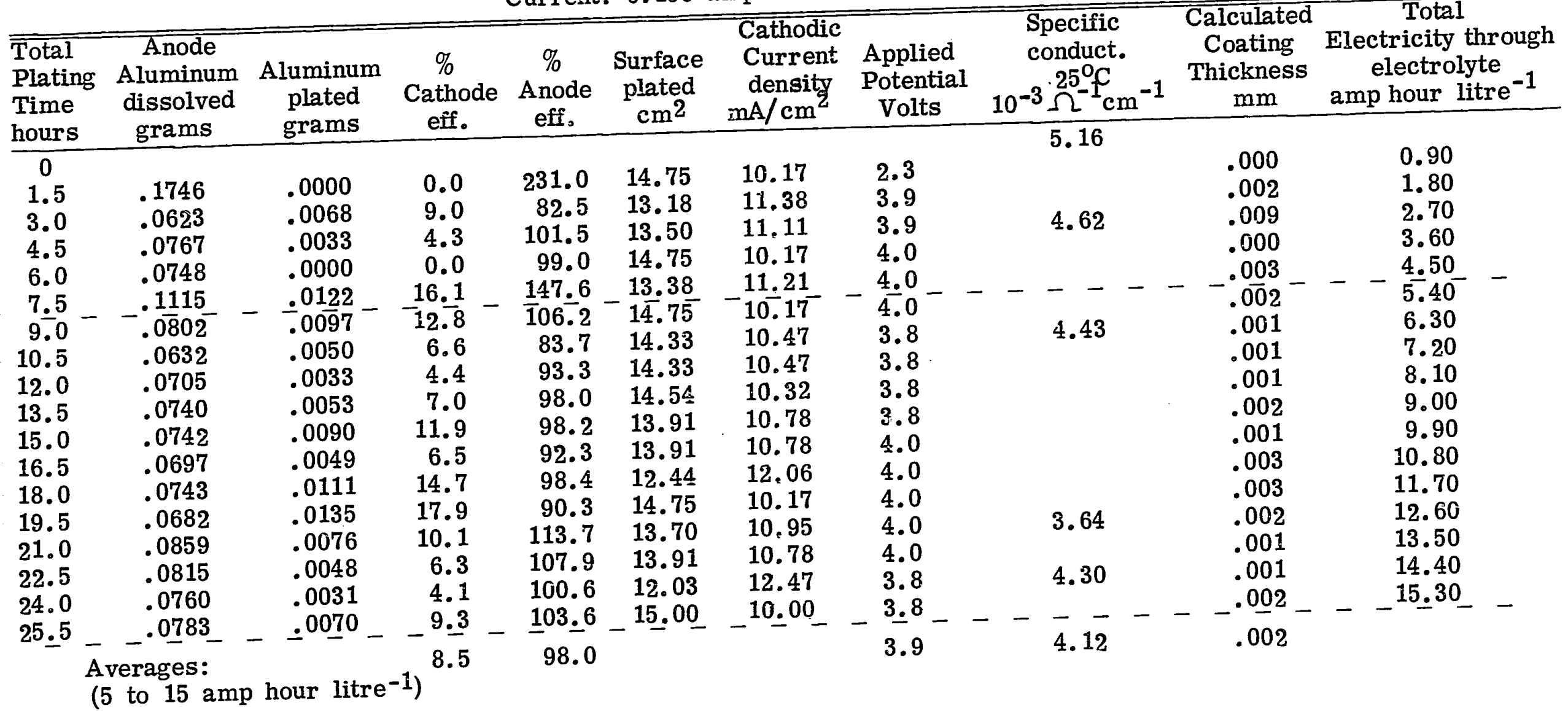


Table A.IV -6

Electrodeposition of Aluminum onto Copper

Solvent: Toluene, $200 \mathrm{ml}$

Solute: $\mathrm{AlBr}_{3}, 200$ g. (53.4 wt. percent)

Current: 0.150 ampere

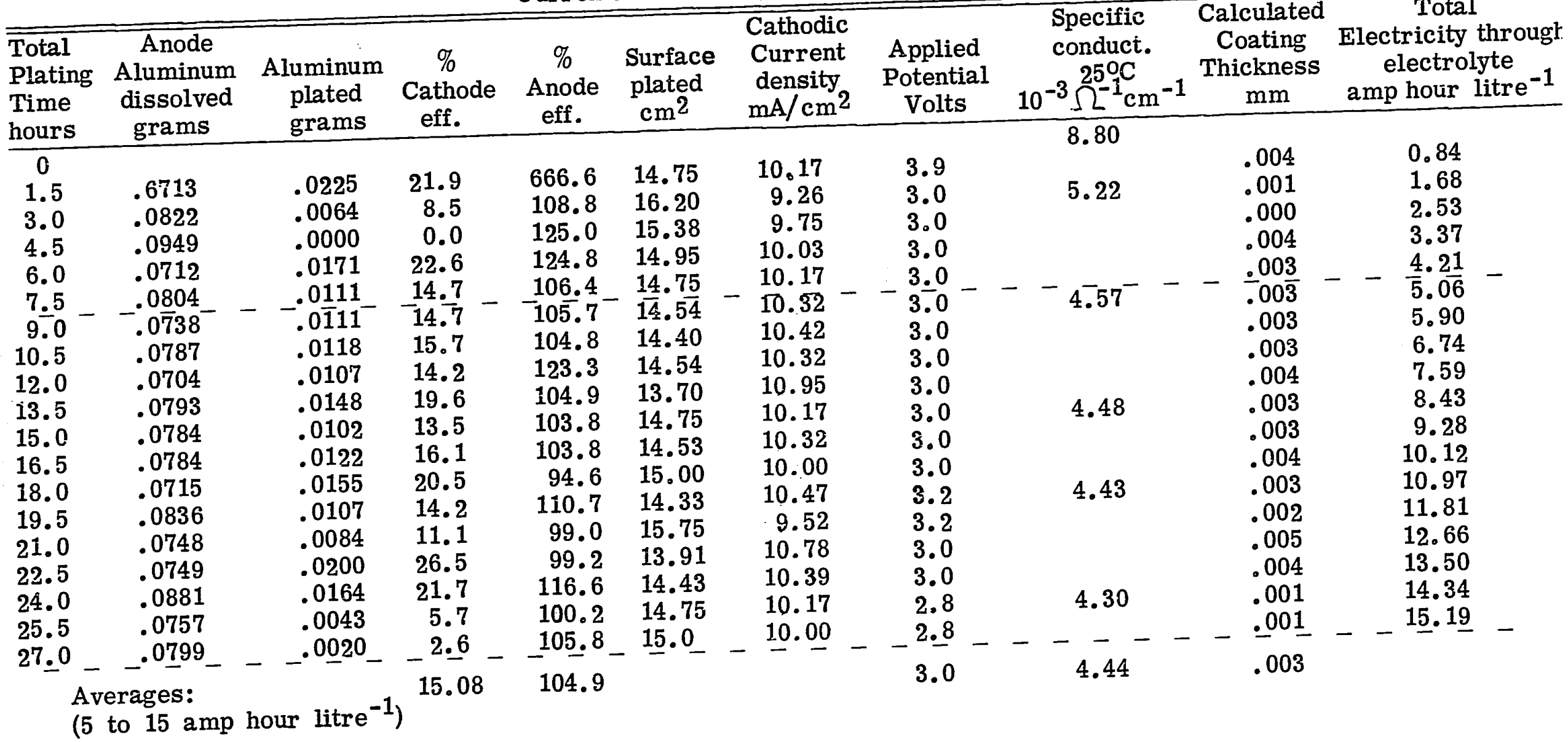


Table A.IV -7

Electrodeposition of Aluminum onto Copper

Solvent: Diethylbenzene - Toluene 1:4, $200 \mathrm{ml}$.

Solute: $\mathrm{AlBr}_{3}, 100 \mathrm{~g}$. (36.4 wt. percent)

Current: 0.100 ampere

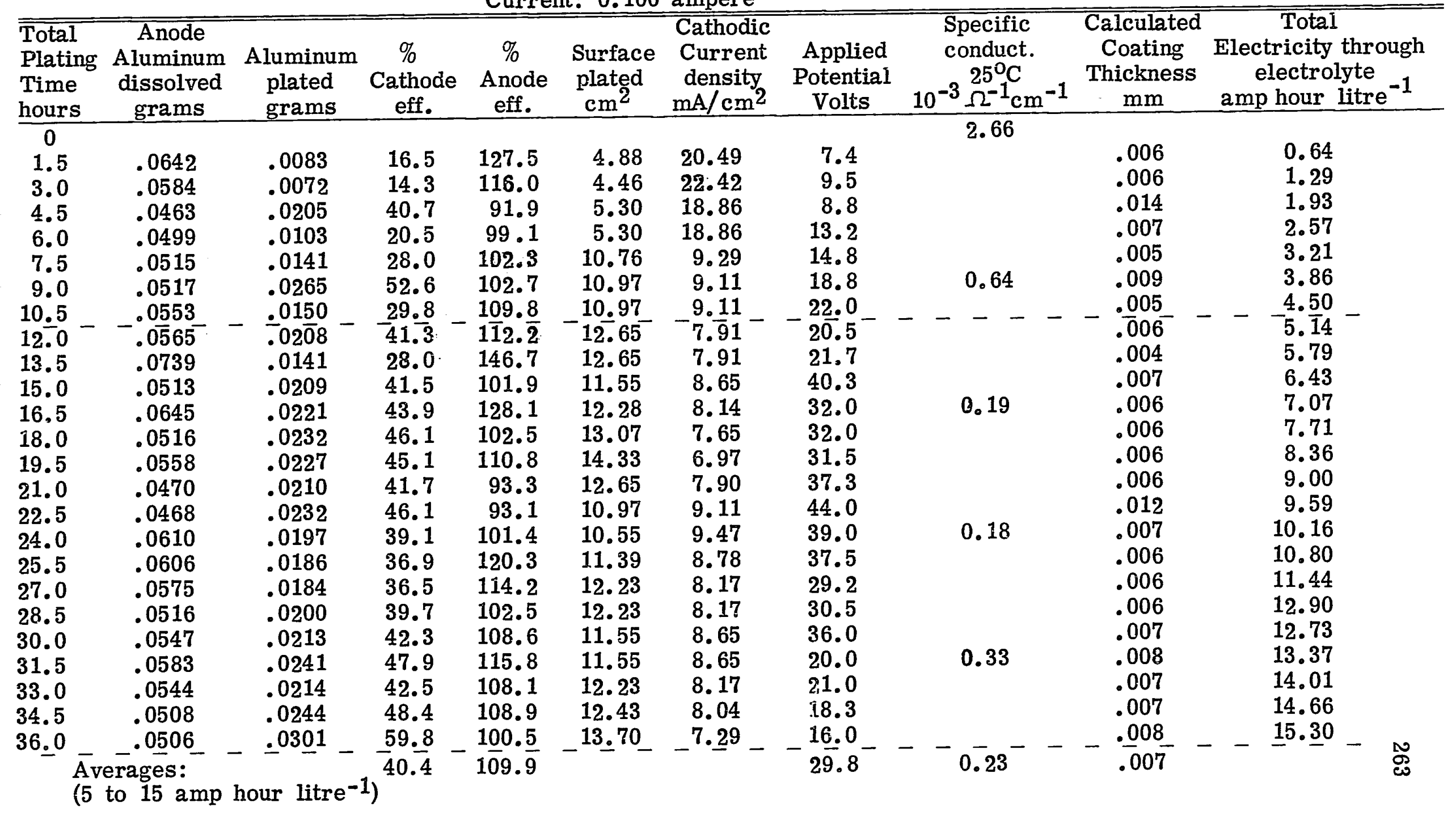


Table A.IV-8

Electrodeposition of Aluminum onto Copper

Solvent: Diethylbenzene - Toluene 1:4, $200 \mathrm{ml}$.

Solute: $\mathrm{AlBr}_{3}, 145$ g. (45.4 wt. percent)

Current: 0.100 ampere

\begin{tabular}{|c|c|c|c|c|c|c|c|c|c|c|c|c|c|c|}
\hline $\begin{array}{l}\text { Total } \\
\text { Plating } \\
\text { Time } \\
\text { hours }\end{array}$ & $\begin{array}{c}\text { Anode } \\
\text { Aluminum } \\
\text { dissolved } \\
\text { grams }\end{array}$ & $\begin{array}{l}\text { Aluminum } \\
\text { plated } \\
\text { grams }\end{array}$ & $\begin{array}{c}\% \\
\text { Cathode } \\
\text { eff. }\end{array}$ & $\begin{array}{c}\% \\
\text { Anode } \\
\text { eff. }\end{array}$ & $\begin{array}{c}\text { Surface } \\
\text { plated } \\
\mathrm{cm}^{2} \\
\end{array}$ & $\begin{array}{l}\text { Cathodic } \\
\text { Current } \\
\text { density } \\
\mathrm{mA} / \mathrm{cm}^{2}\end{array}$ & $\begin{array}{c}\text { Applied } \\
\text { Potential } \\
\text { Volts } \\
\end{array}$ & $\begin{array}{r}5 \\
c \\
10^{-3} \\
\end{array}$ & $\begin{array}{l}\text { Specific } \\
\text { conduct. } \\
25^{\circ} \mathrm{C} \\
-3 \Omega^{-1} \mathrm{~cm} \\
\end{array}$ & & $\begin{array}{c}\text { Calculated } \\
\text { Coating } \\
\text { Thickness } \\
\text { mm } \\
\end{array}$ & & $\begin{array}{l}\text { Total } \\
\text { Electricity } \\
\text { electrol } \\
\text { amp hour }\end{array}$ & $\begin{array}{l}\text { through } \\
\text { lyte } \\
\text { litre }\end{array}$ \\
\hline 0 & & & & & & & & & 1.90 & & & & & \\
\hline 1.5 & .0634 & .0263 & 52.2 & 125.9 & 16.43 & 6.08 & 6.1 & & & & .006 & & 0.60 & \\
\hline 3.0 & .0580 & .0301 & 59.8 & 115.2 & 10.97 & 9.11 & 9.8 & & & & .010 & & 1.21 & \\
\hline 4.5 & .0431 & .0288 & 57.2 & 85.6 & 11.39 & 8.77 & 8.8 & & & & .009 & & 1.81 & \\
\hline 6.0 & .0473 & .0260 & 51.6 & 93.9 & 11.60 & 8.62 & 7.3 & & & & .008 & & 2.42 & \\
\hline 7.5 & .0527 & .0269 & 53.4 & 104.6 & 12.02 & 8.32 & 7.3 & & & & .008 & & 3.02 & \\
\hline 9.0 & .0517 & .0292 & 58.0 & 102.7 & 11.39 & 8.78 & 6.3 & & 1.27 & & .010 & & 3.62 & \\
\hline 10.5 & .0530 & .0304 & 60.4 & 105.2 & 10.55 & 9.47 & 5.7 & & & & .011 & & 4.23 & \\
\hline 12.0 & .0558 & .0214 & 42.5 & 110.8 & 10.13 & 9.87 & 5.5 & - & - & & .008 & & 4.83 & - \\
\hline 13.5 & .0535 & $-\overline{.0235}$ & $46 . \overline{7}$ & $\overline{10} 6 . \overline{2}$ & 9.92 & $10 . \overline{0} 08$ & $\overline{3.9}$ & & & &.$\overline{009}$ & & $\overrightarrow{5} . \overline{44}$ & - \\
\hline 15.0 & .0551 & .0236 & 46.9 & 109.4 & 11.39 & 8.77 & 6.9 & & & & .008 & & 6.04 & \\
\hline 16.5 & .0591 & .0265 & 52.6 & 117.3 & 11.18 & 8.78 & 8.4 & & 0.97 & & .009 & & 6.64 & \\
\hline 18.0 & .0537 & .0331 & 65.7 & 106.6 & 11.18 & 8.78 & 8.0 & & & & .011 & & 7.25 & \\
\hline 19.5 & .0552 & .0257 & 51.0 & 109.6 & 10.65 & 9.38 & 8.1 & & & & .009 & & 7.85 & \\
\hline 21.0 & .0470 & .0226 & 44.9 & 93.3 & 10.65 & 7.51 & 8.0 & & & & .008 & & 8.34 & \\
\hline 22.5 & .0463 & .0229 & 45.5 & 92.1 & 9.93 & 10.07 & 9.7 & & & & .009 & & 8.94 & \\
\hline 24.0 & .0464 & .0268 & 53.2 & 92.0 & 10.34 & 9.67 & 7.6 & & 0.93 & & .010 & & 9.54 & \\
\hline 25.5 & .0538 & .0262 & 52.0 & 106.8 & 10.13 & 9.87 & 8.0 & & & & .010 & & 10.15 & \\
\hline 27.0 & .0518 & .0215 & 42.7 & 102.9 & 9.71 & 10.29 & 8.1 & & & & .008 & & 10.75 & \\
\hline 28.5 & .0396 & .0185 & 36.7 & 78.6 & 10.34 & 9.67 & 7.9 & & & & .007 & & 11.36 & \\
\hline 30.0 & .0525 & .0236 & 46.9 & 104.2 & 10.34 & 9.67 & 8.9 & & & & .008 & & 11.96 & \\
\hline 31.5 & .0517 & .0241 & 47.9 & 102.7 & 9.93 & 10.07 & 7.8 & & 1.06 & & .009 & & 12.56 & \\
\hline 33.0 & .0466 & .0234 & 46.5 & 92.5 & 9.29 & 10.76 & 8.4 & & & & .009 & & 13.16 & \\
\hline 34.5 & .0517 & .0272 & 54.0 & 102.7 & 10.34 & 9.67 & 7.5 & & & & .010 & & 13.77 & \\
\hline 36.0 & .0466 & .0293 & 58.2 & 92.5 & 10.34 & 9.67 & 6.7 & & & & .010 & & 14.36 & \\
\hline 37.5 & . 0519 & .0268 & 53.2 & 103.1 & 11.18 & 8.94 & 6.0 & & & - & .009 & & -14.98 & - S \\
\hline
\end{tabular}


Table A.IV-9

Electrodeposition of Aluminum onto Copper

Solvent: Diethylbenzene - Toluene 1:4, $200 \mathrm{ml}$.

Solute: $\mathrm{AlBr}_{3}, 200 \mathrm{~g}$. (53.4 wt. percent)

Current: 0.100 ampere

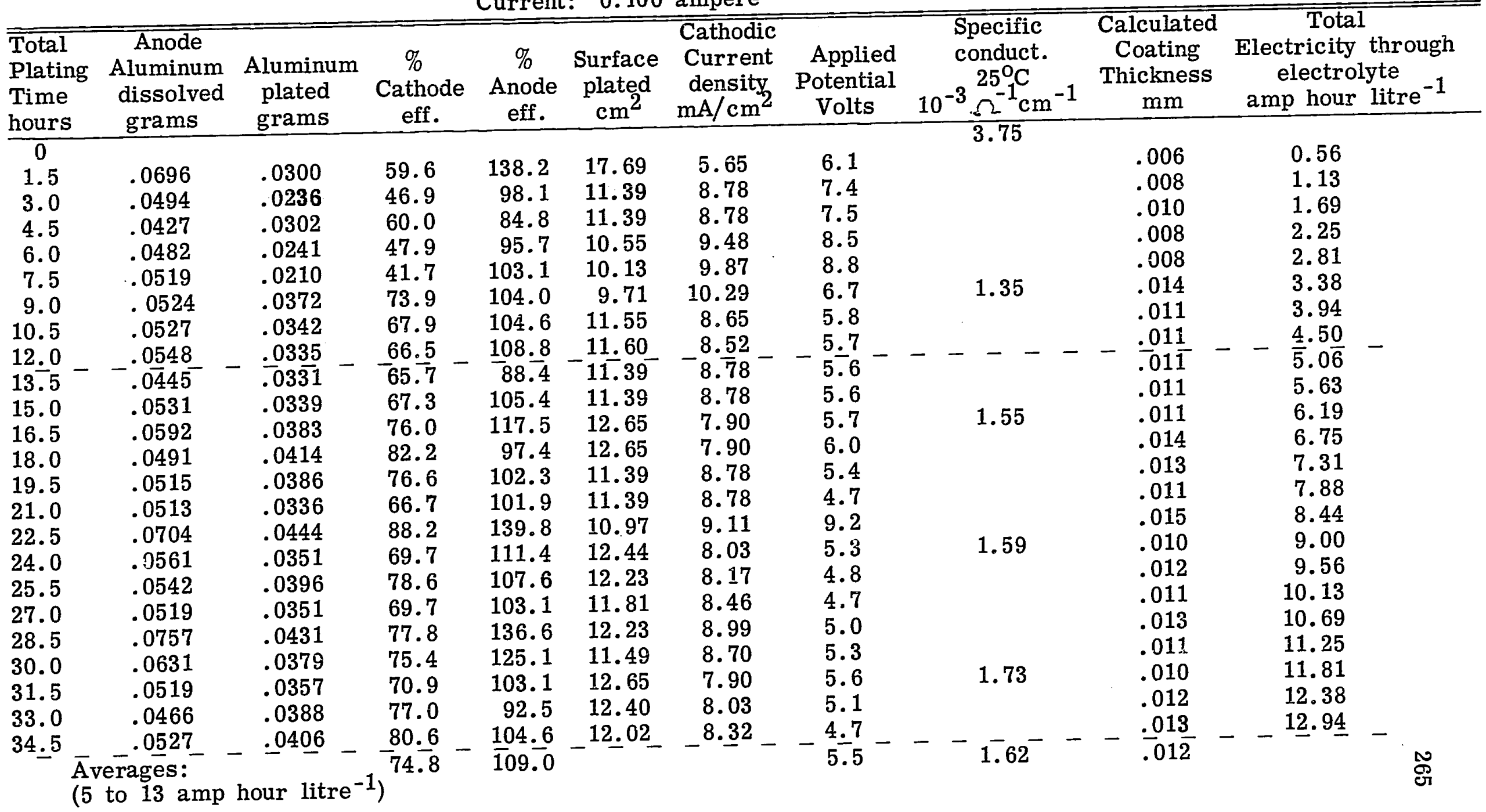


Table A.IV-10

Electrodeposition of Aluminum onto Copper

Solvent: Diethylbenzene - Toluene 1:1, $200 \mathrm{ml}$

Solute: $\quad \mathrm{AlBr}_{3}, 100 \mathrm{~g}$. (36.4 wt. percent)

Current: 0.100 ampere

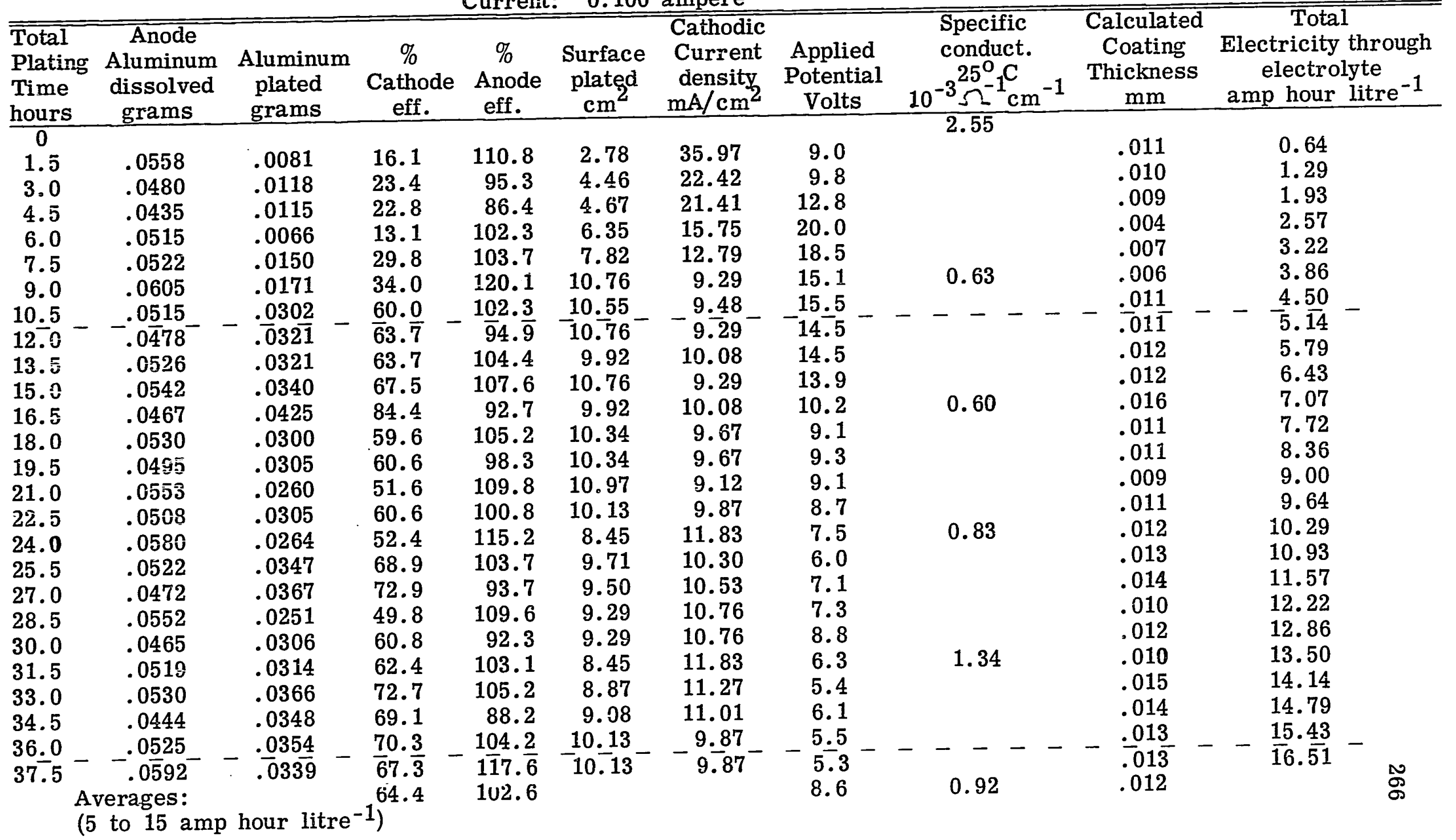


Table A.IV-11

Electrodeposition of Aluminum onto Copper

Solvent: Diethylbenzene - Toluene 1:1, $200 \mathrm{ml}$

Solute: $\mathrm{AlBr}_{3}, 145 \mathrm{~g}$. (45.4 wt. percent)

Current: 0.100 ampere

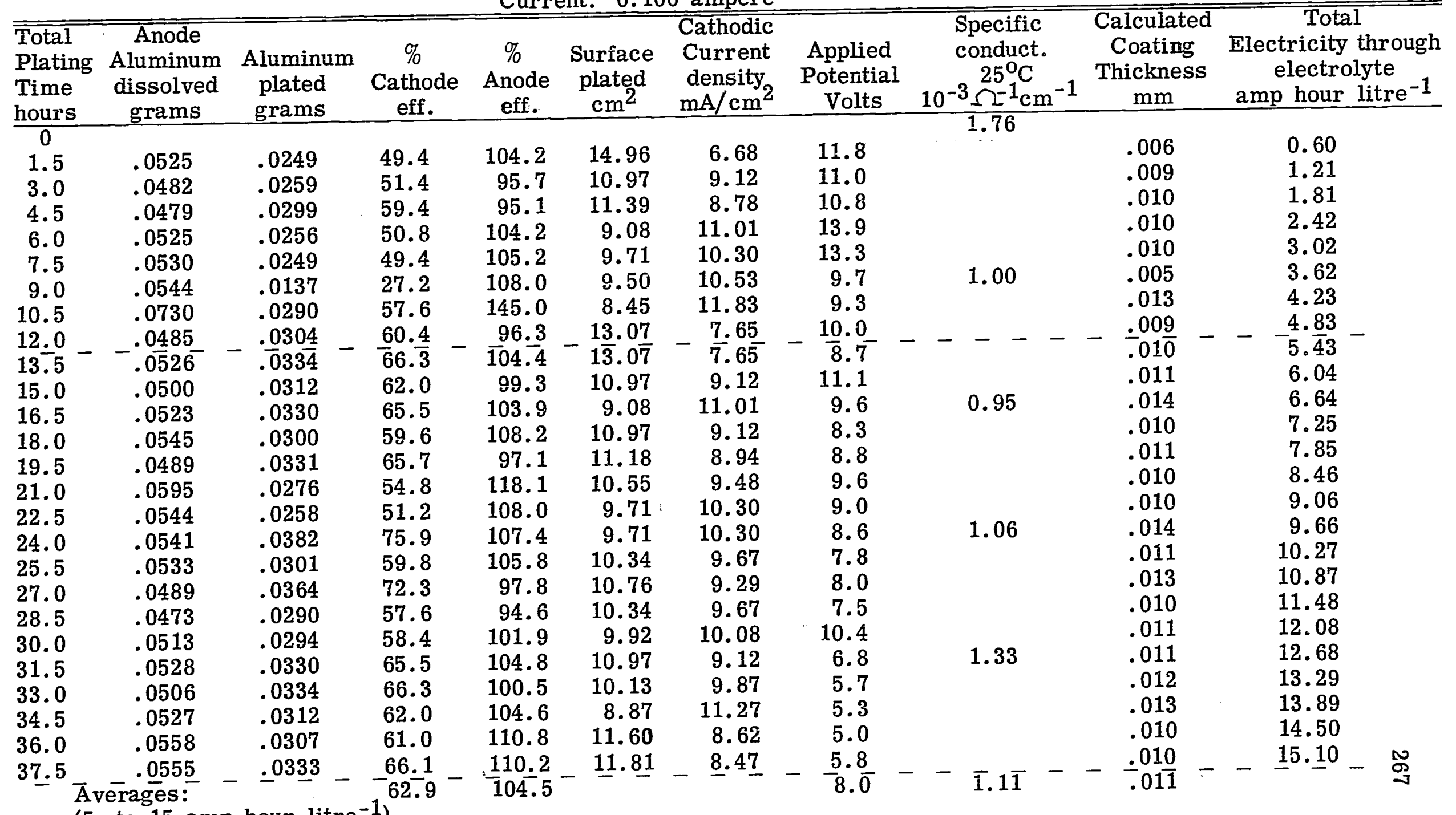
(5 to 15 amp hour litre ${ }^{-1}$ ) 
Table A.IV-12

Electrodeposition of Aluminum onto Copper

Solvent: Diethylbenzene - Toluene 1:1, $200 \mathrm{ml}$.

Solute: $\mathrm{AlBr}_{3}, 200 \mathrm{~g}$. (53.4 wt. percent)

Current: 0.100 ampere

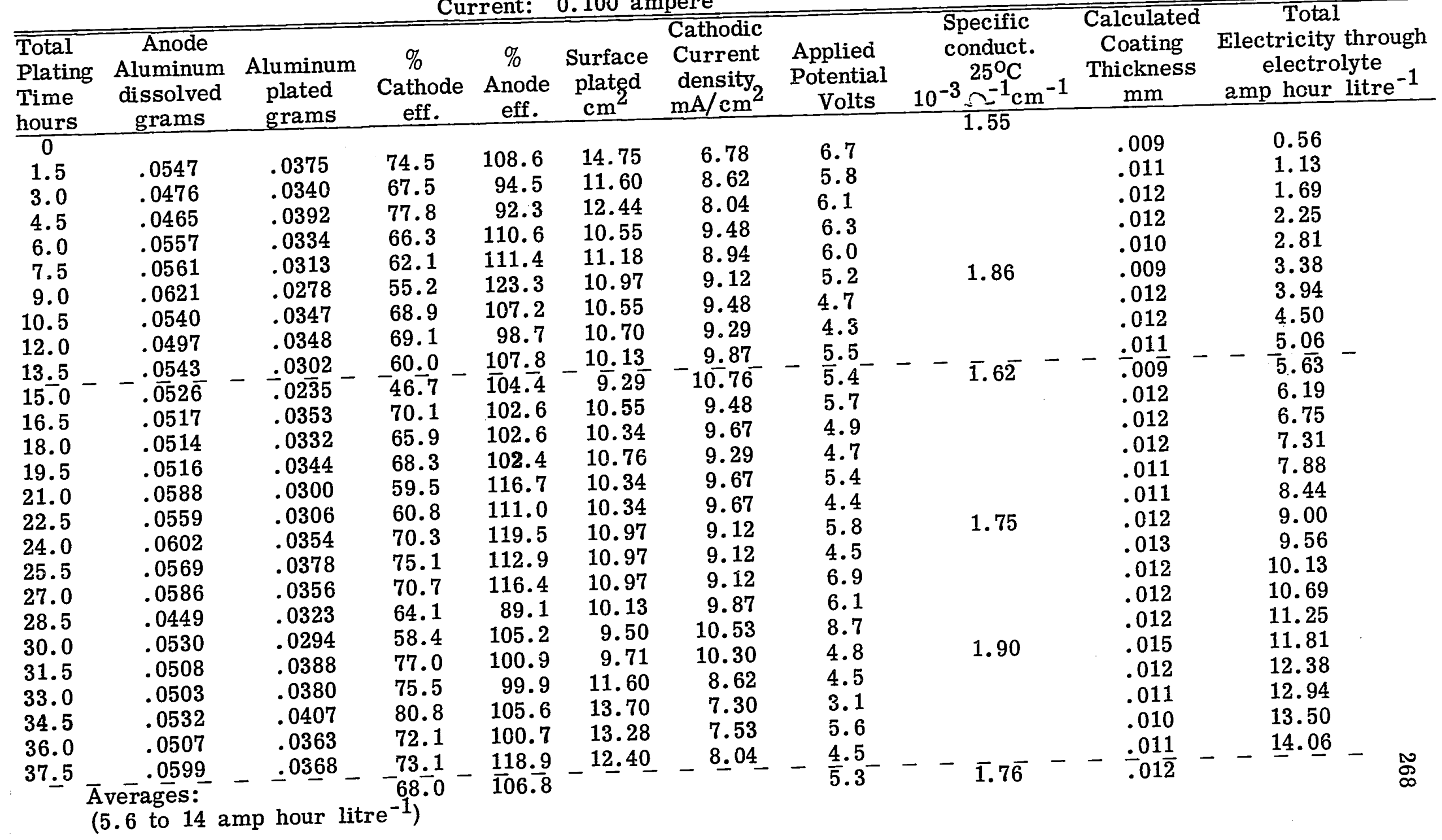


Table Á. IV -13

Electrodeposition of Aluminum onto Copper

Solvent: Diethylbenzene - Benzene 1:4, $200 \mathrm{ml}$.

Solute: $\mathrm{AlBr}_{3}, 100 \mathrm{~g}$. (36.4 wt. percent)

Current: 0.100 ampere

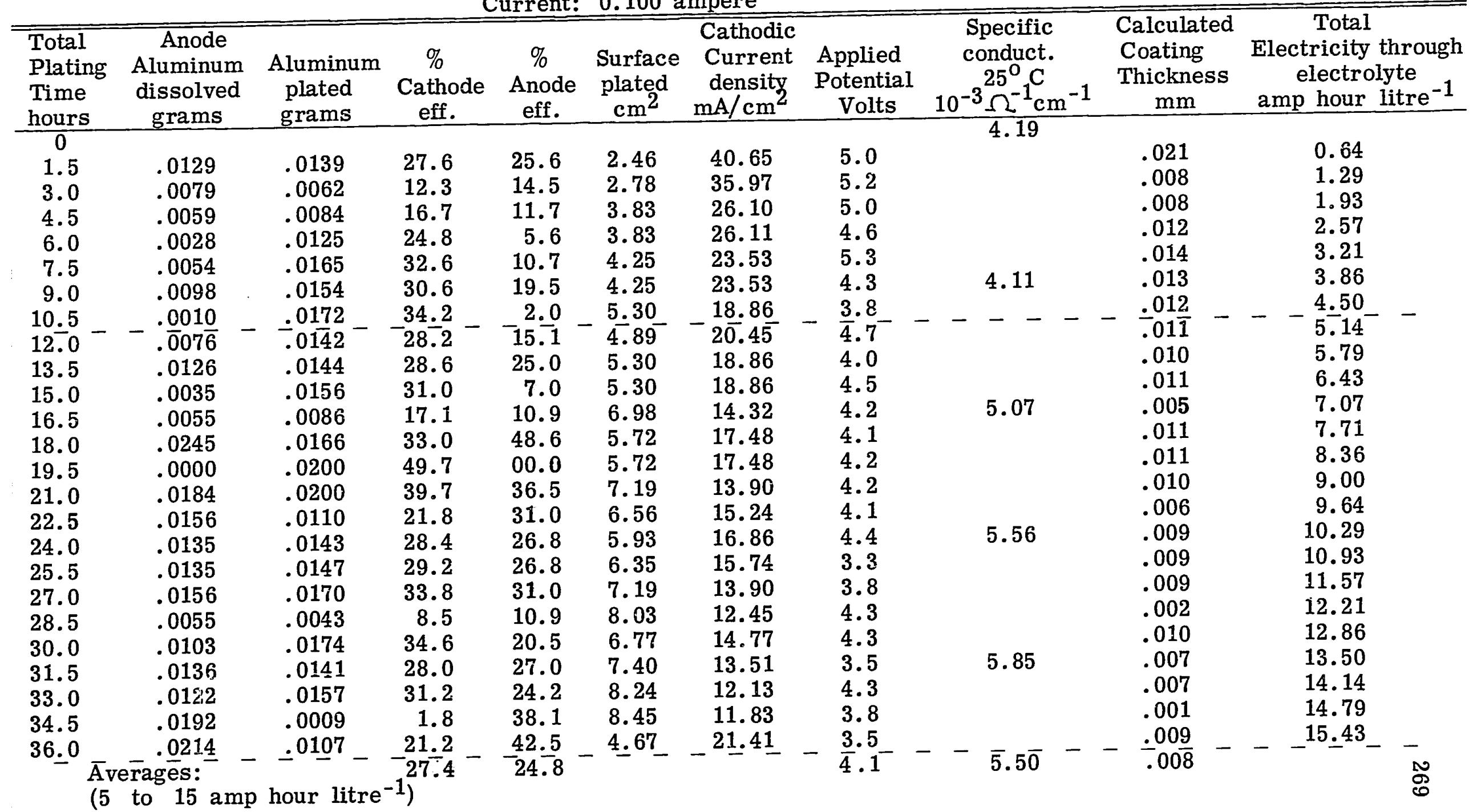


Table A.IV-14

Electrodeposition of Aluminum onto Copper

Solvent: Diethylbenzene - Benzene 1:4, $200 \mathrm{ml}$.

Solute: $\mathrm{AlBr}_{3}, 145 \mathrm{~g}$. (45.4 wt. percent)

Current: 0.100 ampere

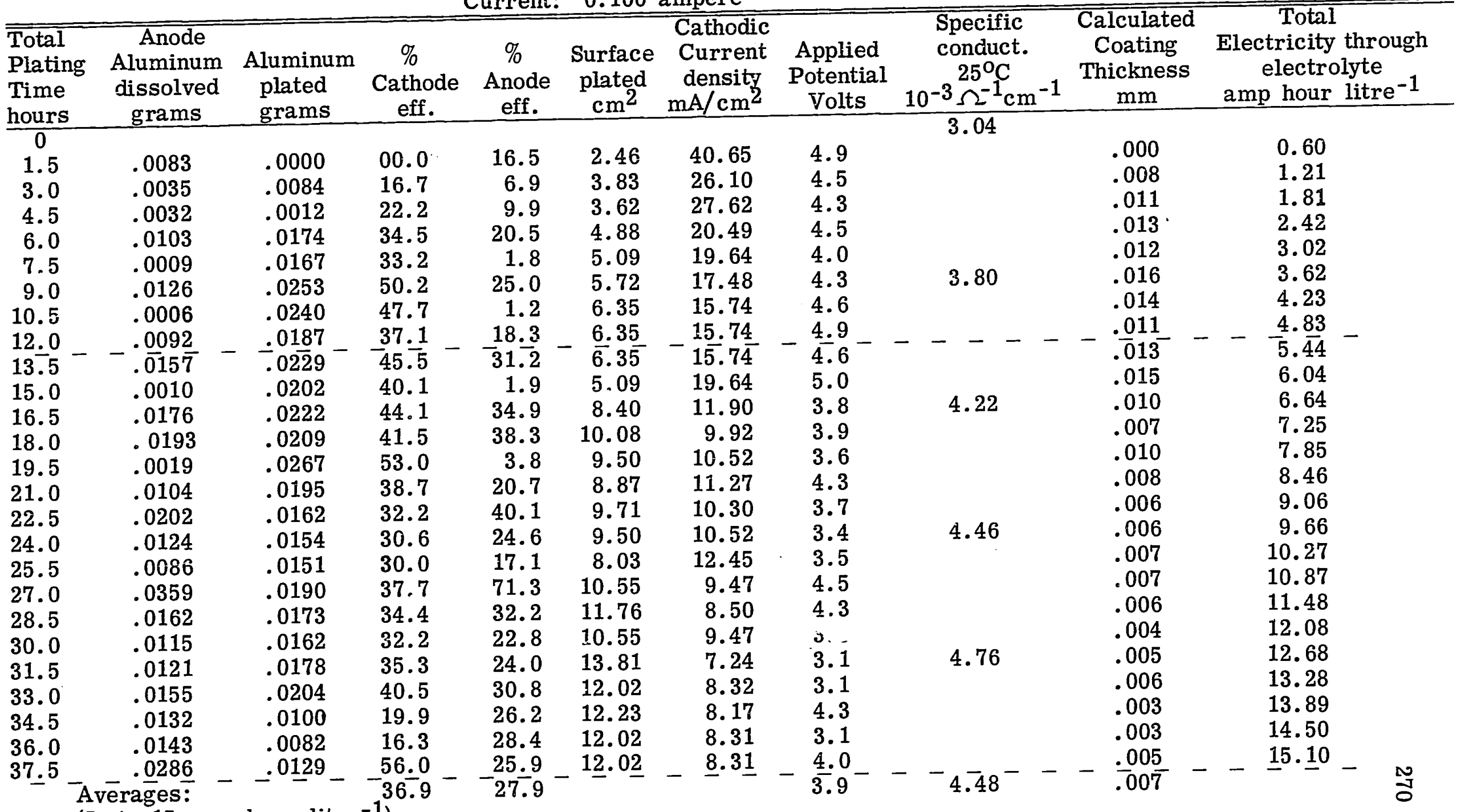

( 5 to 15 amp hour litre ${ }^{-1}$ ) 
Table A..IV-15

Electrodeposition of Aluminum onto Copper

Solvent: Diethylbenzene - Benzene 1:4, $200 \mathrm{ml}$.

Solute: $\mathrm{AlBr}_{3}, 200 \mathrm{~g}$ (53.4 wt. percent)

Current: 0.100 ampere

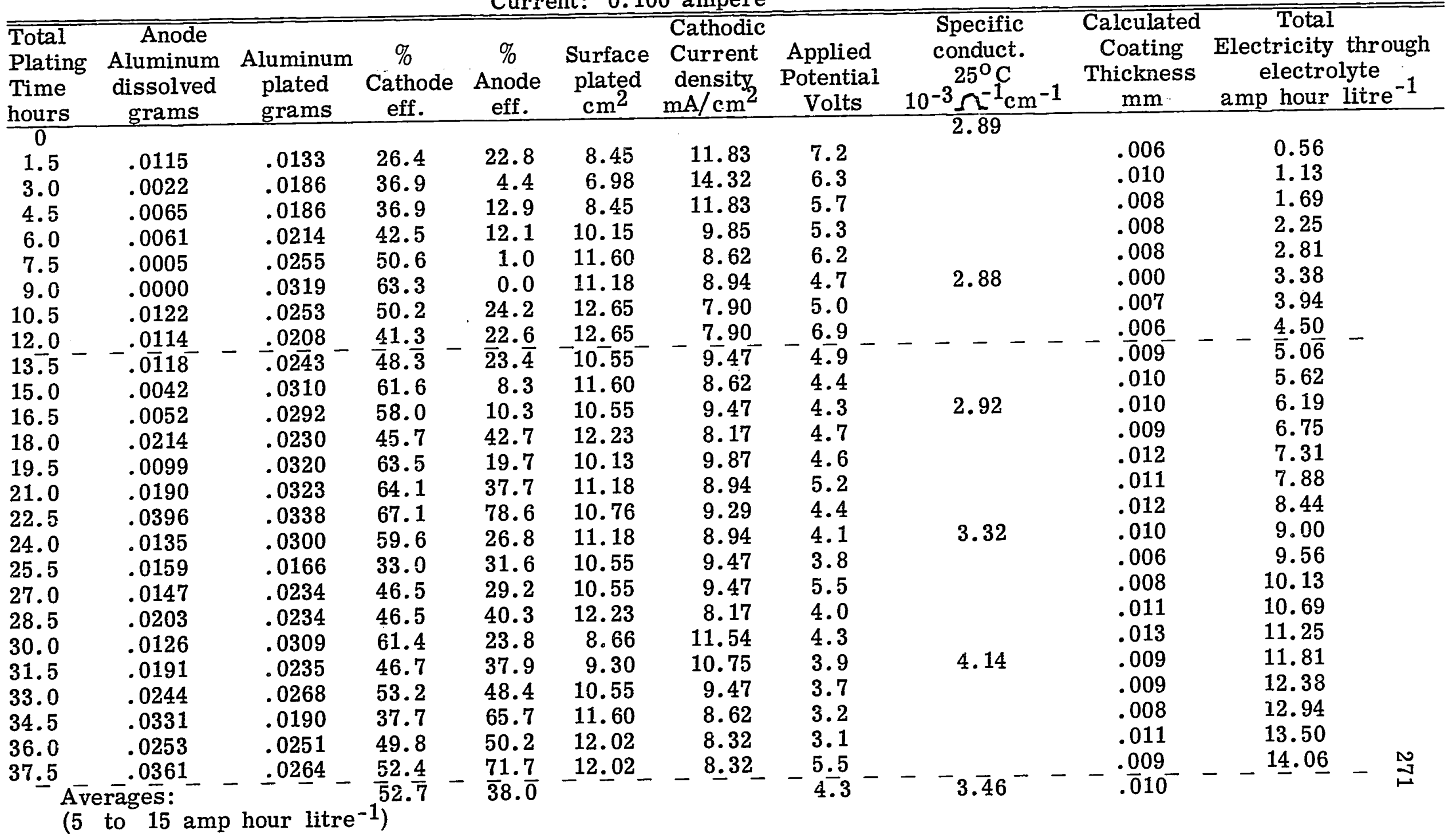


Table A.IV-16

Electrodeposition of Aluminum onto Copper

Solvent: Diethylbenzene - Benzene 1:1, $200 \mathrm{ml}$.

Solute: $\mathrm{AlBr}_{3}, 100 \mathrm{~g}$. (36.4 wt. percent)

Current: 0.100 ampere

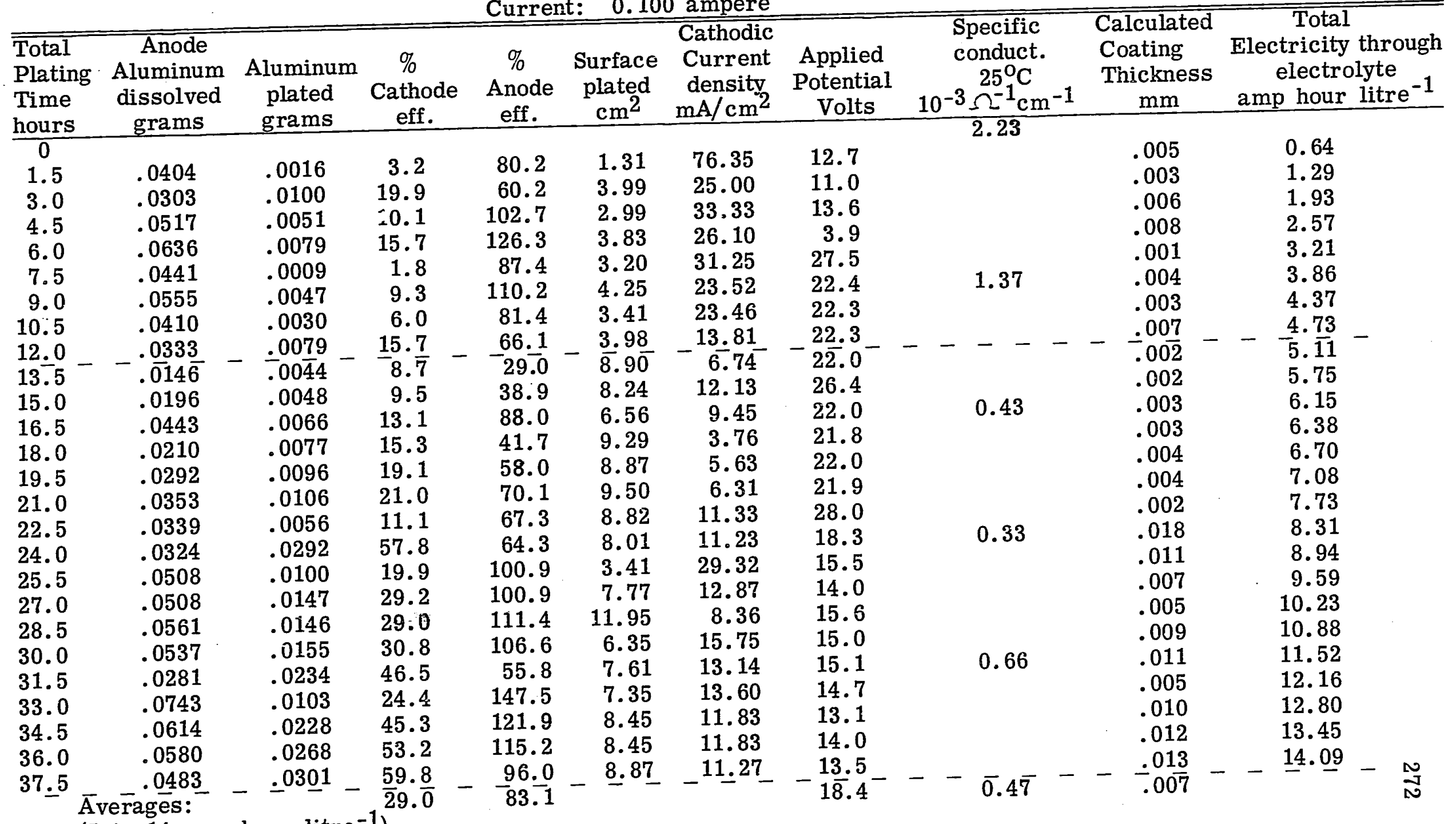

(5 to 14 amp hour litre ${ }^{-1}$ ) 
Table A.IV -17

Electrodeposition of Aluminum onto Copper Solvent: Diethylbenzene - Benzene 1:1, $200 \mathrm{ml}$.

Solute: $\mathrm{AlBr}_{3}, 145 \mathrm{~g}$. (45.4 wt. percent)

Current: 0.100 ampere

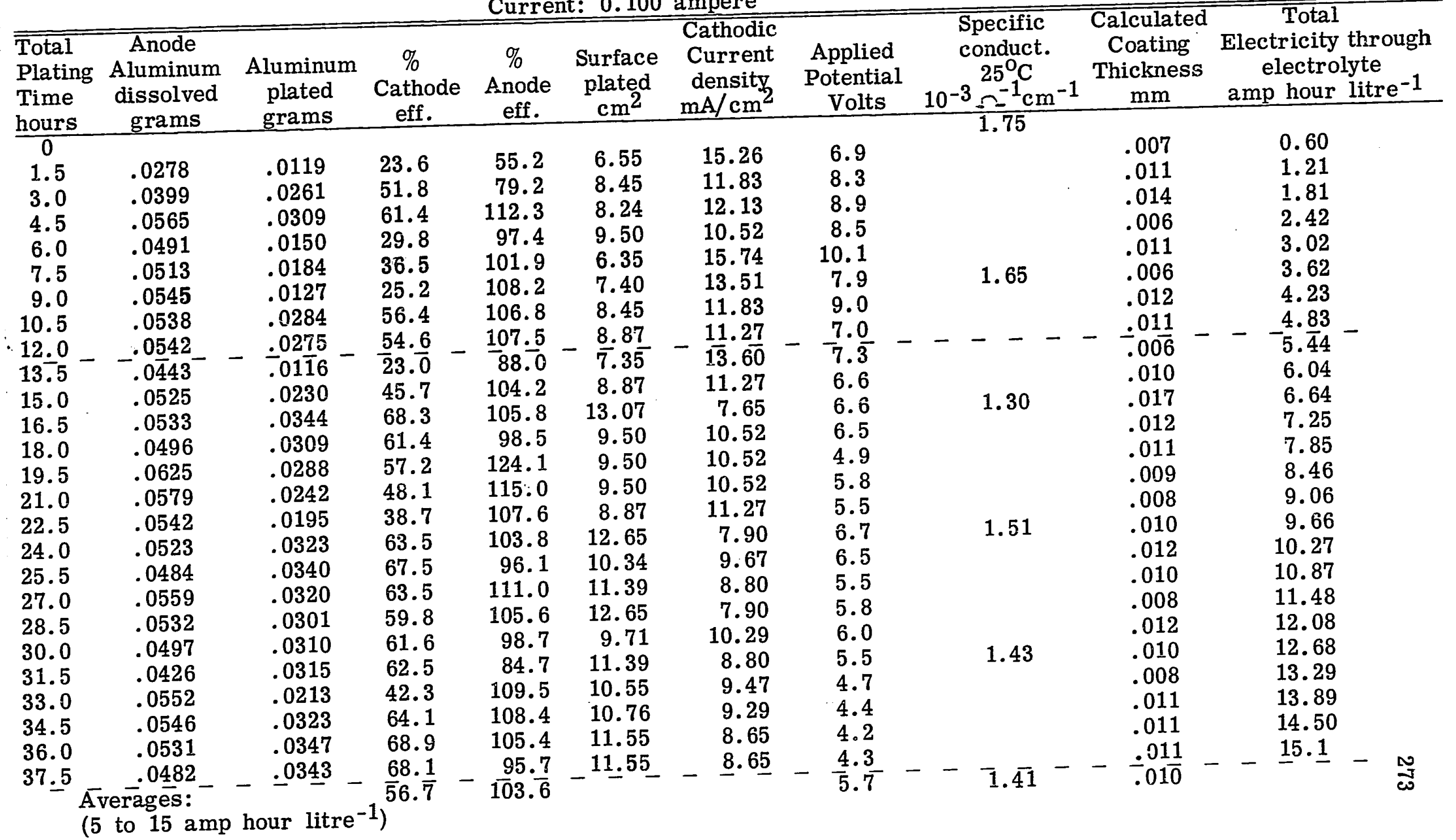




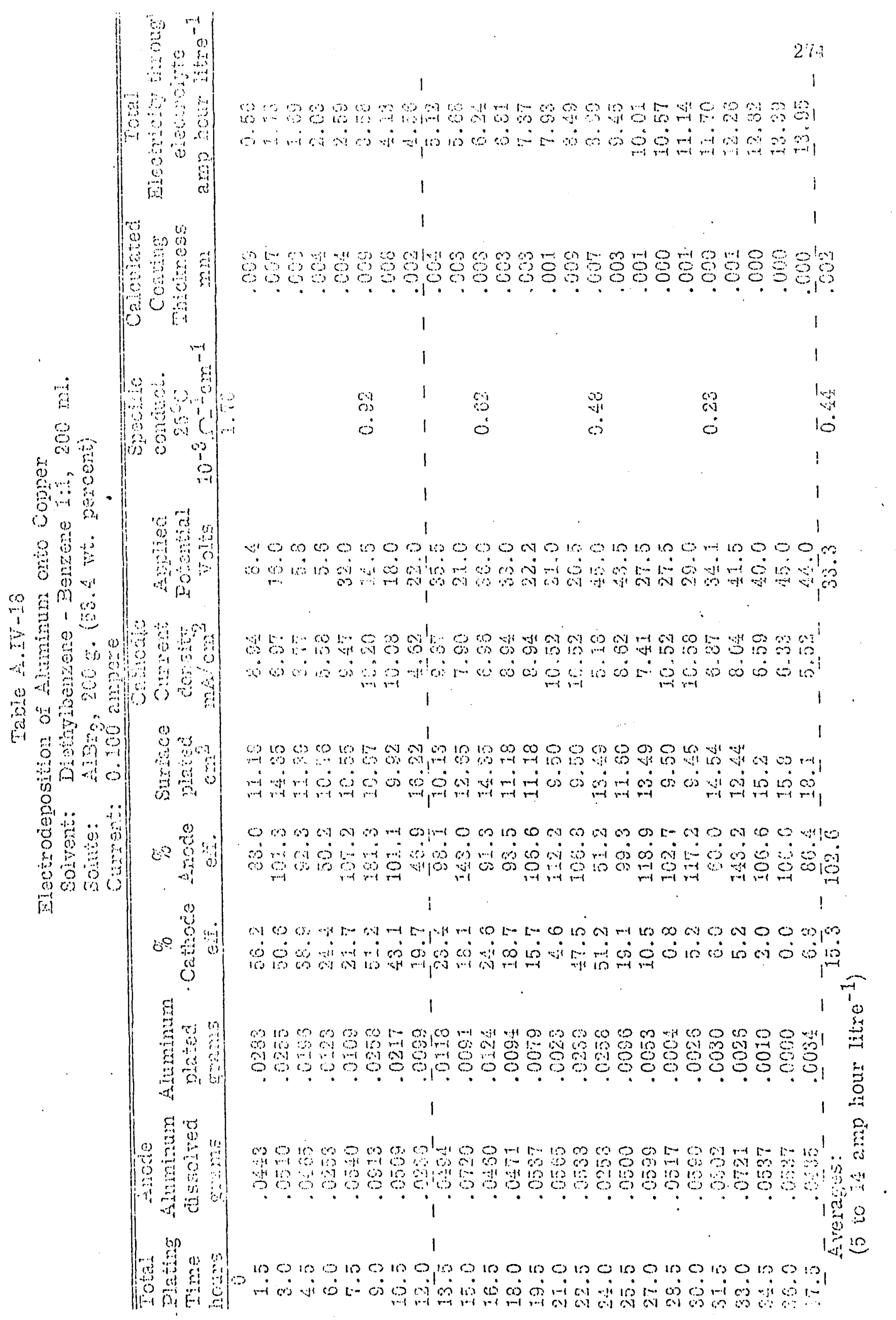


APPENDIX V 


\section{APPENDIX V}

Determination of Aluminum in the Organic Electrolyte

\section{I - Apparatus}

A. Oven to operate at $220^{\circ} \mathrm{F}$.

B. Magnetic stirrer plus Teflon covered magnetic bar.

\section{II - Solutions}

A. 8-hydroxyquinoline $25 \mathrm{~g} / \mathrm{l}$ : dissolve 25 grams of 8-hydroxyquinoline in $50 \mathrm{ml}$ glacial acetic acid, add approximately $900 \mathrm{ml}$ of hot distilled water $\left(140^{\circ} \mathrm{F}\right)$. Cool, filter and dilute to 1 liter.

B. Sodium Hydroxide $200 \mathrm{~g} / 1$ : dissolve 200 grams of $\mathrm{NaOH}$ in approximately $800 \mathrm{ml}$ of distilled water. Cool, filter and dilute to 1 liter.

C. Tartaric acid $250 \mathrm{~g} / 1$ : dissolve 250 grams of tartaric acid in approximately $700 \mathrm{ml}$ of distilled water, filter and dilute to 1 liter.

D. Hydrochloric acid 1:3. Add $250 \mathrm{ml}$ of concentrated hydrochloric acid to $700 \mathrm{ml}$ of distilled water. Cool and dilute to 1 liter.

\section{III - Procedure}

A. Transfer $1 \mathrm{ml}$ of sample into a $400 \mathrm{ml}$ beaker containing $100 \mathrm{ml}$ of distilled water.

B. Add $10 \mathrm{ml} \mathrm{HNO}_{3} 1: 1$ (volume) and boil for 5 minutes.

C. Add $20 \mathrm{ml} \mathrm{H}_{2} \mathrm{SO}_{4}$ 1:1 (volume) and evaporate to about $20 \mathrm{ml}$.

D. Cautiously add $5 \mathrm{ml} \mathrm{HNO}$ and heat to expel the oxide of nitrogen. 
E. Add $20 \mathrm{~g} / 1 \mathrm{NaOH}$ to the solution until it becomes alkaline to litmus paper.

F. Carefully pour this mixture into a $600 \mathrm{ml}$ beaker containing $100 \mathrm{ml}$ of boiling $20 \mathrm{~g} / 1 \mathrm{NaOH}$.

G. Digest for 3 minutes on hot plate, then cool to room temperature.

H. Transfer to a $500 \mathrm{ml}$ volumetric flask, and fill to mark.

I. Transfer to a $600 \mathrm{ml}$ beaker, let stand until precipitate has settled.

J. Decant through a Whatmann No. 40 filter without washing. Collect $250 \mathrm{ml}$ of filtrate in a $250 \mathrm{ml}$ volumetric flask.

K. Transfer the filtrate to a $600 \mathrm{ml}$ beaker, wash out the volumetric flask. Add $15 \mathrm{ml}$ of $25 \mathrm{~g} / 1$ tartaric acid and 2-5 drops methyl red.

L. Add $\mathrm{HCl}$ until a red colour is obtained.

M. Add $10 \mathrm{ml}$ of $3 \% \mathrm{H}_{2} \mathrm{O}_{2}$ and make basic by adding $\mathrm{NH}_{4} \mathrm{OH}$. Then add 10 drops $\mathrm{NH}_{4} \mathrm{OH}$ in excess.

N. Heat to $140^{\circ} \mathrm{F}$ and slowly add $15 \mathrm{ml}$ of 8 -hydroxyquinoline solution. Immediately follow with $3 \mathrm{ml}$ of $\mathrm{NH}_{4} \mathrm{OH}$.

O. Stir vigorously for 10-15 minutes with a magnetic stirrer.

P. Cool and filter through a weighed fitted-glass crucible.

Q. Wash well with $\mathrm{H}_{2} \mathrm{O}$. Dry in oven at $220^{\circ} \mathrm{F}$ for at least $3-4$ hours, cool in dessicator and weigh.

$\underline{\text { IV - Calculations }}$

$$
\mathrm{Al}_{(\mathrm{g} / \mathrm{l})}=(\mathrm{a}-\mathrm{b}) \times .0587 \times 1000
$$

where

$a=$ weight of crucible and precipitate

b = weight of crucible 
Determination of Bromine in the Organic Electrolyte (Volhard Method)

$\underline{I}$ - Apparatus

None.

II - Solutions

A. Sodium Bromide $0.1 \mathrm{~N}$ : transfer $10.291 \mathrm{~g}$ of recrystallized and dried $\left(600^{\circ} \mathrm{C}\right)$ sodium bromide into a beaker, dissolve with distilled water and dilute to 1 liter.

B. Silver Nitrate $0.1 \mathrm{~N}$ : dissolve 17 grams of silver nitrate in distilled water and dilute to 1 liter. This solution is made to exact decinormal strength by standardizing against the $0.1 \mathrm{~N}$ solution of $\mathrm{NaBr}$. The silver nitrate solution should be kept in the dark.

C. Potassium thiocyanate solution $0.1 \mathrm{~N}$ : dissolve 10 grams of pure potassium thiocyanate in distilled water and dilute to 1 liter. This solution is made to exact decinormal strength by standardizing against the $0.1 \mathrm{~N} \mathrm{NaBr}$ solution. The potassium thiocyanate solution should be kept in the dark.

D. Nitric acid 1:1: dilute $500 \mathrm{ml}$ of concentrated nitric acid to 1 liter with distilled water. Boil until the liquid is perfectly colourless. This reagent should be kept in the dark.

E. Ferric Indicator: dissolve some ferric ammonium sulfate in distilled water to make a saturated solution (the quantity required is approximately 40 grams of salts per $100 \mathrm{ml}$ of $\mathrm{H}_{2} \mathrm{O}$ ). 
III - Procedure

A. Transfer $1 \mathrm{ml}$ of electrolyte into $700 \mathrm{ml}$ of $5 \mathrm{~g} / 1 \mathrm{KHCO}_{3}$ solution. The electrolyte is added through a lateral tubing of an inverted beaker (see Fig. A. V-1) so as to prevent escape of $\mathrm{HBr}$ formed during the reaction of $\mathrm{AlBr}_{3}$ with the aqueous bicarbonate solution.

B. Remove the $280 \mathrm{ml}$ inverted beaker from the solution and rinse it well with distilled water.

C. Add $200 \mathrm{ml}$ of $\mathrm{HNO}_{3} 1: 1$ to acidify the solution, cool and dilute to 1 liter.

D. Transfer $50 \mathrm{ml}$ of the dilute solution to a $250 \mathrm{ml}$ volumetric flask and add $5 \mathrm{ml}$ of $\mathrm{HNO}_{3} 1: 1$.

E. Add $10 \mathrm{ml}$ of $0.1 \mathrm{~N} \mathrm{AgNO}_{3}$ with a burette and stir with a magnetic stirrer (Teflon covered magnetic bar) to coagulate the precipitate.

F. Add $1.5 \mathrm{ml}$ of ferric indicator and titrate with $0.1 \mathrm{~N}$ potassium thiocyanate to a permanent reddish-brown colour.

IV - Calculations

$\mathrm{Br}_{(\mathrm{g} / \mathrm{l})}=(\mathrm{a}-\mathrm{b}) \times 7.992 \times \frac{1000}{50}$

where

$a=m l$ of $0.1 \mathrm{~N} \mathrm{AgNO}_{3}$ used

$\mathrm{b}=\mathrm{ml}$ of $0.1 \mathrm{~N} \mathrm{KSCN}$ used 


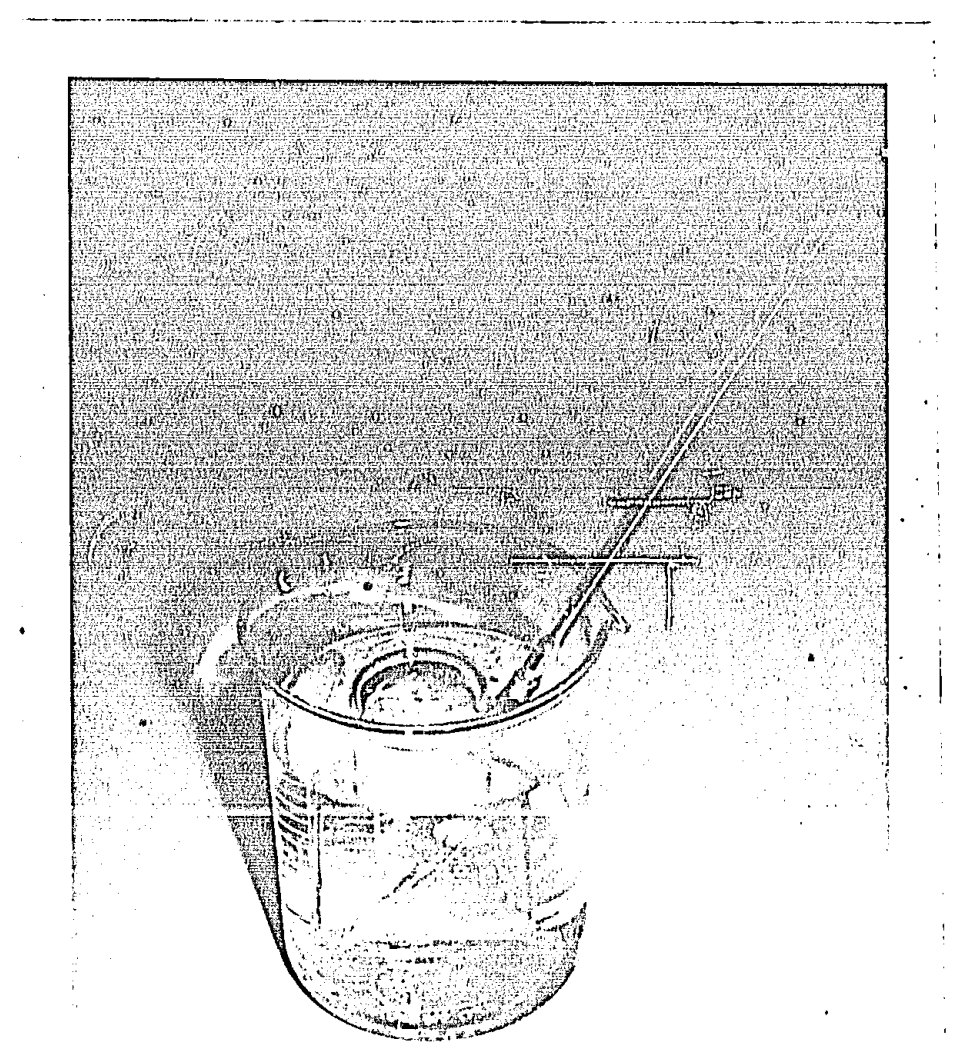

Figure A. V-1. Arrangement for the Dissolution of the Organic Electrolyte in Sodium Bicarbonate Solution for the Determination of $\mathrm{HBr}$. 
281

APPENDIX VI 
Table A. VI-1

Ethyl Bromide Addition to Improve Electrolyte Life

Solvent: Ethylbenzene-Toluene 1:1

Solute: $\mathrm{AlBr}_{3}(50 \mathrm{wt}$. percent)

Addition Agent: Ethyl bromide

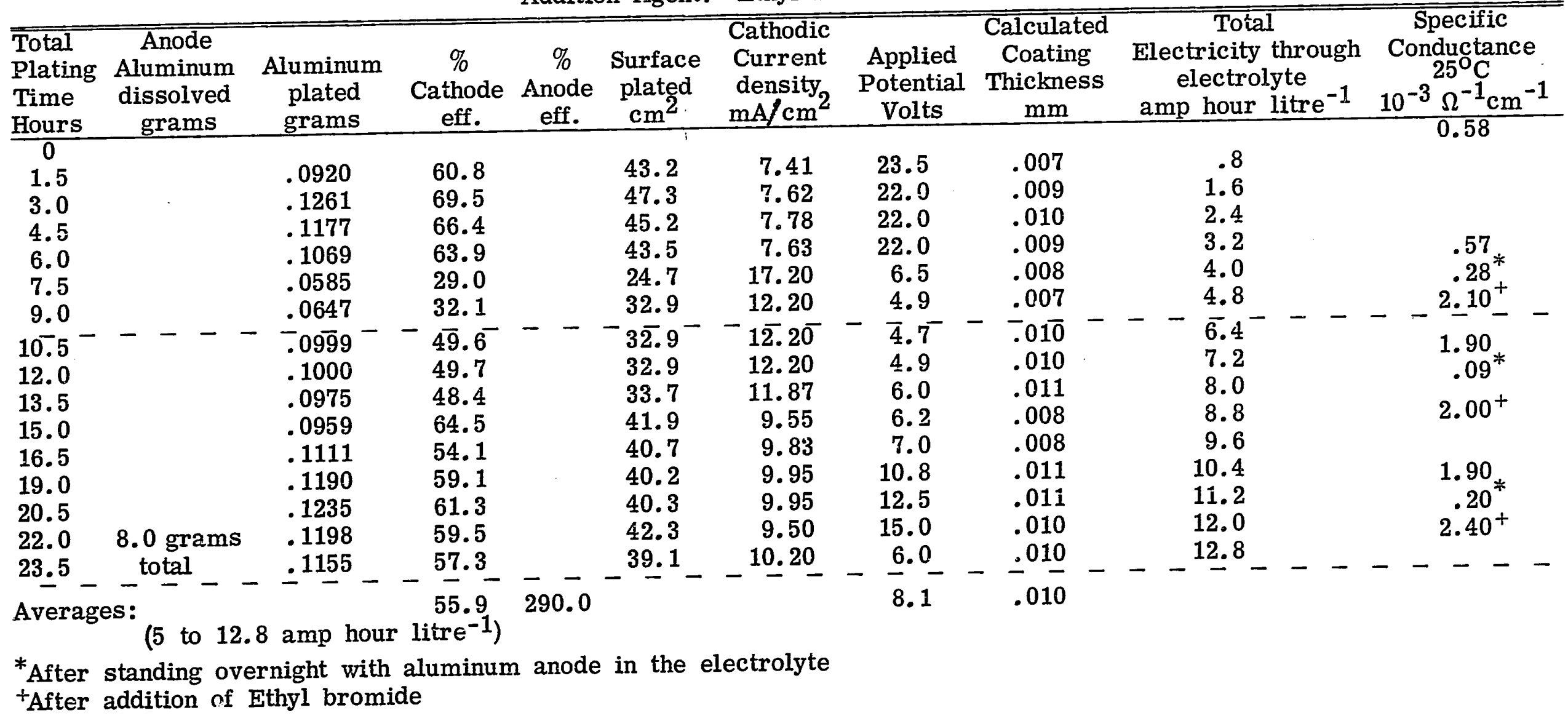


Table A. VI-2

Hydrogen Bromide Addition to Increase Electrolyte Life

Solvent: Ethylbenzene-Toluene 1:1

Solute: $\mathrm{AlBr}_{3}$ (50 wt. percent)

Addition Agent: Hydrogen bromide gas

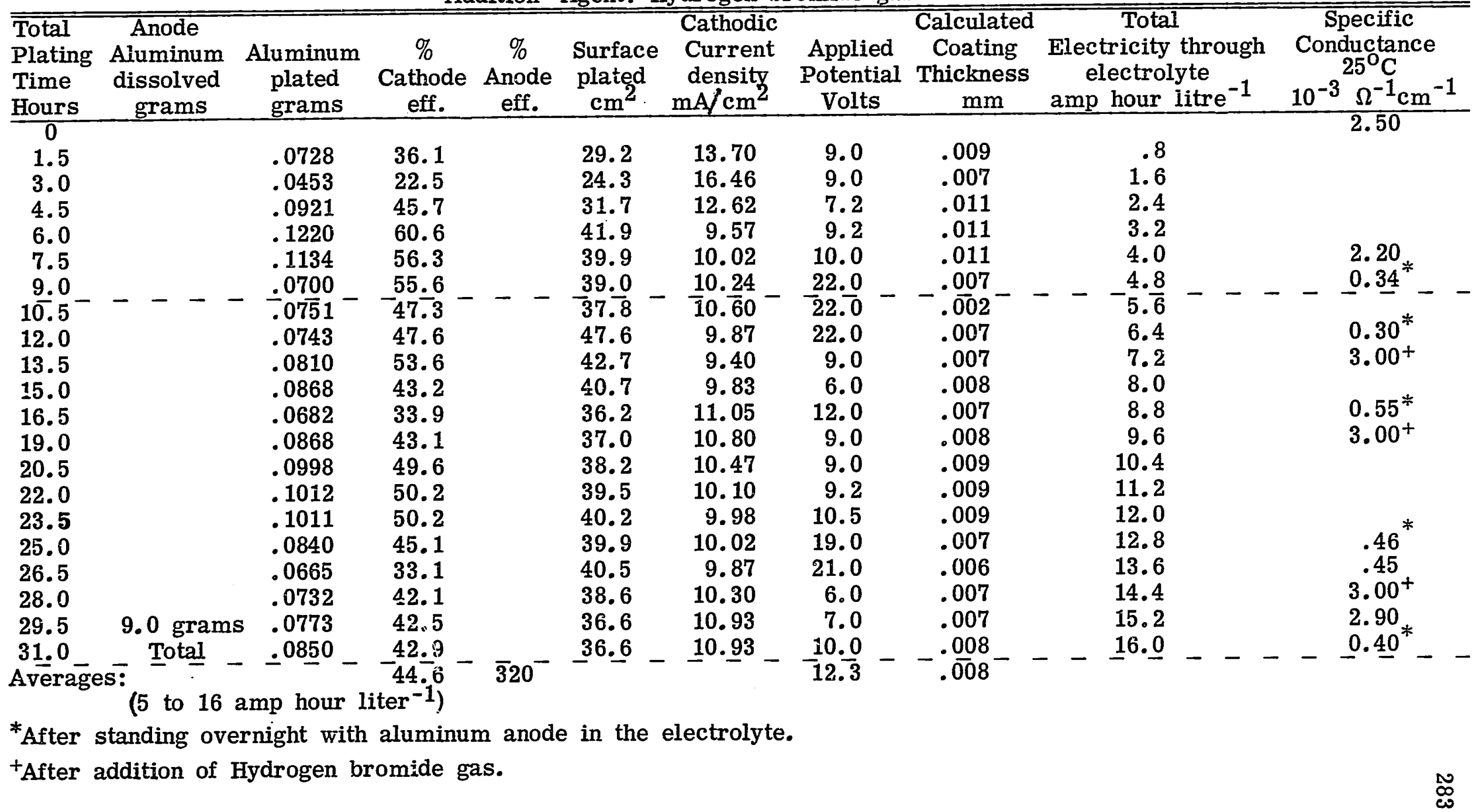


Table A. VI-3

Electrolyte Performance, Extended Tests

Solvent: Ethylbenzene-Toluene 1:1

Solute: $\mathrm{AlBr}_{3}$ (50 wt. percent)

Addition Agent: Hydrogen bromide gas

Current: $300 \mathrm{~mA}$

Current density: $10^{ \pm} .1 \mathrm{~mA} / \mathrm{cm}^{2}$

Specific conductance: $3.0-4.0 \times 10^{-3} \Omega^{-1} \mathrm{~cm}^{-1}$

\begin{tabular}{|c|c|c|c|c|c|c|c|c|}
\hline \multirow{2}{*}{$\begin{array}{l}\text { Total } \\
\text { Plating } \\
\text { Time } \\
\text { (days) } \\
\end{array}$} & \multicolumn{2}{|c|}{ Bath $\mathrm{A}$} & \multicolumn{2}{|c|}{ Bath B } & \multicolumn{2}{|c|}{ Bath C } & \multicolumn{2}{|c|}{ Bath D } \\
\hline & $\begin{array}{c}\text { \% Average } \\
\text { Anode } \\
\text { eff. }\end{array}$ & $\begin{array}{c}\% \text { Average } \\
\text { Cathode } \\
\text { eff. }\end{array}$ & $\begin{array}{c}\% \text { Average } \\
\text { Anode } \\
\text { eff. }\end{array}$ & $\begin{array}{c}\text { \% Average } \\
\text { Cathode } \\
\text { eff. }\end{array}$ & $\begin{array}{c}\% \text { Average } \\
\text { Anode } \\
\text { eff. }\end{array}$ & $\begin{array}{c}\text { \% Average } \\
\text { Cathode } \\
\text { eff. }\end{array}$ & $\begin{array}{l}\text { Average } \\
\text { Anode } \\
\text { eff. }\end{array}$ & $\begin{array}{l}\text { Cathode } \\
\text { eff. }\end{array}$ \\
\hline 1 & 116.5 & 77.2 & 106.9 & 60.9 & 106.1 & 67.0 & 109.6 & 81.2 \\
\hline 2 & 115.8 & 73.6 & 99.1 & 68.9 & 100.0 & 69.3 & 114.9 & 68.6 \\
\hline 3 & 113.4 & 70.5 & 104.6 & 76.1 & 101.9 & 66.0 & 109.3 & 73.6 \\
\hline 4 & 112.2 & 67.6 & 103.2 & 57.1 & 101.8 & 64.1 & 121.6 & 74.8 \\
\hline 5 & 113.3 & 71.6 & 105.4 & 65.8 & 105.8 & 67.4 & 112.2 & 77.8 \\
\hline 6 & 109.7 & 63.0 & 105.8 & 71.7 & 103.3 & 64.5 & 101.4 & 81.0 \\
\hline 7 & 96.8 & 67.6 & 102.2 & 75.2 & 101.0 & 65.4 & 106.7 & 66.4 \\
\hline 8 & 101.6 & 72.9 & 104.8 & 77.2 & 105.0 & 67.1 & 116.7 & 87.4 \\
\hline 9 & 110.4 & 72.7 & 104.0 & 71.5 & 100.2 & 68.3 & 125.1 & 79.4 \\
\hline 10 & 127.0 & 74.7 & 104.1 & 78.3 & 114.0 & -70.2 & $\frac{118.5}{10}$ & $-\frac{68.3}{75}--$ \\
\hline Average & 111.7 & 71.2 & 104.0 & 70.3 & 103.9 & 66. & 113.6 & 75 \\
\hline
\end{tabular}




\section{Table A. VI-4}

Electrolyte Performance at Higher Current Densities

Solvent: Ethylbenzene-Toluene 1:1

Solute: $\mathrm{AlBr}_{3}$ (50 wt. percent)

Addition agent: Hydrogen bromide gas

Current density: 5 to $40^{ \pm} .1 \mathrm{~mA} / \mathrm{cm}^{2}$

Specific Conductance: $3.0-4.0 \times 10^{-3} \Omega^{-1} \mathrm{~cm}^{-1}$

\begin{tabular}{ccccccc}
\hline \hline $\begin{array}{l}\text { Current } \\
\text { density } \\
\text { mA/cm }\end{array}$ & $\begin{array}{c}\% \\
\begin{array}{c}\text { average } \\
\text { anode } \\
\text { eff. }\end{array}\end{array}$ & $\begin{array}{c}\% \text { average } \\
\text { cathode } \\
\text { eff. }\end{array}$ & $\begin{array}{c}\% \text { Bverage } \\
\text { anode } \\
\text { eff. }\end{array}$ & $\begin{array}{c}\% \text { average } \\
\text { cathode } \\
\text { eff. }\end{array}$ & $\begin{array}{c}\% \text { average } \\
\text { anode } \\
\text { eff. }\end{array}$ & $\begin{array}{c}\text { \% average } \\
\text { cathode } \\
\text { eff. }\end{array}$ \\
\hline 5 & 93.7 & 93.5 & 104.6 & 85.5 & 113.2 & 82.5 \\
10 & 101.6 & 73.7 & 103.5 & 74.9 & 113.9 & 69.3 \\
15 & 99.4 & 72.1 & 95.2 & 67.4 & 98.5 & 66.5 \\
20 & 101.2 & 58.7 & 104.0 & 60.5 & 102.4 & 52.7 \\
25 & 101.2 & 49.8 & 106.0 & 47.4 & 102.4 & 51.0 \\
30 & 108.8 & 40.6 & 99.9 & 43.2 & & \\
40 & 109.5 & 40.6 & 103.5 & 41.2 & & \\
\hline Average & 102.2 & & 102.4 & & 106.1 &
\end{tabular}


Table A. VI-5

Control of Electrolyte: Conductivity as an Indication

of Electrolyte Performance

Solvent: Ethylbenzene-Toluene 1:1 (Vol. $575 \mathrm{ml}$ )

Solute: $\mathrm{AlBr}_{3}, 450 \mathrm{~g}$ (50 wt. percent)

Addition agents: Hydrogen bromide gas

Current: $300 \mathrm{~mA}$

Current Density: $10^{ \pm} \mathrm{mA} / \mathrm{cm}^{2}$

\begin{tabular}{ccc}
\hline \hline $\begin{array}{c}\text { Specific } \\
\text { conductance } \\
10^{-3} \Omega^{-1} \mathrm{~cm}^{-1}\end{array}$ & $\begin{array}{c}\text { Average } \\
\text { anode } \\
\text { eff. } \%\end{array}$ & $\begin{array}{c}\text { Average } \\
\text { cathode } \\
\text { eff. } \%\end{array}$ \\
\hline 2.25 & 100.7 & 68.5 \\
2.91 & 103.8 & 75.7 \\
3.50 & 104.1 & 74.9 \\
4.08 & 106.8 & 68.8 \\
5.06 & 119.9 & 67.3 \\
5.93 & 142.7 & 63.1
\end{tabular}


Table A. VI-6

Control of Electrolyte: Conductivity as an Indication

of Operating Performance

Solvent: Ethylbenzene-Toluene 1:1 (Vol. $575 \mathrm{ml}$ )

Solute: $\mathrm{AlBr}_{3}, 450 \mathrm{~g}$ (50 wt. percent)

Addition agents: Hydrogen bromide gas

Current: $300 \mathrm{~mA}$

Current density: $10^{ \pm} .1 \mathrm{~mA} / \mathrm{cm}^{2}$

\begin{tabular}{ccc}
\hline $\begin{array}{c}\text { Specific } \\
\text { conductance } \\
10^{-3} \Omega^{-1} \mathrm{~cm}^{-1}\end{array}$ & $\begin{array}{c}\% \\
\text { cathode } \\
\text { efficiency }\end{array}$ & $\begin{array}{c}\text { Days } \\
\text { of } \\
\text { operation }\end{array}$ \\
\hline 2.6 & 64.5 & 1 \\
2.9 & 66.6 & 2 \\
2.5 & 51.3 & 3 \\
4.5 & 77.2 & 4 \\
4.5 & 73.6 & 5 \\
4.3 & 70.5 & 6 \\
4.2 & 67.6 & 7 \\
4.3 & 71.6 & 8 \\
4.3 & 63.0 & 9 \\
4.1 & 67.6 & 10 \\
4.2 & 72.8 & 11 \\
3.9 & 72.7 & 12 \\
3.8 & 74.7 & 13
\end{tabular}


APPENDIX VII 


\section{APPENDIX VII \\ GENERAL EQUATIONS FOR ELECTRODE KINETICS}

A generalized cathodic equation will serve to illustrate the development of electrode kinetics for current and potential relationship.

The discussion is essentially a simplification of that presented in electrochemistry manuals by several authors. $99,100,101,102$

Equation A. VII-1 represents the overall reaction:

$$
\mathrm{A}^{\mathrm{n}+}+\mathrm{ne}^{-} \rightarrow \mathrm{B}^{\mathrm{O}}
$$

Consider the movement of a positive ion $\mathrm{A}^{\mathrm{n}+}$ from the solution side of the solution/electrode interface across the few angstroms of the double layer, to the metal surface. Several steps are involved in transferring the reacting species across the solution/electrode interface and in placing them on the cathode, but normally one of these steps will have a considerably larger free energy barrier than the others and thus it will control the reaction rate. Figure A.VII-1 shows only the highest peak representing the rate-controlling barrier. When a representative point of a reaction exists at this peak (i.e., when a reaction has proceeded to this extent) the species is called the activated complex of the reacting species.

Somewhere along the way the electron transfer occurs from electrode to ion. The progress of the moving charge can be charted by specifying the position in terms of $x_{1}$ and $x_{2}$ during the movement (Fig. A. VII-1). 
Metal

Electrode

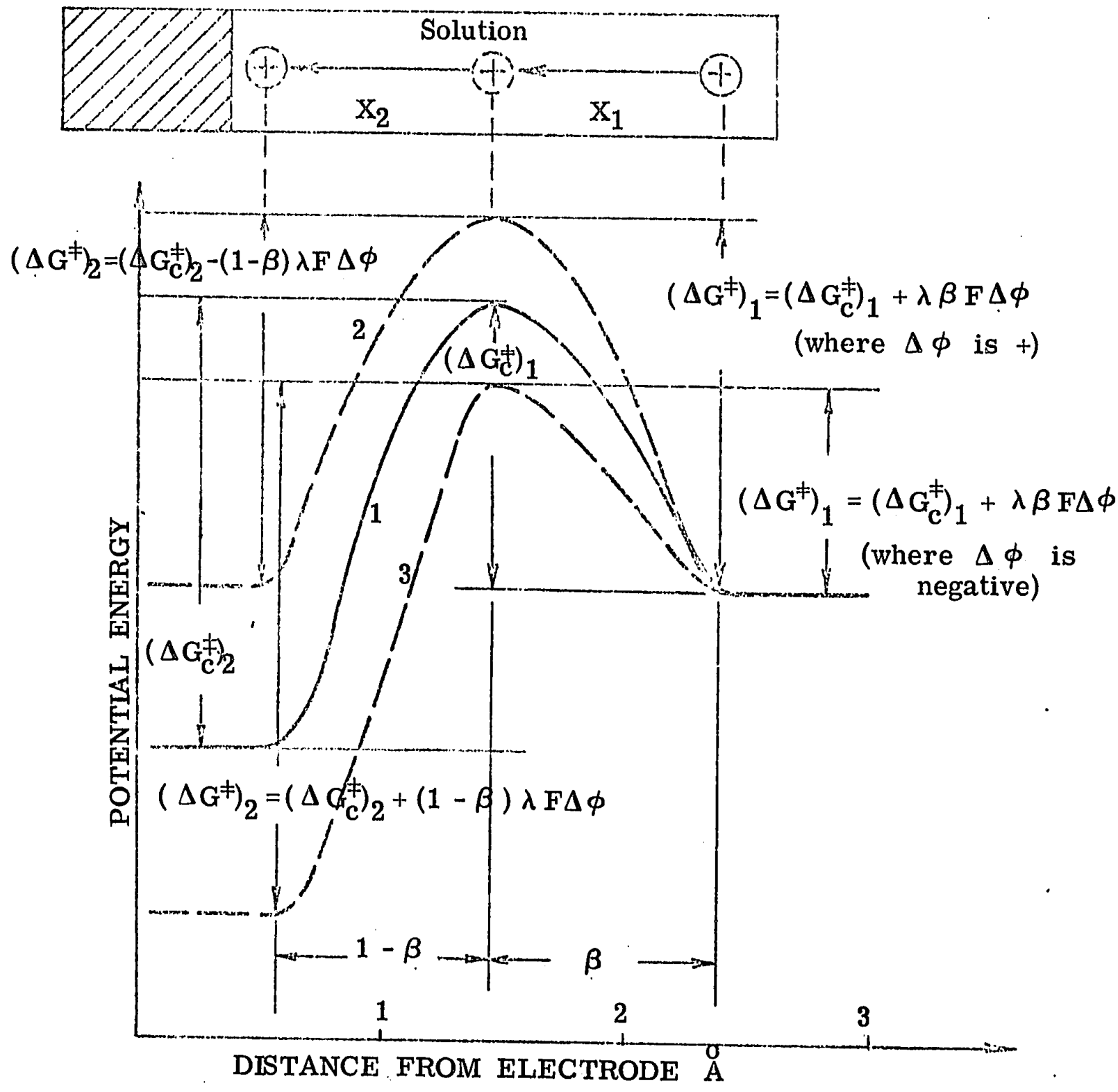

Figure A.VII-1. Potential Energy-Distance Profile Across the Compact Electrical Double Layer for an Active Metal Electrode. The Effects of Applied Potential $(\Delta \phi)$ on the Free Energy of Activation for the Electrodeposition Process Are Shown.

Curve 1: $\Delta \phi=0$

Curve 2: $\Delta \phi>0$

Curve 3: $\Delta \phi<0$ 
As the ion moves (i.e., as $\mathrm{X}_{1}$ and $\mathrm{X}_{2}$ vary) its potential energy changes. By plotting the potential energy against the distance coordinates $\mathrm{x}_{1}$ and $\mathrm{x}_{2}$ the potential-energ $\mathrm{y}$ diagram of Figure A. VII-1 is obtained.

The positive ion has to have a certain activation energy before the charge-transfer reaction is accomplished.

The frequency with which an ion can climb the activation-energy barrier in the transfer from solution to metal and accomplish the charge transfer reaction can be expressed as:

$$
\mathrm{K}_{\mathrm{c}}=\kappa \frac{\mathrm{kT}}{\mathrm{h}} \mathrm{e}^{-\Delta \mathrm{G}_{\mathrm{c}}^{\neq} / \mathrm{RT}}
$$

where $\Delta G_{c}^{\ddagger}$ is the chemical free energy of activation, the change in free energy to climb the top of the barrier when there is zero electric field acting on the ion. $\mathrm{K}_{\mathrm{c}}$ is the rate constant (frequency of successful particle jumps, those in which the particles succeed in passing over the barrier. $\kappa$ is the transmission coefficient (i. e., the fraction of the ions species reaching the activated complex state which proceeds to a reduced product $\stackrel{\circ}{\mathrm{B}}$.). $\mathrm{k}, \mathrm{T}, \mathrm{h}$ and $\mathrm{R}$ have their usual physical significance.

When this frequency is multiplied by the concentration $\mathrm{cA}^{\mathrm{n}+}$ of electron acceptor ions $\mathrm{A}^{\mathrm{n}+}$ on the solution side of the interface, one obtains the forward velocity of the reaction or the rate of the electronation reaction under zero applied potential: 


$$
\begin{aligned}
\mathrm{v}_{\mathrm{c}} & =\mathrm{cA^{ \textrm {n } + }} \frac{\kappa \mathrm{kT}}{\mathrm{h}} \mathrm{e}^{-\Delta \mathrm{G}_{\mathrm{c}}^{\ddagger} / \mathrm{RT}} \\
\text { or } \quad \mathrm{v}_{\mathrm{c}} & =\mathrm{cA}^{\mathrm{n}+} \mathrm{K}_{\mathrm{c}}
\end{aligned}
$$

where $K_{c}=$ rate constant $\sec ^{-1}$

$$
\begin{aligned}
\mathrm{v}_{\mathrm{c}}= & \text { forward velocity of reaction (rate of electronation } \\
& \text { reaction) }\left(\mathrm{mole} / \mathrm{cm}^{2} \mathrm{sec}^{-1}\right) \\
\mathrm{cA}^{\mathrm{n}+}= & \text { concentration in mole } / \mathrm{cm}^{2} \\
\kappa= & \text { transmission coefficient } \\
\mathrm{k}= & \text { Boltzmann constant }\left(13.8 \times 10^{-17} \mathrm{erg} \mathrm{deg}^{-1} \text { molecules }^{-1}\right. \\
& \text { or } \left.3.3 \times 10^{-10} \text { cals } \mathrm{deg}^{-1} \mathrm{molecules}^{-1}\right) \\
\mathrm{h}= & \text { Plank constant }\left(6.62 \times 10^{-27} \mathrm{erg} \mathrm{sec} \mathrm{or}\right. \\
& \left.1.58 \times 10^{-20} \text { cal } \mathrm{sec}\right) \\
\Delta \mathrm{G}_{\mathrm{c}}^{\ddagger}= & \text { chemical free energy of activation cal/mole } \\
\mathrm{R}= & \text { gas constant }\left(1.99 \mathrm{cals} \mathrm{deg}^{-1} \mathrm{~mole}^{-1} \text { or } 8.314\right. \text { joules } \\
& \text { deg } \left.{ }^{-1} \text { mole }{ }^{-1}\right)
\end{aligned}
$$

Also the forward current density is given by:

$$
\vec{i}=v_{c} \wedge F
$$

where $\lambda$ is the number of electrons necessary so that one act of the rate determining step can occur, and $F$ is the Faraday constant (23, 066 cal/volt or 96,500 coulomb).

Furthermore if the rate determining step occurs $\nu$ times when the overall reaction $\mathrm{A}$. VII-1 occurs once, then:

$$
\lambda=\frac{\mathrm{n}}{v}
$$


where $\mathrm{n}$ is the number of electrons involved in the overall electrode process, and $\nu$ is called the stoichiometric number.

The effect of an applied potential

Suppose a potential difference $\Delta \phi$ is applied between the electrode and the initial state of the reaction. If this potential difference is positive it retards the flow of reactants over the energy barrier of the ratedetermining step, i.e., it makes $\left(\Delta \mathrm{G}^{\ddagger}\right)_{1}$ more positive (see Figure A. VII-1). The potential difference increases $\left(\Delta G_{c}^{\ddagger}\right)_{1}$ by $\beta \gamma F \Delta \phi$ where $\beta \Delta \phi$ is the portion of the applied potential which retarded the passage of species to the activated complex state; it is not necessary to account for the potential difference beyond the activated state because work done on the system after it has passed the activated state does not alter the reaction velocity.

The term $\beta$ describes the symmetry of the energy barrier in relation to the overall reaction distance and it is defined as:

$$
\beta=\frac{\text { distance across double layer to summit }}{\text { distance across whole double layer }}
$$

$\beta$ is called the symmetry factor and for a perfect symmetrical energy barrier $\beta=1 / 2$.

Then $\beta \lambda \Delta \phi F$ is the amount by which the energy barrier for the ion-to-electrode transfer is raised and, hence $(1-\beta) \lambda \Delta \phi F$ is the amount it is lowered for the metal to solution reaction (see Figure A. VII-1). Then again for the forward reaction, the electrical contribution
to the free energy of activation $=+\beta \lambda F \Delta \phi$. 
In the presence of an applied positive potential, therefore, the total free energy of activation for the electronation reaction, $\left(\Delta G^{\ddagger}\right)_{1}$, is equal to the chemical free energy of activation $\Delta G_{c}^{\neq}$plus the electrical contribution $\lambda \beta F \Delta \phi$.

$$
\left(\Delta \mathrm{G}^{\ddagger}\right)_{1}=\left(\Delta \mathrm{G}_{\mathrm{c}}^{\ddagger}\right)_{1}+\lambda \beta \mathrm{F} \Delta \phi
$$

Thus the rate $v_{e}$ of the electronation reaction under the influence of the electrical field can be written in any of the following forms:

$$
\begin{aligned}
\vec{v}_{e} & =\frac{\kappa k T}{h} c A^{n+} \exp -\Delta G^{\ddagger} / R T \\
& =\frac{k \mathrm{kT}}{\mathrm{h}} c A^{\mathrm{n}+} \exp -\frac{\left(\Delta \mathrm{G}_{\mathrm{c}}^{\ddagger}\right)_{1}+\lambda \beta \mathrm{F} \Delta \phi}{\mathrm{RT}} \\
& =\mathrm{K}_{\mathrm{c}} \mathrm{cA}{ }^{\mathrm{n}+} \exp -\lambda \beta \mathrm{F} \Delta \phi
\end{aligned}
$$

or by equation $\mathrm{A}$. VII-4 and equation $\mathrm{A}$. VII-8:

$$
\overrightarrow{\mathrm{i}}=\lambda \mathrm{F}^{\kappa} \frac{\mathrm{kT}}{\mathrm{h}} \mathrm{cA} \mathrm{A}^{\mathrm{n}+} \exp -\frac{\left(\Delta \mathrm{G}_{\mathrm{c}}^{\ddagger}\right)_{1}+\lambda \beta \mathrm{F} \Delta \phi}{\mathrm{RT}}
$$

by a similar argument, the relationship for the reverse reaction, i. e., anodic dissolution, is given by:

$$
\leftarrow=\lambda F^{\kappa} \frac{k T}{h} c^{n+} \exp -\frac{\left(\Delta G_{c}^{\ddagger}\right)_{2}-(1-\beta) \lambda F \Delta \phi}{R T}
$$

Where $\left(\Delta G_{c}^{\ddagger}\right)_{2}$ is the chemical free energy of activation of the reverse reaction referred to the initial state of this reaction.

If

$$
\begin{gathered}
\Delta \phi=\Delta \phi_{\mathrm{r}} \text { the reversible potential } \\
\overrightarrow{\mathrm{i}}-\overleftrightarrow{\mathrm{i}}=0 \quad \text { where } \overrightarrow{\mathrm{i}}=\overrightarrow{\mathrm{i}}=\dot{\mathrm{i}}_{0}
\end{gathered}
$$


where $i_{o}$ is designated as the equilibrium exchange-current density and is the current density when the reversible potential is applied. From equation A. VII-12

$$
\begin{aligned}
& i_{0}=\lambda F \kappa \frac{k T}{h} c A^{n+} \exp -\frac{\left(\Delta G_{c}^{\neq}\right)_{1}+\beta \lambda \Delta \phi_{r} F}{R T} \\
& i_{0}=\lambda F \kappa \frac{k T}{h} c A^{n+} \exp -\frac{\left(\Delta G_{c}^{ \pm}\right)_{2}-(1-\beta) \lambda \Delta \phi_{r} F}{R T}
\end{aligned}
$$

The non-reversible drift current density (or simply the current density) when $\Delta \phi>\Delta \phi_{\mathrm{r}}$ is given by the difference between the electronation $\vec{i}$ and de-electronation $\vec{i}$ current:

$$
\dot{i}_{C}=\vec{i}-\vec{i}
$$

Furthermore

$$
\eta=\Delta \phi^{\prime}-\Delta \phi_{\mathbf{r}}
$$

where $\eta$ is the overvoltage which is a measure of how much the applied potential is different than the reversible value $\Delta \phi_{r}$, which may be rewritten as $\Delta \phi=\eta+\Delta \phi_{r}$.

From equations A.VII-10, 11, 13 and 16

$$
\begin{gathered}
\vec{i}=i_{0} \exp -\frac{(\beta \lambda \eta F)}{R T} \\
\overleftrightarrow{i}=i_{o} \exp \frac{((1-\beta) \lambda \eta F)}{R T} \\
i_{C}=\vec{i}-\overleftrightarrow{i}=i_{0}\left[\exp -\frac{(\beta \lambda \eta F)}{R T}-\exp \frac{((1-\beta) \lambda \eta F)}{R T}\right] \text { (A. VII-19) }{ }^{*}
\end{gathered}
$$

and similarly

$$
i_{A}=\vec{i}-\vec{i}=i_{0}\left[\exp \quad \frac{(1-\beta) \lambda \eta F}{R T}-\exp -\frac{(\beta \lambda \vec{\eta} F)}{R T}\right]
$$

\footnotetext{
${ }^{*}$ This equation assumes a high solute concentration $(>1$ molar $)$ in which case the potential $\psi$, due to the diffuse double layer, is negligible, i.e., only the compact double layer is considered.
} 
where $i_{C}$ and $i_{A}$ are the resultant current density for cathodic precipitation and anodic dissolution respectively under an applied potential.

Equations A.VII-19 and 20 are the most general expression for the cathodic and anodic current density, they are termed the ButlerVolmer equations after the workers from whose work they were developed.

Some simplifications of equation A.VII-19 are possible.

\section{A. VII-1 High overvoltages}

When $\exp (-\beta \lambda F \eta / R T)>>\exp (1-\beta) \lambda \eta F / R T$

Equation A. VII-19 takes the form

$$
i_{C}=i_{0} \quad \exp -\frac{\beta \lambda \eta \mathbf{F}}{R T} *
$$

where

$$
\eta=\frac{\mathrm{RT}}{\beta \lambda \mathrm{F}} \quad \ln \mathrm{i}_{\mathrm{o}}-\frac{\mathrm{RT}}{\beta \lambda \mathrm{F}} \ell^{\mathrm{n}} \mathrm{i}_{\mathrm{C}}
$$

or using log base 10:

$$
\eta=\frac{2.303 \mathrm{RT}}{\beta \lambda \mathrm{F}} \log \mathrm{i}_{\mathrm{o}}-\frac{2.303 \mathrm{RT}}{\beta \lambda \mathrm{F}} \log \mathrm{i}_{\mathrm{C}}
$$

Equation A. VII-22 is Tafel's equation,

$$
\eta=a-b \ln i_{C}
$$

Since $\frac{\vec{i}}{\vec{i}}=-\exp \beta \lambda \eta \mathrm{F} / \mathrm{RT}$ the approximation in equation A.VII-21

gives: less than $1 \%$ error for $\eta>40 \mathrm{mV}$ less than $10 \%$ error for $\eta>20 \mathrm{mV}$

$$
\lambda=6, \quad \beta=0.5, \text { and } \mathrm{T}=303^{\circ} \mathrm{K}
$$


or $\quad \eta=a-\frac{R T}{\alpha F} \ln ^{\prime} i_{C}$

(A. VII-24)

So that comparing equations A.VII-22, 23 and 24 it follows that:

$$
\begin{aligned}
a & =\frac{R T}{\beta \lambda F} \ell n i_{0} \\
b & =-\frac{R T}{\beta \lambda F} \\
a & =\beta \lambda
\end{aligned}
$$

Equation A. VII-27 shows that $a$ is a composite quantity and need not be between 0 and 1 since $\beta$ alone has maximum values of 1 . $\lambda$ can have values of 1 or multiples of 1 . Furthermore $a$ is determined directly from the slope of a Tafel line.

\section{A.VII-2 Relations between:iCand $\eta$ at low overvoltages}

$$
\text { For } \eta<<\frac{R T}{\lambda \beta F} \text { or } \eta<<\frac{R T}{(1-\beta) \lambda F} \text {. }
$$

In equation $\mathrm{A}$. VII-19 the exponential containing the overvoltage may be expanded and by retaining only the first two terms of the expansion of each exponential term, equation A.VII-19 becomes

$$
\begin{aligned}
& i_{C} \cong i_{O}\left[1+\frac{\beta \gamma \eta F}{R T}-1+\frac{(1-\beta) \lambda \eta F}{R T}\right] \text { or } \\
& i_{C} \equiv \frac{i_{0} \lambda F \ddot{\eta}}{R T}
\end{aligned}
$$

Thus the current varies linearly with the overvoltages near the revers ible potential.

The relative error in $i$ arising from using equation A. VII-28 is: $:^{100}$ 


$$
\begin{aligned}
& -4.9 \% \text { at } \eta=30 \mathrm{mV} \text { for } \beta=0.5 \lambda=1 \text { at } 25^{\circ} \mathrm{C} \\
& -2.5 \% \text { at } \eta=20 \mathrm{mV} \text { for } \beta=0.5 \lambda=1 \text { at } 25^{\circ} \mathrm{C} \\
& -0.7 \% \text { at } \eta=10 \mathrm{mV} \text { for } \beta=0.5 \quad \lambda=1 \text { at } 25^{\circ} \mathrm{C}
\end{aligned}
$$

\section{A. VII-3 Current and Temperature}

Equation A.VII-13 at reversible potential can be expressed as:

$$
i_{0}=\kappa \lambda F \quad \frac{k T}{h} \mathrm{cA}^{n+} \exp \frac{\left(\Delta \mathrm{G}_{+}^{+}\right)_{1}}{\mathrm{RT}}
$$

Where $(\Delta \stackrel{0}{G} \neq)_{1}$ is the standard free energy of activation for the forward direction of the rate determining step at the reversible potential. Hence,

$$
i_{0}=Q \exp -\frac{\left(\Delta \stackrel{O}{H}^{\ddagger}\right)}{R T}
$$

where

$$
\mathrm{Q}=\kappa \lambda \mathrm{F} \quad \frac{\mathrm{kT}}{\mathrm{h}} \mathrm{cA}^{\mathrm{n}+} \exp \frac{\left(\Delta \mathrm{S}^{\ddagger}\right)}{\mathrm{R}}
$$

and $\Delta \stackrel{\circ}{\mathrm{H}}^{\ddagger}$ and $\Delta \stackrel{\mathrm{O}}{\mathrm{S}}$ are respectively the standard heat and entropy

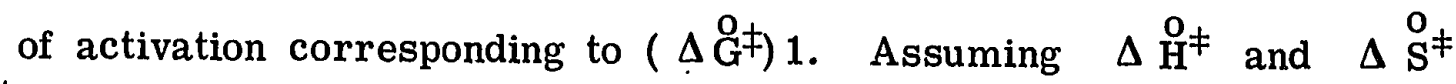
are not temperature dependent and that over small range of temperature $Q$ is constant, the plot of $\ln i_{0}$ against $1 / T$ has a slope of $-\Delta \stackrel{0}{H^{\ddagger}} / R$.

Further when $\eta$ is more negative than $40 \mathrm{mV}$ (high overvoltages) equations A. VII-21 and A. VII-30 give:

$$
\mathbf{i}_{C}=Q \exp -\frac{\left(\Delta \stackrel{\circ}{H}^{\ddagger}+\beta \lambda \eta F\right)}{R T}
$$

Hence taking $\mathrm{Q}$ and $\beta \lambda$ as temperature independent,

$$
\frac{\left(\partial\left(\mathrm{n} \mathrm{i}_{\mathrm{C}}\right)\right.}{(\partial \mathrm{T})_{\eta}}=\frac{\Delta \mathrm{o}^{\neq}+\beta \lambda \eta \mathrm{F}}{\mathrm{RT}^{2}}
$$


Taking $\Delta \mathrm{H}^{\ddagger}=\Delta \stackrel{\mathrm{o}}{\mathrm{H}}+\beta \lambda \eta \mathrm{F}$

(A. VII-33

$$
\frac{\left(\partial\left(\ln i_{C}\right)\right.}{(\partial \mathrm{T})_{\eta}}=\frac{\Delta \mathrm{H}^{\ddagger}}{\mathrm{RT}^{2}}
$$

Integration of equation $\mathrm{A}$. VII-34 gives

$$
\text { or } \quad \begin{aligned}
\ln i_{C} & =-\frac{\Delta H^{\ddagger}}{R T}+\ln B \\
i_{C} & =B \exp -\frac{\Delta H^{\ddagger}}{R T}
\end{aligned}
$$

which is simply an Arrhenius equation. $\Delta \mathrm{H}^{\ddagger}$ is the electrochemical heat of activation at constant overvoltage. Equation A. VII-36 has been used by many workers. 95,96

Now from equation A.VII-22 and with conditions assumed as for equation A. VII-32

$$
\frac{\left(\frac { \partial \eta } { \partial } \left(\frac{\left.{ }^{n} i_{C}\right) T}{T}\right.\right.}{(j)}=-\frac{R T}{\beta \lambda F}
$$

from equation A. VII-32 and equation A.VII-37

$$
\frac{(\partial \eta)}{\left(\partial T^{\prime}\right)_{C}}=-\frac{\Delta \stackrel{o}{H}^{ \pm}+\beta \lambda \eta F}{\beta \lambda F T}
$$

from equation $\mathrm{A}$. VII-33 and equation A. VII-38

$$
\frac{(\partial \eta)}{(\partial \mathrm{T})_{\mathbf{i}_{\mathrm{C}}}}=-\frac{\Delta \mathrm{H}^{\ddagger}}{\beta \lambda \mathrm{FT}}
$$

Equation A. VII-39 was also used by other workers. 95 
APPENDIX VIII 


\section{APPENDIX VIII \\ Summary of the Method Followed for the Spectrochemical Analysis of Aluminum Coatings}

A weighed amount of the aluminum coating $(7 \mathrm{mg})$ was packed into the crater of a specially shaped graphite electrode. The specimen was then excited by a continuous $8 \mathrm{amp}$. D.C. arc to complete burning of the sample. A neutral step filter was placed between the arc and the spectrographic camera in order to obtain transmittances of 10 to $90 \%$ for the analytical lines.

The spectra were photographed on a calibrated emulsion and the intensity ratios of selected pairs of analytical lines were determined photometrically. Concentration of the elements were read from analytical curves relating log intensity ratio to concentrations.

Primary standards used for the preparation of the analytical curves were purchased from the Aluminum Company of Canada in Arvida.

The precision (coefficient of variation) and accuracy of this method are expected to be of the order of 5 to 10 percent of the amount determined. 
APPENDIX IX 


\section{APPENDIX IX}

Materials Investigated for Construction of Industrial Plating Tanks

Figure 5-4 (p. 97 ) shows the reactivity of the ethylbenzene electrolyte with an aluminum anode when the latter is allowed to remain in contact with the electrolyte overnight. This reactivity prohibits the use of aluminum as a construction material for plating tanks.

Other materials investigated are:

Acrylic plastic (Plexiglas)

Polyvinyl chloride (P.V.C.)

Polypropylene

Teflon

These materials were left in contact with the electrolyte in a closed vessel for a period of one month and the following results were obtained:

$\begin{array}{lcc} & & \text { Weight Loss or Gain } \\ \text { Plexiglas } & - & 50 \% \text { loss } \\ \text { Polyvinyl chloride } & - & 90 \% \text { loss } \\ \text { Polypropylene } & - & 5 \% \text { gain } \\ \text { Teflon } & - & 1 \% \text { gain }\end{array}$

Polypropylene is now being tested further as material for plating tanks. Teflon, though an excellent container material, is not particularly desirable because of its exceptionally high initial cost (about 10 times that of polypropylene). 


\section{LIST OF SYMBOLS}

$$
\begin{aligned}
& a=\text { the Tafel equation constant: } \frac{\left(\mathrm{RT} \ln _{\mathrm{O}}\right)}{\gamma \beta \mathrm{F}} \\
& A=\text { anode of polarization cell } \\
& \mathrm{A}^{\mathrm{n}+}=\text { positive ion in solution } \\
& \mathrm{ArH}=\text { solvent (aromatic hydrocarbon) } \\
& \mathrm{b}=\text { the Tafel equation slope: }-\frac{\mathrm{RT}}{\gamma \beta \mathrm{F}} \\
& B=\text { constant of integration (Arrhenius Constant) } \\
& \mathbf{c}=\text { chemical } \\
& \mathrm{C}=\text { cathode of polarization cell } \\
& \mathrm{cA}^{\mathrm{n}+}=\text { positive ion concentration }\left(\mathrm{mole} / \mathrm{cm}^{3}\right) \\
& \mathrm{D}=\text { external diameter of Luggin capillary } \\
& \text { exp }=\text { exponential of } e \text { where } e \text { is the base of natural logarithm } \\
& \mathrm{e}=\text { electrons } \\
& \mathrm{f}=\text { factor for correcting IR drop between cathode and reference } \\
& \text { electrode (Rf1) } \\
& F=\text { Faraday constant: } 96,500 \text { int. coulombs g. equiv. }{ }^{-1} \text { or } \\
& 23066 \text { calorie/volt } \\
& (\Delta G \hbar)=\text { chemical free energy of activation (cal } / \mathrm{mole}) \text {, i.e., free } \\
& \text { energy of activation at zero applied potential } \\
& \left(\Delta \mathcal{G}^{\ddagger}\right)=\text { standard free energy of activation (cal/mole), i.e., free } \\
& \text { energy of activation at reversible applied potential }
\end{aligned}
$$

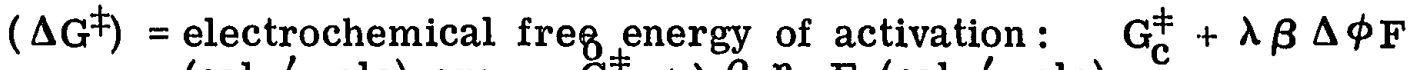

$$
\begin{aligned}
& \text { (cal /mole) or: } G^{\neq}+\lambda \beta \eta \text { F (cal / mole) } \\
& \left(\Delta G^{\ddagger}\right)_{1}=\text { cathodic electrochemical free energy of activation (cal } / \text { mole) } \\
& \left(\Delta G^{\ddagger}\right)_{2}=\text { anodic electrochemical free energy of activation (cal } / \text { mole) } \\
& \mathrm{h}=\text { Planck constant: } 6.624 \times 10^{-27} \text { erg. sec. or } 1.58 \times 10^{-20}
\end{aligned}
$$



$\Delta \mathrm{H}^{\mathrm{O} \neq}=\begin{aligned} & \text { standard heat of activation (cal / mole), i.e., heat of } \\ & \text { activation at reversible applied potential }\end{aligned}$

$\Delta \mathrm{H}^{\ddagger}=$ electrochemical heat of activation (cal / mole): $\quad \stackrel{\mathrm{O}}{\mathrm{H}}^{\ddagger}+\lambda \beta \eta \mathrm{F}$

$\left(\Delta \mathrm{H}^{\ddagger}\right)\left(\eta_{\mathrm{tC}}=\right.$ cathodic electrochemical heat of activation at constant

tC) overvoltage (cal / mole)

$\left(\Delta \mathrm{H}^{\ddagger}\right)_{\mathrm{iC}}=$ cathodic electrochemical heat of activation at constant current density (cal / mole)

$\mathrm{i}=$ current density $\mathrm{mA} / \mathrm{cm}^{2}$

${ }^{\mathbf{i}_{C}}=$ cathodic current density $\mathrm{mA} / \mathrm{cm}^{2}$

$I=$ current $\mathrm{mA}$

$\mathrm{i}_{\mathrm{A}}=$ anodic current density $\mathrm{mA} / \mathrm{cm}^{2}$

$i_{0}=$ exchange current density $\mathrm{A} / \mathrm{cm}^{2}$ (see Section $6.1-\mathrm{D}-\mathrm{i}$ ) for full definition)

$\mathrm{K}_{\mathrm{t}}=$ specific conductance at temperature $\mathrm{t}\left(\Omega^{-1} \mathrm{~cm}^{-1}\right)$

$\mathrm{K}_{25}=$ specific conductance at $25^{\circ} \mathrm{C}\left(\Omega^{-1} \mathrm{~cm}^{-1}\right)$

$\mathrm{K}_{\mathrm{c}}=$ rate constant $\left(\mathrm{sec}^{-1}\right)$

$k=$ Boltzmann constant $\left(13.8 \times 10^{-17}\right.$ erg deg. ${ }^{-1}$ molecules $^{-1}$, or $3.3 \times 10^{-10}$ cals deg. ${ }^{-1}$ molecules $^{-1}$

$\ell=$ distance between Luggin capillary tip and metallic electrode

$\mathrm{mK}_{25}=$ slope of equation for correcting specific conductance at $25^{\circ} \mathrm{C}$

$\mathbf{n}=$ number of electrons involved in the overall electrode process

$0=$ ortho substitution in a benzenic ring

$\mathrm{p}=$ para substitution in a benzenic ring

$\mathrm{m}=$ meta substitution in a benzenic ring

$\mathrm{mA}=$ milliamperes

$\mathrm{mV}=$ millivolts 


$$
\begin{aligned}
& Q=\text { entropy component of free energy }: \lambda F \frac{k T k}{h} c A^{n+} \exp \frac{\left(\Delta S^{\ddagger}\right)}{R} \\
& R=\text { gas constant } 1.99 \text { cals deg. }{ }^{-1} \text { mole }^{-1} \text {, or } 8.314 \text { joules } \\
& \text { deg. }{ }^{-1} \text { mole }^{-1} \\
& \Delta^{\mathrm{O}} \mathrm{S}=\text { standard entropy of activation cal } / \mathrm{mole} \mathrm{deg} \text {. } \\
& \mathrm{T}=\text { absolute temperature }{ }^{\mathrm{o}} \mathrm{K} \\
& v_{c}=\text { forward velocity of reaction in absence of an applied } \\
& \mathrm{V}=\text { volts }
\end{aligned}
$$

$\mathrm{X}_{1} \& \mathrm{X}_{2}=$ position of moving charge toward a cathode

$$
\begin{aligned}
\alpha= & \text { product of } \left.\beta \text { and } \lambda \text { in Tafel equation: } \frac{R T}{\text { slope of Tafel equation } \mathrm{x}}\right] \\
\beta= & \text { symmetry factor (see Section } 6.1-\mathrm{D}-\mathrm{i} \text { for full definition) } \\
\eta= & \text { overvoltage: difference between the applied potential and } \\
& \text { reversible potential at a given current density } \\
\eta_{\mathrm{t}}= & \begin{array}{l}
\text { charge-transfer overvoltage: (see Section } 6.1-\mathrm{C} \text { for full } \\
\text { definition) }
\end{array} \\
\eta_{\mathrm{tC}}= & \text { cathodic charge-transfer overvoltage } \\
\eta_{\mathrm{R}}= & \text { ohmic overvoltage: (see Section } 6.1-\mathrm{C} \text { for full definition) } \\
\eta_{\mathrm{C}}= & \begin{array}{l}
\text { concentration overvoltage (see Section } 6.1-\mathrm{C} \text { for full } \\
\text { definition) }
\end{array} \\
\eta_{\mathrm{CC}}= & \text { cathodic concentration overvoltage } \\
\eta_{\mathrm{Cr}}= & \begin{array}{l}
\text { crystallization overvoltage (see Section } 6.1-\mathrm{C} \text { for full } \\
\text { definition) }
\end{array} \\
\kappa= & \text { transmission coefficient; fraction of ions species reaching } \\
& \text { the activated complex state which proceed } \\
\lambda= & \text { stoichiometric factor; number of electrons involved in one } \\
& \text { act of the rate determining step }
\end{aligned}
$$


$\nu=$ stoichiometric number; number of times the rate determining step occurs while the overall electrode process reaction occurs once

$\pi$ complex $=$ complex consisting of aluminum bromide and an aromatic hydrocarbon

$\sigma$ complex $=$ carbonium ion $(\mathrm{ArH} \cdot \mathrm{H})^{+}$, usually associated with the carbonium ion salt, 76 e.g., $\mathrm{ArH} \cdot \mathrm{H}^{+}+\mathrm{AlBr}_{4}^{-}$.

$\phi_{\mathbf{i}}=$ potential which must be met to maintain the current density at $\mathrm{i}$

$\Delta \phi=$ applied potential

$\phi_{0}=\underset{\text { flow }}{\text { rest }}$ or static potential at which there is no net current

$\Delta \phi_{0}=$ potential which must be applied (and slightly exceeded) to initiate net current flow

$\Delta \phi_{\mathrm{r}}=$ same as $\Delta \phi_{\mathrm{o}}$ under reversible conditions

$\Omega^{-1} \times 10^{-3}=$ millimho

$\epsilon=$ dielectric constant

$\psi=$ potential due to the diffuse double layer 


\section{ACKNOWLEDGEMENTS}

The author wishes to thank Professor W. G. Davenport for supervising this work and for his most constructive criticisms.

Thanks are extended to Professor W.G. Williams, Chairman of the Mining and Metallurgical Engineering Department, to Professor W. T. Thompson and to Mr. R. Minto for their suggestions and encouragement.

The author also wishes to thank Messrs. P. Capuano, M. Knoephel, Be Quach, I. Patterson, R. Striegler and Mrs. M. Blevins for their technical assistance.

The author is indebted to the National Research Council of Canada and to McGill University for financial support. 


\section{REFERENCES}

1. S. A. Tucker and E. G. Thomssen: Trans. Am. Electrochem. Soc, 1909, Vol. 15, pp. 497, 509.

2. P. Marino: Brit. Patent, 10133, July 15, 1915, C.A. Vol. 11, 121 (1917).

3. G. L. Williams: U.S. Patent, 1, 351, 144, Aug. 31, 1920, C. A. Vol. 14, $3200(1920)$.

4. R. Taft and H. Barham: J. Phys. Chemistry, 1930, Vol. 34, pp. 929-53.

5. A.W. Castle, Electroplating Metal Finishing, 7, 291 (1954).

6. A. Brenner, J. of Electrochem. Soc., 106, 148 (1959).

7. A. Brenner, Advan. Electrochem. \& Electrochem. Eng., 5,205 (1967).

8. V.A. Plotnikov: J. Russian Phys. Chem. Soc., 1902, Vol. 3, p. 466.

9. H. E. Patten: Trans. Am. Electrochem. Soc., 1904, Vol. 6, p. 9 .

10. E. Wertyporoch and A. Wohl: Ber., 1931, Vol. $64 \mathrm{~B}$, pp. 1369-80.

11. E. Wertyporoch and B. Adamus: Z. Physik. Chem., 1934, Vol. A168, p. 31 .

12. R.D. Blue and F.C. Mathers: Trans. Am. Electrochem. Soc., 1934, Vol. 65, 339 .

13. H. E. Haring and W. Blum: Trans. Am. Electrochem. Soc., 1923, Vol. 44, pp. 313-45.

14. R.D. Blue and F.C. Mathers: Trans. Am. Electrochem. Soc., 1936, Vol. 69 , p. 519 .

15. R.D. Blue and F.C. Mathers: Metal Cleaning and Finish, 1938, Vol. 10, pp. 114-16.

16. C.C. Downie: Metallurgia, 1938, Vol. 18 , p. 134 . 
17. R. J. Heritage: Bull. Inst. Metal Finish, 1955, Vol. 5, pp. $106-18$.

18. N. I. Ternovaya and O.K. Kudra: Tz. Kievst Politek. Inst., 1962, Vol. 38, pp. 13-22.

19. F.H. Hurley and T.P. Wier: J. Electrochem. Soc., 1951, Vol. 98, pp. 207-12.

20. W.H. Safranek, W.C. Schickner and C. L. Faust: J. Electrochem. Soc., 1952, Vol. 99, pp. 53-59.

21. M.A. Miller and C.D. Baker: U.S. Patent, No. 2,763,605, Sept. 18, 1956, C. A. Vol. 15, 894.

22. V.A. Plotnikov: J. Russ. Phys. Chem. Soc., 1907, Vol. 39, pp. 163-67.

23. D. B. Keyes and S. Swann: Ind. Eng. Chem., 1928, Vol. 20, pp. 1068-69. C.A. Vol. 23, 43.

24. D. E. Couch and A. Brennner: J. Electrochem. Soc., 1952, Vol. 99, p. 234.

25. H. Connor and A. Brenner: J. Electrochem. Soc., 195y, Vol. 103 , p. 657.

26. R. J. Heritage: Trans. Inst. Metal Finishing, 1955, Vol. 32, p. 61 .

27. R. J. Heritage and J. R. Balmer: Product Finishing (British), March, 1957, Vol. 10 , p. 54

28. G. V. Alm and M. J. Binstock: U.S. Department of Commerce Report NAA-SR-2704, October 1, 1958.

29. J. Elze, G. Lange, and D. Meyer: Metallwissenschaft Technik, 1959, Vol. 13, p. 541 .

30. E.W. Cooke and S. Kritzer: WADC Report 59-465 (U.S. Department of Commerce Report PB 161892), November, 1959.

31. K. Ziegler and H. Lehmkuhl: Fed. Rep. of Germ. Patent, No. 1,056,377, March 22, 1962. 
32. F.J. Schmidt and I. J. Hess: NASA Report CR-197, April, 1965.

33. A. G. Buschow, I. J. Hess, and F. J. Schmidt: NASA Report CR-66322, May 19, 1967.

34. F. J. Schmidt and I. J. Hess: Plating, 1966, Vol. 53, p. 229.

35. A. G. Buschow and C. H. Esola: Plating, 1968, Vol. 55, p. 931.

36. F. J. Schmidt, I. J. Hess, C. H. Esola, and A. G. Buschow: SAMPE Proc., April, 1969, Vol. 15, p. 117.

37. J. G. Beach, W. C. Schickner, C.R. Konecny, and C.L. Faust: Battelle Memorial Institute Report No. 912 (DEL), May 7, 1954.

38. J. G. Beach, W.C. Schickner, D. Hopkinson, and C. L. Faust: Battelle Memorial Institute Report No. 992, March 30, 1955.

39. J. G. Beach and C. L. Faust: J. Electrochem. Soc., 1959, Vol. 106, p. 654 .

40. L. D. McGraw: U.S. Patent 3, 268,421, 1966.

41. E. J. Smith and L.D. McGraw: U. S. Patent 3, 355, 368, 1967.

42. J. G. Beach, L.D. McGraw, and C. L. Faust: Plating, 1968, Vol. 55, p. 936.

43. K. Lui, R. Guidotti, and M. Klein: NASA Report CR-66427, July, 1965.

44. R. N. Hanson, D. G. DuPree, and K. Lui: Plating, 1968, Vol. 55, p. 347.

45. J.C. Withers and E.F. Abrams: Plating, 1968, Vol. 55, p. 605 .

46. F.A. Clay, W.B. Harding, and C. J. Stimetz: Plating, 1969, Vol. $56(9)$, p. 1027.

47. N. Ishibashi, M. Yoshio, F. Shi, Y. Hanamura, and N. Shi: U.S. Patent 3,595, 760, July 27, 1971.

48. R.D. Blue and F.C. Mathers: Trans. Am. Electrochem. Soc., 1933, Vol. 63, pp. 23i-38. 
49. N.F. Murphy and A.C. Dumas: Electroplater's Soc., 1956, Vol. 43, pp. 162-63.

50. B. O. Holland: J. Australian Inst. of Metals, 1961, Vol. 6, p. 212.

51. I. A. Menzies and D. B. Salt: Trans. Inst. Metal Finishing, 1965, Vol. 43, pp. 186-91.

52. L. Simanavicius, A. Levinskiene and A. Karpavicius: (V. Kapsukas State Univ., Vilnyus Lith.) Elecktroklimya, 1966.

Vol. 2(1), pp. 87-88 (Russ.)

C. A. Vol. $64,15378$.

53. E. L. Lalbin: British Patent No. 106,400, 1916, C.A. Vol. 11, 2563.

54. W. Menzel: German Patent No. 694, 738, Aug. 1940, C.A. Vol. 47,978 .

55. P.F. Kalynzhuaya: Kim. Zur., 1952, Vol. 18, pp. 661-666. C. A. Vol. 48,5682 .

56. L. Simanavicius and A. Levinskiene: Chem. vi Chem. Tech., 1965, Vol. 7, pp. 143-48. (Russ.) and Elecktroklimya, 1966, Vol. 2(3), pp. 353-55. C. A. Vol. $65,3333$.

57. A. Brenner: Advan. Electrochem. and Electrochem. Eng., 1967, Vol. 5, pp. $205-48$.

58. R. Mott: Trans. Am. Electrochem. Soc., 1904, Vol. 6, p. 9 .

59. H. R\&hler: Z. Elelstrochem., 1910, Vol. 16, p. 419 .

60. T.P. Dirkse and H. T. Briscoe: Metal Ind. (N.Y.), 1938, Vol. 36, pp. 284-5.

61. Muller, Kolzl, Knaus, Planiszig and Prett: Monatsh, 1924, Vol. 44, pp. 219-36.

62. J. L. Beal and C.A. Mann: J. Phys. Chem., 1938, Vol. 42, pp. 283-300. 
63. E. Wertyporoch and B. Adamus: Z. Physik. Chem., 1932, Vol. A 162, pp. 398-414 and Vol. A 168, pp. 31-44, 1934.

64. E. Wertyporoch and A. Silber: Z. Physik. Chem., 1934, Vol. A 168, pp. 124-34.

65. A. Brenner: J. Electrochem. Soc., 1959, Vol. 106, pp. 148-154.

66. G. Gustavson, Bull. Soc. Chim. (2), 1878, Vol. 30, 435 .

67. J. F. Norris and D. Rubinstein: J. Am. Chem. Soc., 1939, Vol. 61, pp. 1163-70.

68. H. C. Brown, H.W. Pearsall: J. Am. Chem. Soc., 1952, Vol. 74, p. 191.

69. H.C. Brown and W.J. Wallace: J. Am. Chem. Soc., 1953, Vol. 75, p. 6268.

70. N. B. Menskutkin: J. Russ. Phys. Chem. Soc., 1908, Vol. 41, p. 1089 .

71. V.A. Plotnikov and N.N. Gratsianskii: Bull. Acad. Sci. U.S.S.R. Classie sei chim., p. 101 (1947).

72. D.D. Eley and P.J. King: Trans. Faraday Soc., 1951, Vol. 47, p. 1287.

73. R.E. Van Dyke: J. Am. Chem. Soc., 1950, Vol. 72 , p. $361 \overline{9}$.

74. D.D. Eley and P.J. King: J. Chem. Soc., 1952, p. 4972 .

75. H.C. Brown and W.J. Wallace: J. Am. Chem. Soc., 1953, Vol. 75, p. 6265.

76. H.C. Brown and J.D. Brady: J. Am. Chem. Soc., 1952, Vol. 74, p. 3570 .

77. N. N. Lebedev: JOCH, 1948, 22, 1505 .

78. V.V. Kirshak, N.N. Lebedev: JOCH, 1948, $\underline{18}, 1766$. 
79. N. N. Lebedev: JOCH, 1951, 21,1788 .

80. U. M. Messler, N. M. Alpatov, O.R. Osipow: Adv. in Chem., 1964, $\underline{33}, 261$.

81. I. E. Gillet: J. Electrochem. Soc., 1961, Vol. 108, p. 71 .

82. L. Simanavicius and A. Levinskiene: Liet. TSR Mokslu Akad. Darb. Ser. B., 1966, (4), pp. 39-47 (Russ.), C.A. 674,60247 .

83. G.A. Capuano, M.Sc. Thesis, Department of Metallurgical Engineering, McGill University, Montreal (1970).

84. United States Military Specification MIL-C-23217A (ASG), dated September 27, 1963.

85. S. Glasstone: An Introduction to Electrochemistry, D. Van Nostrand Co. Inc., pp. 17, 45, 59, 61 (1964).

86. W.C. Schickner: Steel, September 2, 1953, Vol. 133, p. 125 .

87. F. Haber: Z. Physik, $32,208(1900)$.

88. S. Barnartt: J. of Electrochem. Soc., 108, p. $102(1961)$.

89. J. Q'M. Bockris and B. E. Conway: Modern Aspect of Electrochemistry, London, 1954, p. 264.

90. J. O'M. Bockris and A. M. Azzam: Trans. Faraday Society, 48 (1952), p. 145 .

91. R. Piontelli: Gazz Chim. Ital., 83, 357, 370 (1953).

92. R. Piontelli, G. Bianchi and R. Aletti: Z. Elektro chem., 56,86 (1952).

93. R. Piontelli, G. Bianchi, U. Bertocci, C. Guerci and B. Rivolta: Z. Elektro chem., 58, 54 (1954). 
94. R. Piontelli: Z. Elektrochem., 59, $778(195 \overline{5})$.

95. J. N. Agar: Disc. Faraday Soc., 1, p. 81 (1947).

96. A. K. Vijh and B. E. Conway: Chem. Reviews, 67, p. 623 (1967).

97. M. I. Temkin: Zh. Fiz. Khim., 22, 1081.

98. B. E. Conway: "Theory and Principles of Electrode Processes," Ronald Press, New York, Chapter 6 (1965).

99. T. O'M. Bockris: "Modern Aspect of Electrochemistry." Editor: T. O'M. Bockris, Butterworth Scientific Publication, London, Volume 1, Chapter 4 (1954).

100. T. O'M. Bockris and A.K. N. Reddy: Modern Electrochemistry. Plenum Press, New York, Chapters 8 and 9 (1970).

101. K. T. Vetter : Electrochemical Kinetics, Academic Press, New York, London, Chapter 2 (1967).

102. G. Kortum: Treatise on Electrochemistry, Elsvier Publishing Company, Chapter XII (1965).

103. J.A. Butler: "Electrocapillarity," Methuen, London, 1940.

104. T. Hurlen: Acta Chem. Scan., 15, $630(1961)$.

105. S. V. Gorbachev and S.P. Starostenko: Zhur. Fiz. Khim., 28, No. 6, 1120 (1954).

106. L. Simanavicius and P. Dobrovolskis (U.S.S.R.): Issled. obl. osazhdeniya Metal., Mater. Respub. Konf. Elektrokhim. Litov. S.S.R. 11th, 192-4 (Russ.) (1971). C.A. Vol. 76, No. 26, 161592 d.

107. H. Fischer et al.: Z. Elektrochem., $\underline{59}, 440,768$ (1955)

108. I. N. Stranski: Disc. Faraday Soc., 5, 69 (1949). 
109. H. Stephen and T. Stephen: Solubility of Inorganic and Organic Compounds, Macmillan Co., New York, Vol. 1, Part 1, pp. 498-499 and pp. 860-862, 1963.

110. Handbook of Chemistry and Physics, 48th Edition, Chemical Rubber Co., Cleveland, 1967.

111. A.T. Vagramyan and Z.A. Soloveva: Technology of Electrodepositiori, Robert Draper. Ltd., Chapter 1, 1961.

112. R. Parsons: Trans. Faraday Soc., 47, 1332 (1951).

113. B. E. Conway: Trans. Roy. Soc. Can. Sect., III, $54,19(1960)$. 